\title{
Nitric Oxide Reactivity and Unusual Redox Properties of Biomimetic Iron-Sulfur Clusters with Alternative Cluster Ligands
}

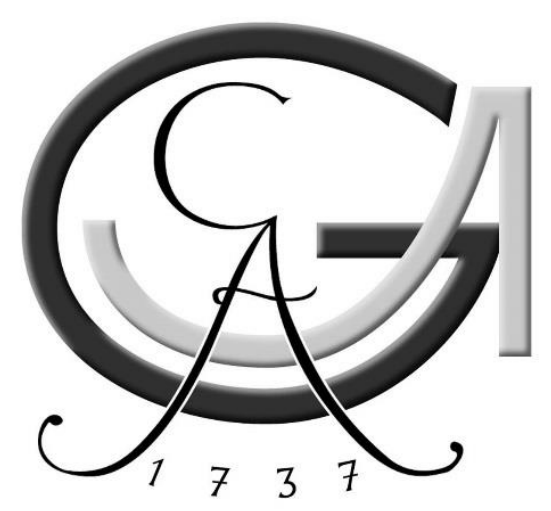

\section{Dissertation}

zur Erlangung des mathematisch-naturwissenschaftlichen Doktorgrades

$$
\begin{gathered}
\text { „Doctor rerum naturalium“ (Dr. rer. nat.) } \\
\text { im Promotionsprogramm BioMetals }
\end{gathered}
$$

der Georg-August-University School of Science (GAUSS)

vorgelegt von

Christine E. Schiewer

aus Menden

Göttingen 2018 
$\underline{\text { Betreuungsausschuss }}$

Prof. Dr. Franc Meyer

Institut für Anorganische Chemie, Georg-August-Universität Göttingen

Prof. Dr. Kai Tittmann

Zentrum für Molekulare Biowissenschaften, Georg-August-Universität Göttingen

Prof. Dr. Ebbe Nordlander

Chemical Center, Lund University, Sweden

Mitglieder der Prüfungskommission

Referent: Prof. Dr. Franc Meyer

Institut für Anorganische Chemie, Georg-August-Universität Göttingen

Korreferent: Prof. Dr. Kai Tittmann

Zentrum für Molekulare Biowissenschaften, Georg-August-Universität Göttingen

Weitere Mitglieder der Prüfungskommission:

Prof. Dr. Inke Siewert

Institut für Anorganische Chemie, Georg-August-Universität Göttingen

Jun. Prof. Dr. Selvan Demir

Institut für Anorganische Chemie, Georg-August-Universität Göttingen

Dr. Franziska Thomas

Institut für Organische und Biomolekulare Chemie, Georg-August-Universität Göttingen

Dr. Matthias Otte

Institut für Anorganische Chemie, Georg-August-Universität Göttingen

Tag der mündlichen Prüfung: 23.02.2018 


\section{Table of Contents}

1.1 Evolution of life and the discovery of iron-sulfur clusters ....................................................... 1

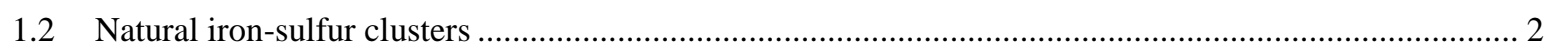

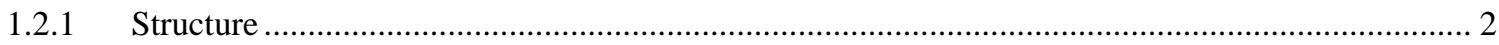

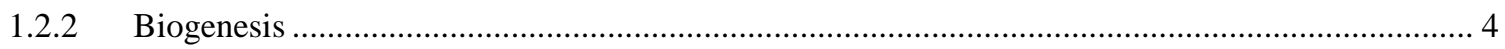

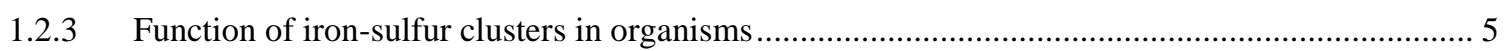

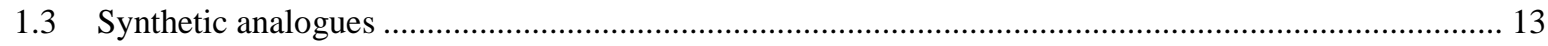

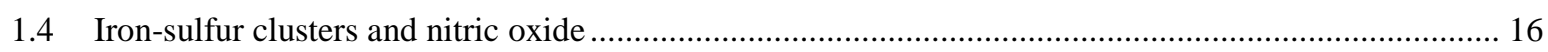

1.4.1 Nitric oxide as vital messenger molecule and cytotoxic effector ............................................ 16

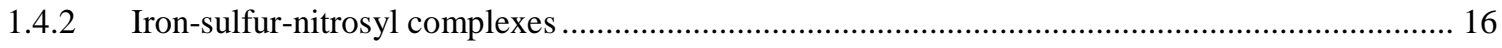

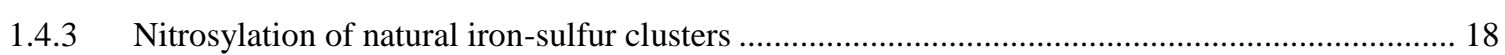

1.4.4 Nitrosylation of biomimetic iron-sulfur clusters ....................................................... 21

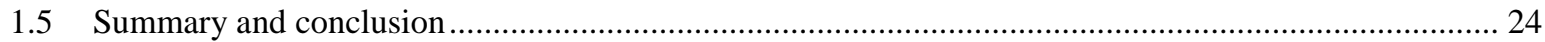

2 Nitrosylation of $[2 \mathrm{Fe}-2 \mathrm{~S}]$ clusters in their diferric, mixed-valent, and protonated state ..................25

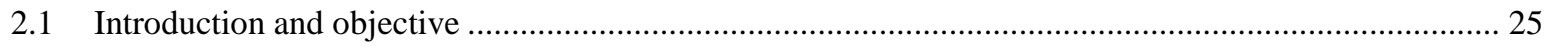

2.2 Nitrosylation of diferric homoleptic coordinated $[2 \mathrm{Fe}-2 \mathrm{~S}]$ clusters ............................................... 27

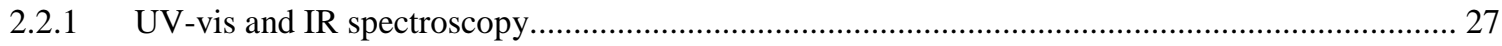

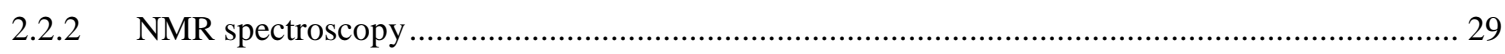

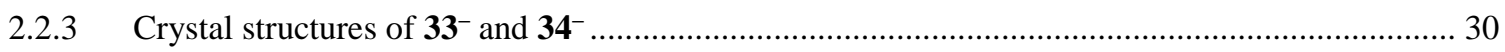

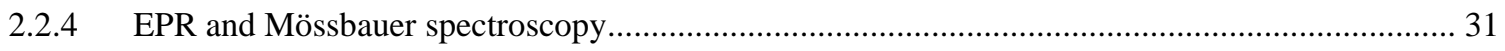

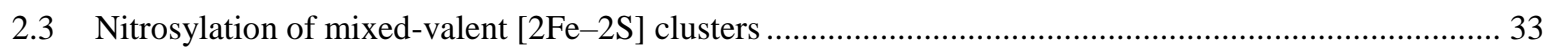

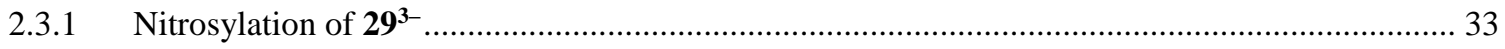

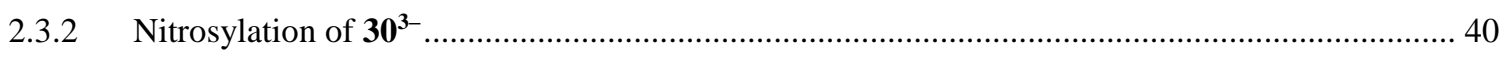

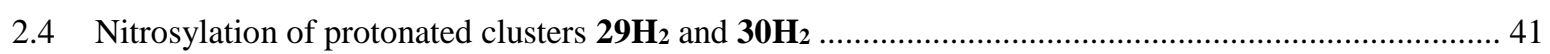

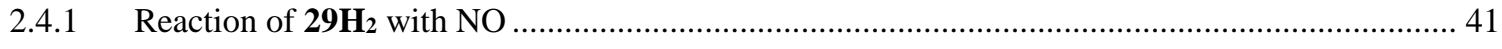

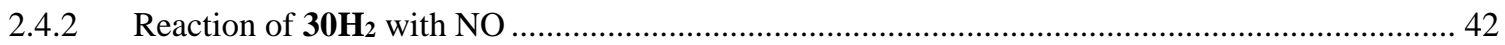

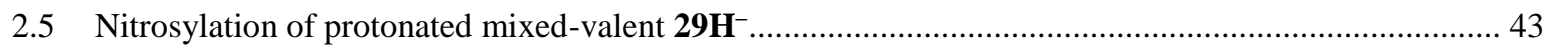

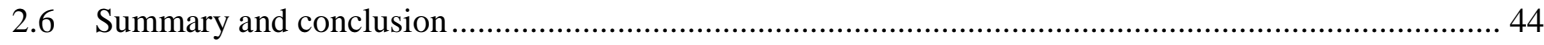

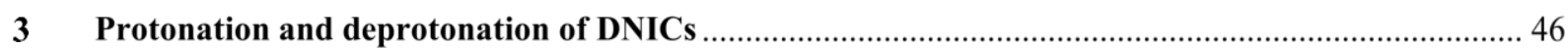

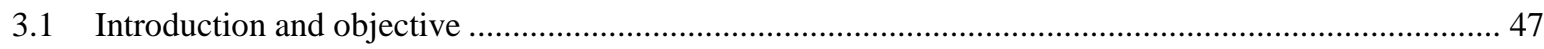

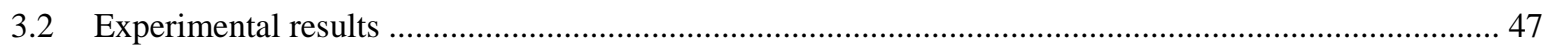

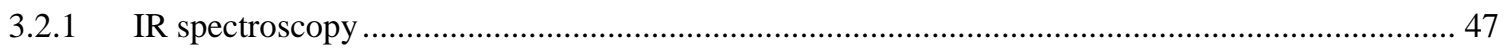

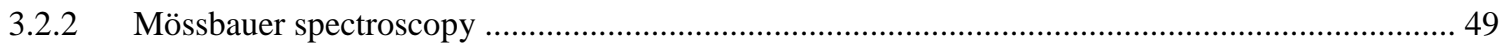

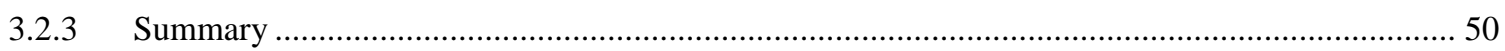

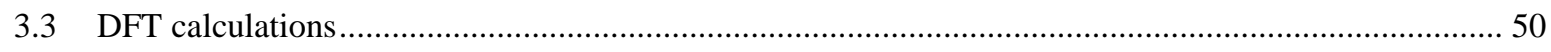

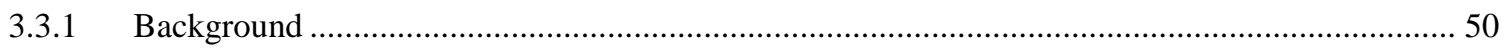

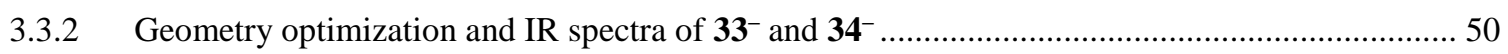

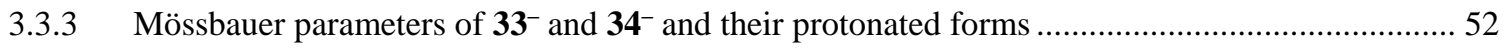




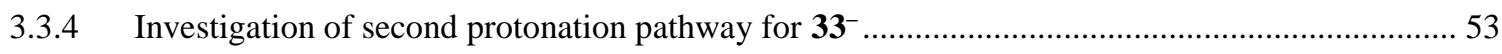

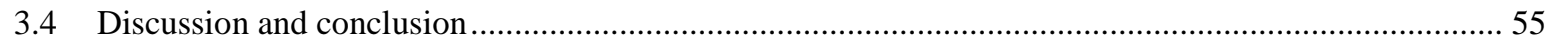

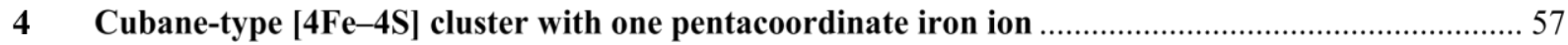

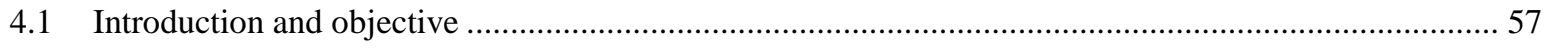

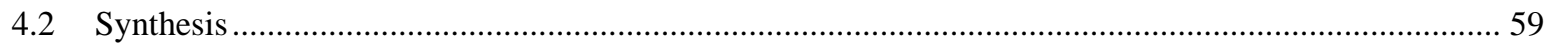

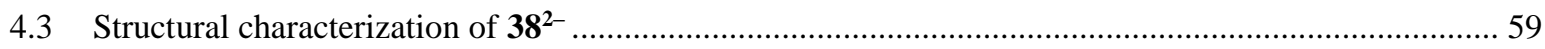

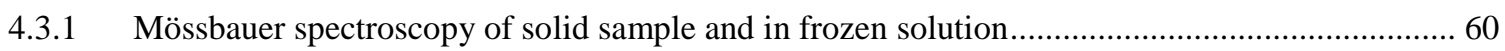

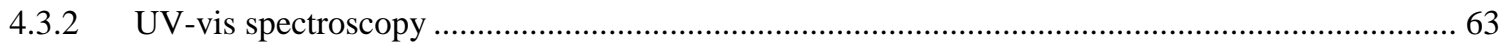

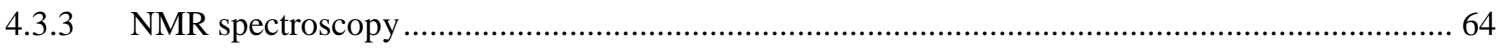

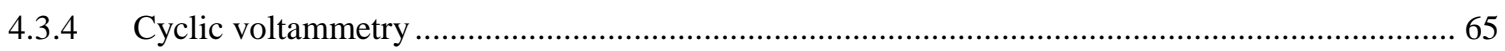

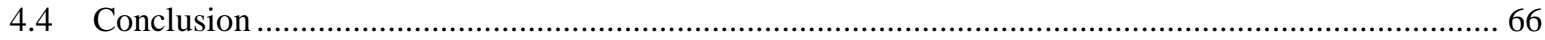

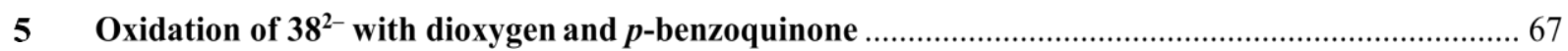

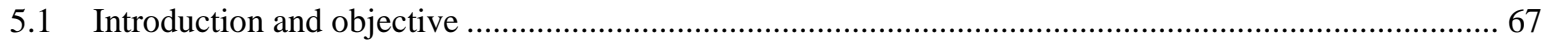

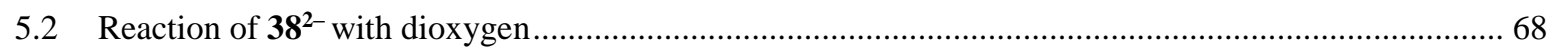

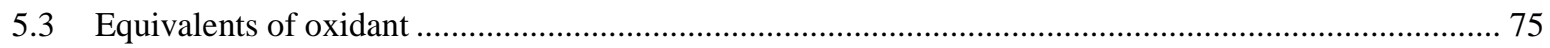

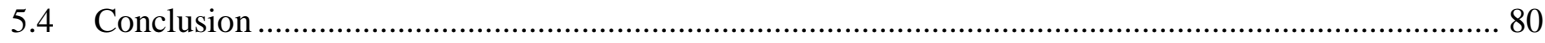

6 Protonation of 5,6-Dithia-1,10-phenanthroline, its application as disulfide/dithiol switch, and as

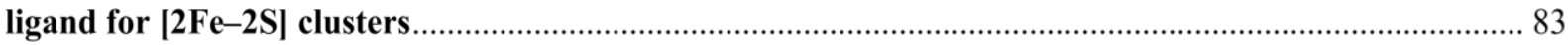

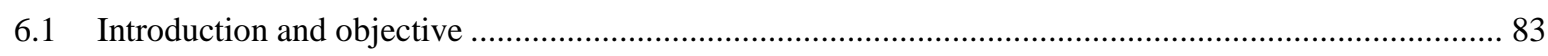

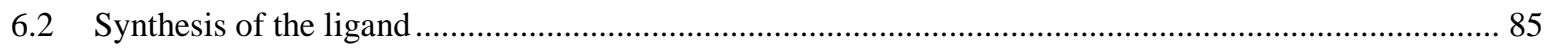

6.3 UV-vis titration of 41 with PhCOOH, TFA and TfOH in MeCN .................................................. 86

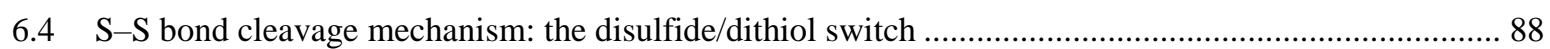

6.5 Preliminary application as a chelate ligand for [2Fe-2S] clusters ........................................... 94

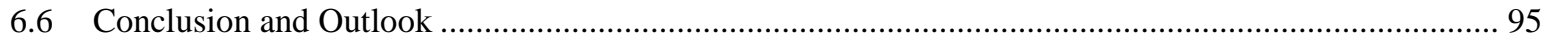

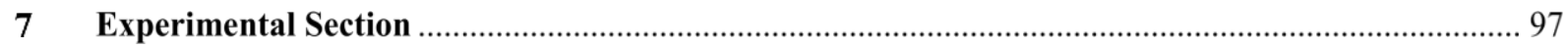

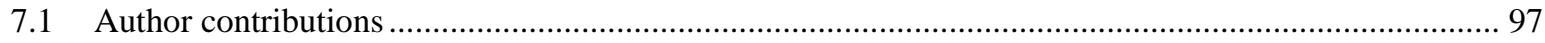

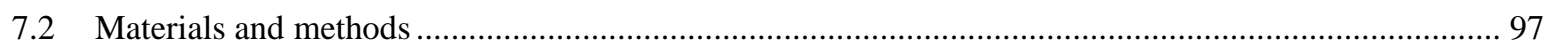

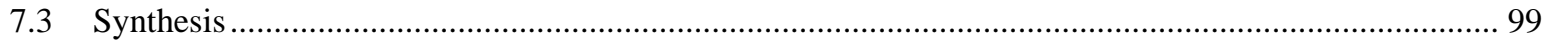

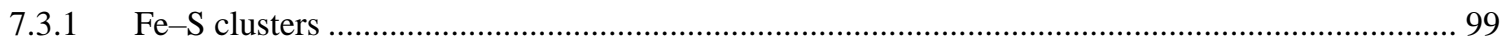

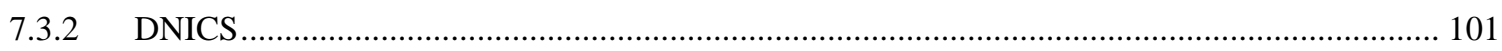

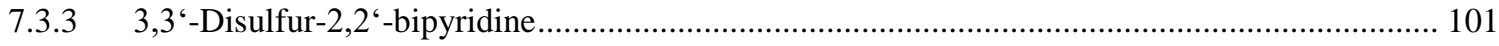

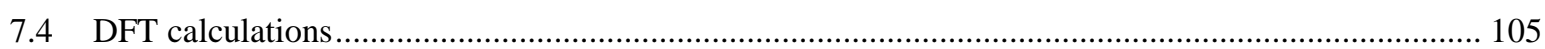

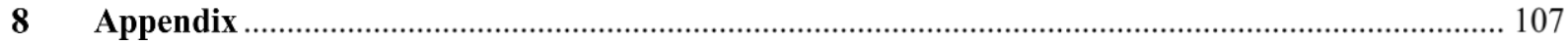

8.1 Benchmark substances for X-ray spectroscopy of iron-sulfur clusters ....................................... 107

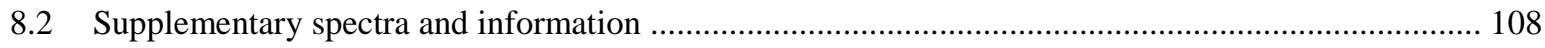


Curriculum Vitae. 



\section{Introduction}

\subsection{Evolution of life and the discovery of iron-sulfur clusters}

Iron-sulfur clusters are ubiquitous and essential prosthetic groups found in bacteria, plants, animals, and archaea. Their structural versatility allows them to fulfill various tasks in organisms, e.g. electron transfer, substrate binding/activation, and iron or sulfur storage. ${ }^{1}$

\section{Evolution}

Iron-sulfur clusters are arguably one of the oldest cofactors and they are believed to be of fundamental importance to the evolution of pioneer organisms in volcanic vents. According to the Iron-Sulfur World theory, ${ }^{2,3}$ these organisms were composed of an organic superstructure and an inorganic substructure which supported the development of the organic superstructure by chemoautotrophy. Carbon fixation was performed at catalytic active metal centers, in which iron was the most abundant transition metal under the reducing potential of the volcanic exhalation. Dissolved ferrous ions underwent sulfidation in an anaerobic, volcanic environment to produce ferrous sulfide (FeS) which in turn ultimately formed pyrite $\left(\mathrm{FeS}_{2}\right)$, the most stable mineral under those conditions. Additionally, pyrite could have provided reducing power to the pioneer organisms.

The Iron-Sulfur World theory is promoted by two discoveries. Firstly, it is possible to imitate the reaction in vitro by carbon fixation from activated acetic acid on nickel and iron sulfide, $(\mathrm{Ni}, \mathrm{Fe}) \mathrm{S}$, under primordial conditions. ${ }^{4}$ Secondly, the universal redox carrier in living organisms, nicotinamide adenine dinucleotide $\left(\mathrm{NAD}^{+}\right)$and nicotinamide dinucleotide phosphate (NADP), are not stable at high temperatures and therefore they had not been available for ancient thermophile organisms. These organisms relied on nonheme iron proteins instead..$^{5}$ Recently published results by Mansy and coworkers describe the synthesis of $[2 \mathrm{Fe}-2 \mathrm{~S}]$ and $[4 \mathrm{Fe}-4 \mathrm{~S}]$ clusters through photooxidation of ferrous ions and photolysis of organic thiols. ${ }^{6}$

\section{Discovery and scientific progress}

Although iron-sulfur clusters are one of the oldest prosthetic groups and abundant in all life forms, they were discovered only in the second half of the $20^{\text {th }}$ century by EPR spectroscopy. ${ }^{7}$ Beinert and Sands detected the famous hallmark " $g=1.94$ signal" in mitochondrial membranes in $1960 .{ }^{8}$ At that time, the source of the signal was unclear and 
controversially discussed in the scientific community. Analytical determination revealed that the proteins only constitute of iron, cysteinate and inorganic, "acid-labile" sulfur atoms. Six years later, Gibson et al. resolved the dispute by explaining the signal with two iron ions that are antiferromagnetically coupled over a sulfur bridge. ${ }^{9}$ Other spectroscopic methods were used to elucidate the structure and electronic properties of iron sulfur proteins, including magnetic susceptibility, electron-nuclear double-resonance (ENDOR), Mössbauer spectroscopy, and crystal structures from X-ray diffraction.

During the 1970's, a significant leap in iron-sulfur cluster research was obtained by Holm and coworkers using synthetic analogues. ${ }^{10,11}$ While model clusters share all basic features with protein-bound clusters, they are unfortunately not stable in aqueous solution or aerobic conditions. Nevertheless, synthetic analogues contributed greatly to the elucidation of the electronic structure of their natural counterparts and offer a reasonable approach to the investigation of general properties of iron-sulfur clusters.

\subsection{Natural iron-sulfur clusters}

\subsubsection{Structure}

The simplest iron-sulfur center, rubredoxin (1, Figure 1.1), consists of only one iron atom that is ligated by four deprotonated cysteine amino acid sidechains from the polypeptide protein backbone in distorted tetrahedral coordination. The name rubredoxin pays tribute to the strong red color due to a ligand to metal charge transfer (LMCT) from the thiolate ligand to the ferric ion. The color bleaches upon reduction to ferrous iron. Rubredoxins are exceptional in the iron-sulfur cluster family because their structural motif excludes "acidlabile", inorganic sulfides. All clusters of higher nuclearity have bridging sulfides that impact the clusters' electronic properties greatly. The cluster core of ferredoxins is constituted of either two iron ions and two sulfides, [2Fe-2S] (2), or four iron ions and four sulfides, $[4 \mathrm{Fe}-4 \mathrm{~S}]$ (4). These prosthetic groups are dubbed ferredoxins because of the iron content and their predominant role as redox carriers in electron transport chains. [4Fe-4S] clusters have a cube-like structure in which four corners that are opposed to each other are occupied by an iron ion and the others by sulfide. When iron is formally removed from one corner, the also biologically relevant cuboidal-type [3Fe-4S] (3b) cluster is formed. Interconversion between a linear and a cuboidal $[3 \mathrm{Fe}-4 \mathrm{~S}]$ clusters was observed in mitochondrial aconitase when exposed to urea or a $\mathrm{pH}$ higher than $9 .{ }^{13}[4 \mathrm{Fe}-4 \mathrm{~S}]$ clusters can be converted into $[2 \mathrm{Fe}-2 \mathrm{~S}]$ clusters under physiological conditions. ${ }^{14}$ Iron-sulfur 
clusters with higher nuclearity are generated through metal substitution in specialized enzymes or merging of simpler iron-sulfur clusters. ${ }^{15}$

Iron-sulfur clusters are most commonly ligated by cysteine; other ligands reported include histidine, aspartate, arginine, serine, or the amide groups of peptides. ${ }^{16}$ These alternative ligands modify the redox potential (Rieske, $\mathbf{2 a})^{17}$, gate electron transport ${ }^{18}$ or couple proton and electron transport (2a and $\mathbf{2 b}) .{ }^{19,20}$

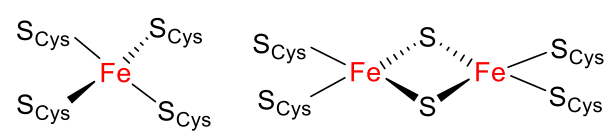

1

$[\mathrm{Fe}]$ Rubredoxin

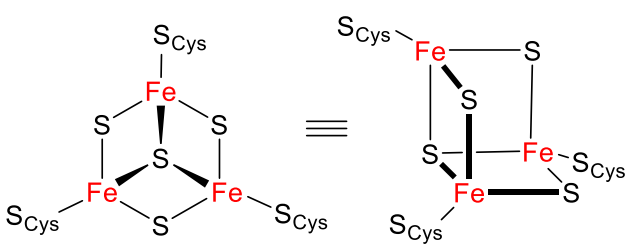

3b [3Fe-4S] cuboidal

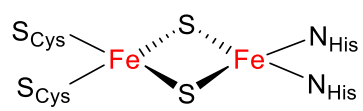

2a

[2Fe-2S] Rieske

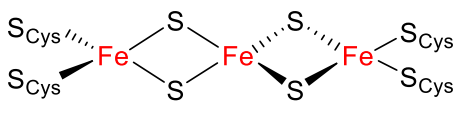

$3 a$

[3Fe-4S]

linear

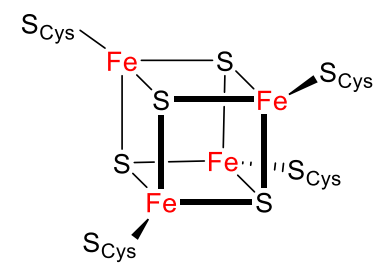

4

[4Fe-4S]

Ferredoxin

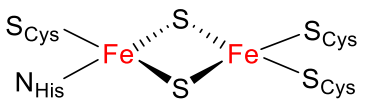

2b

[2Fe-2S]

mitoNEET

Figure 1.1. Common structural motifs in natural iron-sulfur clusters. 


\subsubsection{Biogenesis $^{21}$}

In 1966, Malkin and Rabinowitz reported that certain apoforms of [2Fe-2S] and [4Fe-4S] proteins can be activated in vitro by the simple addition of $\mathrm{S}^{2-}$ and $\mathrm{Fe}^{2+/ 3+}$ ions. ${ }^{22}$ However, biogenesis of $\mathrm{FeS}$ proteins is a complex and delicate process in living cells rather than spontaneous self-assembly. Cluster maturation is catalysed by dedicated enzymatic multicomponent systems, namely the NIF (nitrogen fixation), ISC (iron sulfur cluster) and SUF (sulfur assimilation) machineries in prokaryotes. ${ }^{23-26}$ The NIF system deals with maturation of nitrogenase in nitrogen-fixing bacteria and maturation of general $\mathrm{Fe}-\mathrm{S}$ proteins in some anaerobic organisms lacking nitrogenase. The ISC machinery is found in $\alpha-, \beta$ - and $\gamma$-proteobacteria and in mitochondria. SUF is present in the majority of prokaryotes and in chloroplasts. E. coli, as member of the Enterobacteriaceae family, possesses both, the ISC and SUF machinery. ISC operates under normal conditions, while the SUF machinery subs in when the cell is under oxidative stress or suffers from iron starvation. Fe-S cluster biogenesis is more complex in eukaryotes because it combines ISC and CIA (Cytoplasmic Iron-Sulfur Protein Asssembly). ${ }^{27-29}$ The CIA machinery is responsible for the assembly of cytosolic and nuclear $\mathrm{Fe}-\mathrm{S}$ proteins while ISC matures $\mathrm{Fe}-$ $\mathrm{S}$ clusters in mitochondria. The cytoplasmic CIA depends on the mitochondrial ISC and export machineries. ${ }^{30}$

The importance of Fe-S clusters to life is stressed by mitosoms which reduced their genome content by evolution as far as possible. They still have the ISC machinery, although they cannot even produce ATP by themselves. ${ }^{31}$ On the other hand, Takahashi and coworkers reported recently of $E$. coli mutants that can survive without $\mathrm{Fe}-\mathrm{S}$ cluster assembly. ${ }^{32}$

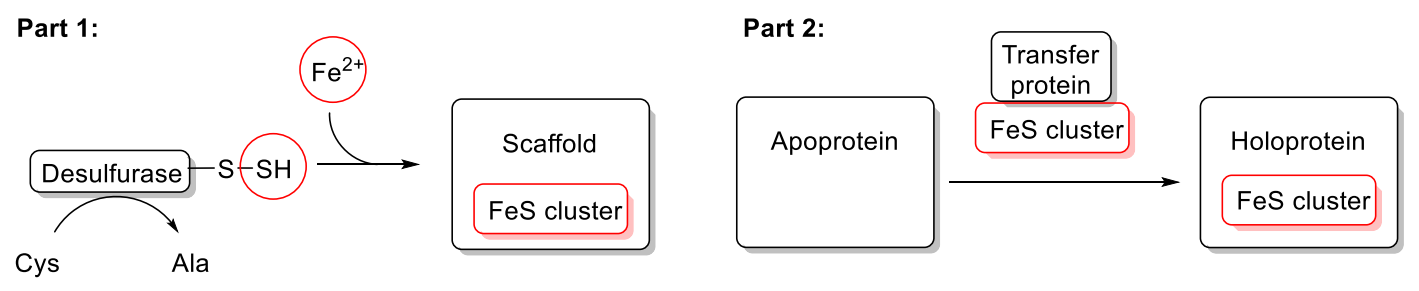

Figure 1.2: Simplified model for the biogenesis of iron-sulfur clusters.

In general, the ISC assembly consists of two parts (Figure 1.2). The first part is the de novo synthesis of a Fe-S cluster on a scaffold protein. A desulfurase releases the sulfur from a cysteine as a persulfide/hydrodisulfide which is transferred to the scaffold protein. Electrons are provided via ferredoxin and ferredoxin reductase for the reduction from $S^{0}$ in 
the cysteine to $S^{2-}$ in the cluster. The iron ions are delivered by specific iron donors. The cluster is bound to the scaffold protein in a labile fashion by conserved cysteine residues as a $[2 \mathrm{Fe}-2 \mathrm{~S}]$ cluster. The intermediate $[2 \mathrm{Fe}-2 \mathrm{~S}]$ cluster can be transformed later into [4Fe$4 \mathrm{~S}$ ] clusters or clusters of higher nuclearity by a dedicated set of ISC machinery. In the second part of the cluster assembly, the labile Fe-S cluster is transferred to the target apoprotein by chaperones or transfer proteins. The transfer proteins are essential in living cells to promote an accurate and specific transport to the correct acceptor site. Finally, the holoprotein is assembled into the polypeptide chain.

In 2017, Adams and coworkers published the discovery that the protein IssA stores iron and sulfur as thioferrate (Figure 1.3) in metalloprotein complexes with a diameter of up to $300 \mathrm{~nm}$. It was shown that thioferrate can provide the iron and sulfur units necessary to reconstruct $[4 \mathrm{Fe}-4 \mathrm{~S}]$ clusters in ferredoxin in vitro. ${ }^{33}$

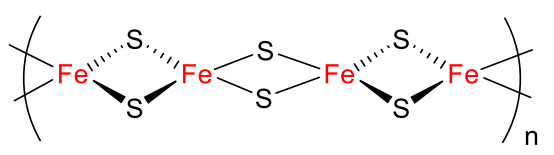

Figure 1.3. Structure of the inorganic polymer thioferrate.

As $\mathrm{Fe}-\mathrm{S}$ proteins are essential to several processes in cells, shortcomings in the biogenesis thereof are linked to several fatal diseases most of which have an impact on the whole organism. Common features are, firstly, that all diseases are rare with a prominent mitochondrial phenotype because the ISC biogenesis is crucial for mammalian cells to survive. Secondly, tissues demanding high energy are primarily affected, e.g. neurons, muscles, heart tissues. Thirdly, iron dysregulation is always implicated. This means that mitochondrial iron accumulation/deposit is a key feature of these diseases. The best researched disease is Friedreich's ataxia, but others include microcytic anaemia and erythropoietic protoporphyria. ${ }^{34,35}$

\subsubsection{Function of iron-sulfur clusters in organisms ${ }^{36}$}

Iron-sulfur clusters as electron carriers: unique and tunable redox properties

Generally, metal ions are more versatile than organic redox molecules in regard to redox behavior. The reduction potential is strongly dependent on the coordination sphere around the cluster, but also hydrogen bonding with peptides and water has a strong influence on the reduction potential. This can be seen by the wide range of redox potentials $(-700$ to $450 \mathrm{mV} v s . \mathrm{SHE})^{16}$ covered by iron-sulfur proteins (Figure 1.4). ${ }^{37}$ Iron-sulfur clusters are 
well suitable for biological electron transport because they can delocalize electron density over both iron and sulfur atoms, as the $\mathrm{Fe}-\mathrm{S}$ bonds are rather covalent. ${ }^{38}$ The reorganization energy is comparatively small due to metal-ligand covalency and valence delocalization when iron is reduced or oxidized. This allows for a very fast electron transfer. There is a much smaller change in the total electron density on the iron than is indicated by the formal valence difference. ${ }^{38}$

Examples for iron-sulfur clusters involved in electron transfer are ferredoxins in the respiratory chain in complexes I, II, and III. In these proteins, the clusters form a wire that delivers electrons one at a time between redox couples that are physically separated. Only few unique Fe-S clusters such as the double-cubane $[8 \mathrm{Fe}-7 \mathrm{~S}]$ cluster of nitrogenase have the potential to act as two electron carrier under physiological conditions. ${ }^{39}$

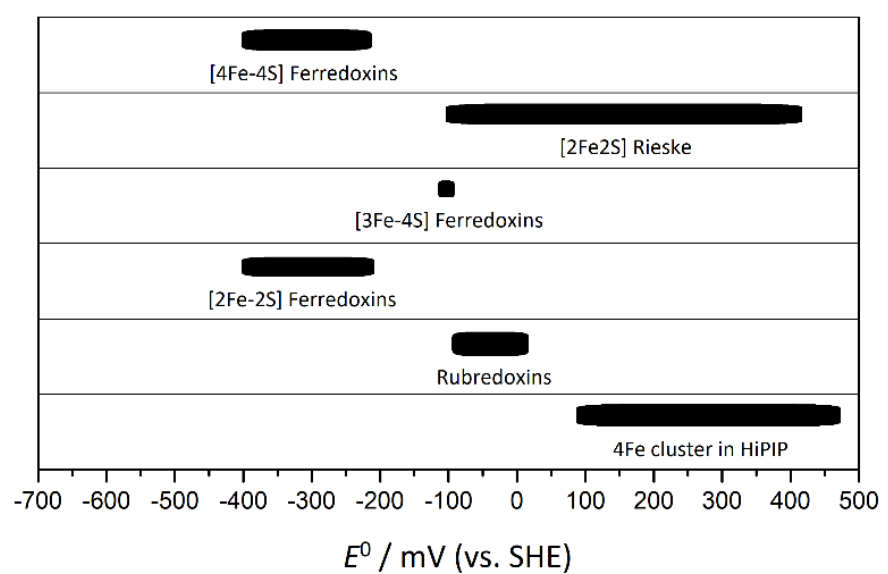

Figure 1.4. Experimental ranges of redox potentials of various iron-sulfur proteins. ${ }^{16,37}$

The most common metal oxidation levels of iron-sulfur clusters include $\mathrm{Fe}^{2+}$ and $\mathrm{Fe}^{3+}$ ions as seen in rubredoxin (Figure 1.5, a) or a mixture thereof in clusters with higher nuclearity. The electronic structure and distribution of charge can be determined with EPR, ENDOR, Mössbauer, and MCD spectroscopy. A summary of the most common oxidation states of rubredoxins and ferredoxins is depicted in Figure 1.5. 
a)

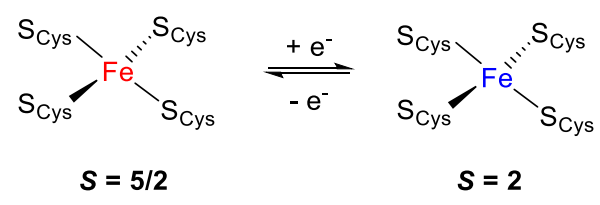

b)

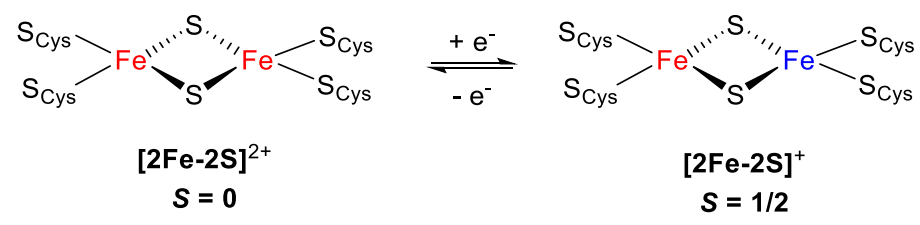

c)
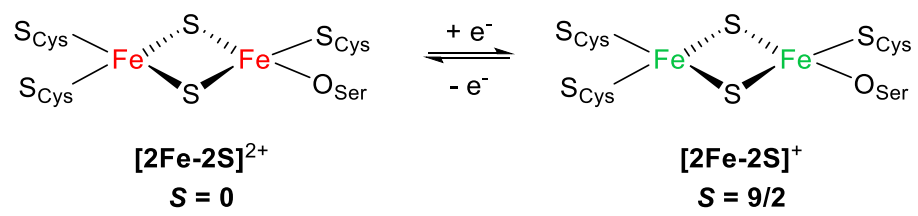

d)
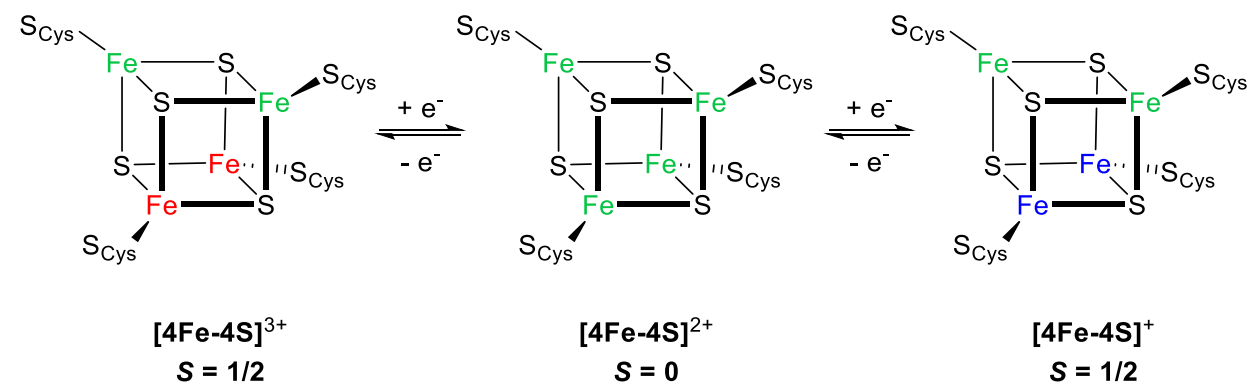

Figure 1.5. Localization and delocalization patterns in common FeS clusters, showing localized $\mathrm{Fe}^{3+}$ (red), localized $\mathrm{Fe}^{2+}$ (blue) sites and delocalized $\mathrm{Fe}^{2.5+} \mathrm{Fe}^{2.5+}$ pairs (green). Indicated also are the core oxidation state and the spin of the cluster. Figure is adapted from literature. ${ }^{1}$

In the case of the diferric $[2 \mathrm{Fe}-2 \mathrm{~S}]$ clusters, two $\mathrm{Fe}^{3+}$ ions with a spin of $5 / 2$ couple antiferromagnetically resulting in an overall spin $S=0$. When the cluster is reduced the electron can either be localized on one iron ion (Figure 1.5, b) or is delocalized over both iron ions leading to an oxidation state of +2.5 each (Figure 1.5, c). The latter was observed in a mutant form of Clostridium pasteurianum ferredoxin in which one cysteine residue was exchanged for serine. ${ }^{40}$ The result is a mixed-valence state with parallel spins and $S=$ 9/2. Case b can be easily distinguished from $c$, as it gives a typical EPR signal at $g=1.94$. The core of $[4 \mathrm{Fe}-4 \mathrm{~S}]$ ferredoxins has a charge of +2 in their resting state (Figure 1.5, $\mathrm{d}$ middle). They are composed of two mixed-valence pairs antiferromagnetically coupled to each other resulting in $S=0$. When this cluster is reduced by one electron, two ferrous iron ions couple ferromagnetically to $S=4$ and a mixed-valence pair couples to $S=9 / 2$. The two pairs then again couple antiferromagnetically resulting in overall $S=1 / 2$. All-ferrous clusters have been reported, however, they are not naturally occurring. ${ }^{12,41,42}[4 \mathrm{Fe}-4 \mathrm{~S}]^{3+}$ is the resting state of the so called high-potential iron proteins (HiPIPs) with one mixedvalence pair and one pair with two ferric ions. ${ }^{43}$ The electron can also tunnel to the other 
pair. ${ }^{44}$ HiPIPs are small globular proteins with little to no secondary structure. ${ }^{45}$ The $[4 \mathrm{Fe}-$ $4 \mathrm{~S}$ ] cluster is bound to four cysteines like in ferredoxins, however the HiPIP cluster is buried within the protein interior in a hydrophobic cavity while the clusters in ferredoxins are more exposed on the surface. The HiPIP cluster implements the $[4 \mathrm{Fe}-4 \mathrm{~S}]^{3+, 2+}$ transition as a result of its hydrophobic environment and hydrogen-bonding network. HiPIPs act as electron donors on the tetraheme cytochrome in photosynthetic bacteria with their exceptionally high redox potential $\left(+100\right.$ to $+450 \mathrm{mV} v s$. NHE) ${ }^{46}$

Alternative ligands as histidine have a great impact on the redox potential and chemical properties of $\mathrm{Fe}-\mathrm{S}$ clusters. ${ }^{16,47}$ Rieske $[2 \mathrm{Fe}-2 \mathrm{~S}]$ proteins (2a, Figure 1.1) are found in respiratory (cytochrome $b c_{1}$ in mitochondria and bacteria) and photosynthetic (cytochrome $b_{6} f$ in chloroplasts) membrane-associated electron transfer complexes,,${ }^{17}$ as well as in some oxygenases. ${ }^{48}$ The $[2 \mathrm{Fe}-2 \mathrm{~S}]$ cluster is bound by two cysteine and two histidine residues. The difference in the net charges of the ligands causes an upshift of the redox potential $\left(-100\right.$ to $+490 \mathrm{mV}$ vs. NHE) for the $[2 \mathrm{Fe}-2 \mathrm{~S}]^{2+/+}$ reduction/oxidation. Rieske proteins conduct proton coupled electron transfer as the proton from the $\mathrm{N}-\mathrm{H}$ group of the imidazole is released easily with $\mathrm{p} K_{\mathrm{a}}$ values of 7.4 and 9.1 in the oxidized diferric state, and around 12.5 in the reduced mixed valence state. ${ }^{49,50} \mathrm{Fe}-\mathrm{S}$ clusters of Rieske proteins are close to the protein surface, and express $\mathrm{pH}$ - and ionic strength-dependent redox behavior. On the other hand, low-potential Rieske proteins have $\mathrm{pH}$-independent redox potentials of around $-150 \mathrm{mV} v s . \mathrm{NHE}^{51}$

Another example for $\mathrm{Fe}-\mathrm{S}$ clusters with alternative ligands are $\mathrm{CDGSH}$ iron-sulfur domains including mitoNEET, Miner 1, and Miner 2. MitoNEET (2b, Figure 1.1) is located in the outer membrane of mitochondria. The homodimer binds one $[2 \mathrm{Fe}-2 \mathrm{~S}]$ cluster in each subunit. The cluster is coordinated by three cysteine and one histidine residue in the CDGSH motif. They are redox-active, their redox potential is $\mathrm{pH}$-dependent and they undergo electron transfer, potentially proton coupled. ${ }^{52-54}$

Histidine ligated $[4 \mathrm{Fe}-4 \mathrm{~S}]$ clusters can be found in the distal clusters of an electron-transfer chain in hydrogenase enzymes. ${ }^{55}$

\section{Sensing and regulation of gene expression ${ }^{56-58}$}

Regulatory enzymes comprise a sensor domain - in this case one or more Fe-S clusters and a functional domain containing a DNA binding site to promoter regions of genes. After environmental stimuli the structure of the regulatory protein changes and allows for 
protein-protein interaction with RNA polymerase (RNAP) or alternation of the DNA architecture which leads to expression of target genes. On the other hand, RNAP can be hindered at recognizing the promoter elements and thus transcription is repressed.

Generally, Fe-S clusters are ideal for sensing environmental signals like gases $\left(\mathrm{O}_{2}, \mathrm{NO}\right)$, reactive oxygen species (ROS, including superoxide $\left(\mathrm{O}_{2}^{-}\right)$) and hydrogen peroxide $\left(\mathrm{H}_{2} \mathrm{O}_{2}\right)$ due to their high reactivity towards those species. Signal induced changes of the Fe-S core like oxidation or even disruption propagate a conformational change of the regulatory protein and subsequently mediate transcriptive activation. Some proteins have a specificity for more than one signaling molecule and they can alter gene expression to obtain the correct adaptive response.

a)

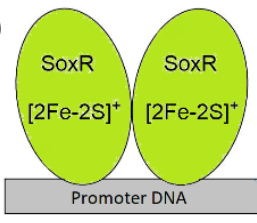

inactive

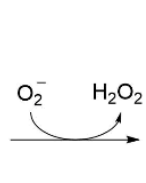

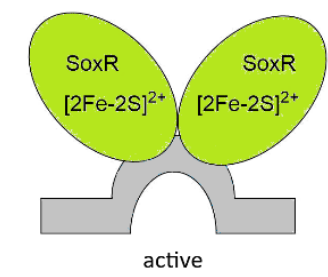

b)

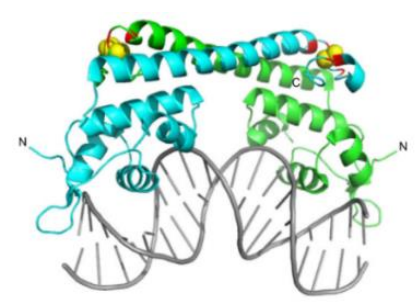

Figure 1.6. a) Cartoon of the mechanism for SoxR transcriptional activation. ${ }^{59}$ b) Crystal structure of oxidized SoxR bound to DNA and induction of sharp DNA bending. ${ }^{57}$

SoxR (superoxide response regulator) is a sensor to oxidative stressors like NO, superoxide $\left(\mathrm{O}_{2}{ }^{-}\right)$, and redox-cycling agents in E. coli. ${ }^{60}$ It is constituted of a dimeric transcriptional activator with one [2Fe-2S] cluster in each $17 \mathrm{kDa}$ monomer (Figure 1.6, a). The resting state is the mixed-valent $[2 \mathrm{Fe}-2 \mathrm{~S}]^{+}$which is reversibly oxidized to $[2 \mathrm{Fe}-$ $2 \mathrm{~S}]^{2+}$. Oxidation reorients the promoter DNA element (Figure 1.6, b) to allow transcription of more than 100 genes in the SoxRS regulon as stress-response against the oxidative stress. Expressed proteins include superoxide dismutase (SOD), oxidized-DNA repair endonucleases and oxidation-resistant enzymes. When oxidative stress abates, reducing systems have SoxR returning in its reduced state.

One of the best studied global regulatory proteins is FNR (fumarate and nitrate reduction) regulator, also known as the "master switch" between aerobic and anaerobic respiration in E. coli. The transcription factor triggers the shift from an anaerobic to aerobic metabolism by sensing the level of oxygen in the cell. ${ }^{61}$ Only the dimeric [4Fe-4S] protein can bind to DNA. The $[4 \mathrm{Fe}-4 \mathrm{~S}]$ cluster converts quickly into two $[2 \mathrm{Fe}-2 \mathrm{~S}]$ clusters in the presence of $\mathrm{O}_{2}$ and the protein loses its dimerization. ${ }^{62}$ This process can be reversed when anaerobic conditions are reestablished. ${ }^{14}$ When it is active it controls 200 genes involved in anaerobic 
oxidation of carbon sources and reduction of electron acceptors, e.g. nitrate, fumarate, and DMSO, and represses genes specifically for aerobic metabolism. ${ }^{57}$ FNR also plays a role in sensing NO (see Chapter 1.4.3). However, NO sensing is a secondary function of FNR because fewer proteins are affected than with $\mathrm{O}_{2}$. Other $\mathrm{O}_{2}$ sensing regulators include NreB in Staphylocci. ${ }^{57}$

It is a challenge to decipher whether reactions of $\mathrm{Fe}-\mathrm{S}$ clusters with signaling molecules are physiologically relevant or simply adventitious. At times proteins react in vitro with signaling molecules although the reaction does not occur in the living organism. Enzymes that react to oxidative stress often also react to nitrosative stress. However, there are also enzymes that are specialized to act on nitrosative stress. NsrR is a wide-spread dedicated NO sensor e.g. in $\beta$ - and $\gamma$-proteobacteria. Upon nitrosylation of the sensing [4Fe-4S] cluster, NsrR loses DNA binding. This process activates genes involved in NO detoxification and damage repair that were repressed before. Expressed genes are hmp, encoding a flavohemoglobin, $y t f E$, implicated in Fe-S cluster repair, and, $n r f$, encoding the NrfA periplasmic nitrite reductase. ${ }^{63}$ Recently, the crystal structure of NsrR from in the dimeric holo form and as apo-DNA complex was reported by Le Brun, Fontecilla-Camps and coworkers. ${ }^{64}$

WhiB-like proteins (Wbl), exclusive to Actinobacteria, fulfill a wide range of functional roles. Among them are cell division, sporulation, nutrient starvation, antibiotic resistance, virulence, and oxidative stress response. ${ }^{57}$ WhiD of $S$. coelocolor and WhiB1, B3, and B4 of Mycobacterium tuberculosis contain a NO-sensitive [4Fe-4S] cluster ligated by four cysteine residues. Following cluster nitrosylation or in their apo-protein form, Wbl proteins bind DNA with high affinity. Further information on nitroslyation of Wbl proteins is provided in chapter 1.4.3. ${ }^{57}$

Maintaining homeostasis of iron is essential in cells. Iron serves in cofactors such as heme and $\mathrm{Fe}-\mathrm{S}$ clusters in most organisms, but an excess of iron under aerobic conditions catalyzes the formation of reactive oxygen species (ROS) that ultimately destroy cellular compounds like proteins, DNA and lipids. IscR (Proteobacteria) and SufR (Cyanobacteria) sense the $\mathrm{Fe}-\mathrm{S}$ cluster levels as part of control genes in $\mathrm{Fe}-\mathrm{S}$ biogenesis. IRP (iron regulatory protein) controls and maintains the iron homeostasis in mammals. ${ }^{65}$ 
Iron-sulfur clusters in enzymes: substrate binding and activation

$\mathrm{Fe}-\mathrm{S}$ clusters are involved in the activation of small molecules in bacteria and archaea. The enzyme nitrogenase catalyzes the reduction of dinitrogen to ammonia via the catalytically active Fe-Mo subprotein. The Fe-Mo subprotein contains two $\mathrm{Fe}-\mathrm{S}$ clusters of high nuclearity: the $\mathrm{P}^{\mathrm{N}}$-cluster and the iron molybdenum cofactor (FeMoCo, Figure 1.7). The $\mathrm{P}^{\mathrm{N}}$-cluster mediates intramolecular electron transfer to the FeMoCo where the reduction of dinitrogen takes place. The FeMoCo comprises of a large $\left[\mathrm{MoFe}_{7} \mathrm{~S}_{9}\right.$-homocitrate] complex with an unusual interstitial carbon atom in the center. ${ }^{66,67}$ Quantum mechanical calculations suggest that the central carbon is bound through six covalent $\mathrm{C}-\mathrm{Fe}$ bonds and thus is well stabilized. ${ }^{68}$ Some bacteria are able to produce alternative nitrogenases with vanadium or iron ions if molybdenum supply is scarce. ${ }^{69}$ Vanadium nitrogenase is also capable of reducing carbon monoxide and converting it to ethylene, ethane, or propane. ${ }^{70}$

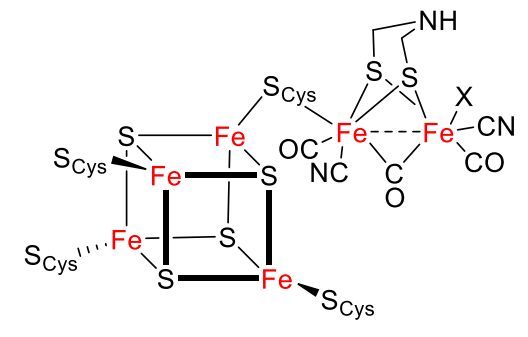

[FeFe]-[4Fe4S] hydrogenase (H-cluster)

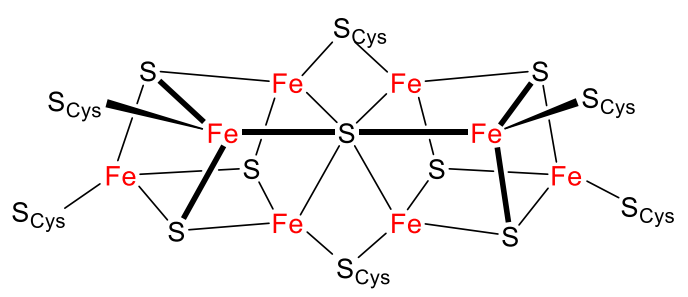

$\mathrm{P}^{\mathrm{N}}$-cluster

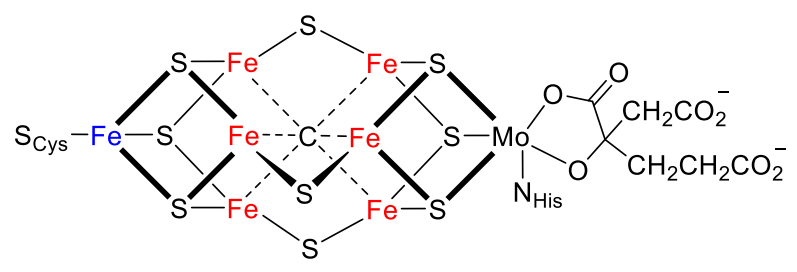

FeMoCo

Figure 1.7. Examples for enzymatic active iron-sulfur clusters in hydrogenases and nitrogenase.

Hydrogenases produce or consume hydrogen. In [NiFe] and [FeFe] hydrogenases several [4Fe-4S] clusters fulfill the task of electron mediator or reservoirs (e.g. the H-cluster, Figure 1.7). ${ }^{71}$ At the active site cyanide and carbonyl ligands stabilizes low oxidation states of the metal ions. Other iron-sulfur cluster containing enzymes are sulfite and nitrite reductases and $\mathrm{Ni}-\mathrm{Fe} \mathrm{CO}$ dehydrogenase $(\mathrm{CODH})$.

Aconitase is an example for non-redox catalysis as no redox chemistry takes place at the $\mathrm{Fe}-\mathrm{S}$ cluster. It converts citrate to isocitrate in the citric acid cycle of all bacteria and 
eukaryotes. In its inactive form, it constitutes of a $[3 \mathrm{Fe}-4 \mathrm{~S}]$ and in its active form of a [4Fe4S] cluster in which one iron has no cysteine ligand and thus serves as a Lewis acid to bind the substrate. ${ }^{72}$ During the catalysis the hydroxy group and a proton of adjacent carbon atoms of citrate are removed and reattached in reversed order. ENDOR spectroscopy was used to elucidate the enzyme-substrate complex, which was later confirmed by crystallography (Figure 1.8). ${ }^{73}$

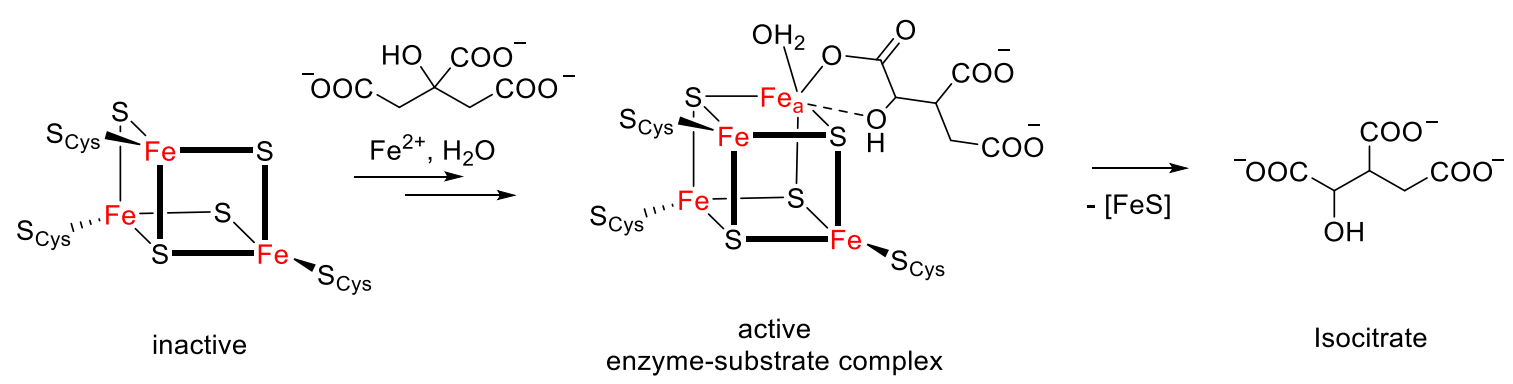

Figure 1.8. Active site of aconitase: reaction of citrate to isocitrate.

The radical-SAM superfamily consists of more than 2800 proteins. These enzymes bind $S$ adenosyl methionine (SAM or AdoMet) in a similar fashion like aconitase via carboxylate and amino groups to a unique iron atom of a $[4 \mathrm{Fe}-4 \mathrm{~S}]$ cluster that is not ligated by cysteine (Figure 1.9). ${ }^{74,75}$ However, the $\mathrm{Fe}-\mathrm{S}$ cluster is redox active during catalysis, in contrast to aconitase. A 5'-deoxyadenosyl radical is formed which then abstracts a hydrogen atom from the organic substrate to initiate a radical mechanism used in the biosynthesis of amino acids, nucleotides, co-enzymes and antibiotics. ${ }^{76-78}$

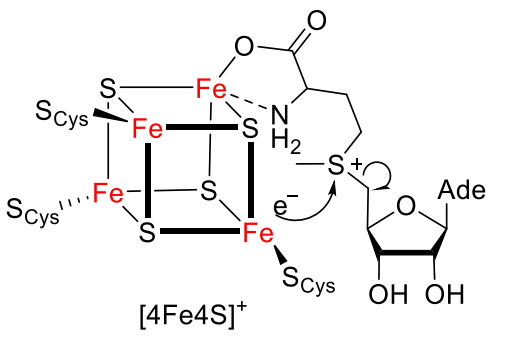

Radical SAM enzyme-substrate complex

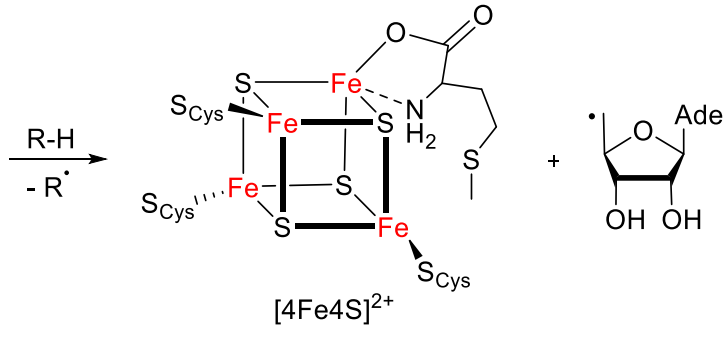

Products after hydrogen abstraction

Figure 1.9. Radical mechanism at active site of a SAM enzyme.

As an example, biotin synthase from E. coli belongs to the radical SAM family. ${ }^{79}$ It employs two molecules of AdoMet to activate two C-H groups in dethiobiotin. An auxiliary $\left.\left[\mathrm{Fe}_{2} \mathrm{~S}_{2} \text { (cys) }\right)_{3}(\arg )\right]$ cluster $^{80}$ in biotin synthase degrades and provides the bridging sulfur atom for the conversion of dethiobiotin to biotin. ${ }^{81}$ 


\section{Other functions of iron-sulfur clusters}

Other functions include $\mathrm{Fe}$ or cluster storage in ferredoxins or polyferredoxins, structural stabilization comparable to $\mathrm{Zn}$-finger proteins (Endonuclease III), regulation of enzyme activity (Glutamine PRPP amidotransferase, Ferrochelatase), disulfide reduction (ferredoxin: thioredoxin reductase, hetero-disulfide reductase), and donation of sulfur during the biosynthesis of some $\mathrm{S}$-containing natural products (biotin synthase, [4Fe-4S] cluster of lipoic acid synthase (LIAS)). ${ }^{82}$

\subsection{Synthetic analogues}

Biologists have established reliable protocols to extract intact $\mathrm{Fe}-\mathrm{S}$ clusters from their protein environment through exchange with exogenous thiolate donors since the 1970s. ${ }^{83}$ At the same time, low-molecular-weight complexes as analogues for biological $\mathrm{Fe}-\mathrm{S}$ clusters were synthesized by chemists. Generally, the synthetic systems model the natural clusters well in terms of structure and function except for a more negative redox potential.
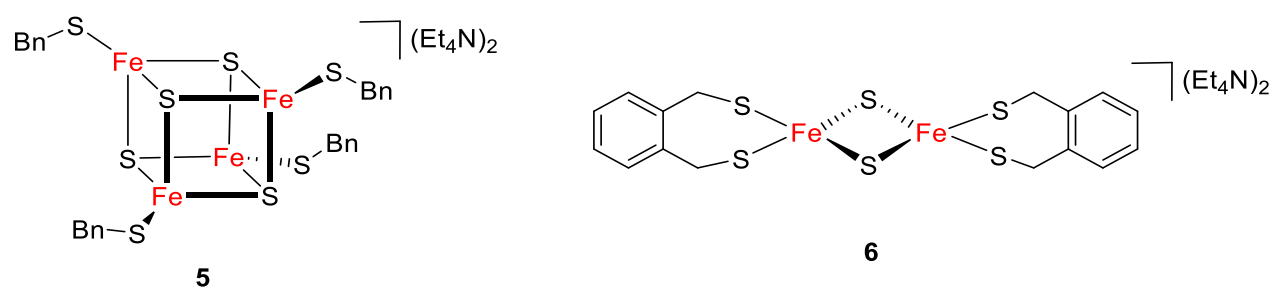

Figure 1.10: First synthetic cubic [4Fe-4S] cluster $(\mathbf{5})$ and $[2 \mathrm{Fe}-2 \mathrm{~S}]$ cluster $(\mathbf{6})$.

Holm and coworkers synthesized the first model cluster in $1972 .{ }^{84}$ It was a cubic [4Fe-4S] cluster (5) with thiobenzyl ligands mimicking cysteine (Figure 1.10). One year later they published the first synthetic $[2 \mathrm{Fe}-2 \mathrm{~S}]$ cluster with $o$-xylyldithiolato ligands $(6) .{ }^{85}$ The clusters can be obtained in self-assembly reactions from ferric iron, thiols, and sulfide. Since then many model complexes for rubredoxins and clusters of higher nuclearity have been reported. ${ }^{10,86-88}$ A selection of synthetic clusters is depicted in Figure 1.11 and Figure 1.12 . 

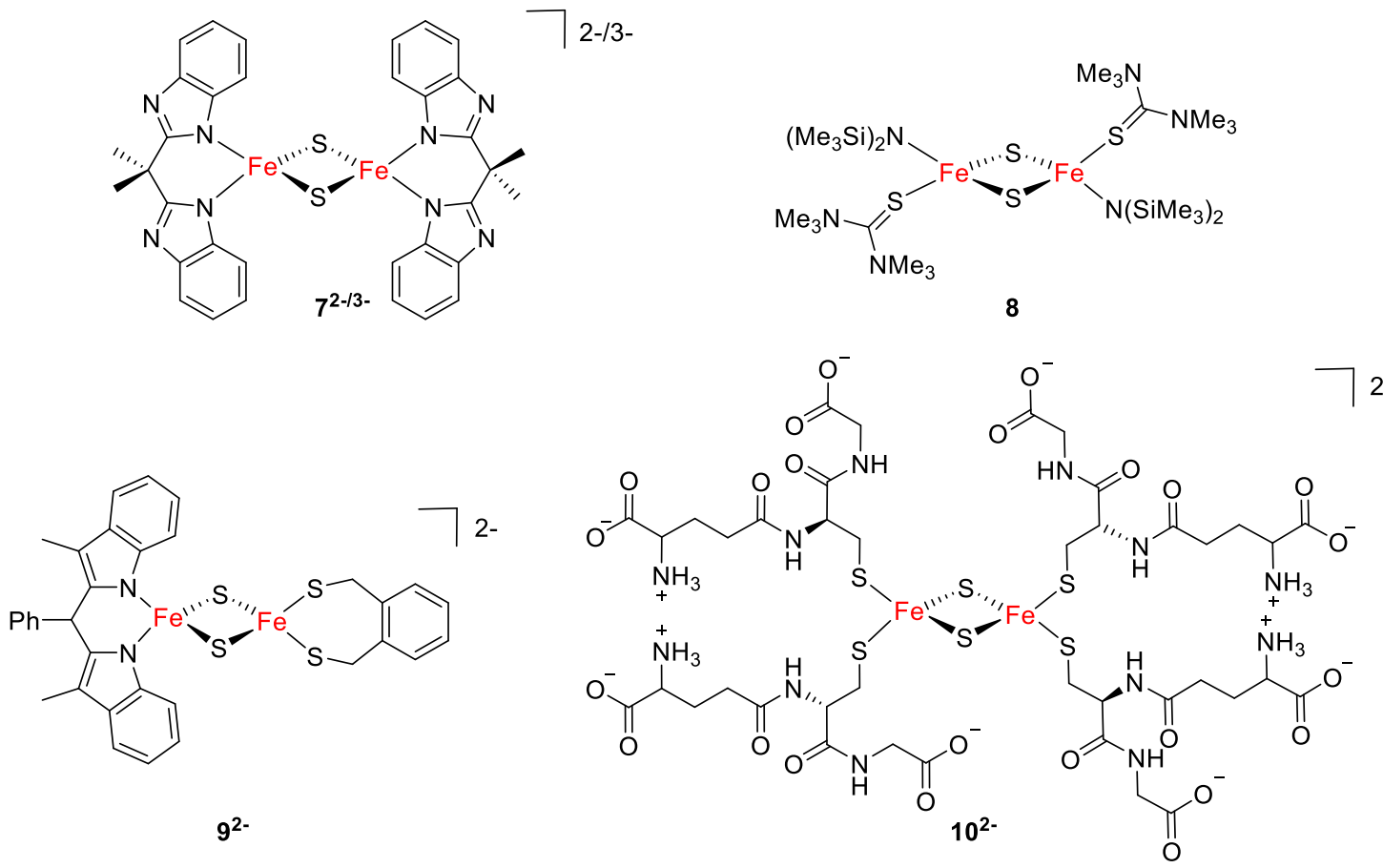

Figure 1.11: Selection of low-molecular-weight [2Fe-2S] clusters: first cluster with N-ligation and first cluster to be isolated in the mixed-valence state $\left(\mathbf{7}^{\mathbf{2}-13-}\right),{ }^{89,90}$ first neutral cluster with $\mathrm{N}\left(\mathrm{SiMe}_{3}\right) 2$ as strong $\pi$-donor ligands $(\mathbf{8}),{ }^{91}$ first heteroleptic [2Fe-2S] cluster $\left(\mathbf{9}^{\mathbf{2}}\right),{ }^{92}$ glutathione-complexed cluster $\left(\mathbf{1 0}^{\mathbf{2}}\right) .{ }^{93}$

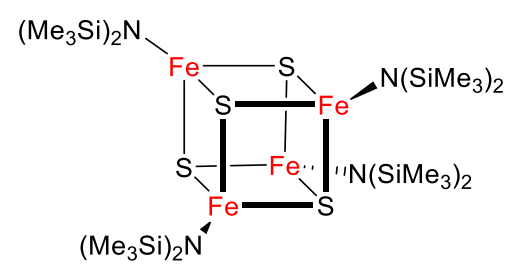

11

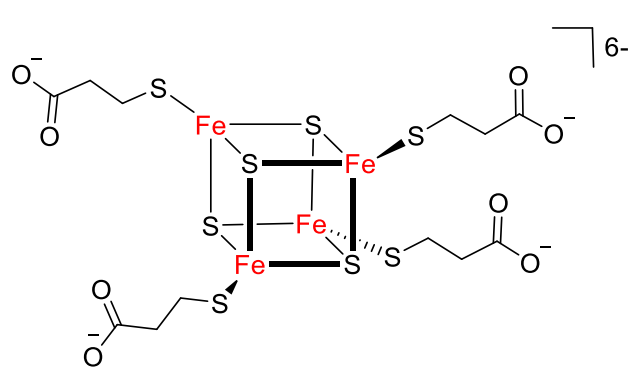

$13^{6-}$
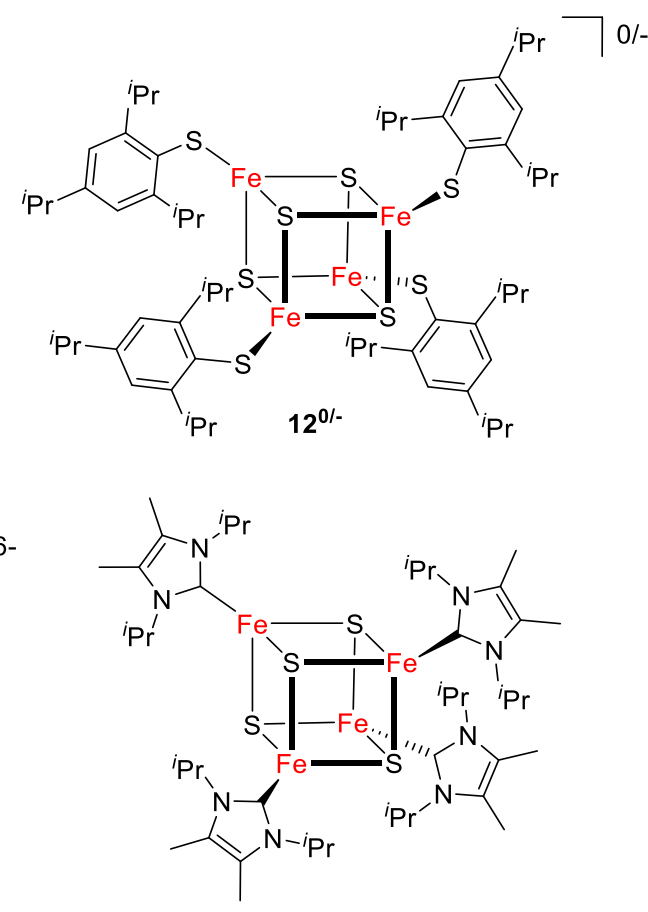

14

Figure 1.12: Selection of low-molecular-weight [4Fe-4S] clusters: first all ferric [4Fe-4S] cluster (11), ${ }^{91,94}$ first HiPIP model with sterically encumbered thiolate ligands $\left.\left(\mathbf{1 2}^{\mathbf{0} /-}\right),{ }^{95,96} \mathrm{c}\right)$ first water soluble $[4 \mathrm{Fe}-4 \mathrm{~S}]$ cluster $\left(\mathbf{1 3}^{\mathbf{6}-}\right),{ }^{97,98}$ first all ferrous [4Fe-4S] cluster (14). ${ }^{99}$ 
Tatsumi and coworkers achieved the synthesis of a 3:1 site-differentiated [4Fe-4S] cluster with the help of sterically encumbered thiolate ligands $\left(\mathbf{1 5}^{\mathbf{0} /-}\right.$, Figure 1.13$) .{ }^{100}$ It mimics the distal $\left[\mathrm{Fe}_{4} \mathrm{~S}_{4}\right.$ (cys) ${ }_{3}$ (his) $]$ cluster in $[\mathrm{FeNi}]$ hydrogenase.

A tridentate cavitand ligand system $\left(\mathbf{L}(\mathbf{S H})_{3}\right.$ in Figure 1.13) produces a cluster with a single iron site with more labile ligation $\left(\mathbf{1 6}^{\mathbf{2}}\right) .{ }^{101,102}$ The apical iron ion can be removed under mild oxidative conditions to obtain a cuboidal $[3 \mathrm{Fe}-4 \mathrm{~S}]$ cluster. This $[3 \mathrm{Fe}-4 \mathrm{~S}]$ cluster in turn can be used as starting material for heterometallic [M 3Fe-4S] clusters $(\mathrm{M}=\mathrm{Mn}, \mathrm{Co}$, $\mathrm{Ni}, \mathrm{Cu}, \mathrm{Zn}, \mathrm{Cd}, \mathrm{Tl}, \mathrm{Mo}, \mathrm{V}, \mathrm{Re}, \mathrm{Ag}, \mathrm{W}, \mathrm{Nb}, \mathrm{Pb}$, or Cr). ${ }^{103,104}$

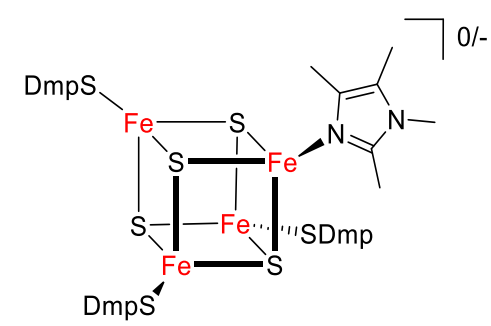

15

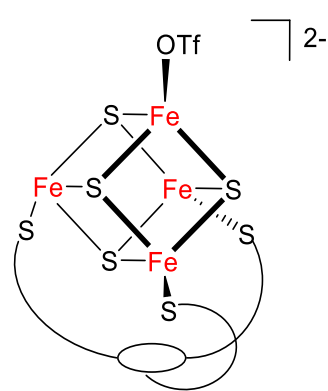

16
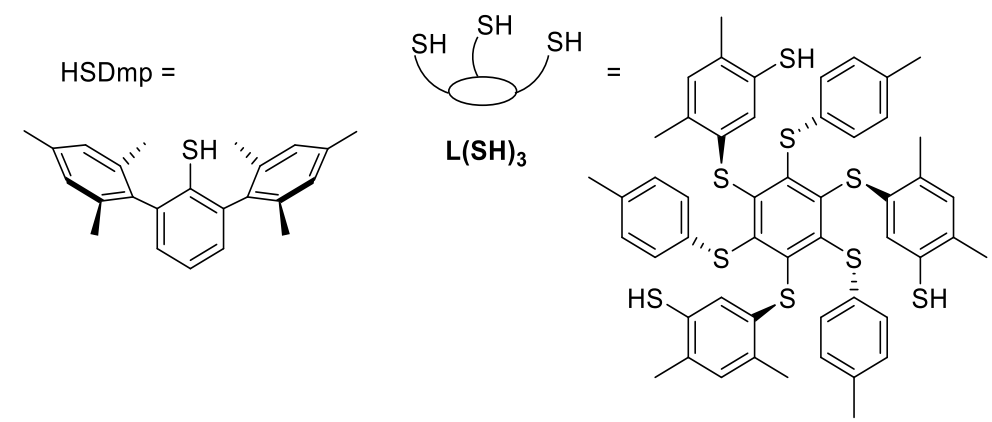

Figure 1.13. Site-differentiated cluster by Tatsumi and coworkers $\left(\mathbf{1 5}^{\mathbf{0}-}\right)^{100}$ and by Holm and coworkers $\left(\mathbf{1 6}^{\mathbf{2}}\right) .{ }^{101}$

Today's research does not only focus on mimicking the structure and electro-chemistry of natural $\mathrm{Fe}-\mathrm{S}$ clusters, but also their enzymatic properties. Special attention is paid to the $\mathrm{Fe}-\mathrm{S}$-cluster-containing enzyme nitrogenase because of its ability to activate nitrogen. Holland and coworkers moved away from the idea that it is necessary to copy the whole structure to obtain an active complex. They created the mononuclear iron complex $17^{-}$with a sulfur-rich coordination sphere that binds dinitrogen (Figure 1.14). ${ }^{105,106}$ 
a)
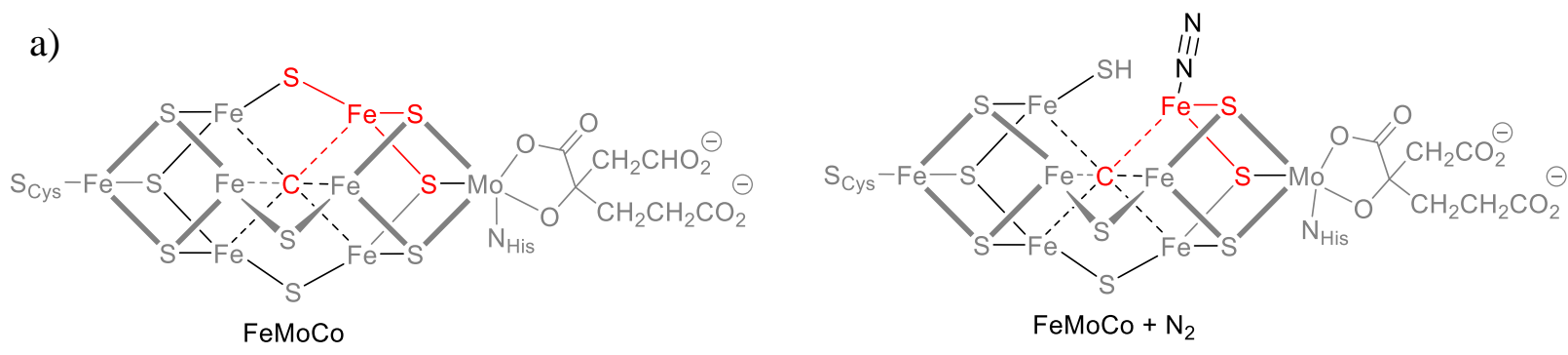

b)
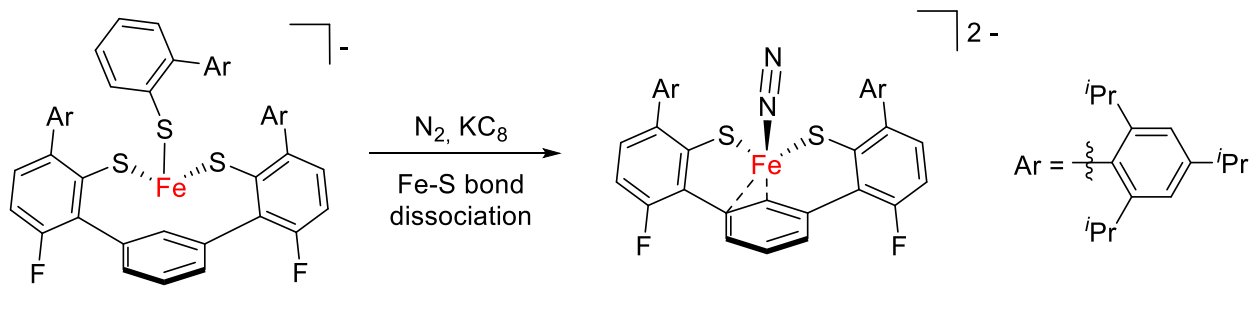

$17^{-}$

Figure 1.14: a) Possible binding mode of dinitrogen at FeMoCo; b) mononuclear iron-sulfur-carbon cluster $\mathbf{1 7}$ as synthetic model system for nitrogenase's active site. ${ }^{105}$

\subsection{Iron-sulfur clusters and nitric oxide}

1.4.1 Nitric oxide as vital messenger molecule and cytotoxic effector

NO plays a role in a wide variety of biological processes. ${ }^{107,108}$ It is formed in cells by members of the NO synthase (NOS) family or by nitrite reductases. ${ }^{109,110}$ The reaction of NO with the heme-iron in guanylyl cyclase has been investigated thoroughly since the 1960s. This reaction starts a cascade which ultimately leads to relaxation of the cardiovascular system. ${ }^{11-114} \mathrm{NO}$ also plays an important role in neurotransmission ${ }^{115}$ and immune regulation. ${ }^{116,117}$ Physiological amounts of NO are neuroprotective, but higher concentrations can be neurotoxic. Nitrosative stress can lead to damage of DNA and amino acids. ${ }^{118}$ Despite its radical character, the half time life of the NO molecule in the cell can be surprisingly long $(0.002-2 \mathrm{~s}){ }^{119}$

\subsubsection{Iron-sulfur-nitrosyl complexes}

The primary biological target for NO are metal-containing proteins. In the resulting metalnitrosyl complexes the NO-ligand is redox non-innocent. Three redox states are biologically relevant: the nitrosonium cation $\left(\mathrm{NO}^{+}\right)$, $\mathrm{NO}$ radical (NO), and nitroxyl anion $\left(\mathrm{NO}^{-}\right)$. However, the iron and NO oxidation state is difficult to assign because of a small energy gap between the transition metal $3 \mathrm{~d}$ and $\mathrm{NO} \pi^{*}$-orbitals. Therefore, the electronic structure of iron-nitrosyl complexes is normally described by the Enemark-Feltham notation, in which the iron $3 \mathrm{~d}$ and $\mathrm{NO} \pi^{*}$ electrons " $\mathrm{x}$ " of the molecule are neither assigned 
to the iron ion nor the nitrosyl moieties " $n$ " $\left(\left\{\mathrm{Fe}(\mathrm{NO})_{\mathrm{n}}\right\}^{\mathrm{x}}\right) .{ }^{120}$ Transition metal $\mathrm{NO}^{+}$adducts have a N-O stretching frequency of $1700-2000 \mathrm{~cm}^{-1}$. When $\mathrm{NO}$ behaves formally as $\mathrm{NO}^{-}$ the stretching frequency is $1500-1700 \mathrm{~cm}^{-1} \cdot 107$

The first reported iron-sulfur-nitrosyl clusters were Roussin's black salt (RBS, 18) and Roussin's Red Salt (RRS, 19) in $1858 .{ }^{121}$ RBS and RRS cannot bind to the protein without prior ligand exchange and are therefore biologically irrelevant. ${ }^{122}$

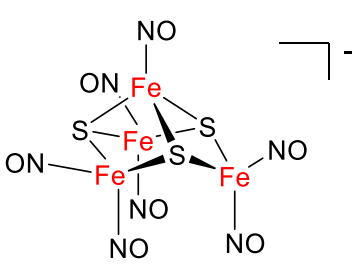

$18^{-}$

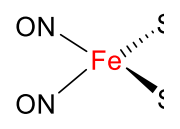

19

Figure 1.15. First reported iron-sulfur-nitrosyl complexes: Roussin's Black Salt (RBS, $\left.\mathbf{1 8}^{-}\right)$and Roussin's Red Salt (RRS, 19²-).

Biologically relevant iron-sulfur-nitrosyl complexes are dinitrosyl-iron complexes (DNIC, $\mathbf{2 0}^{-}$) and the esters of Roussin's salt (RREs, $\left.\mathbf{2 1}^{-}, \mathbf{2 2}\right)$ or derivatives thereof $\left(\mathbf{2 3}^{-}, \mathbf{2 4}^{-}\right)$. They are the products of nitrosylation of Fe-S clusters (chapter 1.4.3). EPR spectroscopy is an excellent tool for recognizing DNICs and reduced RREs due to their signature isotropic $g$ value of 2.03 or 1.99 , respectively. ${ }^{123}$ However, assignment of EPR-silent species is more challenging. IR, Mössbauer, UV/vis, and Raman spectroscopies lack full diagnostic ability to discriminate between the different species. A method that has become more popular in the scientific community in recent years is nuclear resonance vibrational spectroscopy (NRVS). ${ }^{124,125}$ It allows for distinction between different iron-nitrosyl species and has been applied to nitrosylized [4Fe-4S] ferredoxin, ${ }^{126}$ Rieske, ${ }^{127}$ WhiD, and NsrR proteins. ${ }^{128}$ Today NRVS data is available for various iron-sulfur clusters and nitrosyl complexes which allows for comparison of fingerprint regions in order to decipher the product after nitrosylation of an $\mathrm{Fe}-\mathrm{S}$ cluster. ${ }^{128-133}$ 


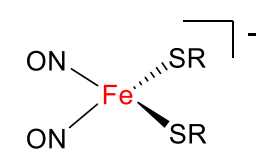

$20^{-}$

Dinitrosyl Iron

Complex (DNIC)

$S=1 / 2, g_{a v}=2.03$

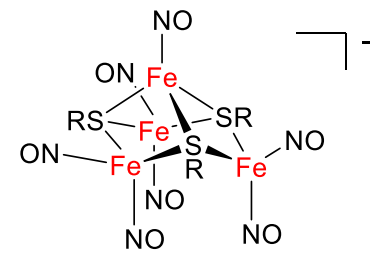

21.

Roussin's Black Ester

(RBE)
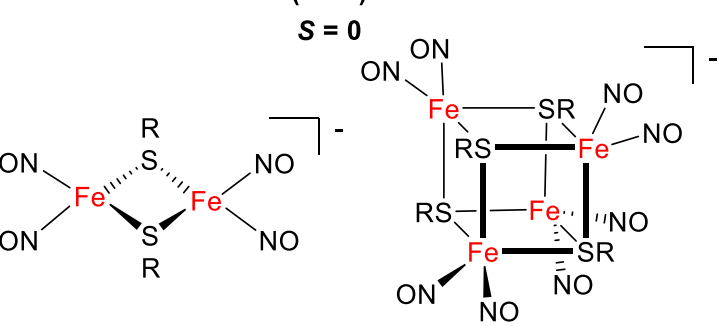

23-

reduced Roussin's Red

Ester (rRRE)

$S=1 / 2, g_{a v}=1.99$

$24^{-}$

dimerized RRE

(dRRE)

$S=0$

Figure 1.16. Identified reaction products from nitrosylation of $\mathrm{Fe}-\mathrm{S}$ proteins. The residues (SR) stand for cysteine in proteins and thiolates in model clusters.

Conversion between different iron-sulfur-nitrosyl complexes is possible and depends on the concentration of NO, the redox states of iron and sulfur, and the availability of sulfide and thiol ligands. ${ }^{134}$ For example, $\mathrm{S}$-based oxidation of a DNIC with $\mathrm{O}_{2}$ results in formation of a RRE. ${ }^{135}$

\subsubsection{Nitrosylation of natural iron-sulfur clusters}

Nitrosylation of $\mathrm{Fe}-\mathrm{S}$ proteins usually disrupts the cluster, affects the loss of the enzyme's activity and ultimately has cytotoxic effects. ${ }^{119,136}$ On the other hand, it is possible to reverse the reaction in vitro and generate $[2 \mathrm{Fe}-2 \mathrm{~S}]$ clusters from DNICs via the key intermediate RRE. ${ }^{137}$ Yang et al. found that nitrosylation does not necessarily cause cell death as nitrosylized $\mathrm{Fe}-\mathrm{S}$ enzymes are efficiently repaired in aerobically growing $E$. coli cells by cysteine desulferase (IscS) in the presence of L-cysteine in vitro. ${ }^{138,139}$

$[4 \mathrm{Fe}-4 \mathrm{~S}],[2 \mathrm{Fe}-2 \mathrm{~S}]$ clusters and $[2 \mathrm{Fe}-2 \mathrm{~S}]$ clusters with alternative ligands yield different products after reaction with NO. The results of prior research are summarized in the following paragraphs. 


\section{$[4 \mathrm{Fe}-4 \mathrm{~S}]$ clusters}

Aconitase and IRP1 were the first Fe-S proteins that were reacted with NO in vitro in 1997 after cellular studies indicated that $\mathrm{Fe}-\mathrm{S}$ proteins are targeted by NO. ${ }^{140}$ As a result, proteinbound dinitrosyl-iron-dithiolato complexes were identified by EPR spectroscopy by their typical $g$-value of 2.03. In the following years, other [4Fe-4S] proteins were reacted with NO and DNICs were found to be the main product by EPR spectroscopy, e.g. HiPIP proteins $^{141}$ or regulatory proteins like Fur (ferric uptake regulatory protein) ${ }^{142}$ and NorR (NO responsive transcription factor). ${ }^{143,144}$ In 2011 Ding and coworkers published a paper in which they supported the idea that $\mathrm{Fe}-\mathrm{S}$ proteins are the major source of protein-bound DNICs in E. coli cells under nitric oxide stress. ${ }^{145}$

New technology such as NRVS and more careful examination of the products after nitrosylation have led to the discovery of EPR-silent reaction products like RRE (22), dimerized RRE $\left(\mathbf{2 4}^{-}\right)$, or RBS/RBE $\left(\mathbf{1 8}^{-} / \mathbf{2 1}^{-}\right)$. Spin-quantification showed that DNICs account only for a fraction of the total iron content. ${ }^{140,146,147}$ Le Brun, Cramer and coworkers found that the main product after nitrosylation of NsrR is a mixture of EPRsilent RRE (22) and RBE $\left(\mathbf{2 1}^{-}\right)$or RBS $\left(\mathbf{1 8}^{-}\right)$. The results are supported by NRVS and DFT calculations. Unfortunately, RBS and RBE are not distinguishable by NRVS and other spectroscopic methods: RBE has the same constitution as RBS except that one to three bridging sulfides are replaced by thiolates from cysteines. ${ }^{128,148}$ FNR and WhiB react with $8 \mathrm{NO}$ molecules yielding octanitrosyl clusters $\left[\mathrm{Fe}_{4}(\mathrm{NO})_{8}(\mathrm{Cys})_{4}\right]^{0}$ (dimerized RRE). ${ }^{147,149,150}$

\section{$[2 \mathrm{Fe}-2 \mathrm{~S}]$ clusters}

In general, nitrosylation leads to loss of the enzyme's activity, but nitrosylated SoxR has transcriptional activity similar to that of SoxR after oxidative stress. ${ }^{151}$ It is important to consider the oxidation state of the $[2 \mathrm{Fe}-2 \mathrm{~S}]$ cluster in SoxR as the oxidized and the mixedvalence cluster yield different products. When oxidized SoxR is exposed to NO, two DNICs are formed in intact bacteria as well as in the purified enzyme as shown by EPR, dichroic spectral features, and EXAFS. ${ }^{59,151,152}$ Spin quantification with EPR spectroscopy suggests full conversion of the $[2 \mathrm{Fe}-2 \mathrm{~S}]$ cluster. However, mixed-valence SoxR exposed to NO for $1 \mathrm{~min}$ and then frozen at $77 \mathrm{~K}$ revealed a mixture of rRRE, RRE, and only a small amount of DNIC as product. In E. coli cells rRRE is quickly converted into stable protein-bound DNICs. ${ }^{152}$ In summary, rRRE and RRE can be considered intermediates on the reaction pathway to DNICs. It is noteworthy that $E$. coli has a repair system for the nitrosylated 
iron-sulfur clusters in SoxR as the DNIC signal disappears after 15 min..$^{59,151-153}$ The [2Fe$2 \mathrm{~S}$ ] cluster of spinach ferredoxin I reacts with $\mathrm{NO}$ and traces of $\mathrm{O}_{2}$ to protein-bound RRE and DNIC, determined by IR spectroscopy. ${ }^{154}$

\section{[2Fe-2S] clusters with histidine ligation}

A thiolate-bridged dinuclear dinitrosyl iron species (RRE) has been identified as main product of nitrosylation of Rieske-type [2Fe-2S] ferredoxin ToMOC protein beside a cysteine-bound DNIC as minor product. ${ }^{127}$ NRVS spectroscopy indicated that the RRE is the main product of the nitroslyation. Also as indirect proof, the nitrosylation product was reduced with sodium dithionite $\left(\mathrm{Na}_{2} \mathrm{~S}_{2} \mathrm{O}_{4}\right)$ and an EPR signal typical for a rRRE was detected $\left(g_{\perp}=2.008, g_{\|}=1.971\right)$.

Recently, Ding and coworkers reported that the reduced CDGSH-type [2Fe-2S] clusters bind one NO molecule without degradation of the cluster (Figure 1.17). ${ }^{155}$

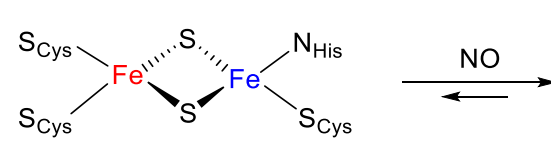

2b

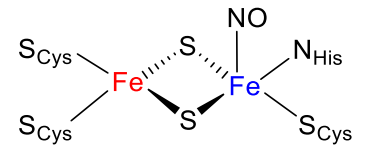

25

Figure 1.17. Nitrosylation of reduced CDGSH-type [2Fe-2S] cluster.

To conclude, the scientific community assumed that DNICs are the sole product of nitrosylation of Fe-S clusters since 1997 as they are easy to identify by EPR spectroscopy. However, spin quantification did not account for all the starting material. More recent investigations identified intermediates like RRE to play a major role, however the reaction pathway has not been fully elucidated to date. Mononitrosyl [2Fe-2S] clusters like 25 seem to be the exception as no other case is reported so far. 


\subsubsection{Nitrosylation of biomimetic iron-sulfur clusters}

Peptide-based $\mathrm{Fe}-\mathrm{S}$ clusters

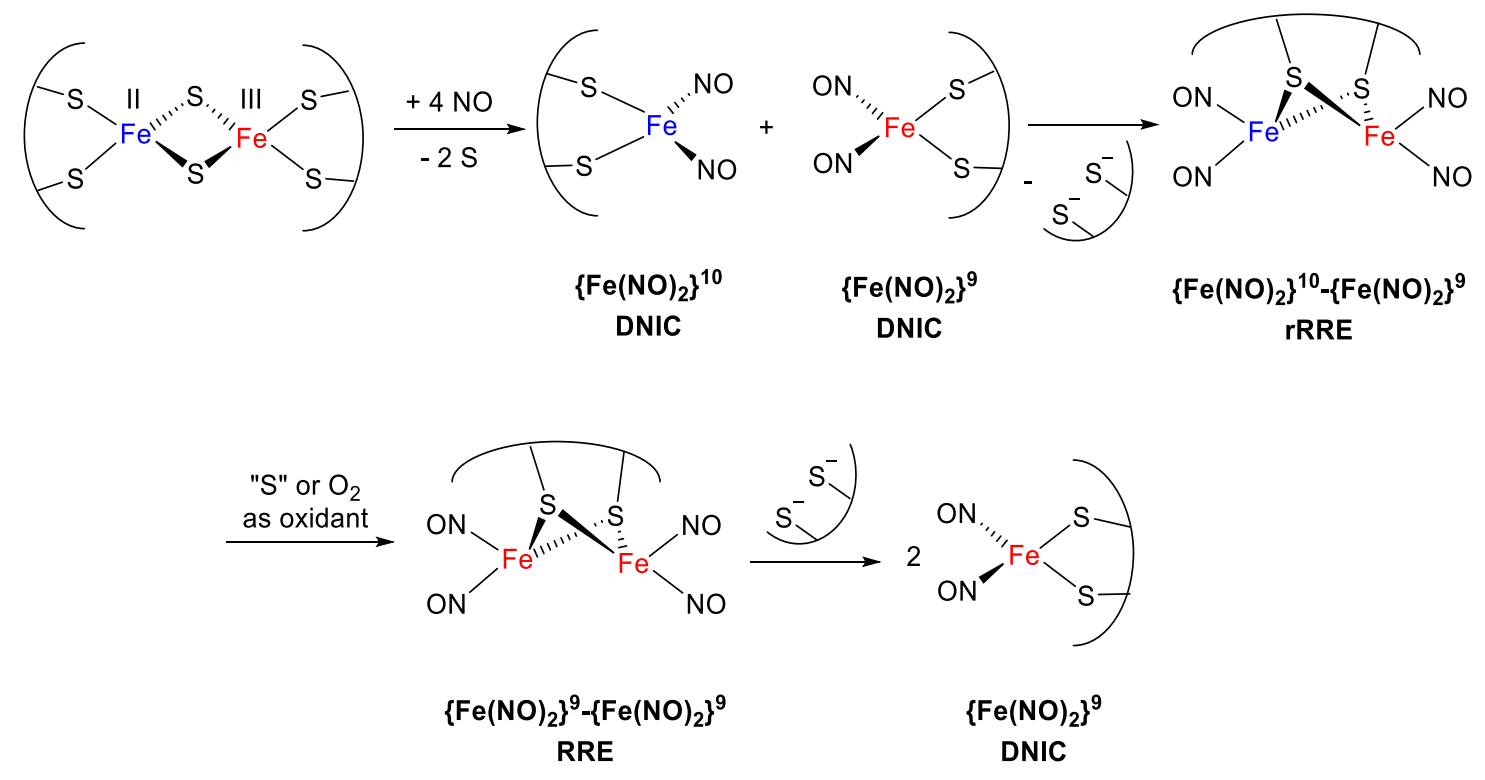

Figure 1.18. Proposed mechanism for nitrosylation of mixed-valent bidentate-peptide bound [2Fe-2S] cluster. The sequence of the bidentate-peptide is (Lys-Cys-(Ala) ${ }_{n}$-Cys-Lys, $\left.n=1-4\right) .{ }^{156}$

Liaw and coworkers investigated the reaction pathway of the nitrosylation of $\mathrm{Fe}-\mathrm{S}$ clusters. They expanded from low-molecular-weight biomimetic chemistry to the synthesis of peptide-based analogues, dubbed "bridged biological assemblies". They synthesized peptide-bound DNICs and neutral/reduced RREs. ${ }^{156}$ The products were water-soluble and characterized mainly by a combination of UV-vis and IR spectroscopy, aside from EPR, CD, ESI-MS and XAS. The peptides were either bidentate (Lys-Cys-(Ala) ${ }_{n}$-Cys-Lys, $n=1-$ 4) or monodentate (Lys-Cys-Ala-Ala-Lys) binding via the cysteine residues. As a result, the chelating bidentate-cysteine-bound proteins stabilize the $\left\{\mathrm{Fe}(\mathrm{NO})_{2}\right\}^{9}$ moiety in DNICs and destabilize the RRE form, i.e. when cysteines are in close proximity on the peptide chain, DNICs are the main product of nitrosylation (Figure 1.18). Whether protein-bound RREs, rRREs or DNICs are formed, appears to rely heavily on the oxidation state of the iron and the chelating effect of the binding protein. The results rationalize why the nitrosylation of the mixed-valent Rieske-type $[2 \mathrm{Fe}-2 \mathrm{~S}]$ cluster of the ToMOC protein ${ }^{127}$ and of the mixed-valent $[2 \mathrm{Fe}-2 \mathrm{~S}]$ cluster of SoxR ${ }^{151}$ have a different outcome. Based on their research, Liaw and coworkers proposed that the former yields unstable $\left\{\mathrm{Fe}(\mathrm{NO})_{2}\right\}^{9}$ and $\left\{\mathrm{Fe}(\mathrm{NO})_{2}\right\}^{10}$ monodentate-peptide-containing DNICs after reductive elimination of sulfur (Figure 1.19). The subsequently formed reduced RRE is oxidized to protein-bound $\mathrm{RRE}$ as the final product. The reaction mechanism of the latter resembles the one for 
nitrosylation of mixed-valent $[2 \mathrm{Fe}-2 \mathrm{~S}]$ clusters with coordination of bidentate-peptides (Figure 1.18). The chelating ligand stabilizes the $\left\{\mathrm{Fe}(\mathrm{NO})_{2}\right\}^{9}$ DNIC. On the other hand, [4Fe-4S] clusters generate RREs regardless of the denticity of the peptide according to Liaw and coworkers. The hypothesis is supported by the reaction of $[4 \mathrm{Fe}-4 \mathrm{~S}]$ regulatory enzymes, WhiD ${ }^{149}$ and Nsr, ${ }^{150}$ with NO.

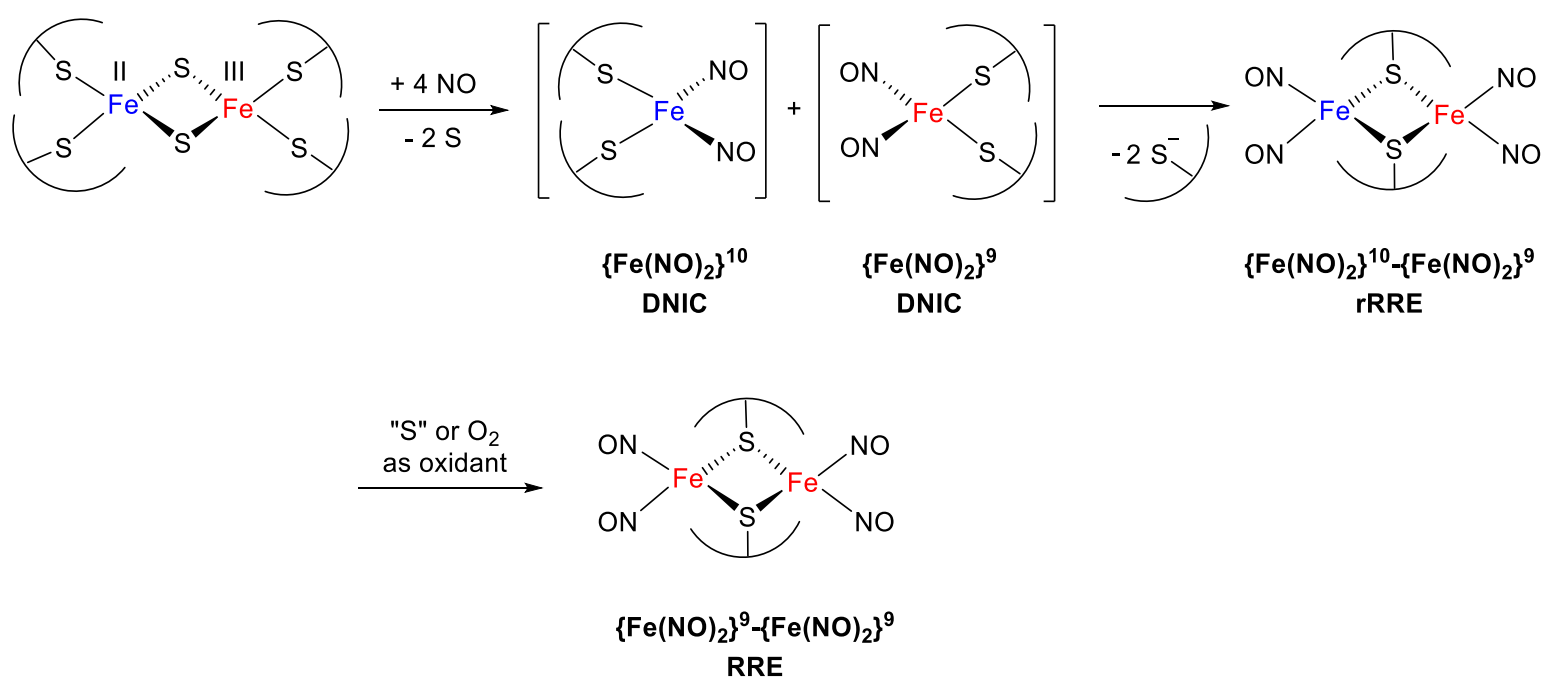

Figure 1.19. Proposed mechanism for nitrosylation of mixed-valent monodentate-peptide coordinated [2Fe-2S] cluster.

The sequence of the monodentate-peptide is (Lys-Cys-Ala-Ala-Lys). ${ }^{156}$

Interestingly, peptides with the sequence Lys-Cys-Ala-Ala-His-Lys served as monodentate ligands as well, binding only with the cysteine and not with the histidine residue. This supports the theory that the binding affinity for histidine is much lower than for cysteine. Liaw and coworkers investigated the binding affinity by a series of ligand displacement experiments and came to the sequence depicted in Figure 1.20. ${ }^{157}$

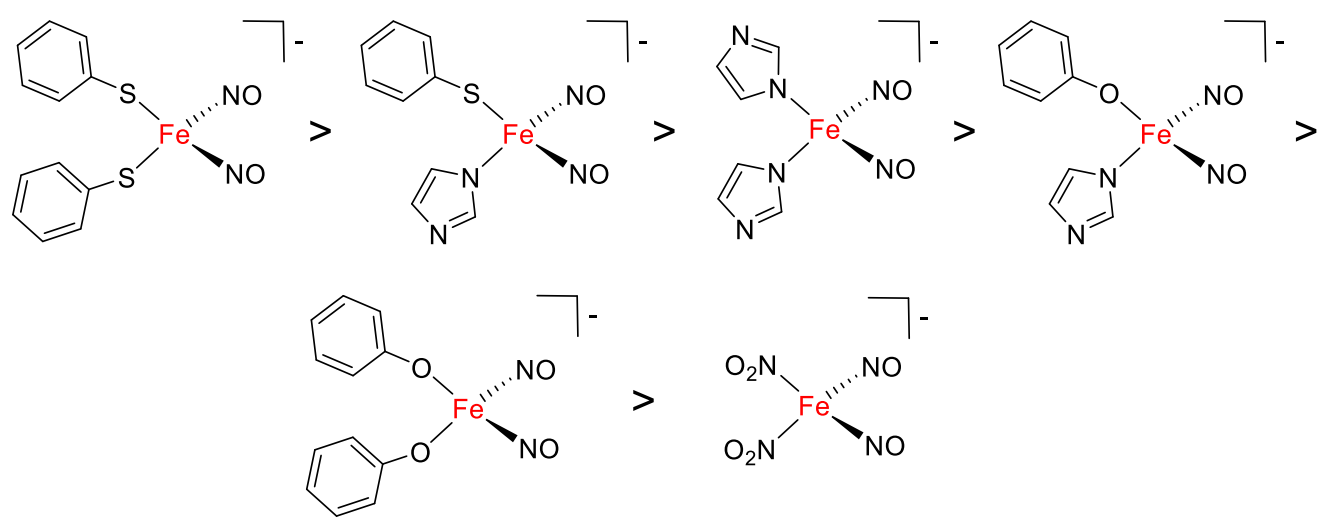

Figure 1.20. Relative binding affinity of nitrite, phenoxide, imidazolate and thiolate towards the $\left\{\mathrm{Fe}(\mathrm{NO})_{2}\right\}^{9}$-moiety. ${ }^{157}$ 
Low-molecular-weight $\mathrm{Fe}-\mathrm{S}$ clusters

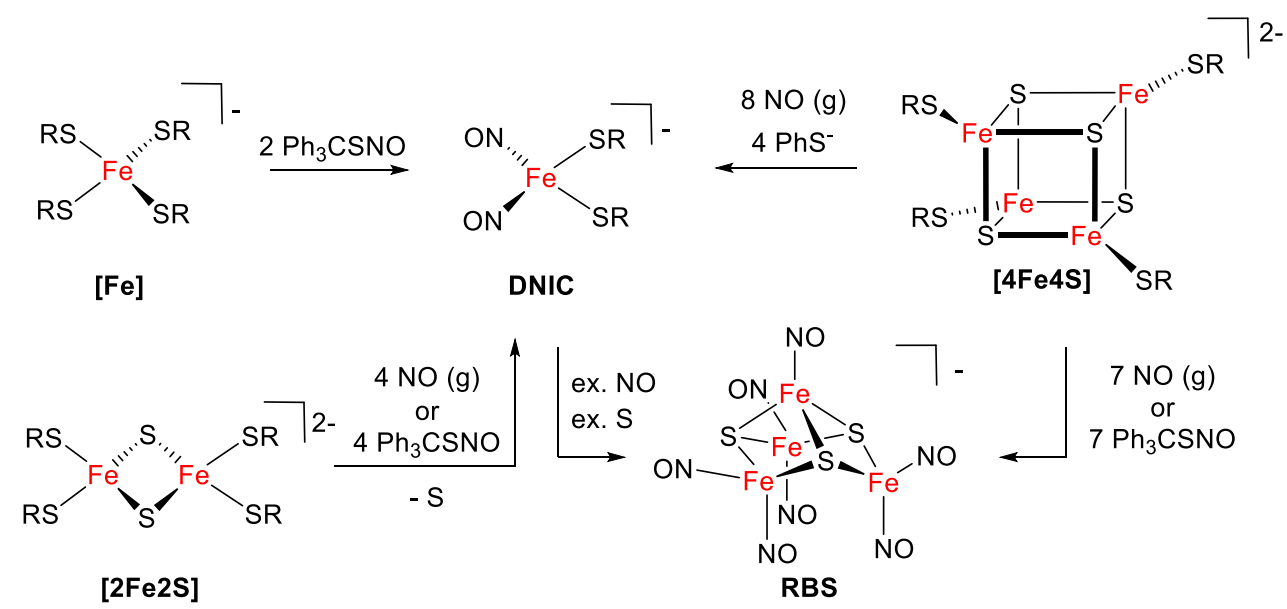

Figure 1.21. Nitrosylation of synthetic analogues of rubredoxins, $[2 \mathrm{Fe}-2 \mathrm{~S}]$ and $[4 \mathrm{Fe}-4 \mathrm{~S}]$ ferredoxins. ${ }^{158}$

Stochiometric nitrosylation of synthetic rubredoxin and ferredoxin model systems generates DNICs with concomitant reductive elimination of the bridging sulfide ligands as elemental sulfur (Figure 1.21). ${ }^{158-160}$ On the other hand, an excess of NO in the presence of elemental sulfur yields RBS.

When an $\mathrm{H}$-atom donor such as $\mathrm{PhSH}$ or ${ }^{\mathrm{t}} \mathrm{Bu}_{3} \mathrm{PhOH}$ is present during nitrosylation of the cluster $\left[\mathrm{Fe}_{2} \mathrm{~S}_{2}(\mathrm{SPh})_{4}\right]^{2-}$, the products are thiolate-coordinated DNIC and $\mathrm{PhSSPh}$ or ${ }^{t} \mathrm{Bu}_{3} \mathrm{PhO} \cdot$, respectively (Figure 1.22). The bridging sulfide ligands are released as $\mathrm{H}_{2} \mathrm{~S}$ establishing a link between the two messenger molecules $\mathrm{NO}$ and $\mathrm{H}_{2} \mathrm{~S} .{ }^{161}$

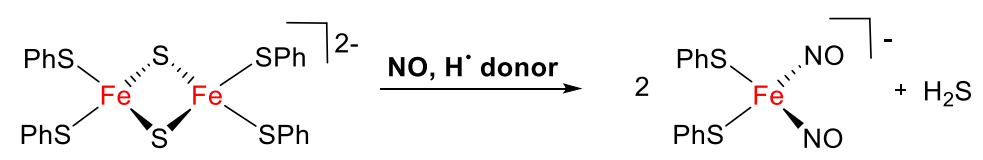

Figure 1.22. Reaction of [2Fe-2S] cluster with $\mathrm{NO}$ and $\mathrm{H}$-atom donor generates DNIC and $\mathrm{H}_{2} \mathrm{~S}$.

Nitrosylation of site-differentiated cluster $\left[\mathrm{Fe}_{4} \mathrm{~S}_{4}\left(\mathrm{LS}_{3}\right) \mathrm{X}\right] \mathbf{1 5}^{2-}$ produces the $S=1 / 2$ nitrosylcluster $\left[\mathrm{Fe}_{4} \mathrm{~S}_{4}(\mathrm{NO})_{4}\right]^{-}\left(\mathbf{2 6}^{-}\right)$en route to the formation of diamagnetic RBS $\mathbf{1 8}^{-}$(Figure $1.23) .^{162}$ 


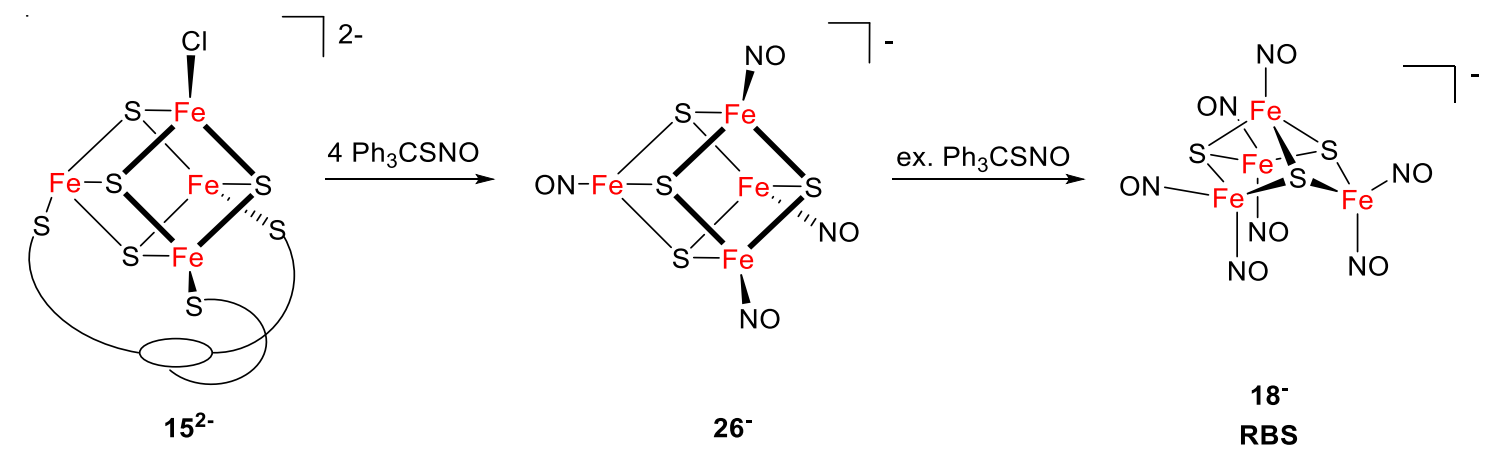

Figure 1.23. Nitrosylation of site differentiated $[4 \mathrm{Fe}-4 \mathrm{~S}]$ cluster. ${ }^{162}$

\subsection{Summary and conclusion}

$\mathrm{Fe}-\mathrm{S}$ clusters are essential in all three kingdoms of life. They are structurally diverse because smaller units can be assembled in a modular fashion to build large multinuclear clusters like in nitrogenases. Chemists have synthesized biomimetic analogues since the 1980s with exceptional contributions by Holm and coworkers. Natural and model clusters have been well investigated with respect to their structural and electronic properties. However, new binding motifs and functions are still discovered today, setting new goals and offering new challenges for the synthesis of appropriate model systems. Some natural Fe-S clusters are essential parts of enzymes with extraordinary capacities, i. a., in the defense against nitric stress.

NO reacts readily with $\mathrm{Fe}-\mathrm{S}$ clusters to form iron-sulfur-nitrosyl complexes with concomitant degradation of the cluster core. The investigation of $\mathrm{Fe}-\mathrm{S}$ cluster nitrosylation was conducted with real proteins (Ding, LeBrun, Liaw), peptide-bound (Liaw) and lowmolecular-weight models (Lippard, Kim), just to mention a few protagonists in the field. Several iron-sulfur-nitrosyl species have been identified via IR, UV-vis, and NRVS spectroscopy, but the most common reaction products of the nitrosylation of [2Fe-2S] and [4Fe-4S] clusters are dinitrosyl iron species. To date, researchers concentrated on the reactivity of diferric $[2 \mathrm{Fe}-2 \mathrm{~S}]$ clusters and mostly neglected other physiologically relevant oxidation and protonation states. Investigations in that direction are still necessary to complete the picture. 


\section{Nitrosylation of [2Fe-2S] clusters in their diferric, mixed-valent, and protonated state}

\subsection{Introduction and objective}

Our group published low-molecular-weight heteroleptic and homoleptic [2Fe-2S] model clusters for Rieske $\left(\mathbf{9}^{\mathbf{2}-\mathbf{3}-}, \mathbf{2 7}^{\mathbf{2 - 1 3}-}, \mathbf{2 9}^{\mathbf{2}-/ 3-}\right)^{92,163-165}$ and mitoNEET proteins $\left(\mathbf{2 8}^{\mathbf{2 - / 3}-}\right.$ and 30 $^{2-13-}$, Figure 2.1). ${ }^{166,167}$ All clusters have been spectroscopically characterized in their diferric $\left(\mathrm{Fe}^{\mathrm{III}} / \mathrm{Fe}^{\mathrm{III}}\right)$ and mixed-valence $\left(\mathrm{Fe}^{\mathrm{III}} / \mathrm{Fe}^{\mathrm{II}}\right)$ oxidation states. The proton-responsive nitrogen atoms in the backbone of the benzimidazolato moieties allow for protonation of the clusters $27^{2-}-\mathbf{3 0}^{2-}$ in contrast to $\mathbf{9}^{\mathbf{2}-\mathbf{3}-}$. The reactions of the homoleptic clusters 29 and 30 in differnet oxidation and protonation states with nitric oxide are presented in this chapter.

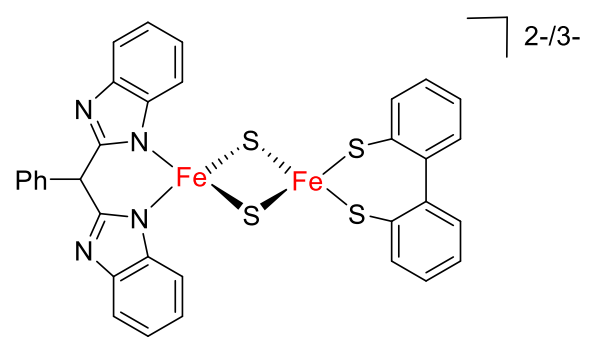

$27^{2-13-}$

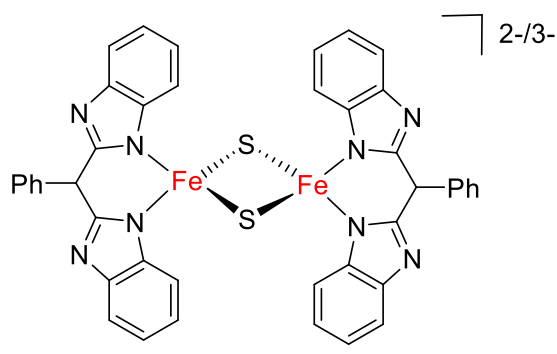

$29^{2-13-}$

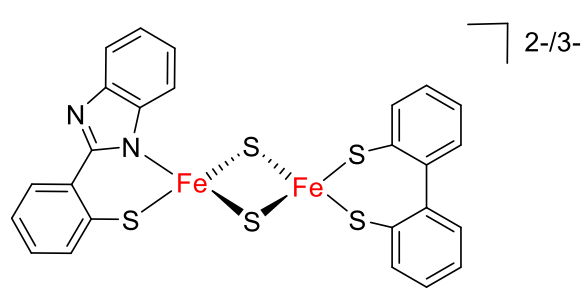

$28^{2-13-}$

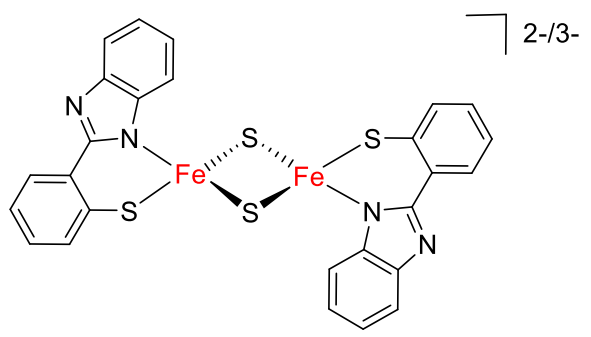

$30^{2-13-}$

Figure 2.1. Rieske model $\left(\mathbf{2 7 ^ { 2 - 1 3 - }}\right),{ }^{164}$ mitoNEET model $\left(\mathbf{2 8}^{2-13-}\right),{ }^{166}$ homoleptic Rieske model $\left(\mathbf{2 9 ^ { 2 - 1 3 - }}\right),{ }^{163,165}$ homoleptic mitoNEET model $\left(\mathbf{3 0}^{2-13-}\right) \cdot{ }^{167}$

Lippard and coworkers have reacted Rieske model $\mathbf{9}^{2-}$ with four equivalents of gaseous NO or $\mathrm{Ph}_{3} \mathrm{CSNO}$ (Figure 2.2). ${ }^{168}$ The $N, N$-bis(indolate) coordinated DNIC $\mathbf{3 1}^{-}$was characterized by EPR, IR and Mössbauer spectroscopy, but the dithiolate coordinated DNIC 32- could not be isolated as it reacts further to form RBS. The same reactivity was observed for nitrosylation of the heteroleptic Rieske model $\mathbf{2 7}^{\mathbf{2}}$ : Only the $\mathrm{N}, \mathrm{N}$ - 
bis(benzimidazolato) coordinated DNIC was obtained from the reaction mixture. ${ }^{169}$ Therefore, it was decided to discard the dithiolate ligands and focus on homoleptic, nitrogen-coordinated $[2 \mathrm{Fe}-2 \mathrm{~S}]$ clusters and their reactivity towards NO.

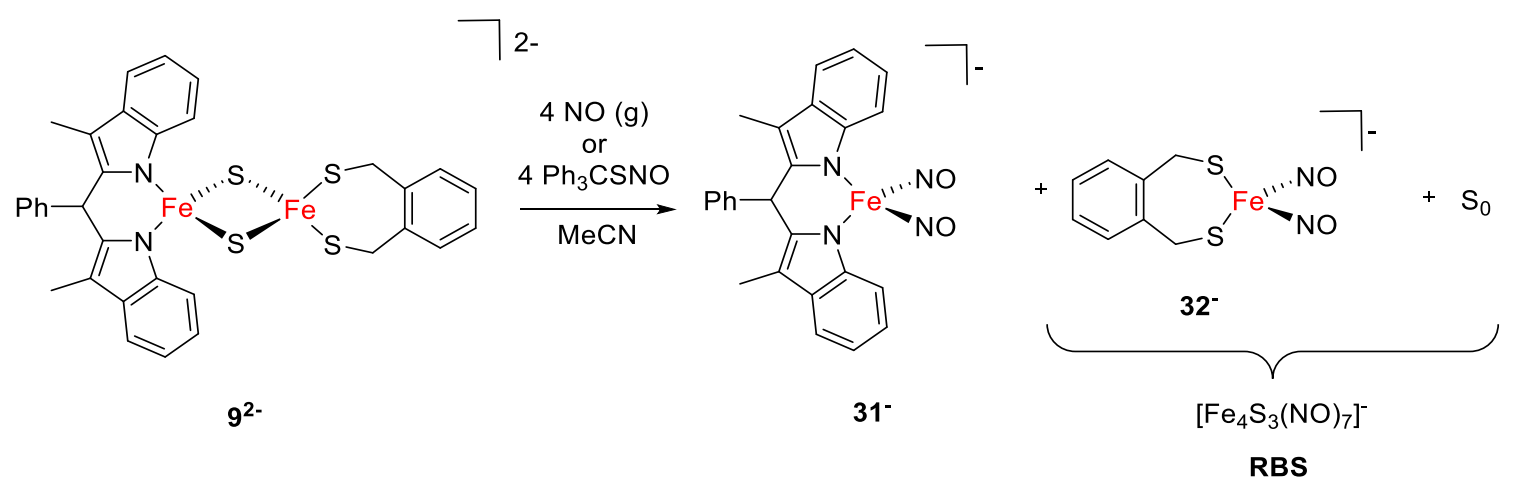

Figure 2.2. Nitrosylation of heteroleptic [2Fe-2S] by Lippard and coworkers. ${ }^{168}$ 


\subsection{Nitrosylation of diferric homoleptic coordinated [2Fe-2S] clusters}

The DNICs were accessed following one of two synthetic strategies shown below (Figure 2.3). In route 1 two equivalents of NO per iron ion were added into the headspace of a flask charged with a diferric [2Fe-2S] cluster in MeCN. Precipitated elemental sulfur was separated from the solution by washing with $\mathrm{Et}_{2} \mathrm{O}$. Subsequently, the DNIC was extracted with THF and precipitated from this solution by layering with hexane. Route 2 started from a previously reported precursor $\left[\mathrm{FeCl}_{2}(\mathrm{NO})_{2}\right]^{-}{ }^{168}$ In a ligand exchange reaction with the potassium salt of the ligand $\mathbf{K}_{2}(\mathbf{N N})$ or $\mathbf{K}_{2}(\mathbf{S N})$ the respective DNIC $33^{-}$or $3^{-}$was formed. The latter reaction served to confirm the identity of the products obtained via Route 1.
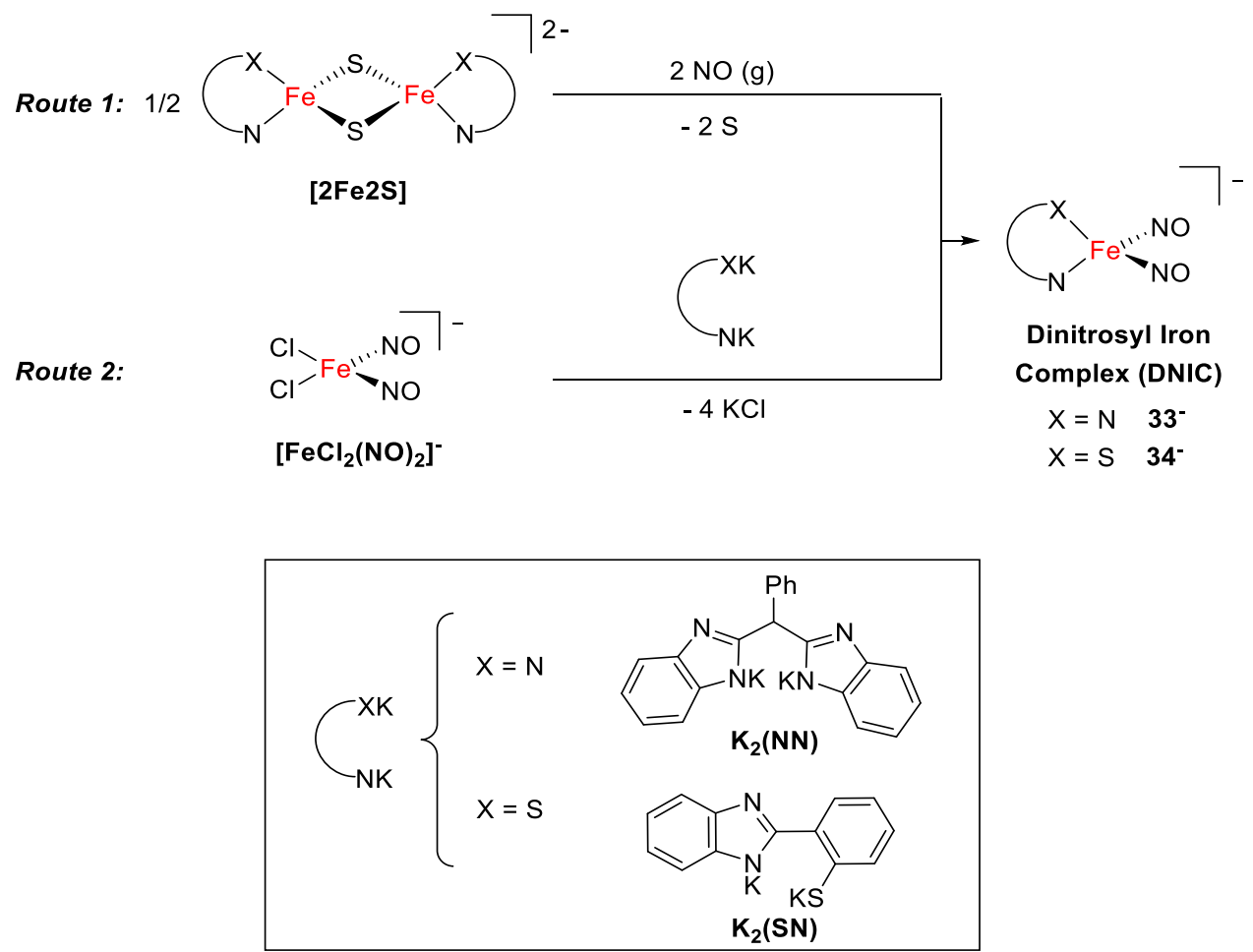

Figure 2.3 Synthesis of DNIC $\mathbf{3 3}^{-}$and $\mathbf{3 4}^{-}$via two routes.

\subsubsection{UV-vis and IR spectroscopy}

Reaction of $\mathbf{2 9}^{\mathbf{2}-}$ or $\mathbf{3 0}^{\mathbf{2}-}$ with NO results in a color change from red to brown or purple to brown, respectively. The nitrosylation was monitored by UV-vis spectroscopy (Figure 2.4, $\mathrm{a}$ and $\mathrm{c}$ ). The intense absorption of the sample bleaches until the sample exhibits a featureless spectrum. In the IR spectra, two new bands at $1780,1714 \mathrm{~cm}^{-1}$ for the $\mathrm{N}-\mathrm{O}$ stretching frequencies of $\mathbf{3 3}^{-}$and $1751,1700 \mathrm{~cm}^{-1}$ for $\mathbf{3 4}^{-}$are detected (Figure 2.4, b and d). Care was taken to employ only four equivalents of NO gas because an excess of gas leads to the formation of Roussin's Black Salt (RBS). RBS is detected in the IR spectrum 
if the reaction runs longer than 4 hours. Therefore, the reaction was stopped after 3 hours and residual solvent and NO was removed before work-up.

a)

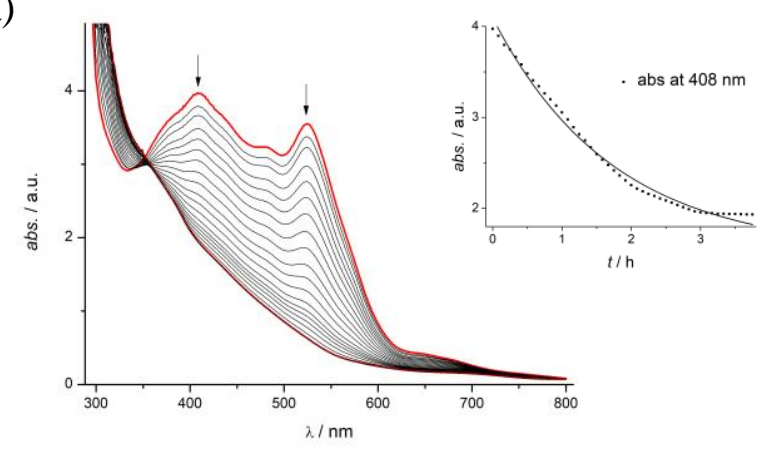

c)

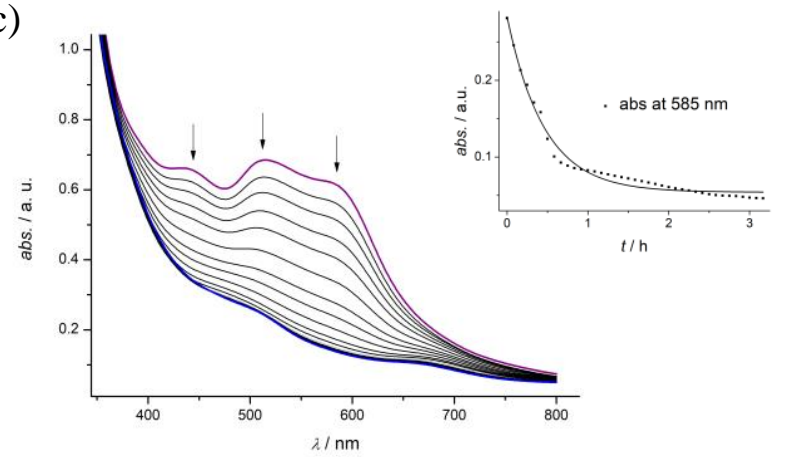

b)

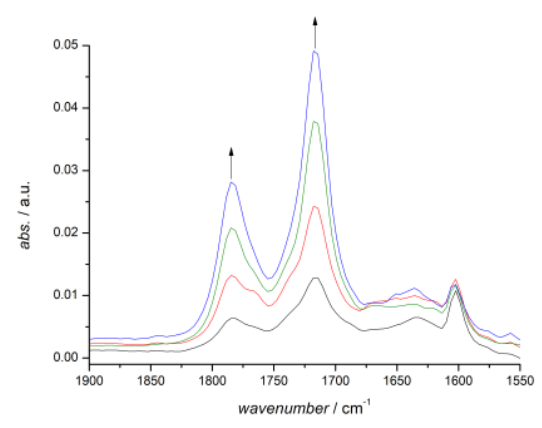

d)

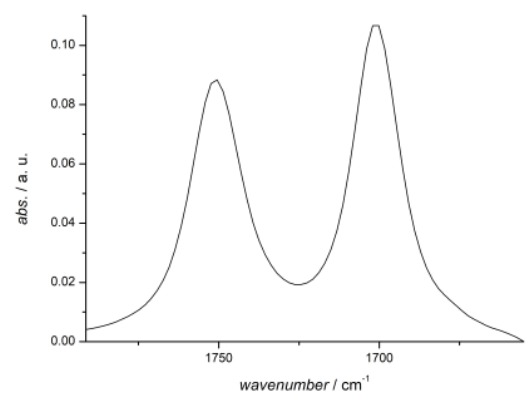

Figure 2.4. a) UV-vis spectra of the nitrosylation of $\mathbf{2 9}^{\mathbf{2}-}$ taken every $5 \mathrm{~min}(\Sigma 180 \mathrm{~min})$. The inserted graph depicts the decrease of the absorbance $v s$. time at $408 \mathrm{~nm}(\Sigma 225 \mathrm{~min})$. An exponential fit gave an observed rate constant $k_{\mathrm{obs}}$ of $1.60 \times 10^{-4} \mathrm{~s}^{-1}(\dagger)$. b) Excerpt of the IR spectra from the reaction mixture in MeCN after 15, 30, 60, and 120 min. The arising bands at 1780 and $1714 \mathrm{~cm}^{-1}$ are attributed to formation of $\mathbf{3 3}^{-}$.c) UV-vis spectra of the nitrosylation of $\mathbf{3 0}^{\mathbf{2}-}$ taken every $10 \mathrm{~min}(\Sigma 150 \mathrm{~min})$. The inserted graph depicts the decrease of the absorbance at $512 \mathrm{~nm} v s$. time ( $\Sigma 223 \mathrm{~min})$. An exponential fit gave an observed rate constant $k_{\text {obs }}$ of $6.03 \times 10^{-4} \mathrm{~s}^{-1}(\dagger)$. d) Excerpt of the IR spectrum of the reaction mixture after $3 \mathrm{~h}$ in $\mathrm{MeCN}$ with bands at 1751 and $1700 \mathrm{~cm}^{-1}$ indicating formation of $\mathbf{3 4}^{-}$. ( $\dagger$ ) The poor fits of the kinetic traces (inserts a and c) indicate a more complicated reaction sequence and rate law. 


\subsubsection{NMR spectroscopy}

The ${ }^{1} \mathrm{H}$ NMR spectrum of the nitrosylation of $\mathbf{2 9}^{2-}$ measured hourly for a total of 14 hours shows the decrease of the signals that are attributed to the diferric [2Fe-2S] cluster (Figure 2.5), but no new signals are detected. The signals of the reaction product DNIC $\mathbf{3 3}^{-}$is probably broadened beyond recognition due to its paramagnetic nature.

a)

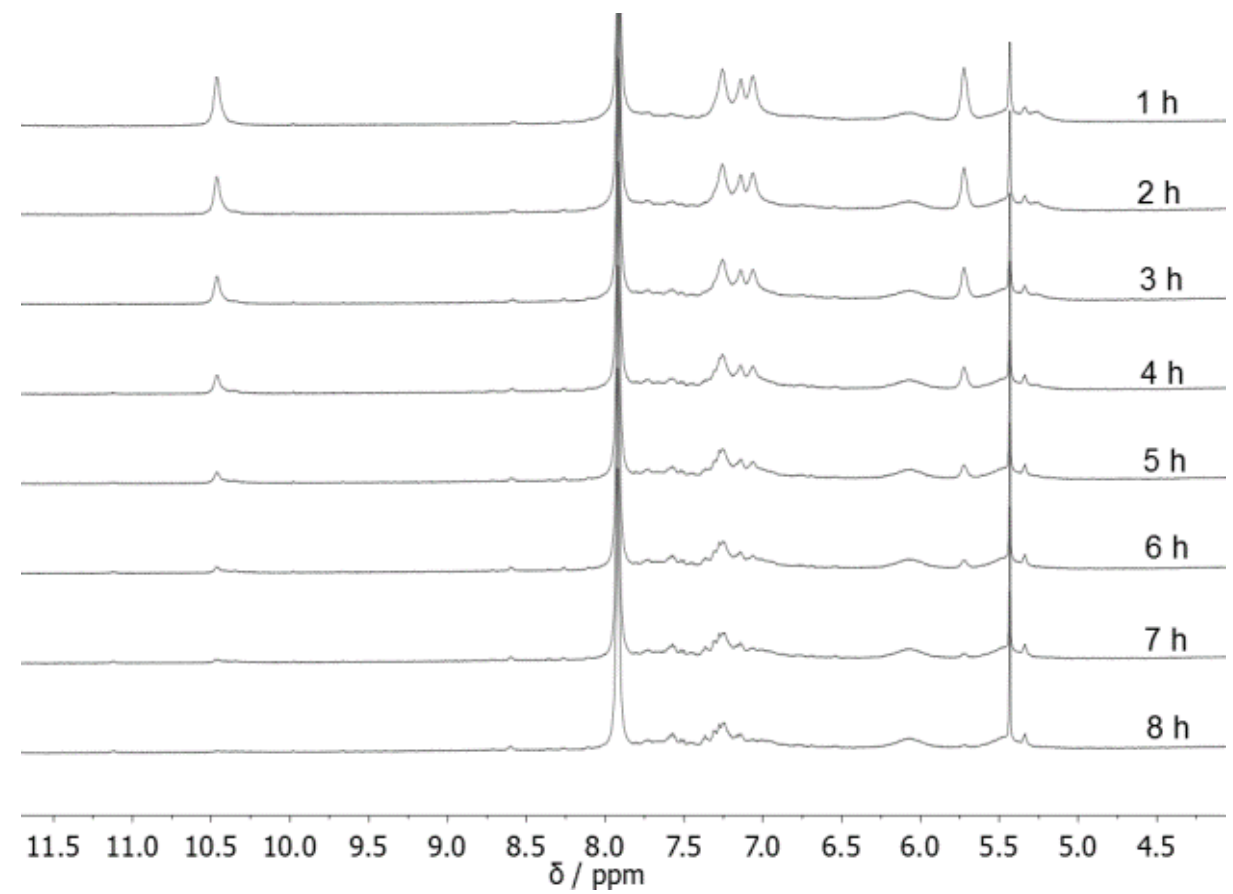

b)

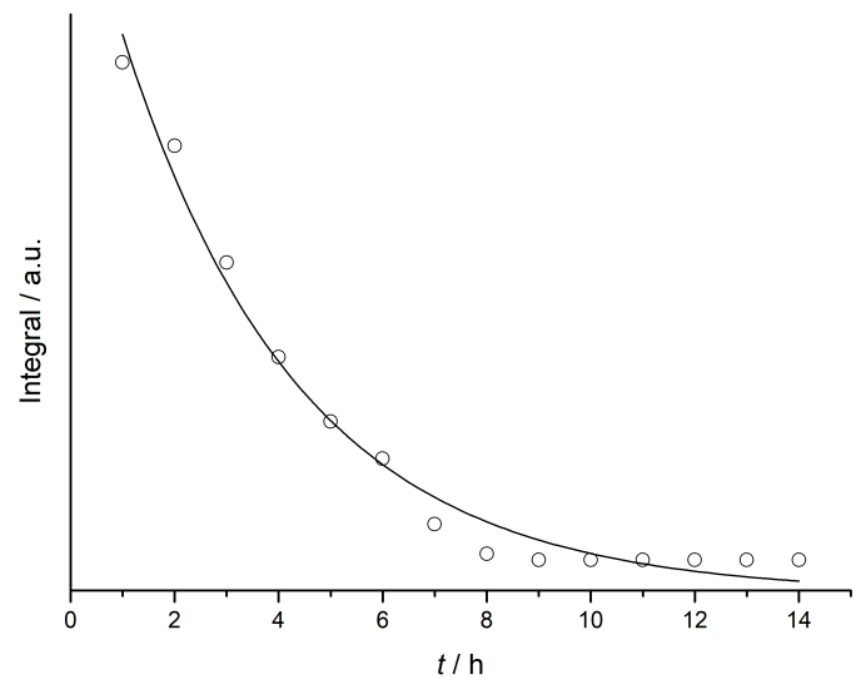

Figure 2.5. a) Hourly measured ${ }^{1} \mathrm{H}$ NMR spectra of nitrosylation of $\mathbf{2 9}^{\mathbf{2}-}$ in $\mathrm{MeCN}-\mathrm{d}_{3}$, b) area of the integral at $10.46 \mathrm{ppm}$ $v s$. time. An exponential fit gave an observed rate constant $k_{\mathrm{obs}}$ of $8.15 \times 10^{-5} \mathrm{~s}^{-1}$. The poor fits of the kinetic trace indicate a more complicated reaction sequence and rate law. 


\subsubsection{Crystal structures of $\mathbf{3 3}^{-}$and $\mathbf{3 4}^{-}$}

Various counter ions $\left(\mathrm{NEt}_{4}{ }^{+}, \mathrm{PPh}_{4}{ }^{+}, \mathrm{PPN}^{+}\right)$were tested to optimize the crystallization conditions of the reaction products $33^{-}$and $\mathbf{3 4}^{-}$. All of them are non-coordinating hence only little effect can be seen on spectroscopic properties of the DNICs. Single crystals suitable for X-ray diffraction were obtained from a DCM solution of (PPN)33 layered with hexane (Figure 2.6, a) or from diffusion of $\mathrm{Et}_{2} \mathrm{O}$ in a $\mathrm{MeCN}$ solution of (PPN)34 (Figure 2.6, b). Both anions crystalized with $\mathrm{PPN}^{+}$as counter ion. Their core geometry is best described as strongly distorted tetrahedral which is induced by the strain of the chelating ligand. Bond distances of $\mathrm{Fe}-\mathrm{N}(\mathrm{O})$ and $\mathrm{N}-\mathrm{O}$ are in the usual range for anionic $\left\{\mathrm{Fe}(\mathrm{NO})_{2}\right\}^{9}$ complexes. ${ }^{170}$ The nitrosyl moiety binds in a slightly bend fashion with angles $\Varangle \mathrm{Fe}-\mathrm{O}-\mathrm{N}$ between 157.3 and $171.3^{\circ}$ (selected bond dimensions are given in Table 2.1 and Table 2.2).
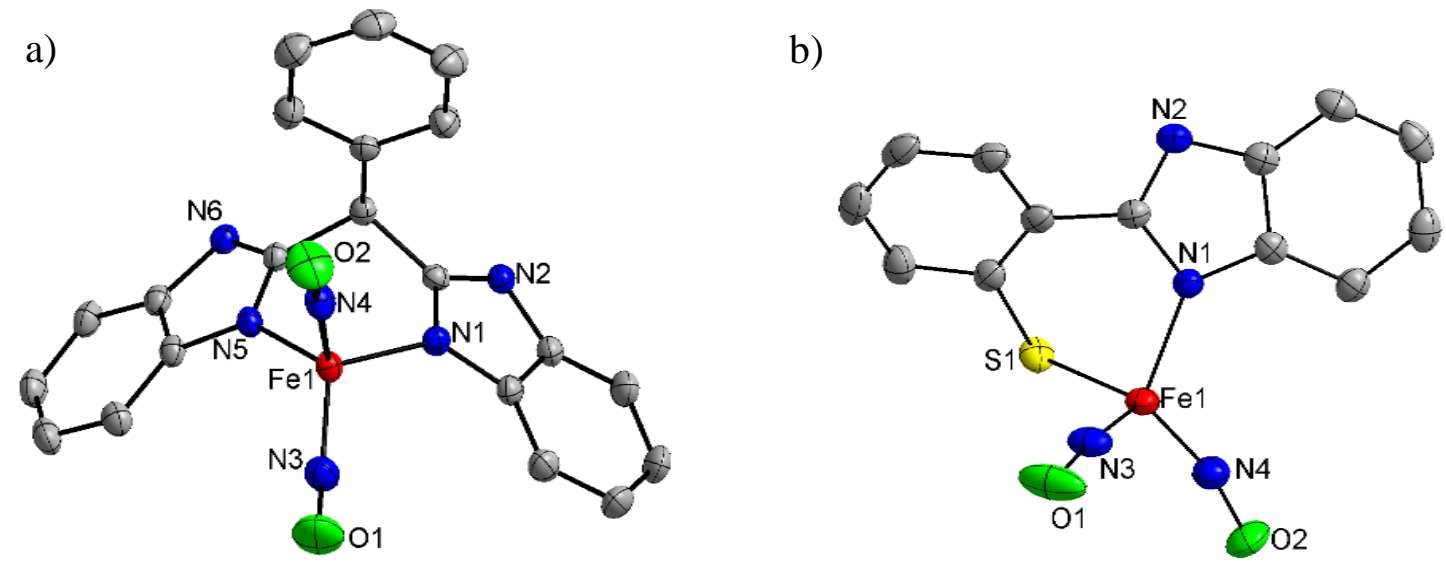

Figure 2.6. Molecular structures of the anion $\mathbf{3 3}^{-}$(a) and $\mathbf{3 4}^{-}$(b). The counter ions $\left(\mathrm{PPN}^{+}\right)$and hydrogen atoms are omitted for clarity. The thermal displacement ellipsoids are shown at 50\% probability.

Table 2.1. Selected bond lengths $(\AA)$ of $\mathbf{3 3}^{-}$and $\mathbf{3 4}^{-}$:

\begin{tabular}{c|c|c} 
& $\mathbf{3 3}^{-}$ & $\mathbf{3 4}^{-}$ \\
\hline \hline $\mathrm{Fe}(1)-\mathrm{N}(4)$ & $1.683(2)$ & $1.681(2)$ \\
\hline $\mathrm{Fe}(1)-\mathrm{N}(3)$ & $1.701(3)$ & $1.676(2)$ \\
\hline $\mathrm{Fe}(1)-\mathrm{N}(1)$ & $1.979(2)$ & $1.970(2)$ \\
\hline $\mathrm{Fe}(1)-\mathrm{N}(5)$ & $1.996(2)$ & - \\
\hline $\mathrm{Fe}(1)-\mathrm{S}(1)$ & - & $2.2544(8)$ \\
\hline $\mathrm{O}(1)-\mathrm{N}(3)$ & $1.169(6)$ & $1.171(3)$ \\
\hline $\mathrm{O}(2)-\mathrm{N}(4)$ & $1.165(9)$ & $1.185(3)$
\end{tabular}


Table 2.2. Selected angles $\left(^{\circ}\right)$ of $\mathbf{3 3}^{-}$and $\mathbf{3 4}^{-}$:

\begin{tabular}{c|c|c}
$\mathrm{N}(1)-\mathrm{Fe}(1)-\mathrm{N}(5)$ & $93.75(9)$ & - \\
\hline $\mathrm{N}(4)-\mathrm{Fe}(1)-\mathrm{N}(5)$ & $108.80(11)$ & - \\
\hline $\mathrm{N}(4)-\mathrm{Fe}(1)-\mathrm{N}(3)$ & $111.52(13)$ & $113.70(12)$ \\
\hline $\mathrm{N}(4)-\mathrm{Fe}(1)-\mathrm{N}(1)$ & $111.77(10)$ & $117.04(10)$ \\
\hline $\mathrm{N}(3)-\mathrm{Fe}(1)-\mathrm{N}(1)$ & $111.90(11)$ & $111.34(10)$ \\
\hline $\mathrm{N}(3)-\mathrm{Fe}(1)-\mathrm{N}(5)$ & $117.92(10)$ & - \\
\hline $\mathrm{N}(3)-\mathrm{Fe}(1)-\mathrm{S}(1)$ & - & $105.36(10)$ \\
\hline $\mathrm{N}(4)-\mathrm{Fe}(1)-\mathrm{S}(1)$ & - & $94.51(6)$ \\
\hline $\mathrm{N}(1)-\mathrm{Fe}(1)-\mathrm{S}(1)$ & - & $169.1(2)$ \\
\hline $\mathrm{O}(1)-\mathrm{N}(3)-\mathrm{Fe}(1)$ & $157.3(3)$ & $160.5(2)$
\end{tabular}

\subsubsection{EPR and Mössbauer spectroscopy}

EPR spectroscopy confirms an $S=1 / 2$ ground state and a rhombic EPR signal points towards a distorted coordination geometry around the metal ion. The EPR spectrum of $\mathbf{3 3}^{-}$recorded at $160.4 \mathrm{~K}$ in frozen solution in THF gave an anisotropic $g$-value of [2.068, 2.039, 2.014] (Figure 2.7, a). The $g_{\text {av }}$ of 2.040 compares well to literature. ${ }^{168}$ The EPR spectrum of $\mathbf{3 4}^{-}$ gave an anisotropic $g$-value of $[2.055,2.038,2.015]$ at $145 \mathrm{~K}$ in frozen solution in THF $\left(g_{\mathrm{av}}\right.$ $=2.034$, Figure $2.7, \mathrm{~b}$ ). As a conclusion, the $\mathbf{N N}$ versus $\mathbf{S N}$ capping ligands have only a minor influence on the electronic state of the iron ion. This statement is supported by Mössbauer spectroscopy as both DNICs give similar parameters. Two doublets were fitted to the experimental data of a solid sample of DNIC $\mathbf{3 3}^{-}$(Figure 2.7, c). The main signal (red) was assigned to $\mathbf{3 3}^{-}$and the minor signal (blue) to an $\mathrm{Fe}^{\mathrm{II}}$ impurity. The isomer shift and quadrupole splitting of $\mathbf{3 3}^{-}$at $80 \mathrm{~K}$ are $0.28 \mathrm{~mm} \mathrm{~s}^{-1}$ and $0.99 \mathrm{~mm} \mathrm{~s}^{-1}$, respectively. $\mathbf{3 4}^{-}$ shows an isomer shift of $0.18 \mathrm{~mm} \mathrm{~s}^{-1}$ and a quadrupole splitting of $0.90 \mathrm{~mm} \mathrm{~s}^{-1}$ in frozen THF solution (Figure 2.7, d). A UV-vis spectrum of crystalline material redissolved in THF displays bands at 430 and $705 \mathrm{~nm}$ for $\mathbf{3 3}^{-}$and 470,545 , and 685 for $\mathbf{3 4}^{-}$with low $\varepsilon_{\text {rel }}$ of around $300 \mathrm{M}^{-1} \mathrm{~cm}^{-1}$ (Figure 2.7, e and f). ESI-MS and ${ }^{1} \mathrm{H}$ NMR spectroscopy appear to be unsuitable methods for characterization of $\mathbf{3 3}^{-}$and $\mathbf{3 4}^{-}$, efforts to obtain good spectra have been unsuccessful. 
a)

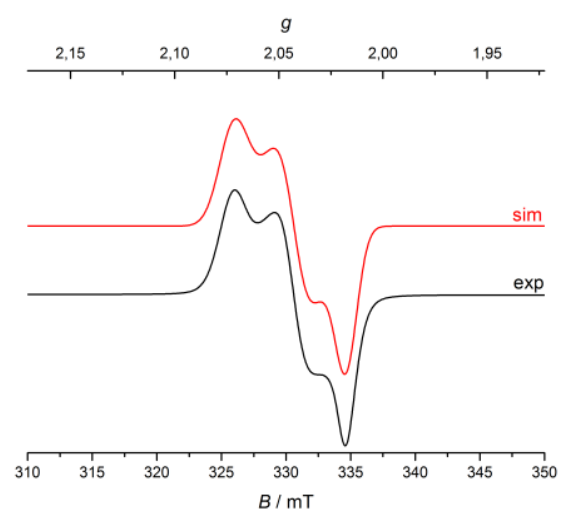

c)

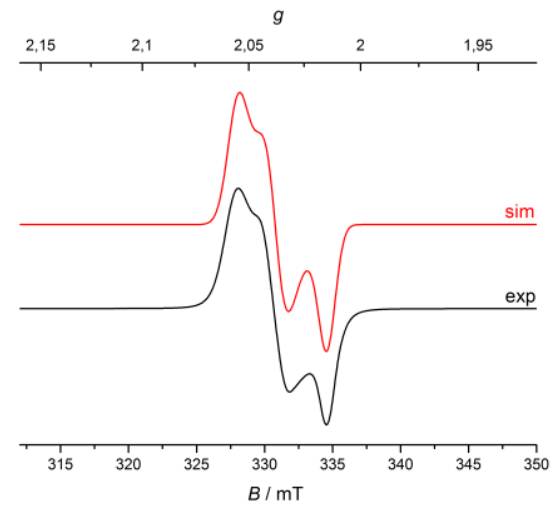

e)

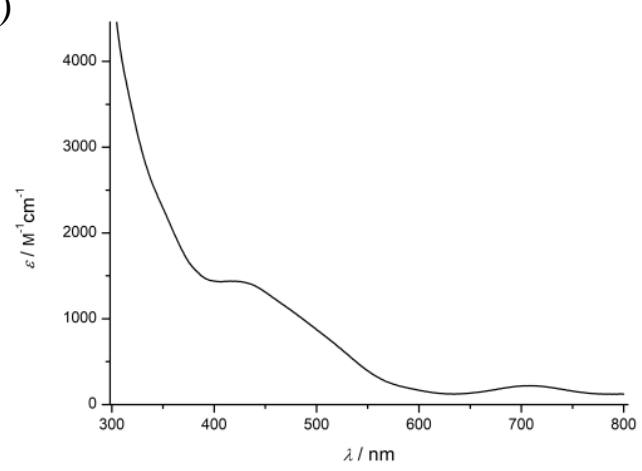

b)

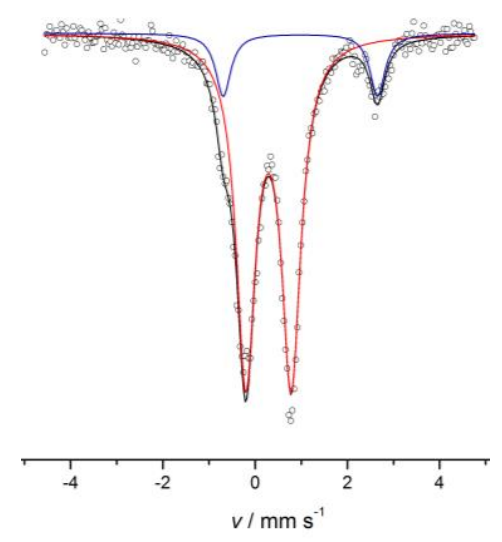

d)

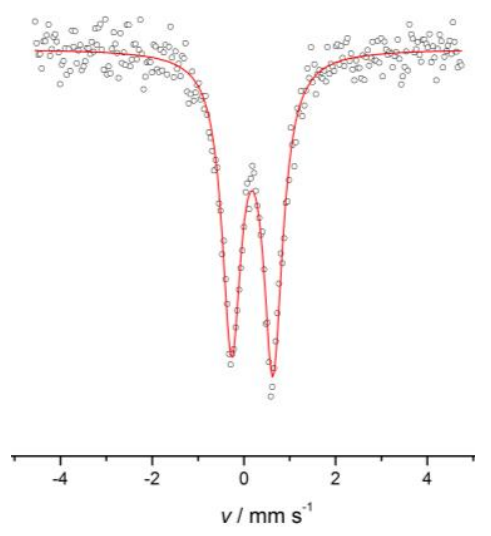

f)

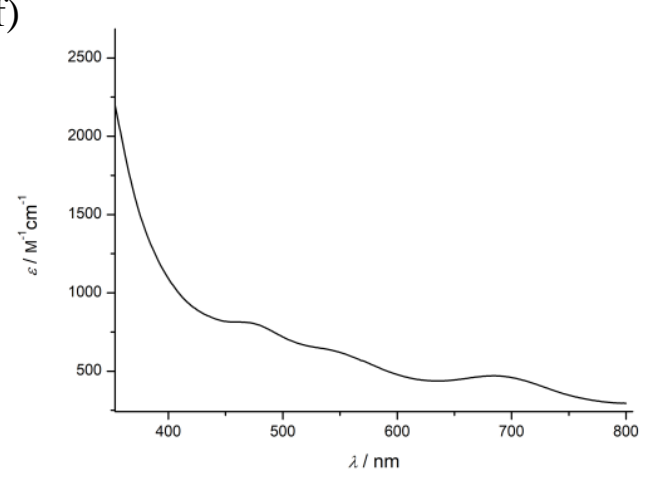

Figure 2.7. a) X-band EPR spectrum of $\mathbf{3 3}^{-}$recorded at $160.4 \mathrm{~K}$ in frozen solution (THF, black). The red line is a powder simulation with $g=(2.068,2.039,2.014)$. b) Zero-field Mössbauer spectrum of $\mathbf{3 3}^{-}$at $80 \mathrm{~K}$. The solid lines represent the result of a fit with Lorentzian doublets (red for $\mathbf{3 3}^{-}$and blue for an impurity). Summation of the two subspectra affords the black line. c) X-band EPR spectrum of $\mathbf{3 4}^{-}$recorded at $145 \mathrm{~K}$ in frozen solution (THF, black). The red line is a powder simulation with $g=(2.055,2.038,2.015)$. d) Zero-field Mössbauer spectrum of $\mathbf{3 4}^{-}$in frozen THF solution at $80 \mathrm{~K}$, e) $\mathrm{UV}$-vis spectrum of $\mathbf{3 3}^{-}$in THF at rt, f) UV-vis spectrum of $\mathbf{3 4}^{-}$in THF at rt. 


\subsection{Nitrosylation of mixed-valent $[2 \mathrm{Fe}-2 \mathrm{~S}]$ clusters}

\subsubsection{Nitrosylation of $\mathbf{2 9}^{\mathbf{3}}$}

\subsubsection{UV-vis spectroscopy}

When a solution of the reduced cluster $\mathbf{2 9}^{3-}$ in $\mathrm{MeCN}$ was exposed to 5 equivalents of $\mathrm{NO}$, three distinct reaction steps can be identified by UV-vis spectroscopy (Figure 2.8). During the first $30 \mathrm{~min}$, the bands at 408 and $528 \mathrm{~nm}$ increase and an intermediate 1 is formed (Figure 2.8, a). These two bands are indicative for the diferric cluster $\mathbf{2 9}^{\mathbf{2}}$. Intermediate 1 is stable for approximately $30 \mathrm{~min}$. Then the band at $528 \mathrm{~nm}$ decreases in intensity while the other maximum shifts from 408 to $419 \mathrm{~nm}$ suggesting that a second intermediate is formed (Figure 2.8, b) which ultimately decomposes over several hours (Figure 2.8, c).

a)
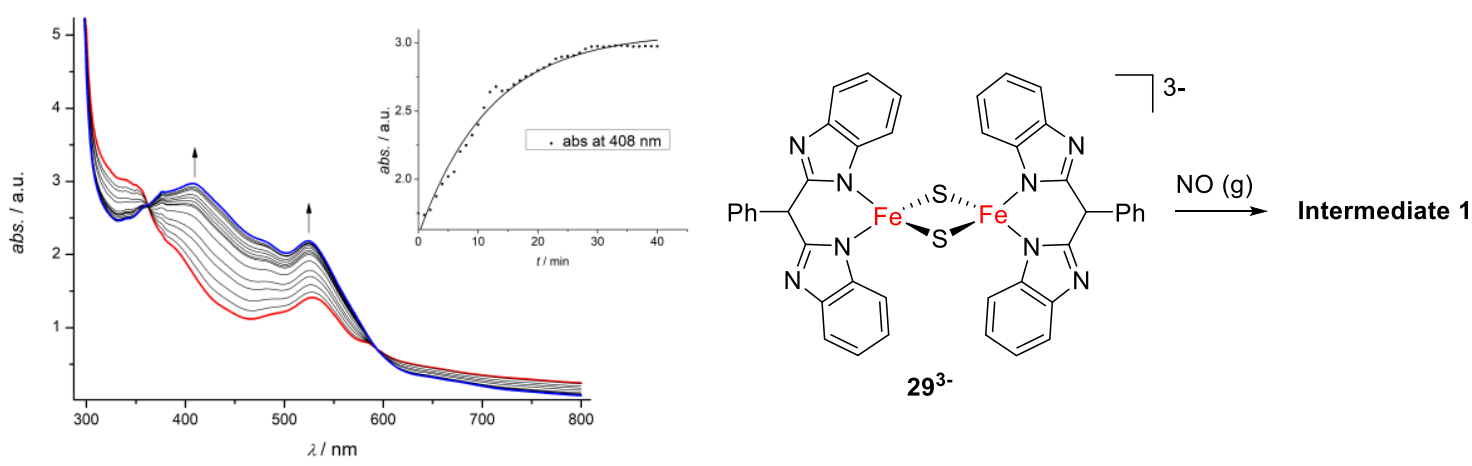

b)

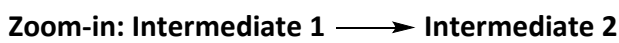

c) Intermediate $2 \longrightarrow$
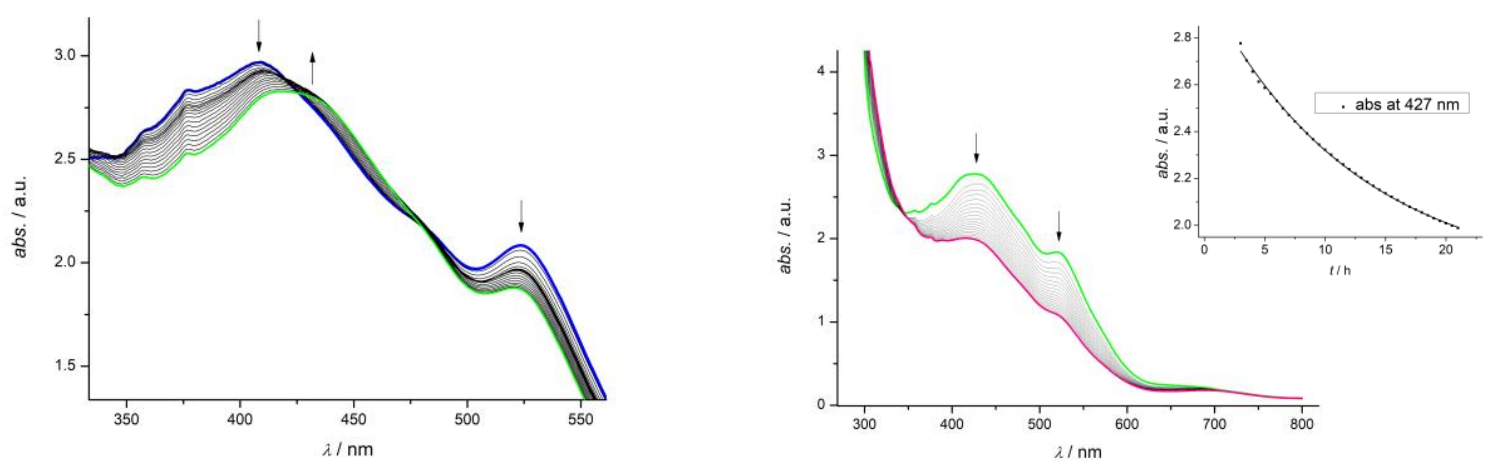

Figure 2.8. a) First step of nitrosylation of $\mathbf{2 9}^{\mathbf{3}-}$ monitored by UV-vis spectroscopy ( $\Sigma 40 \mathrm{~min}$ ). The inserted graph depicts absorbance at $408 \mathrm{~nm} v s$. time. An exponential fit gave a observed rate constant $k_{\text {obs }}$ of $1.38 \times 10^{-3} \mathrm{~s}^{-1}$. The poor fit of the kinetic trace indicates a more complicated reaction sequence and rate law. b) Excerpt of UV-vis spectra measured after 50 - 140 min reaction time: Shift of maximum from 408 to $419 \mathrm{~nm}$. c) Degradation of intermediate 2 monitored by UVvis spectroscopy over the course of $18 \mathrm{~h}$. The inserted graph depicts absorbance at $427 \mathrm{~nm} v$ s. time. An exponential fit gave an observed rate constant $k_{\text {obs }}$ of $2.24 \times 10^{-5} \mathrm{~s}^{-1}$. 
Conducting the reaction at lower temperature $\left(-30^{\circ} \mathrm{C}\right)$ does not affect the reaction pattern monitored by UV-vis spectroscopy or the timescale of the reaction, however, addition of only one equivalent of NO has a strong effect (Figure 2.9). For the first $15 \mathrm{~min}$ only a small change of the UV-vis spectrum is detected. Therefore, the first three data points are excluded from the exponential fit in the inserted graph. After this induction period, the reaction to intermediate 1 takes twice as long and the rate constant is almost an order of magnitude smaller (Figure 2.9, a). Under these conditions, intermediate 1 is stable for almost 10 hours before it starts to decay. When the nitrosylation is conducted with 5 equivalents of $\mathrm{NO}$, intermediate 1 is only stable for approximately one hour and transforms into intermediate 2 . Formation of intermediate 2 is not detected with only one equivalent of NO. Instead, the overall absorption decreases over several hours (Figure 2.9, b). The absence of any DNIC product is confirmed by IR spectroscopy of the reaction mixture after treatment with one equivalent of NO.

a)

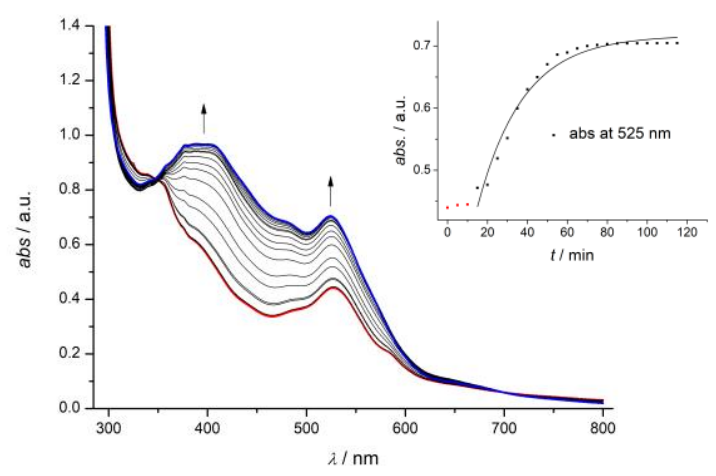

b)

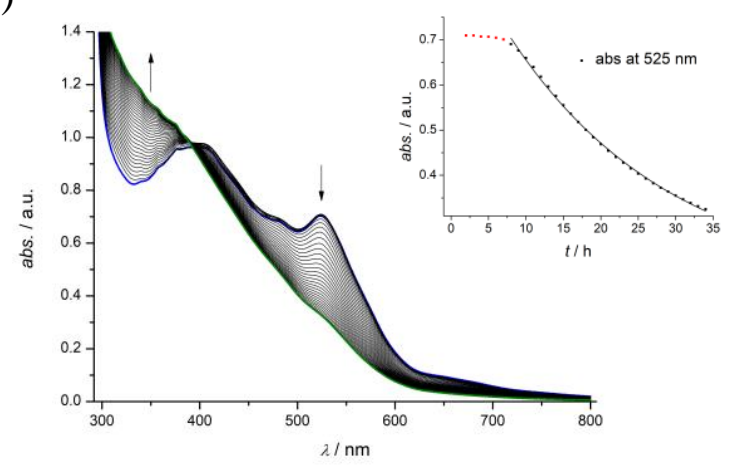

Figure 2.9. UV-vis spectroscopy of nitrosylation with only one equivalent NO. a) First two hours of reaction ( $24 \times 5 \mathrm{~min})$. Insert: exponential fit of the absorption at $525 \mathrm{~nm} v s$. time gives a rate constant $k_{\mathrm{obs}}$ of $7.33 \times 10^{-4} \mathrm{~s}^{-1}(\dagger)$. b) $2-34 \mathrm{~h}$ after addition of NO (spectrum each hour). Insert: exponential fit of the absorption at $525 \mathrm{~nm} v s$. time gives a rate constant $k_{\mathrm{obs}}$ of $1.27 \times 10^{-5} \mathrm{~s}^{-1}(\dagger) .(\dagger)$ Data points in red are excluded from the fitting process. The poor fits of the kinetic traces (inserts $\mathrm{a}$ and $\mathrm{b}$ ) indicate a more complicated reaction sequence and rate law. 


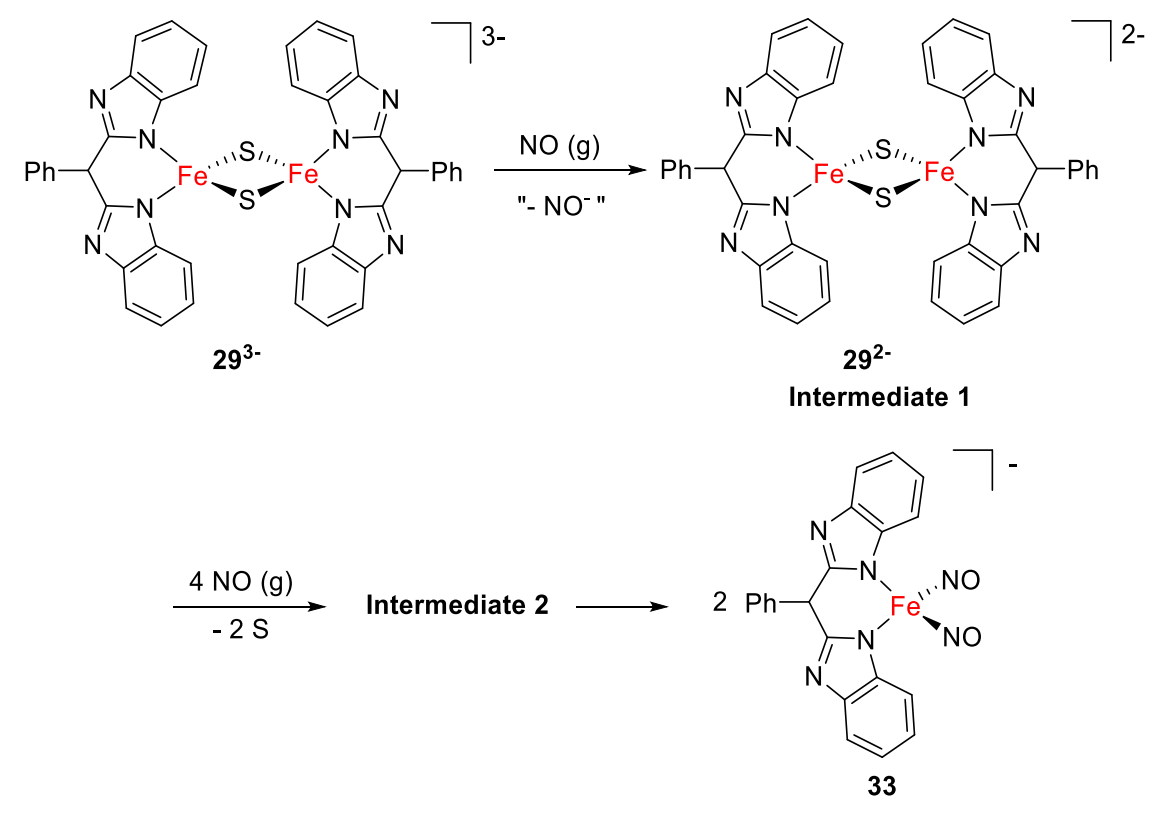

Figure 2.10. Proposed reaction pathway of the nitrosylation of the mixed-valent cluster $\mathbf{2 9}^{\mathbf{3}}$.

Taken all the information from the UV-vis measurements into consideration, a reaction pathway with two intermediates is proposed (Figure 2.10). Intermediate 1 can be identified as diferric $\mathbf{2 9}^{\mathbf{2}}$ from the assignment of the bands in the UV-vis spectrum. It is formed via oxidation of mixed-valence $29^{3-}$ by one equivalent of NO. The identity of intermediate 2 cannot be deduced from UV-spectroscopy only.

\subsubsection{IR spectroscopy and ESI-MS of intermediate 1}

An IR spectrum was measured of the reaction mixture after $30 \mathrm{~min}$ at $-30{ }^{\circ} \mathrm{C}$ and subsequent removal of the solvent (Figure 2.11, a). The spectrum of the redissolved residue in THF confirms that intermediate 1 corresponds to $\mathbf{2 9}^{\mathbf{2}}$. Most of the signals can be assigned to differic $\mathbf{2 9}^{\mathbf{2}-}$ (red) or residual 29-3 (orange). Both give similar signals in the IR spectrum. In the region where usually nitrosylized products (green rectangle) resonate, peaks were detected at 1665 and $1683 \mathrm{~cm}^{-1}$ with high intensity and $1745 \mathrm{~cm}^{-1}$ with low intensity. The signal at $1745 \mathrm{~cm}^{-1}$ may belong to some RBS. However, $v_{\mathrm{NO}}$ of DNIC $\mathbf{3 3}^{-}$is not found. On the other hand, DNIC $\mathbf{3 3}^{-}$is clearly the main product in the IR spectrum of the reaction mixture after 3.5 hours (Figure 2.11, b). ESI-MS confirms that the cluster core is still unimpaired after a reaction time of $30 \mathrm{~min}$ (Figure 2.12), whereas the signals characteristic for $\mathbf{2 9}^{\mathbf{2}-}$ disappeared in the sample taken after 3.5 hours of reaction time. 
a)

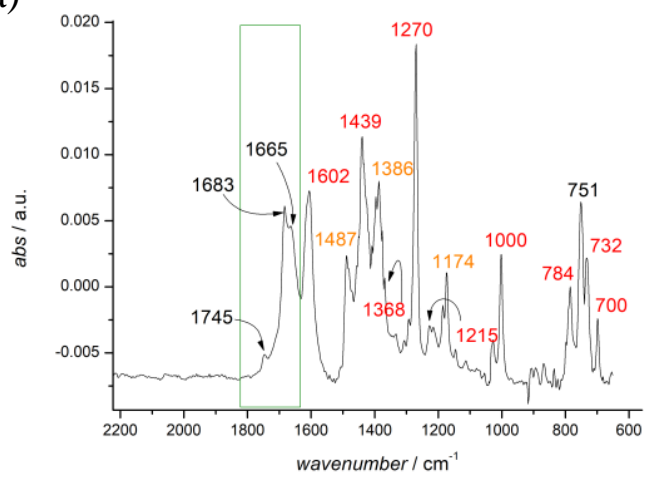

b)

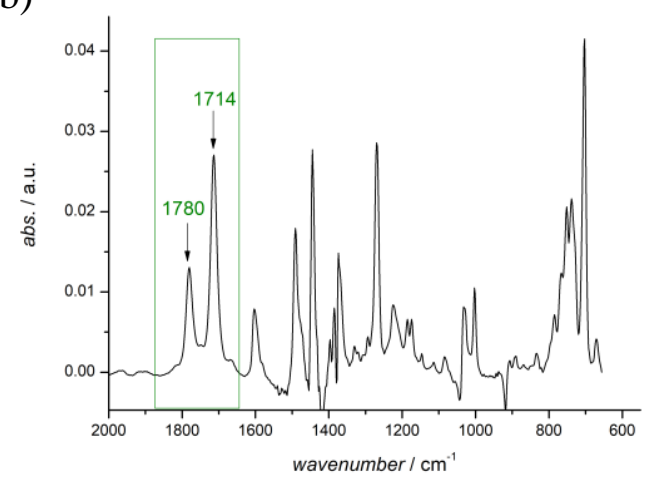

Figure 2.11. IR spectrum of reaction mixture after a) $30 \mathrm{~min}$. and b) $3.5 \mathrm{hrs}$. The green rectangle encompasses the region where $v_{\text {NO }}$ are usually found. Numbers in green mark NO-stretching frequencies from DNIC $\mathbf{3 3}^{-}\left(1780,1714 \mathrm{~cm}^{-1}\right)$ in $\mathrm{MeCN}$, numbers in red mark diferric $\mathbf{2 9}^{\mathbf{2}-}$ and in orange $\mathbf{2 9}^{\mathbf{3}}$. Numbers in black are not assigned.

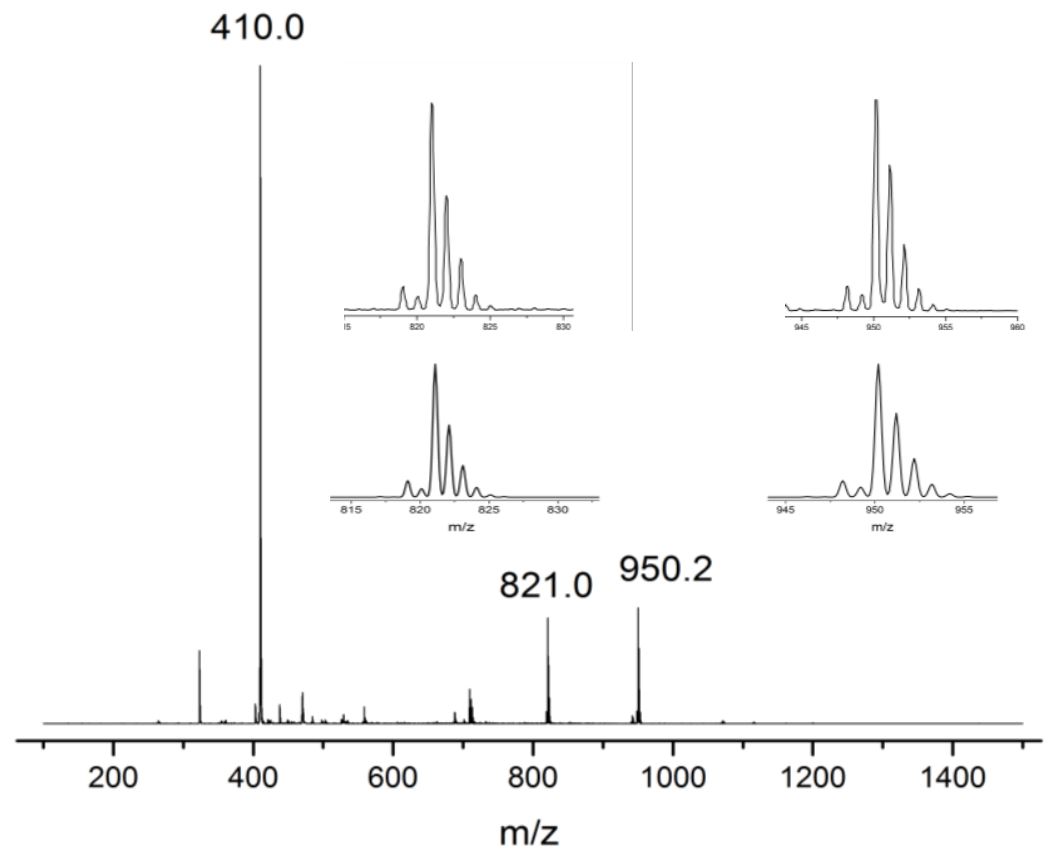

Figure 2.12. ESI(-)MS of intermediate 1 in $\mathrm{MeCN}$. The inserts depict experimental and simulated data of peak [M-NEt $]^{-}$ $(950.2 \mathrm{~m} / \mathrm{z})$ and $[\mathrm{M}-2 \mathrm{NEt} 4+\mathrm{H}]^{-}(821.0 \mathrm{~m} / \mathrm{z}) .410 \mathrm{~m} / \mathrm{z}$ corresponds to $\left[\mathrm{M}-2 \mathrm{NEt}_{4}\right]^{2-}$.

\subsubsection{NMR spectroscopy}

A solution of $\mathbf{2 9}^{3-}$ in DMF- $\mathrm{d}_{7}$ was frozen and the inert gasphase was replaced with a mixture of $\mathrm{NO}$ and argon that equaled 4 equivalents of $\mathrm{NO}$ with respect to $\mathbf{2 9}^{\mathbf{3}-}$. The solution was thawed and ${ }^{1} \mathrm{H}$ NMR spectra were recorded over a period of $120 \mathrm{~min}(10 \times 2 \mathrm{~min}$ and $20 \times 5 \mathrm{~min}$ ). A selection of spectra is depicted in Figure 2.13. The signal intensity for $\mathbf{2 9}^{\mathbf{3}-}$ decreases within 20 min while a new set of signals characteristic for $\mathbf{2 9}^{\mathbf{2}}$ emerges. The 
integrals of the peaks at 11.78 (indicative for $\mathbf{2 9}^{3-}$ ) and also $10.46 \mathrm{ppm}$ (indicative for $\mathbf{2 9}^{\mathbf{2}-}$ ) were divided by the sum of both integrals in order to obtain their ratio which was plotted against the time (Figure 2.14). The first data points are deduced from the first spectrum taken. As they do not depict a ratio 1:0 $\left(\mathbf{2 9}^{3-}: \mathbf{2 9}^{\mathbf{2}}\right)$ it is obvious that the first few minutes of the reaction were not captured due to the set-up (e.g. time necessary for shimming). The first spectrum is defined as $t=0$.

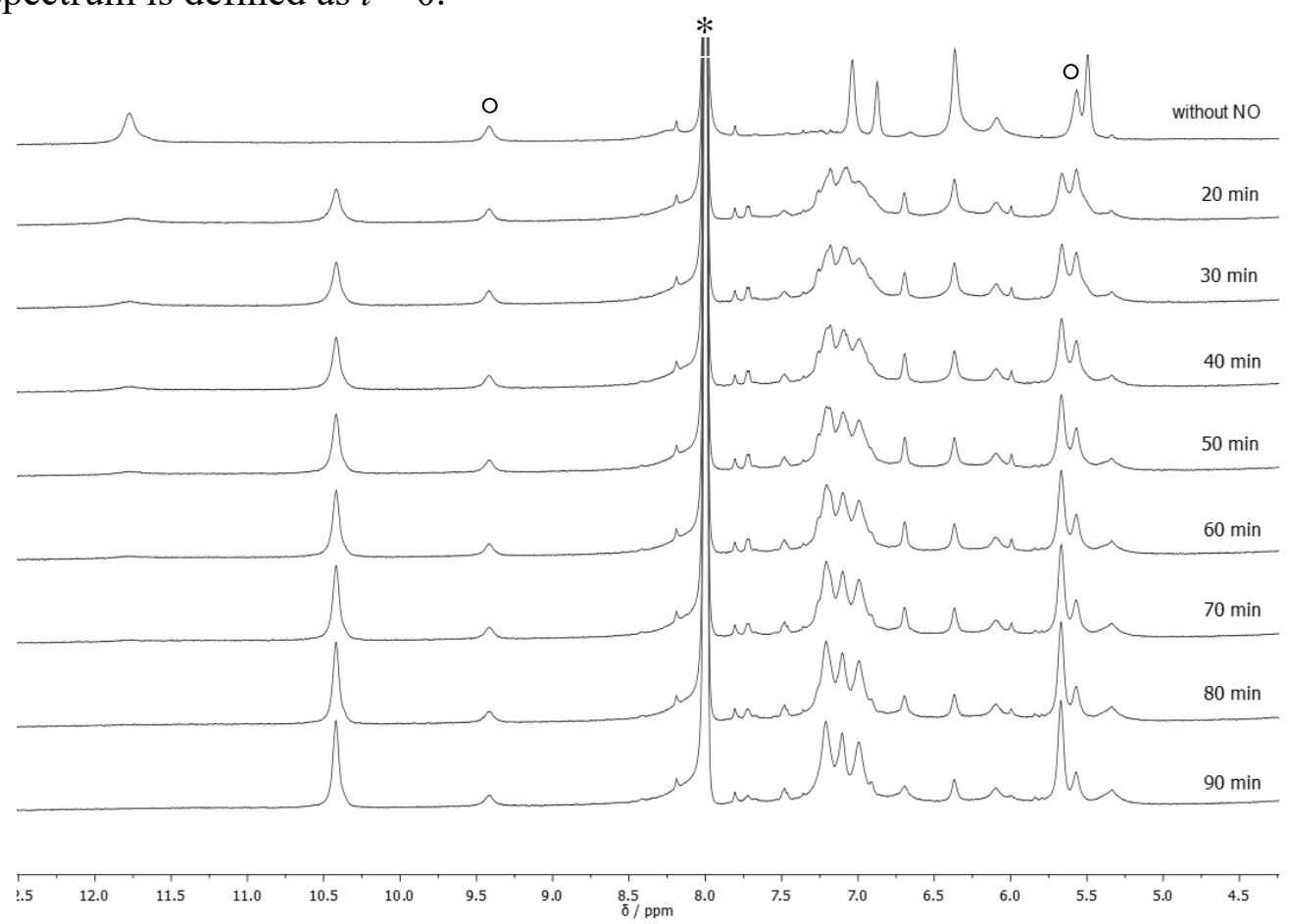

Figure 2.13. Nitrosylation of mixed-valent $\mathbf{2 9}^{3-}$ monitored by ${ }^{1} \mathrm{H}$ NMR spectroscopy. Depicted is a selection of spectra within the first $90 \mathrm{~min}$ of the reaction. * residual DMF. ${ }^{\circ}$ unknown impurity.

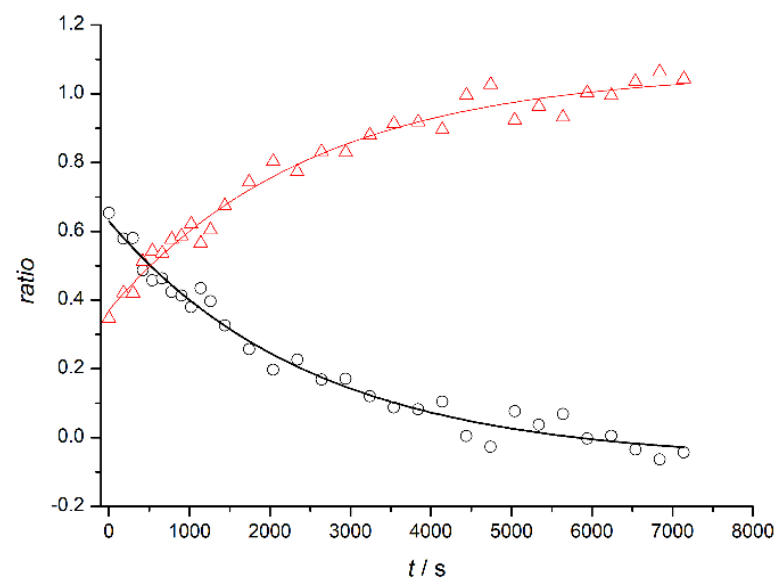

Figure 2.14. Ratio of integral for peak at $11.78 \mathrm{ppm}$ (black circles) and integral for peak at $10.46 \mathrm{ppm}$ (red triangles). An exponential fit gave reaction rate $k_{\mathrm{obs}}$ of $3.98 \times 10^{-4} \mathrm{~s}^{-1}$. 
The oxidation of $\mathbf{2 9}^{3-}$ appears to be one magnitude slower in the NMR tube $\left(k_{\mathrm{obs}}=\right.$ $\left.3.98 \times 10^{-4} \mathrm{~s}^{-1}\right)$ than in the UV-vis cuvette $\left(k_{\mathrm{obs}}=1.38 \times 10^{-3} \mathrm{~s}^{-1}\right)$. The reaction conditions seem to differ greatly in a NMR tube and a UV-vis cuvette. The substrate concentration is significantly higher for NMR spectroscopy than UV-vis spectroscopy. According to this observation, pseudo-first order kinetics are not applicable for this reaction. Another reason for differing $k_{\mathrm{obs}}$ could simply be different diffusion coefficient of the gaseous NO dependent on the shape of the glassware.

\subsubsection{Mössbauer spectroscopy of intermediate 1 and 2}

Intermediate 1 (int. 1) was isolated by stopping the reaction of $29^{3-}$ with 5 equivalents of NO after 35 min by removal of solvent and excess NO under reduced pressure. UV-vis spectroscopy confirmed the formation of int.1 $\left(\mathbf{( 2 9}^{2-}\right)$ (Figure 8.1 in appendix). The Mössbauer spectrum of the obtained solid was measured at $80 \mathrm{~K}$ and $6 \mathrm{~K}$ (Figure 8.2 in appendix). A more dissolved spectrum at low temperature $(6 \mathrm{~K})$ allowed for easier and more precise fitting of the data. The main signal at $6 \mathrm{~K}$ has an isomer shift of $0.26 \mathrm{~mm} \mathrm{~s}^{-1}$ and a quadrupole splitting of $1.00 \mathrm{~mm} \mathrm{~s}^{-1}$ indicative of an $\mathrm{Fe}^{\mathrm{III}}$ species. Other iron-species are detected with a transmission of $<0.5 \%$. The experimental parameters of the main signal allow an assignment to either the diferric cluster $\mathbf{2 9}^{\mathbf{2}-}$ or DNIC $\mathbf{3 3}^{-}$(Table 2.3). However, an IR spectrum of the reaction solution does not show the typical nitrosyl bands at 1780 and $1714 \mathrm{~cm}^{-1}$ (Figure 2.11), which supports the formation of $\mathbf{2 9}^{\mathbf{2}-}$. Affirmation for $\mathbf{2 9}^{\mathbf{2}-}$ to be the main product is found in the NMR spectrum of the sample after 35 min (Figure 2.16, cf. green vs. blue line).

Intermediate 2 was captured with a $33 \%{ }^{-57} \mathrm{Fe}$-enriched sample (Figure 8.3 in appendix). The reaction was stopped after $90 \mathrm{~min}$ as the UV-vis spectrum showed full conversion to intermediate 2 (Figure 8.4 in appendix). The Mössbauer spectrum of the frozen solution and a ${ }^{1} \mathrm{H}$ NMR spectrum of the sample feature the diferric $\mathbf{2 9}^{\mathbf{2}-}$ cluster as main species (Figure 8.3 in the appendix and Figure 2.16 below, violet line). In conclusion, the [2Fe$2 \mathrm{~S}$ ] core remains intact during transformation of intermediate 1 to 2 . The difference in the UV-vis spectra between both species must be assigned to a peripheral change on the ligand of the cluster as the Mössbauer parameters of $\mathbf{3 3}^{-}$and $\mathbf{2 9}^{\mathbf{2}}$ do not differ greatly (Figure 2.15). A pentacoordinated intermediate in which $\mathrm{NO}$ binds to the iron ion can be excluded according to Mössbauer spectroscopy. 
Table 2.3. Mössbauer parameters of compounds relevant to nitrosylation of $\mathbf{2 9}^{\mathbf{3}}$ with 5 eq. NO.

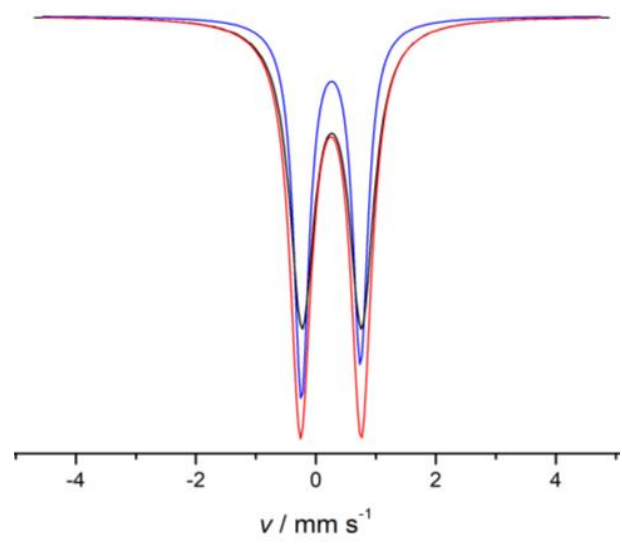

\begin{tabular}{c|c|c|c} 
& $\delta / \mathrm{mm} \mathrm{s}^{-1}$ & $\Delta E_{\mathrm{Q}} / \mathrm{mm} \mathrm{s}^{-1}$ & ref. \\
\hline \hline 29 $^{3-}\left(\mathrm{Fe}^{\mathrm{III}}\right)$ & 0.47 & 1.41 & 165 \\
$\left(\mathrm{Fe}^{\mathrm{II}}\right)$ & 0.69 & 2.90 & \\
\hline $\mathbf{2 9}^{2-}$ & 0.25 & 0.98 & 165 \\
\hline int. 1 & 0.26 & 1.00 & \\
\hline int. 2 & 0.27 & 0.99 & \\
\hline 33- & 0.29 & 0.99 &
\end{tabular}

Figure 2.15. Overlay of Mössbauer fits.of diferric $\mathbf{2 9}^{\mathbf{2}-}(80 \mathrm{~K}$, blue $)$ and of the reaction mixture of $\mathbf{2 9}^{\mathbf{3}-}$ with 5 eq. NO after $30 \mathrm{~min}$ (int. 1, $6 \mathrm{~K}$, red) and $90 \mathrm{~min}$ (int. 2, $80 \mathrm{~K}$, black).

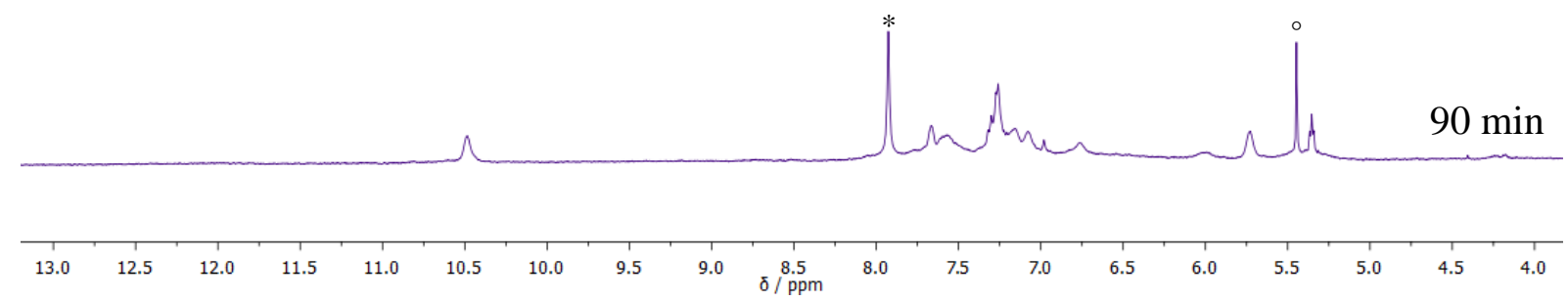

Figure 2.16. ${ }^{1} \mathrm{H}$ NMR spectrum of mixed-valent $\mathbf{2 9}^{\mathbf{3}-}$ (red in DMF-d 7 ), diferric $\mathbf{2 9}^{\mathbf{2}-}$ (green in MeCN-d $\mathrm{d}_{3}$ ), reaction stopped after $35 \mathrm{~min}$ by removal of the solvent in vacuo (blue in $\mathrm{MeCN}-\mathrm{d}_{3}$ ), and reaction stopped after 90 min by removal of the solvent in vacuo (violet in DMF-d7). $(*)$ marks the residual DMF solvent peak and $\left(^{\circ}\right)$ marks DCM. 


\subsubsection{Nitrosylation of $\mathbf{3 0}^{\mathbf{3}-}$}

When a solution of $\mathbf{3 0}^{\mathbf{3}-}$ in $\mathrm{MeCN}$ is exposed to 5 equivalents of $\mathrm{NO}$ the absorbance in the UV-vis spectra increases until a maximum is reached after 15 min (Figure 2.17, a). The resulting spectrum indicates the formation of diferric $\mathbf{3 0}^{\mathbf{2}}$ with bands at 434, 512, and $585 \mathrm{~nm}$ and a purple colored solution. Then the absorbance decreases over several hours indicating the degradation of the $[2 \mathrm{Fe}-2 \mathrm{~S}]$ core (Figure 2.17, b). Finally, a brown solution is obtained in which the typical nitrosyl stretching frequencies of $\mathbf{3 4}^{-}$are found in the IR spectrum at 1740 and $1694 \mathrm{~cm}^{-1}$ (Figure 2.17, c). These observations support a mechanistic scenario in which $\mathbf{3 0}^{\mathbf{3}-}$ is oxidized to $\mathbf{3 0}^{\mathbf{2}}$ by a first equivalent of NO and subsequently $\mathbf{3 4}^{-}$ is formed (Figure 2.18). The reaction pathway is more straight forward in comparison to nitrosylation of $\mathbf{2 9}^{\mathbf{3}-}$ (Chapter 2.3.1) as only one intermediate is formed, namely diferric cluster $\mathbf{3 0}^{\mathbf{2}}$.

a)

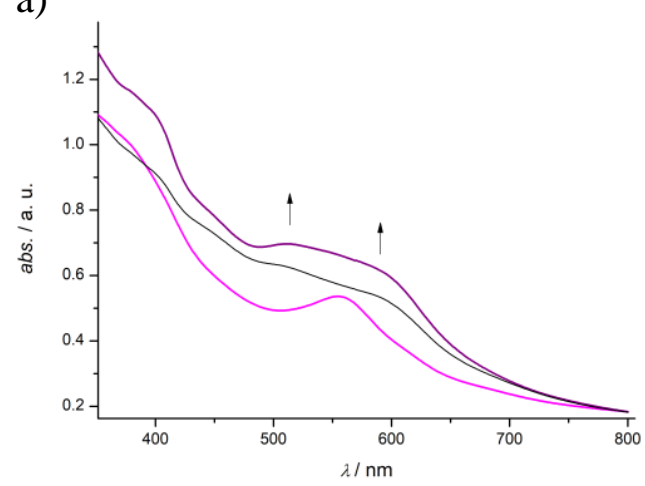

b)

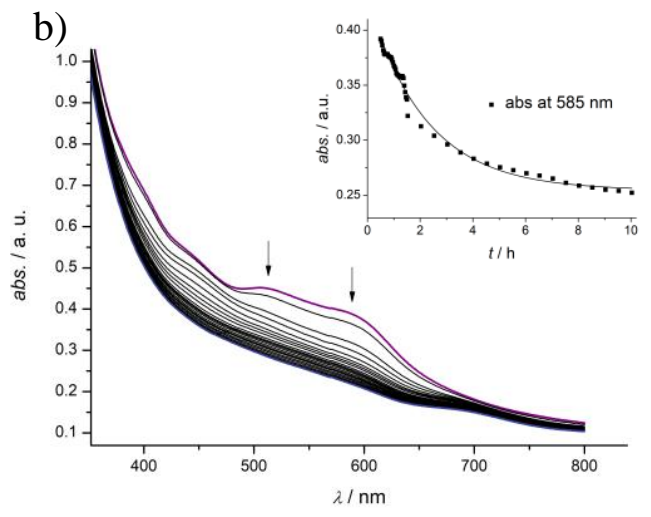

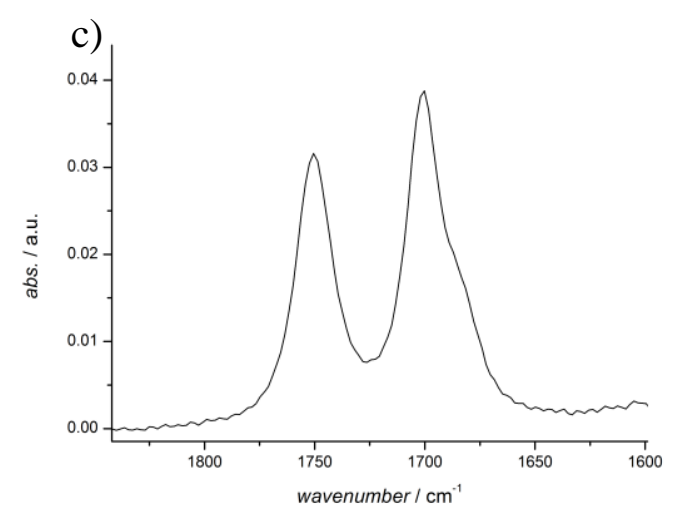

Figure 2.17. UV-vis spectra of nitrosylation of $\mathbf{3 0}^{3-}$ a) 0-15 min (spectrum taken every $5 \mathrm{~min}$ ) and b) $30 \mathrm{~min}-10 \mathrm{~h}$ (spectrum taken every $30 \mathrm{~min}$ ). The inserted graph depicts the absorbance at $585 \mathrm{~nm} v s$. time. An exponential fit gave a rate constant $k_{\text {obs }}$ of $1.25 \times 10^{-4} \mathrm{~s}^{-1}$. The poor fit of the kinetic trace indicates a more complicated reaction sequence and rate law. c) Excerpt of the IR spectrum of the reaction mixture after $5 \mathrm{~h}$. The bands can be assigned to DNIC $\mathbf{3 4}^{-}$. 


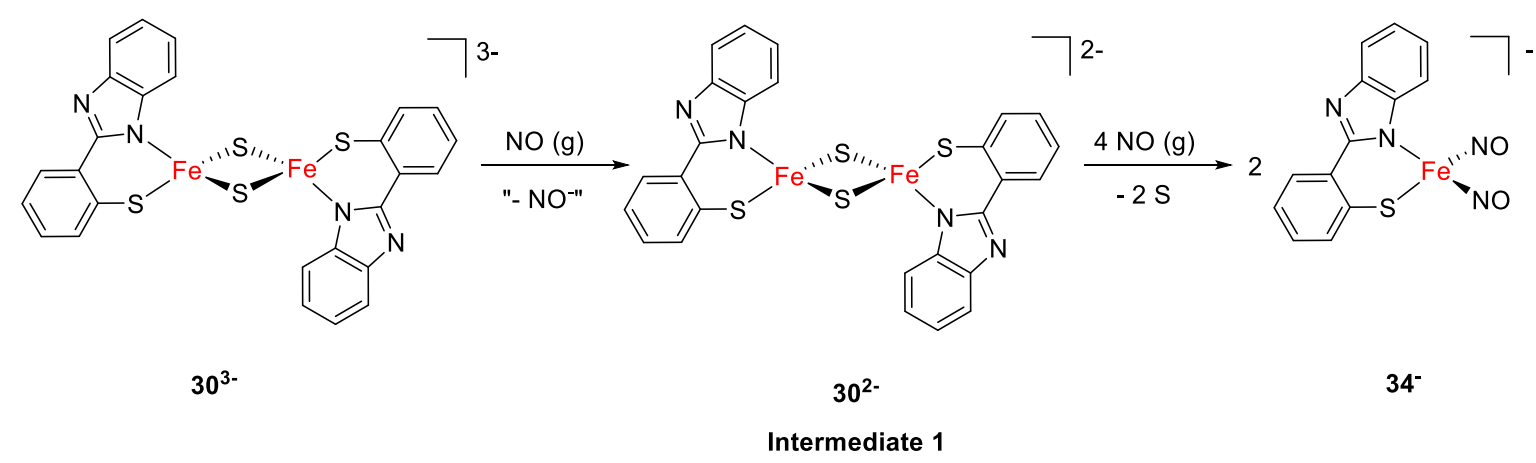

Figure 2.18. Proposed reaction pathway for nitrosylation of mixed-valent cluster $\mathbf{3 0}^{\mathbf{3}-}$ with 5 equivalents of NO.

\subsection{Nitrosylation of protonated clusters $\mathbf{2 9 \mathbf { H } _ { 2 }}$ and $\mathbf{3 0 H _ { 2 }}$}

\subsubsection{Reaction of $\mathbf{2 9 \mathbf { H } _ { 2 }}$ with NO}

Full protonation of the proton responsive ligands from $\mathbf{2 9}^{2-}$ can be achieved by addition of 7 equivalents of the acid 2,6-dimethylpyridinium tetrafluoroborate (DMPH). The product is a doubly protonated cluster $\mathbf{2 9 \mathbf { H } _ { 2 }}$ with concomitant tautomerism of the proton of the methine bridge (Figure 2.19). ${ }^{163}$ Protonation of $\mathbf{2 9}^{\mathbf{2}-}$ is accompanied by rise of a characteristic, prominent band at about $380 \mathrm{~nm}\left(\varepsilon=64000 \mathrm{M}^{-1} \mathrm{~cm}^{-1}\right)$ in the UV-vis spectrum.

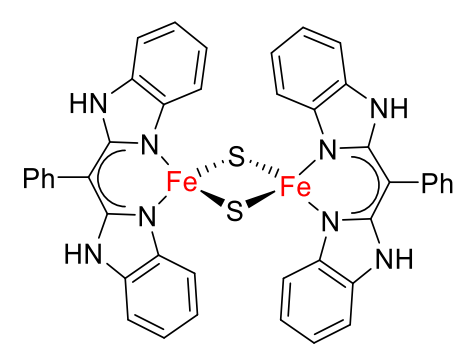

$29 \mathrm{H}_{2}$

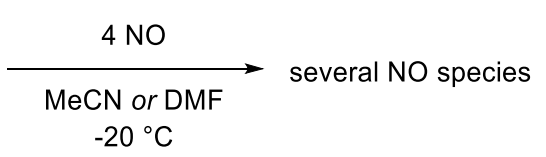

$-20^{\circ} \mathrm{C}$

Figure 2.19. Nitrosylation of doubly protonated cluster $\mathbf{2 9 H} 2$ produces several species.

When the nitrosylation of $\mathbf{2 9 \mathbf { H } _ { 2 }}$ is monitored by UV-vis spectroscopy (Figure 2.20, a), degradation of the $[2 \mathrm{Fe}-2 \mathrm{~S}]$ core is evident from bleaching of the sample. The reaction proceeds with a rate in the same order of magnitude as observed for nitrosylation of $\mathbf{2 9}^{\mathbf{2}}$ $\left(k_{\text {obs }}(\mathbf{2 9 H})=3.98 \times 10^{-4} \mathrm{~s}^{-1}, k_{\text {obs }}\left(\mathbf{2 9}^{2-}\right)=1.60 \times 10^{-4} \mathrm{~s}^{-1}\right)$. Several bands are detected in the region for NO species in the IR spectrum of the THF extract, but only RBS can be identified with bands at 1795 (w), 1740 (s), and 1705 (w) (Figure 2.20, b). Bands at 1652 and $1628 \mathrm{~cm}^{-1}$ can be assigned to residual DMPH. The presence of unreacted DMPH is not surprising due to the excess needed for full protonation of the cluster. The surplus of acid 
possibly prevents the formation of a DNIC-species or accelerates its decomposition, ultimately yielding RBS. Further information on the protonation product of DNIC $\mathbf{3 3}^{-}$and its stability are presented in chapter 3.

The characteristic bands for the corresponding base lutidine are not detected (bands at 1593 and $\left.1580 \mathrm{~cm}^{-1}\right)$. Possibly, it was removed with the solvent under reduced pressure prior to the IR measurement.

a)

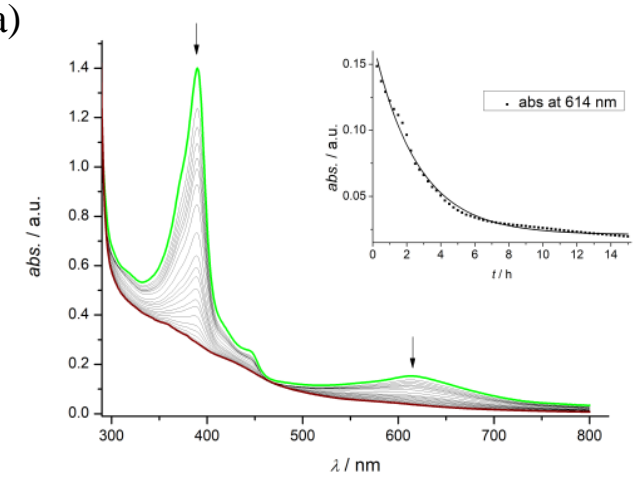

b)

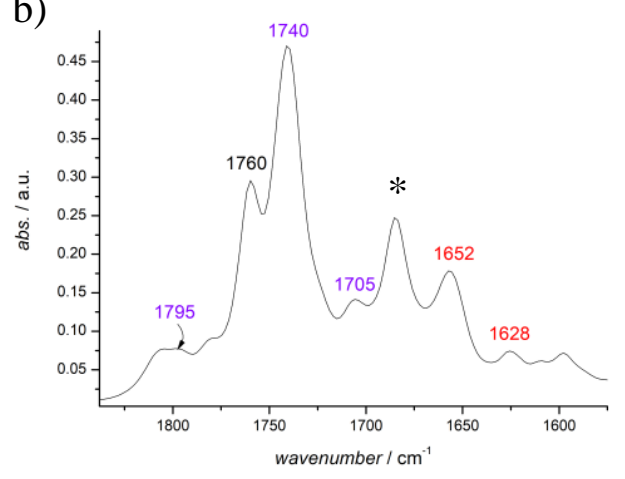

Figure 2.20. a) UV-vis spectra monitoring nitrosylation of protonated cluster $\mathbf{2 9 \mathbf { H } _ { 2 }}(15 \mathrm{~min})$ in DMF at $-20{ }^{\circ} \mathrm{C}$. The inserted graph depicts absorption at $614 \mathrm{~nm} v s$. time $\left(k_{\mathrm{obs}}\right.$ of $\left.3.98 \times 10^{-4} \mathrm{~s}^{-1}\right)$. The poor fit of the kinetic trace indicates a more complicated reaction sequence and rate law. b) IR spectrum of THF extract after a reaction time of $2 \mathrm{~h}$. Bands labeled in purple can be assigned to RBS, bands labeled in red to residual DMPH. (*) marks residual DMF at $1685 \mathrm{~cm}^{-1}$.

\subsubsection{Reaction of $\mathbf{3 0 H _ { 2 }}$ with $\mathrm{NO}$}

a)

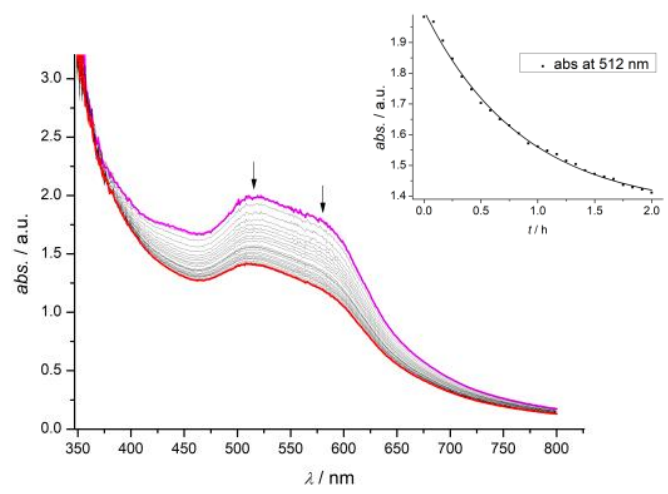

b)

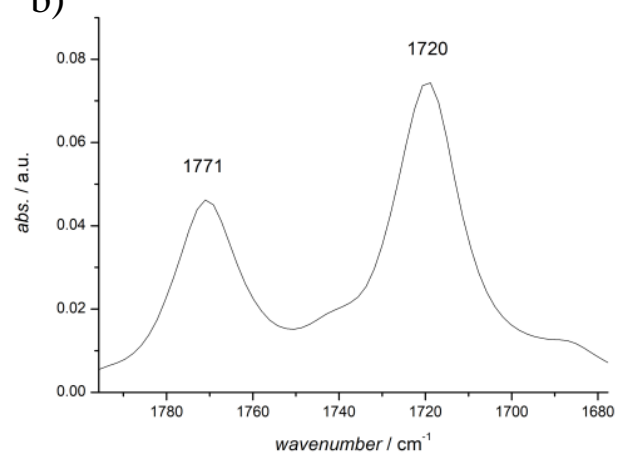

Figure 2.21. a) Nitrosylation of $\mathbf{3 0} \mathbf{H}_{2}$ monitored by UV-vis spectroscopy. The inserted graph depicts absorption at $512 \mathrm{~nm}$ $v s$. time ( $k_{\mathrm{obs}}$ of $3.21 \times 10^{-4} \mathrm{~s}^{-1}$ ). The poor fit of the kinetic trace indicates a more complicated reaction sequence and rate law. b) IR spectrum of THF extract from the reaction mixture after $2 \mathrm{~h}$.

Protonation of $\mathbf{3 0}^{\mathbf{2}-}$ takes place readily with only two equivalents of DMPH. The reaction of $\mathbf{3 0 H} \mathbf{H}_{2}$ with 4 equivalents of NO causes the decrease of overall absorbance in the UV-vis 
spectra (Figure 2.23, a). The observed rate constant $k_{\mathrm{obs}}=3.21 \times 10^{-4} \mathrm{~s}^{-1}$ is in the same order of magnitude as for nitrosylation of $\mathbf{3 0}^{2-}\left(k_{\mathrm{obs}}\left(\mathbf{3 0}^{2-}\right)=6.03 \times 10^{-4} \mathrm{~s}^{-1}\right)$. The reaction appears to be more selective than nitrosylation of $\mathbf{2 9 \mathbf { H } _ { 2 }}$ because only two bands, at 1771 and $1720 \mathrm{~cm}^{-1}$, are detected in the typical NO region of the IR spectrum (Figure 2.21, b). These bands are proposed to belong to protonated 34H (Figure 2.22) Further evidence for the proposed molecule is presented in chapter 3 .

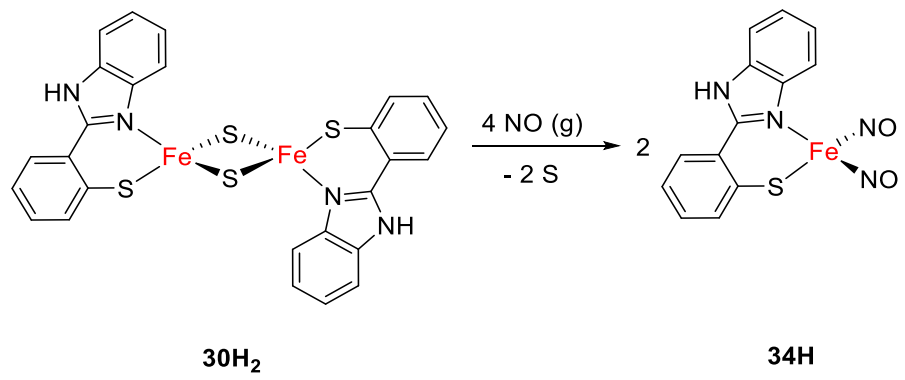

Figure 2.22. Proposed reaction equation for nitrosylation of $\mathbf{3 0 H}_{\mathbf{2}}$.

\subsection{Nitrosylation of protonated mixed-valent $\mathbf{2 9 \mathbf { H } ^ { - }}$}

The mixed-valent cluster 29-3 $^{3-}$ was treated with 1 or 2 equivalents of DMPH and 5 equivalents of NO and monitored with UV-vis spectroscopy (Figure 2.23 a and Figure 2.24 a). Decrease of the overall absorbance indicates disassembly of the cluster core. New bands in the IR spectrum indicate the formation of an NO species and residual DMPH (Figure $2.23 \mathrm{~b}$ and Figure $2.24 \mathrm{~b}$; DMPH is marked in red). The main band resonates at $1685 \mathrm{~cm}^{-1}$ in both cases. Assignment of the signal to a product was impossible so far. No $\mathrm{H}_{2} \mathrm{~S}$ was detected in the gasphase, probed with MS.

a)

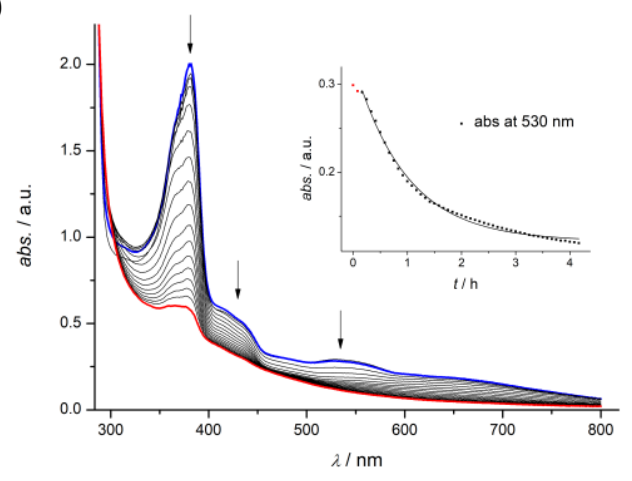

b)

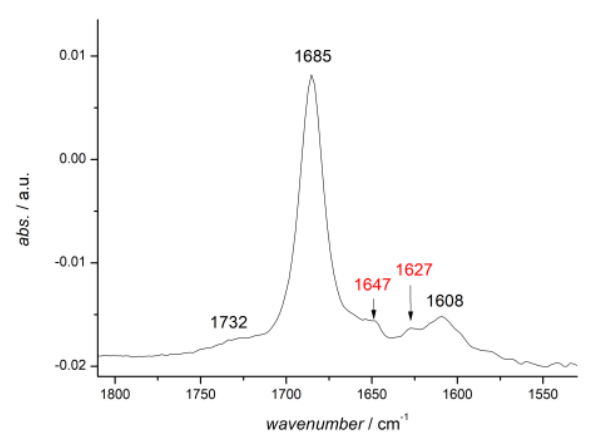

Figure 2.23. a) UV-vis spectra of $\mathbf{2 9}^{\mathbf{3}}$ after addition of 1 equivalent of DMPH and 5 equivalents of $\mathrm{NO}$ at $-30^{\circ} \mathrm{C}$ in $\mathrm{MeCN}$. Exponential fit of the data in the inserted graph gave a rate constant $k_{\mathrm{obs}}$ of $2.8 \times 10^{-4} \mathrm{~s}^{-1}$. The poor fit of the kinetic trace indicates a more complicated reaction sequence and rate law. b) IR spectrum of the THF extract of the reaction mixture. The signals labeled in red can be assigned to DMPH (1650 and $\left.1630 \mathrm{~cm}^{-1}\right)$. 
a)

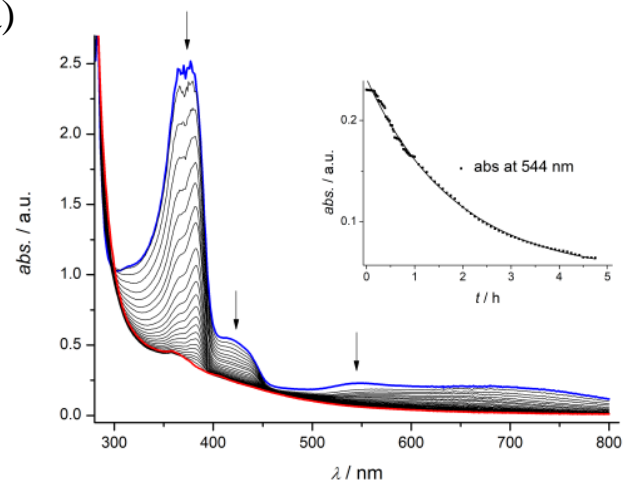

b)

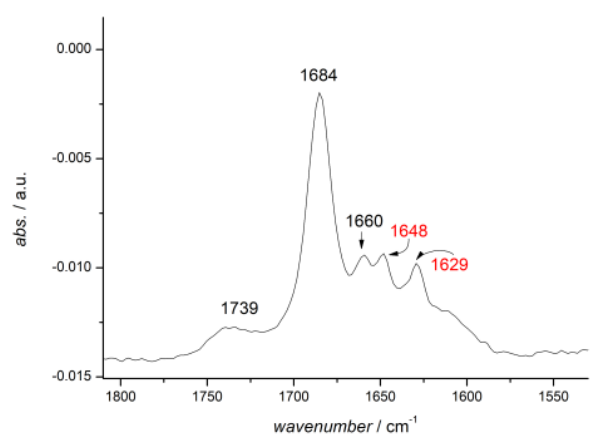

Figure 2.24. a) UV-vis spectra of $\mathbf{2 9}^{3-}$ after addition of 2 equivalents of DMPH and 5 equivalents of NO at $-30{ }^{\circ} \mathrm{C}$ in $\mathrm{MeCN}$. Exponential fit of the data in the insert gave a rate constant $k_{\text {obs }}$ of $1.48 \times 10^{-4} \mathrm{~s}^{-1}$. The poor fit of the kinetic trace indicates a more complicated reaction sequence and rate law. b) IR spectrum of the solution after removal of solvent. The signals labeled in red can be assigned to DMPH $\left(1650\right.$ and $\left.1630 \mathrm{~cm}^{-1}\right)$.

\subsection{Summary and conclusion}

DNICs readily form from nitrosylation of diferric $[2 \mathrm{Fe}-2 \mathrm{~S}]$ clusters $\left(\mathbf{2 9}^{\mathbf{2}-}\right.$ and $\left.\mathbf{3 0}^{\mathbf{2}-}\right)$ with $\mathrm{N}, \mathrm{N}-\left(\mathbf{3 3}^{-}\right)$and $\mathrm{S}, \mathrm{N}$-chelating $\left(\mathbf{3 4}^{-}\right)$ligands. Both DNICs were fully characterized by UVvis, IR, EPR, Mössbauer spectroscopy and X-ray crystallography. Liaw and coworkers proposed that chelating systems stabilize DNICs and destabilize RREs (Figure 1.18). ${ }^{156}$ They also postulated that thiolate binding is more stable than imidazolate binding (Figure 1.20). ${ }^{157}$ The results in this thesis support this proposal and concur with the results from Lippard and coworkers (Figure 2.2). ${ }^{158,168}$

Extensive literature on nitroslylation of synthetic diferric [2Fe-2S] clusters is available (chapter 1.4.4), however, the reactivity of reduced [2Fe-2S] clusters towards NO is sparsely investigated, although it is the preferred oxidation state under physiological conditions. In this thesis, it was shown that mixed-valent $[2 \mathrm{Fe}-2 \mathrm{~S}]$ clusters $\left(\mathbf{2 9}^{\mathbf{3}-}\right.$ and $\left.\mathbf{3 0}^{\mathbf{3}}\right)$ first undergo oxidation to form intermediate 1 upon nitrosylation. The dubbed intermediate 1 is in fact diferric $\mathbf{2 9}^{--}$and $\mathbf{3 0}^{\mathbf{2}}$, respectively, supported by UV-vis, IR, NMR, and Mössbauer spectroscopy. Interestingly, in nitrosylation of $\mathbf{2 9}^{\mathbf{3}-}$ a second intermediate is observed in UV-vis spectroscopy. However, no other spectroscopic method could detect a compound different from intermediate 1 . In a second step, intermediate 1 or 2 degrade slowly into the two DNICs $\mathbf{3 3}^{-}$and $\mathbf{3 4}^{-}$. These finding are diametric to Liaw's proposed mechanism for the nitrosylation of protein-bound mixed-valent [2Fe-2S] clusters in which rRREs and RREs are the intermediates. According to his hypothesis, the cluster undergoes ligand exchange and then forms a $\left\{\mathrm{Fe}(\mathrm{NO})_{2}\right\}^{10}$ - and a $\left\{\mathrm{Fe}(\mathrm{NO})_{2}\right\}^{9}$ - DNIC which then reacts 
further to rRRE and finally undergoes oxidation. The findings presented in this thesis do not concur. RREs were not detected as intermediates during the nitrosylation of $\mathbf{2 9}^{\mathbf{3}}$ and $\mathbf{3 0}^{\mathbf{3}-}$. However, it was easily possible to identify the oxidized diferric $[2 \mathrm{Fe}-2 \mathrm{~S}]$ cluster as intermediate due to a relative low reaction rate. Only after oxidation of the clusters further reaction to the respective DNICs take place. The observation of different pathways could be explained by the redox potential: Low-molecular-weight models for Fe-S proteins often have a more negative redox potential than clusters coordinated by proteins. A more negative redox potential facilitates an oxidation as first step of nitrosylation.

Another biologically relevant reaction is the protonation of histidine ligands in Rieske and mitoNEET proteins. The nitroslylation of protonated diferric and mixed-valent model clusters was presented in this chapter. Apparently, the reaction pathways are more complicated in the presence of the acid DMPH. The cluster core of $\mathbf{2 9 H _ { 2 }}$ and $\mathbf{3 0 H}_{2}$

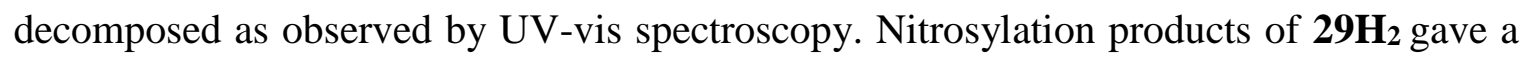
multitude of signals in the $v_{\mathrm{NO}}$-region of the IR spectrum. In contrast, the nitrosylation product of $\mathbf{3 0 \mathbf { H } _ { 2 }}$ displays only two signals. The signals are assigned to the symmetric and asymmetric stretching frequency of the protonated DNIC 34H. Further investigations on this matter are presented in the next chapter. 



\section{Protonation and deprotonation of DNICs}

\subsection{Introduction and objective}

A library of DNICs with various ligands like chelates, carbenes, and $\mathrm{CO}$ have been synthesized to date. ${ }^{134,168,171,172}$ Classical DNICs are isolated as $\left\{\mathrm{Fe}(\mathrm{NO})_{2}\right\}^{9}$, according to the Enemark-Feltham notation, with a coordination number of four. Nonclassical DNICS have higher coordination numbers of five or six. ${ }^{173}$ The once reduced state, $\left\{\mathrm{Fe}(\mathrm{NO})_{2}\right\}^{10}$, is often accessible; on the contrary, one-electron oxidation of a $\left\{\mathrm{Fe}(\mathrm{NO})_{2}\right\}^{9} \mathrm{DNIC}$ was only achieved by stabilizing the product with a delocalized aminyl radical ligand system. ${ }^{174}$ DNICs have been recognized as storage and transport agents of NO. ${ }^{175,176}$ Especially watersoluble DNICs are used as cellular NO donor agents promoting anti-inflammatory as well as anti-cancer activity. ${ }^{177,178}$

In the following chapter, the reactivity of DNICs $\mathbf{3 3}^{-}$and $\mathbf{3 4}^{-}$towards acid and base is presented. The investigations were done in vitro and in silico.

\subsection{Experimental results}

\subsubsection{IR spectroscopy}

When 2,6-dimethylpyridinium tetrafluoroborate (DMPH) is added to $\mathbf{3 3}^{-}$in $\mathrm{MeCN}$, the IRsignals of the NO-groups shift from 1780 and $1714 \mathrm{~cm}^{-1}$ to 1820 and $1743 \mathrm{~cm}^{-1}$ and the signals appear broader (Figure 3.1, a). A signal that is attributed to skeletal vibration $\left(1606 \mathrm{~cm}^{-1}\right)$ is split into two signals and shifts to lower wavenumbers (1595 and $1581 \mathrm{~cm}^{-1}$, Appendix Figure 8.6) which proves not only an influence of protonation on the nitrosylmoieties, but also on the complex's ligand. It is likely that the protonated ligand donates less electron density to the iron ion. Therefore, backbonding from the metal $\left(\mathrm{Fe}(\mathrm{d}) \rightarrow \mathrm{NO}\left(\pi^{*}\right)\right)$ is reduced and the $\mathrm{N}-\mathrm{O}$ bond strengthened as higher wavenumbers correspond to a higher bond energy. The intensity of $v_{\text {NO }}$ decreases while $v_{\text {ligand }}$ remains as intense as before. The bands of excess DMPH (1680(w), 1650(s), 1630(s) $\left.\mathrm{cm}^{-1}\right)$ appear in the IR spectrum after the addition of more than one equivalent. Protonation of the precursor $\left[\mathrm{FeCl}_{2}(\mathrm{NO})_{2}\right]^{-}$has no effect on the NO stretches in the IR spectrum confirming that the protonation takes place at the ligand site rather than on the nitrosyl-moieties. 
The protonation is reversible when 1,8-diazabicyclo(5.4.0)undec-7-ene (DBU) is added. All IR-bands shift back to the original location after addition of one equivalent of DBU and they do not move further when more DBU is added (Figure 3.1, b).

a)

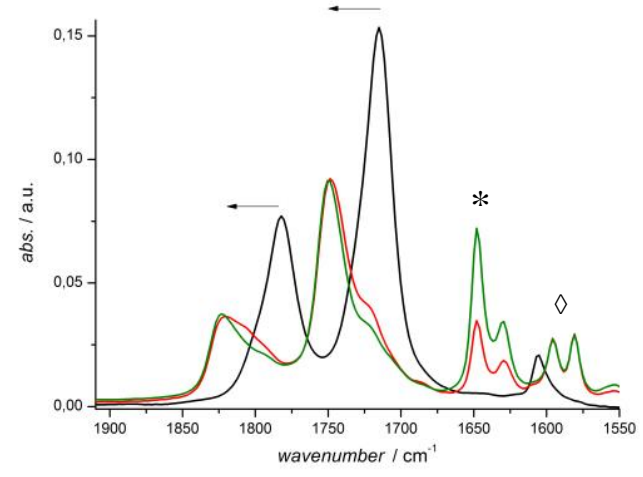

b)

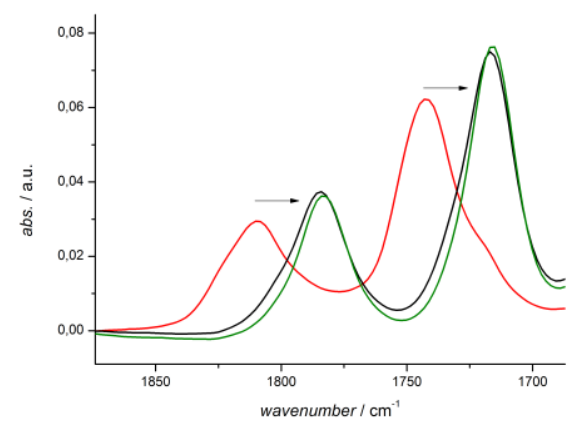

Figure 3.1. a) IR spectra of $\mathbf{3 3}^{-}$(black) after addition of 1.0 (red), and 1.5 eq. DMPH (green). b) IR spectrum of protonated 33 (red), and after addition of 1.0 (black), and 2.0 eq. DBU (green). DMPH (*), skeletal vibration $(\diamond)$.

$\mathbf{3 4}^{-}$exhibits similar spectroscopic behavior as $\mathbf{3 3}^{-}$. Upon protonation, the IR bands blueshift from 1700 and $1751 \mathrm{~cm}^{-1}$ to 1722 and $1775 \mathrm{~cm}^{-1}$ and back to their original values when DBU is added (Figure 3.2). The process can be repeated several times without loss of intensity of $34^{-}$. Considering this, the protonated species of $34^{-}$appears to be more stable in comparison to $\mathbf{3 3}^{-}$.

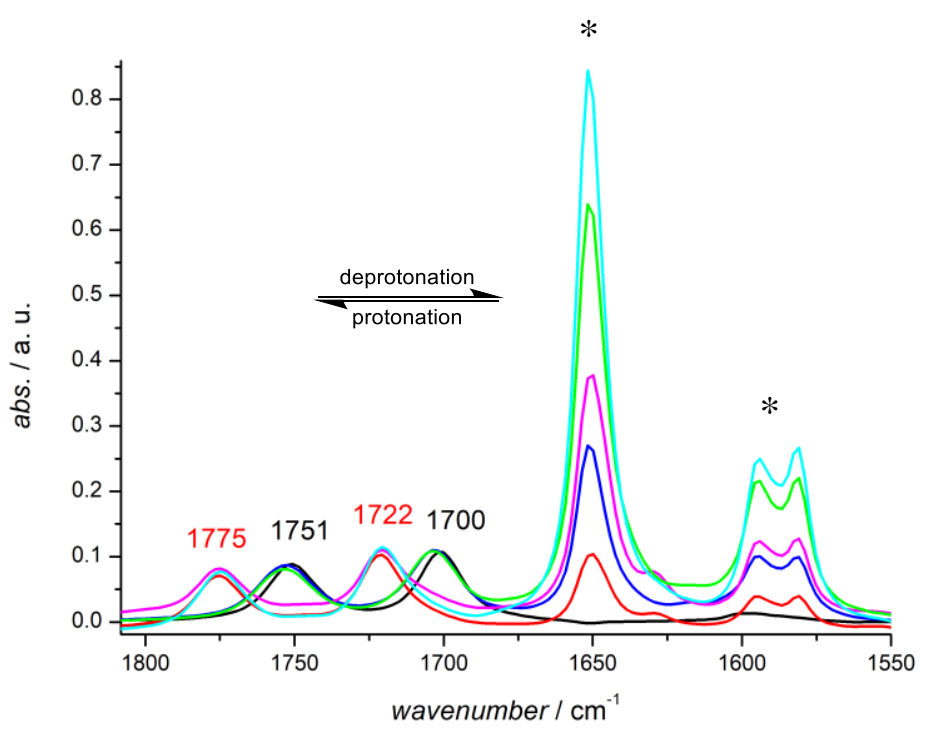

Figure 3.2. IR spectra of reversible protonation of $\mathbf{3 4}^{-}$(black) with DMPH and deprotonation with DBU in MeCN. Spectra are corrected for sample concentration. Bands from DBU are marked with an asterisks (*). 


\subsubsection{Mössbauer spectroscopy}

Addition of DMPH to a solution of $\mathbf{3 3}^{-}$in THF yields two species in the Mössbauer spectrum (Figure 3.3, a). One species has very similar parameters to $\mathbf{3 3}^{-}$(Figure 3.3, b). The other species exhibits a larger isomer shift $\left(1.40 \mathrm{~mm} \mathrm{~s}^{-1}\right)$ and quadrupole splitting $\left(3.40 \mathrm{~mm} \mathrm{~s}^{-1}\right.$ ). These Mössbauer parameters suggest the presence of an $\mathrm{Fe}^{\mathrm{II}}$ species. The more acid is added the more of species 2 is visible in the spectrum suggesting degradation of the nitrosyl species. The analogous protonation of $\mathbf{3 4}^{-}$forms only one product according to Mössbauer spectroscopy (Figure 3.4, a). The parameters of the product differ only slightly from the parameters of $\mathbf{3 4}^{-}$(Figure $3.4, \mathrm{~b}$ ).

a)

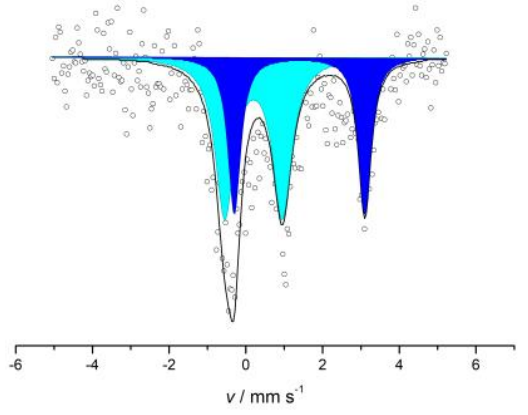

b)

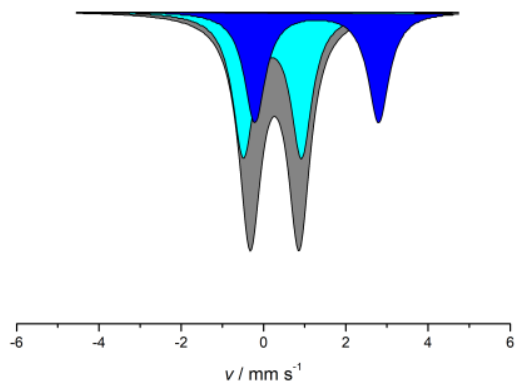

Figure 3.3. a) Zero-field Mössbauer spectrum of $\mathbf{3 3}^{-}$after protonation with DMPH in THF at $80 \mathrm{~K}$. Parameters of species 1 (cyan): $\delta_{\mathrm{IS}}=0.20 \mathrm{~mm} \mathrm{~s}^{-1}, \Delta E_{\mathrm{Q}}=1.50 \mathrm{~mm} \mathrm{~s}^{-1}$, fwhm $=0.6 \mathrm{~mm} \mathrm{~s}^{-1}, 60 \%$; parameters of species 2 (blue): $\delta_{\mathrm{IS}}=$ $1.40 \mathrm{~mm} \mathrm{~s}^{-1}, \Delta E_{\mathrm{Q}}=3.40 \mathrm{~mm} \mathrm{~s}^{-1}$, fwhm $=0.4 \mathrm{~mm} \mathrm{~s}^{-1}, 40 \%$. b) Overlay of Mössbauer spectra of $\mathbf{3 3}^{-}$(grey), species 1 (cyan) and species 2 (blue).

a)

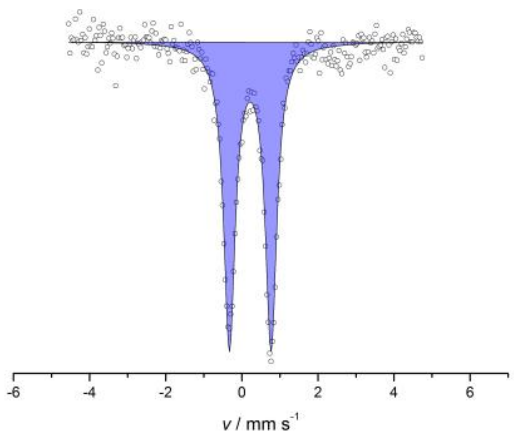

b)

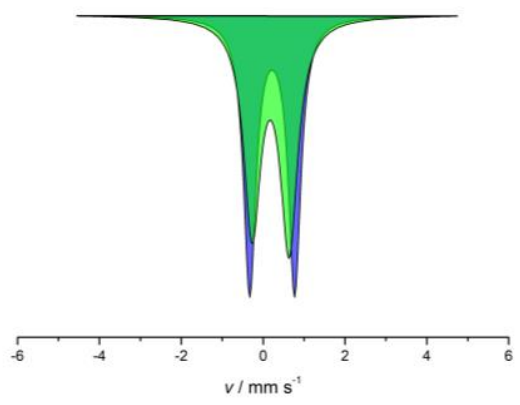

Figure 3.4. a) Zero-field Mössbauer of $\mathbf{3 4}^{-}$after addition of DMPH in THF at $80 \mathrm{~K}$. Parameters of fit (blue): $\delta_{\mathrm{IS}}=$ $0.22 \mathrm{~mm} \mathrm{~s}^{-1}, \Delta E_{\mathrm{Q}}=1.09 \mathrm{~mm} \mathrm{~s}^{-1}$, fwhm $=0.37 \mathrm{~mm} \mathrm{~s}^{-1}$. b) Overlay of Mössbauer spectra of $\mathbf{3 4}^{-}$(green) and protonated 34H (blue). 


\subsubsection{Summary}

The protonation site of DNICs $3^{-}$and $\mathbf{3 4}^{-}$is most likely at the NN and NS capping ligand because the NO stretching frequencies $v_{\mathrm{NO}}$ of the chloro-ligated DNIC, $\left[\mathrm{FeCl}_{2}(\mathrm{NO})_{2}\right]^{-}$, are not affected by the addition of acid. In contrast, $v_{\mathrm{NO}}$ of DNICs $3^{-}$and $\mathbf{3 4}^{-}$shift to higher wavenumbers after addition of one equivalent of DMPH. The shift can be reversed by addition of one equivalent of DBU.

33- degrades with every cycle of protonation and deprotonation to form a side product, dubbed species 2, that was identified in the Mössbauer spectrum with $\delta=1.40 \mathrm{~mm} \mathrm{~s}^{-1}$ and $\Delta E_{\mathrm{Q}}=3.40 \mathrm{~mm} \mathrm{~s}^{-1} . \mathbf{3 4}^{-}$is more stable in regard to protonation as the cycle of protonation and deprotonation can be repeated several times and no side product is formed according to Mössbauer spectroscopy.

Generally, assignment of oxidation states of $\left\{\mathrm{Fe}(\mathrm{NO})_{\mathrm{x}}\right\}$ complexes from Mössbauer parameters is difficult due to the covalent bond between iron and the nitrosyl moieties. The isomer shift is very sensitive to $\pi$-back-bonding. ${ }^{179-181}$ DFT calculations were employed to support experimental results.

\subsection{DFT calculations}

\subsubsection{Background}

Ye and Neese published a computational study on the electronical structure of DNICs in 2010. ${ }^{182}$ They found that the $\left\{\mathrm{Fe}(\mathrm{NO})_{2}\right\}^{9}$ moiety can be described as a resonance hybrid between $\left\{\mathrm{Fe}^{\mathrm{II}}\left({ }^{\circ} \mathrm{NO}\right)\left(\mathrm{NO}^{-}\right)\right\}$and $\left\{\mathrm{Fe}^{\mathrm{III}}\left(\mathrm{NO}^{-}\right)_{2}\right\}$. The first resonance structure describes a hsferrous ion coupled to an overall $(\mathrm{NO})_{2}{ }^{-}$ligand $\left(S(\mathrm{NO})_{2}=3 / 2\right)$. In the second resonance structure, a hs-ferric ion couples antiferromagnetically to two $\mathrm{NO}^{-}$ligands. Both valence structures lead to an overall spin $S=1 / 2$. The bonding between the iron ion and the two NO ligands is seen as covalent. Ye and Neese were able to infer IR and Mössbauer parameters in good agreement with experimental data from their calculations.

\subsubsection{Geometry optimization and IR spectra of $\mathbf{3 3}^{-}$and $\mathbf{3 4}^{-}$}

All computation in this thesis were carried out with the ORCA program package. ${ }^{183} \mathrm{X}$-ray data of the anions were employed as starting coordinates for the geometry optimization. Geometry optimizations and frequency calculations were performed with the BP86, TPSS, B3LYP and TPSSh density functionals. The def2-TZVP basis set was applied in combination with the auxiliary basis set def2-TZV/J. The conductor-like screening model 
(COSMO) was employed as the experimental parameters of $v_{\mathrm{NO}}$ shift slightly in dependence of the solvent used (Table 3.1). MeCN and THF were modeled in form of an infinite dielectric.

Table 3.1. IR parameter for $v_{\mathrm{NO}}\left[\mathrm{cm}^{-1}\right]$ of $\mathbf{3 3}^{-}$and $\mathbf{3 4}^{-}$(BP86/def2-tzvp) in a) MeCN and b) THF.

\begin{tabular}{c|c|c|c|c} 
& $\exp ^{\mathrm{a})}$ & calc $^{\mathrm{a})}$ & $\exp ^{\mathrm{b})}$ & calc $^{\mathrm{b})}$ \\
\hline $\mathbf{3 3}^{-}$ & 1780,1714 & 1749,1673 & 1773,1705 & 1752,1681 \\
\hline $\mathbf{3 4}^{-}$ & 1751,1700 & 1709,1643 & 1744,1694, & 1716,1657
\end{tabular}

BP86 and TPSS functionals give the best result for IR frequencies of nitrosyl moieties in comparison to the other functionals (Table 3.1 and Table 8.1 in appendix). The calculated values diverge from the experimental ones by a scaling factor of approximately 1.02 (red shifted). The deviation is smaller when THF is used instead of MeCN in the COSMO package. Overall the IR spectrum is well reproduced (Figure 3.5).

a)

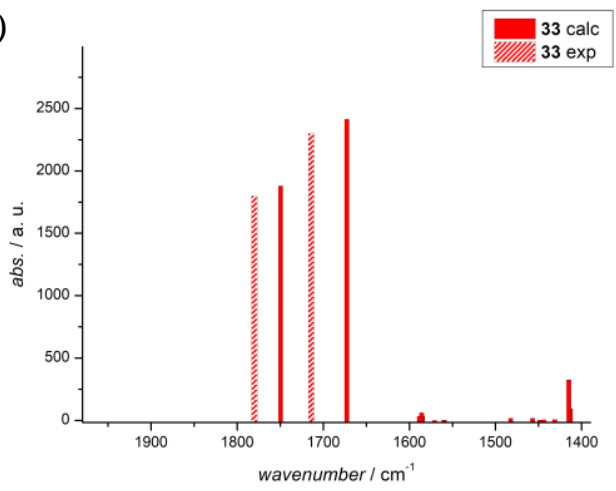

c)

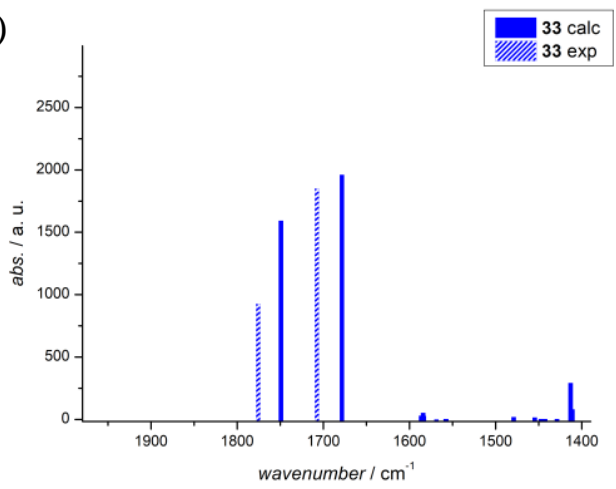

b)

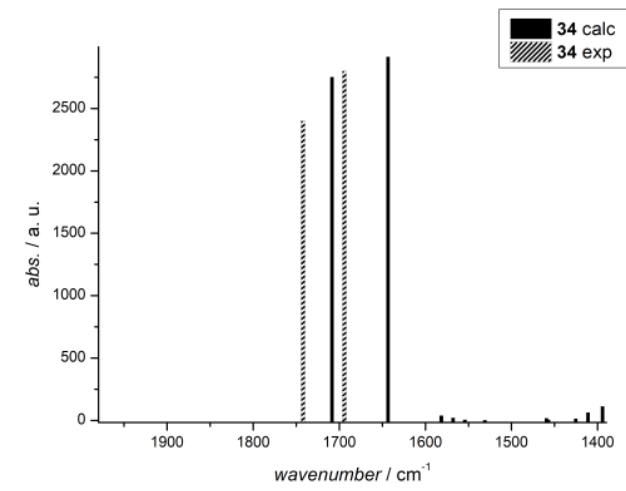

d)

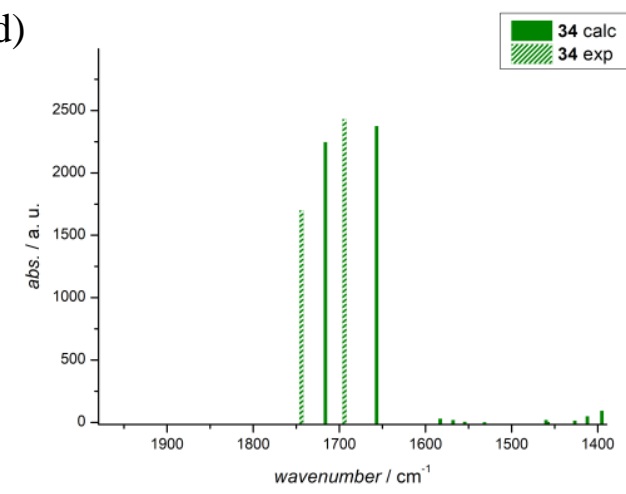

Figure 3.5. Comparison of calculated and experimental data. a) $\mathbf{3 3}^{-}$in $\mathrm{MeCN}$, b) $\mathbf{3 4}^{-}$in $\mathrm{MeCN}$, c) $\mathbf{3 3}^{-}$in $\mathrm{THF}$, d) $\mathbf{3 4}^{-}$ in THF. 


\subsubsection{Mössbauer parameters of $\mathbf{3 3}^{-}$and $\mathbf{3 4}^{-}$and their protonated forms}

Geometry optimized anions $\mathbf{3 3}^{-}$and $\mathbf{3 4}^{-}$from chapter 3.3.2 were employed for the calculation of Mössbauer parameters $\delta_{\mathrm{IS}}$ and $\Delta E_{\mathrm{Q}}$. For the protonated species, one $\mathrm{H}$-atom was added to one imidazole- $N$ atom with the program Chemcraft and the charge was changed to zero. Optimized structures of $\mathbf{3 3 H}$ and $\mathbf{3 4 H}$ are shown in Figure 3.6. The Mössbauer parameters were computed using the CP(PPP) basis set for Fe and def2-TZVP for the other atoms. ${ }^{184-186}$ Isomer shifts $\delta_{\text {IS }}$ were calculated from the electron densities at the Fe nucleus $\rho_{0}$. Quadrupole splittings were conveniently stated in the ORCA output file by calculation incorporating the electric field gradient (see chapter 7.4 for more information).

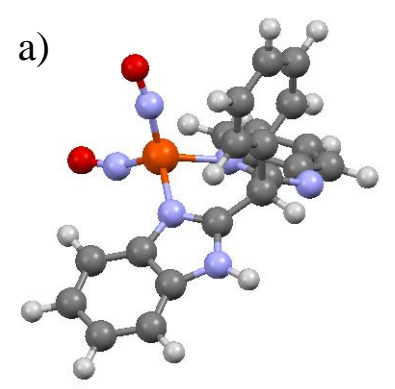

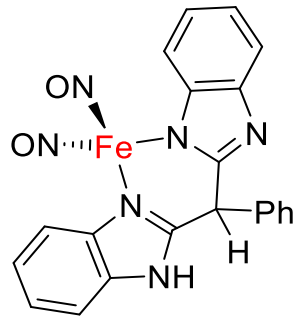

$33 \mathrm{H}$
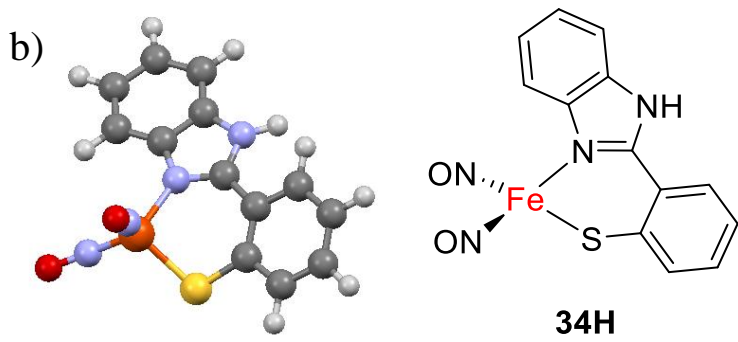

Figure 3.6. Geometry optimized structure of $\mathbf{3 3 H}$ (a), and $\mathbf{3 4 H}$ (b).

The Mössbauer parameters of $\mathbf{3 3}-\mathbf{3 3 H}$ and $\mathbf{3 4}-\mathbf{3 4 H}$ are summarized in Table 3.2. Results for other functionals are presented in the appendix (Table 8.3). The quadrupole splitting especially for $\mathbf{3 4}-\mathbf{3 4 H}$ fits well and for $\mathbf{3 3}-\mathbf{3 3 H}$ adequately. The value becomes larger upon protonation which is in agreement with the experiment. DFT calculation gives an increase of the isomer shift after protonation of DNIC 33 and 34. Experimentally, this increase is only observed for $\mathbf{3 4 / 3 4 H}$. The trend regarding the isomer shift after protonation of $\mathbf{3 3}$ is not reproduced possibly because the protonation site of $\mathbf{3 3 H}$ is described incorrectly in Figure 3.6.

Table 3.2. Experimental Mössbauer parameters in THF and calculated values (B3LYP/def2-tzvp).

\begin{tabular}{l|l|l|l|l||l|l|l|l|l} 
& \multicolumn{2}{|l|}{$\delta_{\text {IS }} / \mathrm{mm} \mathrm{s}^{-1}$} & \multicolumn{2}{l||}{$\Delta E_{\mathrm{Q}} / \mathrm{mm} \mathrm{s}^{-1}$} & & \multicolumn{2}{l|}{$\delta_{\mathrm{IS}} / \mathrm{mm} \mathrm{s}^{-1}$} & \multicolumn{2}{l}{$\Delta E_{\mathrm{Q}} / \mathrm{mm} \mathrm{s}^{-1}$} \\
\hline \hline & $\exp$ & calc & $\exp$ & calc & & $\exp$ & calc & $\exp$ & calc \\
\hline $\mathbf{3 3}^{-}$ & 0.28 & 0.05 & 0.99 & 1.07 & $\mathbf{3 4}$ & 0.18 & 0.00 & 0.90 & 0.98 \\
\hline $\mathbf{3 3 H}$ & 0.20 & 0.10 & 1.50 & 1.33 & $\mathbf{3 4 H}$ & 0.22 & 0.05 & 1.09 & 1.16
\end{tabular}




\subsubsection{Investigation of second protonation pathway for $\mathbf{3 3}^{-}$}

The wrong trend in the calculation of the isomer shift of $\mathbf{3 3}-\mathbf{3 3 H}$ might be explained by a different pathway for the protonation of $\mathbf{3 3}$ in comparison to $\mathbf{3 4}$. In theory, $\mathbf{3 3}^{-}$can be protonated twice while $\mathbf{3 4}^{-}$can be protonated once, assuming that the protonation site is on the imidazole-N of the ligand. However, it is obvious from the experiment that one equivalent DMPH is sufficient for full protonation of $\mathbf{3 3}^{-}$. A rearrangement of the $\mathrm{H}$ atom in the backbone of the bis(benzimidazolato) ligand of $\mathbf{3 3}^{-}$can take place as a consequence of the protonation (Figure 3.7, a). The same behavior was reported for the protonation of the bis(benzimidazolato) coordinated [2Fe-2S] cluster (compare Figure 2.19). ${ }^{163}$ This protonation goes in hand with an intense absorbance at $380 \mathrm{~nm}$ in the UV-vis spectrum ( $\varepsilon=64000 \mathrm{M}^{-1} \mathrm{~cm}^{-1}$ ) and a color change of the solution from red to green. Such an intense band was not seen in the UV-vis spectrum of the protonated DNIC. The solution remained reddish-brown after protonation. Nevertheless, the rearrangement (Figure 3.7, a) was investigated by DFT calculations.

a)
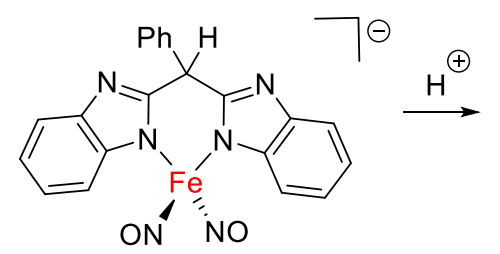

33<smiles></smiles><smiles></smiles>

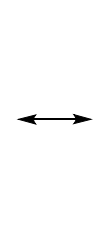<smiles>N#C[P+]([O-])N1C(=C(c2ccccc2)c2nc3ccccc3n2-c2ccccc2)Nc2ccccc21</smiles>

33H-rearranged

b)

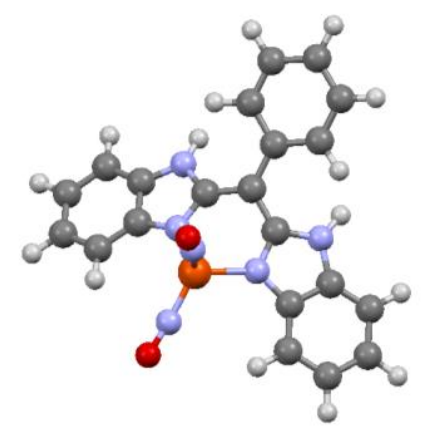

Figure 3.7. a) Proposed mechanism for rearrangement of $\mathrm{H}$ atom on bis(imidazolate) ligand of 33. b) Geometry optimized structure of $\mathbf{3 3 H}$-rearranged. 
A geometry optimization was run on 33H-rearranged (bp86/def2-tzvp) with a charge of \pm 0 and a spin of $S=1 / 2$. In the optimized structure the carbon atom in the backbone bound to the phenyl group is almost in a planar coordination environment (Figure 3.7, b). The IR data obtained from the optimized structure differ strongly from the experimental data (Table 3.3). A scaling factor of 1.07 would be necessary to arrive at the experimental values. Much better agreement of experimental and simulated data was achieved for the once protonated structures $\mathbf{3 3 H}$ and $\mathbf{3 4 H}$. The scaling factor is the same as for the notprotonated species (1.02). This result in combination with the absence of a characteristic UV-vis band for the rearranged ligand suggest that the molecular structure of $\mathbf{3 3 H}$ does not feature a rearrangement.

a)

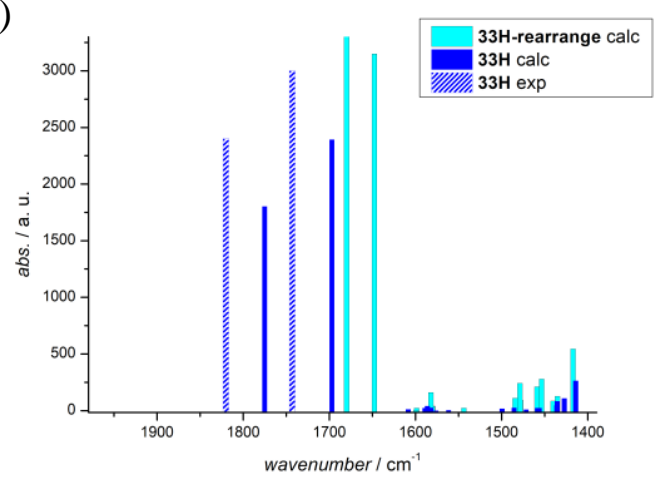

b)

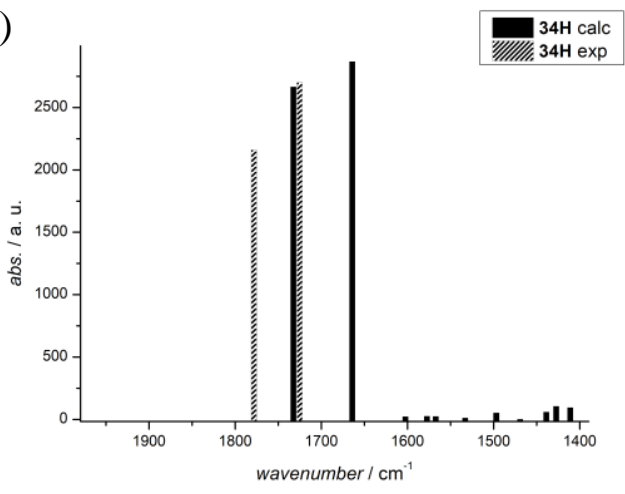

Figure 3.8. Comparison of calculated and experimental data for $\mathbf{3 3 H}, \mathbf{3 3 H}$-rearranged (a) and $\mathbf{3 4} \mathbf{H}$ (b).

Table 3.3. Experimental and calculated $v_{\text {NO }}$ parameters of protonated species (BP86/def2-tzvp).

\begin{tabular}{l|c|c}
\multirow{2}{*}{} & \multicolumn{2}{|c}{$v_{\mathrm{NO}} / \mathrm{cm}^{-1}$} \\
\cline { 2 - 3 } & calc & $\exp$ \\
\hline $\mathbf{3 3 H}$ & 1775,1722 & \multirow{2}{*}{1820,1743} \\
\hline 33H-rearranged & 1680,1648 & \\
\hline $\mathbf{3 4 H}$ & 1735,1667 & 1775,1722
\end{tabular}




\subsection{Discussion and conclusion}

$\mathbf{3 3}^{-}$and $\mathbf{3 4}^{-}$are readily protonated with DMPH and deprotonated with DBU. The protonation/deprotonation is reversible, however, protonation of $\mathbf{3 3}^{-}$forms a side product that cannot reenter the de-/protonation cycle. DFT calculations support the idea the protonation site is on the $\mathrm{N}$-atom of the benzimidazolate ligand. The NO stretching frequencies of $\mathbf{3 3}^{-}$and $\mathbf{3 4}^{-}$are well reproduced. The observation that $v_{\mathrm{NO}}$ shifts to higher wavenumbers after addition of acid is also confirmed. The deviations of the calculated from the experimental result are between 21 and $57 \mathrm{~cm}^{-1}$. Ye and Neese observed deviations from the experimental values of 61 to $72 \mathrm{~cm}^{-1}$ for their system. ${ }^{182}$ Therefore, calculated IR spectra are in reasonable agreement with the experimental data.

When the bis(benzimidazolato) coordinated [2Fe-2S] cluster $\mathbf{2 9}^{\mathbf{2}-}$ is protonated, a rearrangement of the methine- $\mathrm{H}$ of the ligand takes place (Figure 2.19). This behavior is unlikely for DNIC 33H as calculations reveal a very different IR spectrum for that species. Single protonation on the $\mathrm{N}$-atom of the aromatic ring, however, leads to reliable results for the IR frequencies that again compare well to experimental values.

Calculations of Mössbauer parameters show that the isomer shift and the quadrupole splitting increase upon protonation of the DNICs. While this holds true for the protonation of $\mathbf{3 4}^{-}$, protonation of $\mathbf{3 3}^{-}$affects a shift to a smaller value of the isomer shift. No explanation has been found for the divergent behavior thus far. Still, it is possible to derive from calculations that species 2 after protonation of $\mathbf{3 3}^{-}$does not seem to be a DNIC that is simply protonated on the ligand because isomer shift and quadrupole splitting significantly differ from the calculated values.

Although protonation of DNIC $\mathbf{3 3}^{-}$and $\mathbf{3 4}^{-}$was investigated by IR and Mössbauer spectroscopy as well as DFT calculation, the molecular structure of the protonated species remains elusive. Samples of ${ }^{57} \mathrm{Fe}$-enriched $\mathbf{3 4}^{-}$and $\mathbf{3 4 H}$ were prepared for NRVS measurements and sent to the group of Prof. Schünemann at TU Kaiserslautern in order to gain more insight. 



\section{Cubane-type $[4 \mathrm{Fe}-4 \mathrm{~S}]$ cluster with one pentacoordinate iron ion}

\subsection{Introduction and objective}

The vast majority of iron ions in Fe-S clusters have a distorted tetrahedral coordination ( $c f$. chapter 1.2.1). Five-fold coordination is unusual and results in an activation of the participating iron ion. In nature, several systems make use of this feature. One enzyme discussed in this regard in the scientific community is biotin synthase. Its [2Fe-2S] cluster is ligated by three cysteines and one arginine. ${ }^{187}$ Arginine is an exceptional ligand that offers the possibility for mono- and bidentate binding. ${ }^{188} \mathrm{X}$-ray crystallography was not able to determine the binding mode of the arginine residue due to low resolution of the crystal structure determination. Five-fold coordination of the iron ion cannot be excluded from the data available.

Synthetic [2Fe-2S] clusters with five-coordinated iron atoms have provided more insight into the matter. On the one hand, an intermediate with a five-coordinated iron ion was postulated by DFT calculation for the slow isomerization of a $[2 \mathrm{Fe}-2 \mathrm{~S}]$ cluster via a solvent-mediated associative proccess. ${ }^{167}$ On the other hand, models for five-coordinated $[2 \mathrm{Fe}-2 \mathrm{~S}]$ clusters were synthesized with tridentate capping ligands $\left(\mathbf{3 5}^{\mathbf{2}}, \mathbf{3 6} \mathbf{3 6}^{\mathbf{2}}\right.$, Figure 4.1). ${ }^{189,190}$ With these model structures the effect of pentacoordination was investigated. Secondary bonding was more pronounced for a thioether- $S$ compared to an ether- $O$ in $\mathbf{3 5}^{\mathbf{2}-}$ . In both $\mathbf{3 5}^{2-}$ and $\mathbf{3 6}^{2-}$ the $\mathrm{Fe} \cdot \cdots \mathrm{Fe}$ distance and $\mathrm{Fe}-\mathrm{S}-\mathrm{Fe}$ angles increase due to the distortion induced by the ligand. The secondary interaction affects a more positive Mössbauer isomer shift for both compounds. An increase of the quadrupole splitting is detected for $\mathbf{3 5}^{\mathbf{2}}$ in comparison to related four-coordinate $[2 \mathrm{Fe}-2 \mathrm{~S}]$ clusters. The quadrupole splitting of $\mathbf{3 6}^{\mathbf{2}}$ is unusually small, but relates well to calculated values from DFT studies.
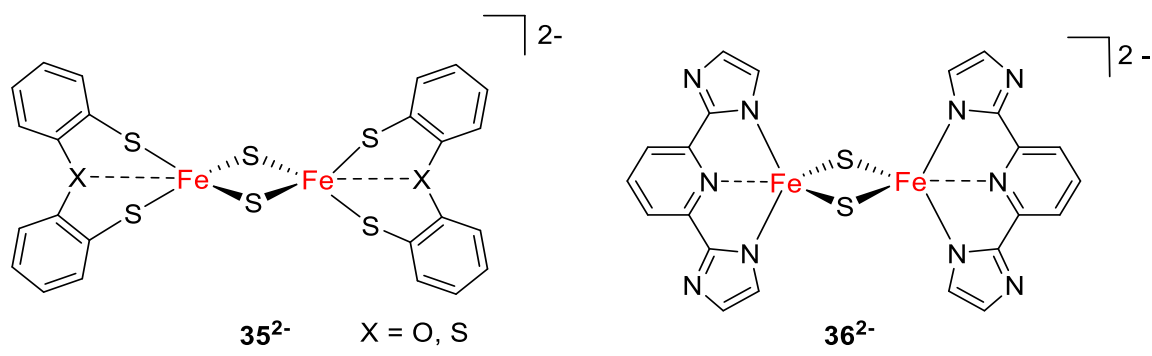

Figure 4.1. Five-coordinated low-molecular weight [2Fe-2S] clusters. ${ }^{189,190}$ 
Site-differentiated $[4 \mathrm{Fe}-4 \mathrm{~S}]$ clusters occur in nature with aconitase as the prototypical example. The enzyme is involved in the catalytic step of transforming citrate into isocitrate (chapter 1.2 .3 , p. 12). A single iron ion is bound to $\mathrm{H}_{2} \mathrm{O} / \mathrm{OH}^{-}$in its resting state and to oxygen atoms of the substrate in its active state. ${ }^{191}$ Other examples of $[4 \mathrm{Fe}-4 \mathrm{~S}]$ proteins with one iron site different from the other three include ferredoxin III from Desulfovibrio africanus $^{192,193}$ and ferredoxin of Pyrococcus furiosus ${ }^{194}$. These clusters have one iron ion bound to an aspartic acid instead of a cysteine. Synthetic site-differentiated clusters with various different ligands are presented in chapter 1.3 (p. 15). In 1983 Johnson et al. synthesized a series of $\left(\mathrm{Et}_{4} \mathrm{~N}\right)_{2}\left[\mathrm{Fe}_{4} \mathrm{~S}_{4}\left(\mathrm{SC}_{6} \mathrm{H}_{4}-O-\mathrm{X}\right)_{4}\right]$ with $\mathrm{X}=\mathrm{NH}_{2}, \mathrm{OMe}, \mathrm{OH}$, and $\mathrm{SMe}$ to examine the possible formation of five-coordinate Fe sites in cubane-type clusters. ${ }^{195}$ The $\mathrm{X}=\mathrm{OH}$ cluster contains three conventional tetrahedral $\mathrm{FeS}_{4}$ sites and one distorted trigonalbipyramidial $\mathrm{FeS}_{4} \mathrm{O}$ site $\left(\mathbf{3 7}^{\mathbf{2}}\right)$. The structure was confirmed by X-ray crystallography and Mössbauer spectroscopy. The reduced $37^{-}$and oxidized $37^{3-}$ were studied in depth by Le Pape et al. with EPR single-crystal and proton ENDOR spectroscopy. ${ }^{196,197}$

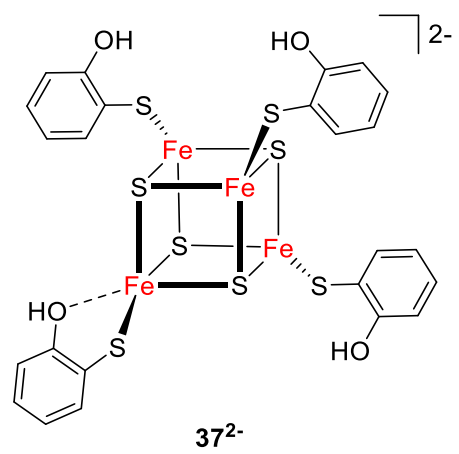

Figure 4.2. Five-coordinated low-molecular-weight [4Fe-4S] cluster. ${ }^{183}$

The objective of this chapter is to carry on investigations of five-coordinated cubane-type [4Fe-4S] clusters. Johnson et al. failed in obtaining a crystal structure for $\left(\mathrm{Et}_{4} \mathrm{~N}\right)_{2}\left[\mathrm{Fe}_{4} \mathrm{~S}_{4}\left(\mathrm{SC}_{6} \mathrm{H}_{4}-o-\mathrm{NH}_{2}\right)_{4}\right]$. But Mössbauer spectroscopy was used instead to determine the solid state isomer. The spectrum showed only one single quadrupole doublet which indicates that all iron ions are in the same coordination environment. In this chapter the characterization of the cluster in the solid state and in solution is presented. 


\subsection{Synthesis}

A self-assembly approach was followed to synthesize the target molecule $\mathbf{3 8}$ effectively and allow for convenient exchange of counter ions. 2-Aminothiophenol was deprotonated with sodium methoxide in methanol. Then iron(III)chloride and lithium sulfide were added. In a self-assembly reaction, a 2-amino-benzenethiol ligated [4Fe-4S] cluster is formed and precipitates upon addition of a halide salt of $\mathrm{Et}_{4} \mathrm{~N}^{+}$or $\mathrm{PhMe}_{3} \mathrm{~N}^{+}$(Figure 4.3). The precipitate is filtered from the solution and the product is extracted with MeCN. Crystalline material suitable for crystal structure analysis was obtained by diffusion of diethyl ether in a MeCN solution of the clusters.

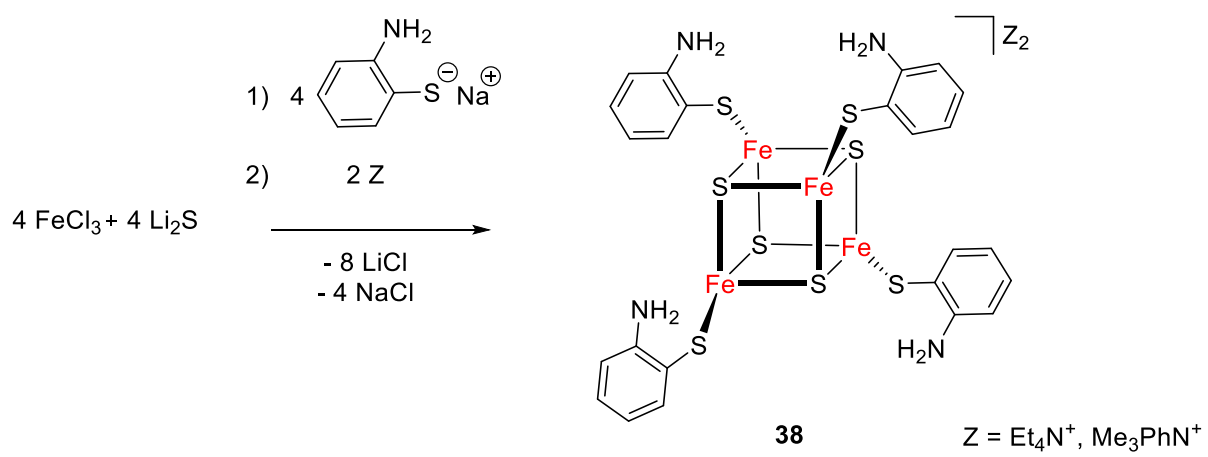

Figure 4.3. Synthesis of $[4 \mathrm{Fe}-4 \mathrm{~S}]$ cluster $\mathbf{3 8}$ with two different counter ions.

\subsection{Structural characterization of $\mathbf{3 8}^{\mathbf{2}}$}

Surprisingly, the crystal structure reveals different ligand binding in dependence on the counter ion (Figure 4.4). All four ligands bind via the thiol group in a monodentate fashion when $\mathrm{Et}_{4} \mathrm{~N}^{+}$is introduced as counterion, thus the cluster in $\left(\mathrm{Et}_{4} \mathrm{~N}\right)_{2} \mathbf{3 8}$ contains four conventional tetrahedral $\mathrm{FeS}_{4}$ sites. The cluster crystallizes in the orthorhombic space group $\mathrm{Aba} 2$ and no solvent cocrystallizes in the unit cell. The anion $\mathbf{3 8}^{\mathbf{2}-}$ is $\mathrm{C}_{2}$ symmetric.

The crystallization of two $\mathrm{Me}_{3} \mathrm{PhN}^{+}$as counterion induces a change of the coordination number of one iron ion. The ligand at $\mathrm{Fe}(1)$ is rotated and forms a chelating ring with the bond distance $\mathrm{Fe}-\mathrm{S}$ of $2.3318 \AA$, being only $0.059 \AA$ A longer than the mean of the three other terminal Fe-S distances. This bond represents a primary interaction. The distance between the iron ion to the amine group is shorter $(2.2770 \AA)$. The symmetry of the molecule is broken due to this constitutional change. The molecule crystallizes in the triclinic space group P-1 with two $\mathrm{Me}_{3} \mathrm{PhN}^{+}$and one $\mathrm{MeCN}$ molecule. 
a)

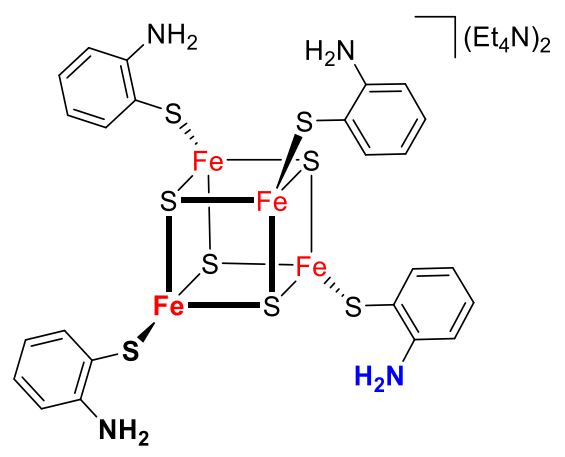

$\left(\mathrm{Et}_{4} \mathrm{~N}\right)_{2} 38$

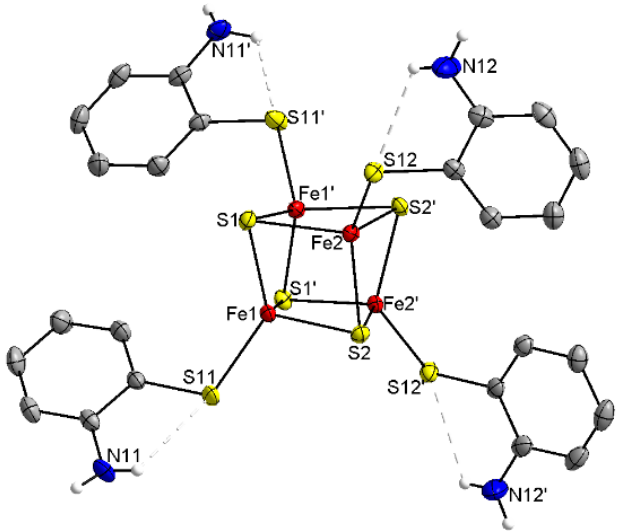

b)
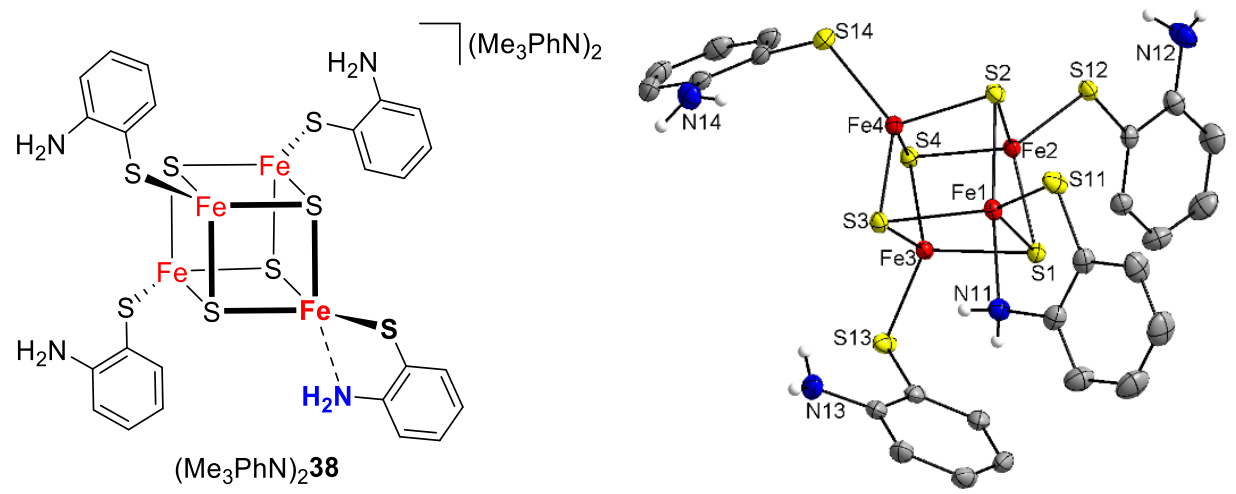

Figure 4.4: Crystal structure and drawing of $\left(\mathrm{Et}_{4} \mathrm{~N}\right)_{2} \mathbf{3 8}(\mathrm{a})$ and $\left(\mathrm{Me}_{3} \mathrm{PhN}\right)_{2} \mathbf{3 8}(\mathrm{b})$. Thermal displacement ellipsoids are shown at $50 \%$ probability, carbon bound hydrogen atoms and counter ions are omitted for more clarity.

Table 4.1: Selected bond length $(\AA)$ and angles $\left({ }^{\circ}\right)$ of $\left(\mathrm{Et}_{4} \mathrm{~N}\right)_{2} \mathbf{3 8}$ and $\left(\mathrm{Me}_{3} \mathrm{PhN}\right)_{2} \mathbf{3 8}$. $\left(\mathrm{Et}_{4} \mathrm{~N}\right)_{2} 37$ is shown for comparison. ${ }^{195}$

\begin{tabular}{c|c|c||c} 
& $\left(\mathrm{Et}_{4} \mathrm{~N}\right)_{2} \mathbf{3 8}$ & $\left(\mathrm{Me}_{3} \mathrm{PhN}\right)_{2} \mathbf{3 8}$ & $\left(\mathrm{Et}_{4} \mathrm{~N}\right)_{2} \mathbf{3 7}^{195}$ \\
\hline $\mathrm{Fe}(1) \cdots \mathrm{S}(11)$ & $2.2666(6)$ & $2.3318(4)$ & 2.313 \\
\hline $\mathrm{Fe}(1) \cdots \mathrm{N}(11)$ & $5.145^{(\mathrm{i})}$ & $2.2770(13)$ & - \\
\hline $\mathrm{Fe} \cdots \mathrm{O}$ & - & - & 2.318 \\
\hline $\mathrm{Fe}_{\mathrm{av}} \cdots \mathrm{S}_{\text {thiolate }}$ & - & 2.2725 & 2.278
\end{tabular}

(i) non-binding

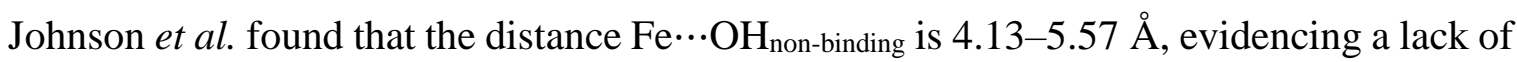
interaction. For $\left(\mathrm{Et}_{4} \mathrm{~N}\right)_{2} 38$ distances $\mathrm{Fe} \cdots \mathrm{NH}_{2}$,non-binding were found between 5.026 and $5.145 \AA$. The crystal structure of $\left(\mathrm{Me}_{3} \mathrm{PhN}\right)_{2} \mathbf{3 8}$ exposes very different distances between

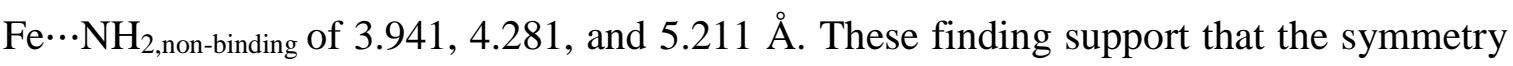
of $\left(\mathrm{Me}_{3} \mathrm{PhN}\right)_{2} \mathbf{3 8}$ is rescinded and that the ligands bind very unsymmetrically.

\subsubsection{Mössbauer spectroscopy of solid sample and in frozen solution}

$\left(\mathrm{Et}_{4} \mathrm{~N}\right)_{2} 38$ exhibits an isomer shift $\delta_{\text {IS }}$ of $0.43 \mathrm{~mm} \mathrm{~s}^{-1}$ and a quadrupole splitting $\Delta E_{\mathrm{Q}}$ of $0.88 \mathrm{~mm} \mathrm{~s}^{-1}$ in the zero-field Mössbauer spectrum (Figure 4.5, a). These values are similar 
to the values reported by Johnson et al. when taking into consideration that they referenced the isomer shift to $\mathrm{Fe}$ metal at $4.2 \mathrm{~K}$. The values are typical for $\left[\mathrm{Fe}_{4} \mathrm{~S}_{4}(\mathrm{SR})_{4}\right]^{2-}$ with $\mathrm{R}$ substituents lacking secondary interaction sites. Such clusters exhibit one or two closely overlapping quadrupole doublets with $\delta_{\text {IS }}=0.32-0.36 \mathrm{~mm} \mathrm{~s}^{-1} .{ }^{195}$ The $o-\mathrm{NH}_{2}$ groups do not appreciably interact with the core.

a)

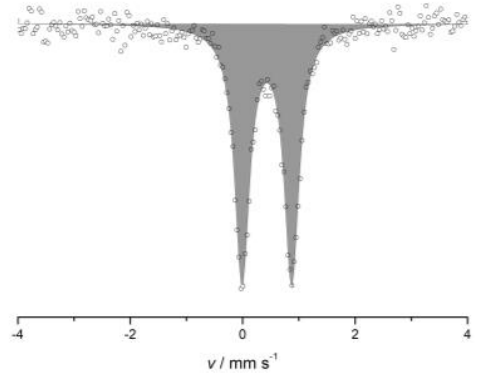

b)

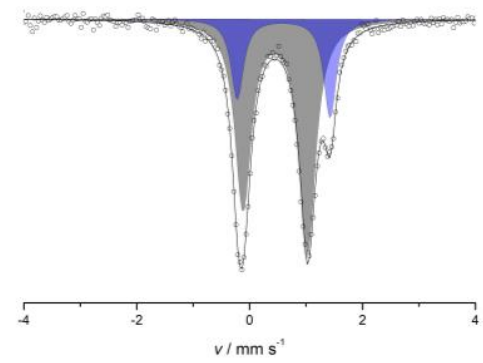

c)

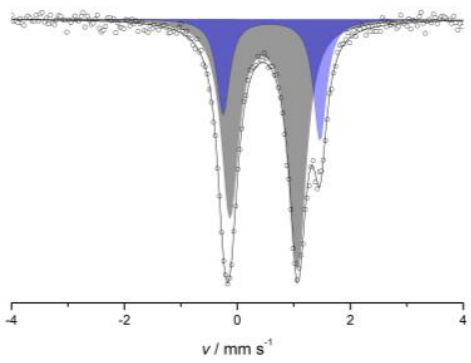

Figure 4.5. Zero-field Mössbauer spectra of $\left(\mathrm{Et}_{4} \mathrm{~N}\right)_{2} \mathbf{3 8}$ at $80 \mathrm{~K}(\mathrm{a}),\left(\mathrm{Me}_{3} \mathrm{PhN}\right)_{2} \mathbf{3 8}$ at $80 \mathrm{~K}(\mathrm{~b}),\left(\mathrm{Me}_{3} \mathrm{PhN}\right)_{2} 38$ at $14 \mathrm{~K}$ (c).

Table 4.2: Mössbauer parameters of $\left(\mathrm{Et}_{4} \mathrm{~N}\right)_{2} \mathbf{3 8},\left(\mathrm{Me}_{3} \mathrm{PhN}\right)_{2} \mathbf{3 8}$, and related clusters.

\begin{tabular}{|c|c|c|c|c|c|c|}
\hline & $T / \mathrm{K}$ & $\begin{array}{l}\delta_{\mathrm{IS}} / \\
\mathrm{mm} \mathrm{s}^{-1}\end{array}$ & $\begin{array}{l}\Delta E_{\mathrm{Q}} / \\
\mathrm{mm} \mathrm{s}^{-1}\end{array}$ & $\begin{array}{l}\Gamma / \\
\mathrm{mm} \mathrm{s}^{-1}\end{array}$ & $\left(l_{\mathrm{R} / \mathrm{L}}\right)$ & $\begin{array}{l}\text { Rel. Int. / } \\
\%\end{array}$ \\
\hline 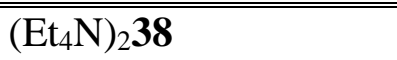 & 80 & 0.43 & 0.88 & 0.32 & - & 100 \\
\hline$\left(\mathrm{Et}_{4} \mathrm{~N}\right)_{2} \mathbf{3 8}^{195}$ & $4.2-80$ & $0.33^{\mathrm{b})}$ & 0.88 & 0.34 & - & 100 \\
\hline \multirow[t]{4}{*}{$\left(\mathrm{Me}_{3} \mathrm{PhN}\right)_{2} 38$} & 80 & 0.46 & 1.14 & 0.35 & 0.8 & 75 \\
\hline & & 0.60 & 1.64 & 0.27 & 0.8 & 25 \\
\hline & 14 & 0.47 & 1.20 & 0.37 & 0.8 & 72 \\
\hline & & 0.61 & 1.71 & 0.28 & 0.8 & 28 \\
\hline$\left(\mathrm{Me}_{3} \mathrm{PhN}\right)_{2} 38(\mathrm{MeCN})$ & & 0.44 & 1.05 & 0.40 & 1.02 & 100 \\
\hline \multirow[t]{3}{*}{$\left(\mathrm{Et}_{4} \mathrm{~N}\right)_{2} \mathbf{3 7}^{195}$} & 80 & $0.30^{\mathrm{b})}$ & 0.76 & 0.26 & - & 22 \\
\hline & & $0.34^{\mathrm{b})}$ & 1.23 & 0.34 & - & 55 \\
\hline & & $0.49^{\mathrm{b})}$ & 1.82 & 0.26 & - & 23 \\
\hline$\left(\mathrm{Et}_{4} \mathrm{~N}\right)_{2} \mathbf{3 7}(\mathrm{MeCN})^{195}$ & 80 & $0.32^{\mathrm{b})}$ & 1.03 & 0.43 & - & $97^{a}$ \\
\hline
\end{tabular}

a) Minority spectral component present with intensity of $3 \%$, b) standard: Fe at $4.2 \mathrm{~K}$.

In the case of $\left(\mathrm{Me}_{3} \mathrm{PhN}\right)_{2} \mathbf{3 8}$ a shoulder is visible in the Mössbauer spectrum (Figure 4.5, b and c). The experimental data is best fitted with two doublets in a ratio of $3: 1$. The asymmetry of the doublets was considered with an asymmetry factor $\left(l_{\mathrm{R} / \mathrm{L}}\right)$ of 0.8 . A reason 
for the asymmetry in Mössbauer spectra can be an anisotroic orientation of crystals in the magnetic field. The asymmetry factor was correlated to be the same in both subspectra. The respective isomer shifts are $0.46 \mathrm{~mm} \mathrm{~s}^{-1}$ (grey) and $0.60 \mathrm{~mm} / \mathrm{s}$ (blue) and a quadrupole splitting of $1.14 \mathrm{~mm} \mathrm{~s}^{-1}$ (grey) and $1.64 \mathrm{~mm} \mathrm{~s}^{-1}$ (blue). The quadrupole splitting is dependent on the electrical field gradient of the iron core which is indirectly influenced by the coordination sphere and the binding ligands. The fact that two species in a ratio of 3:1 are found confirms the result from the crystal structure that one iron ion is set in a different surrounding than the other three iron ions. The isomer shift of the main signal corresponds well to the isomer shift of $\left(\mathrm{Et}_{4} \mathrm{~N}\right)_{2} 37$. The isomer shift of the smaller signal (blue) is higher. Johnson et al. attribute the high isomer shift to five-coordinate Fe atoms. The remaining doublets have parameters that are common for conventional $\left[\mathrm{Fe}_{4} \mathrm{~S}_{4}\left(\mathrm{SR}_{4}\right)\right]^{2-}$ clusters with tetrahedral $\mathrm{FeS}_{4}$ sites. They report an increase by $0.15-0.20 \mathrm{~mm} / \mathrm{s}$ at $4.2 \mathrm{~K}$ as a presumed consequence of five-coordination.

The Mössbauer spectrum of $\left(\mathrm{Et}_{4} \mathrm{~N}\right)_{2} 37$ has three doublets with the approximate ratio of 1(A):2(B):1(C). ${ }^{195}$ Johnson et al assign the signals as followed: One iron is in a fivecoordinated environment because of the secondary bonding interaction of the hydroxy group. This coordination leads to an unusual large isomer shift $\delta=0.49 \mathrm{~mm} \mathrm{~s}^{-1}$ and a large quadrupolar interaction $\Delta E_{\mathrm{Q}}=1.82 \mathrm{~mm} \mathrm{~s}^{-1}$ (species $\mathrm{C}$ ). The other three iron atom have the usual tetrahedral surrounding in the first coordination sphere. However, two iron atoms give the same signal in Mössbauer spectroscopy due to a mirror pseudosymmetry of the whole molecule (species B) while one parameter is slightly lower (species A).

A solution of $\left(\mathrm{Me}_{3} \mathrm{PhN}\right)_{2} 38$ in $\mathrm{MeCN}$ was slowly cooled to $-196{ }^{\circ} \mathrm{C}$ in order to freeze the state in solution and compare it the results from crystalline material. The Mössbauer spectrum of the solution can only be fitted to one doublet with an isomer shift of $0.44 \mathrm{~mm} \mathrm{~s}^{-1}$ and quadrupole splitting of $1.05 \mathrm{~mm} \mathrm{~s}^{-1}$ (Figure 4.6). The signal from the fivecoordinated iron atom disappears. The small asymmetry in the signal is fitted with a right/left correlation of 1.02. The quadrupole splitting of the frozen solution is smaller than the quadrupole splitting of the solid sample. Apparently, the inequality of the iron ions is canceled and all of them give the same signal in Mössbauer spectroscopy. 


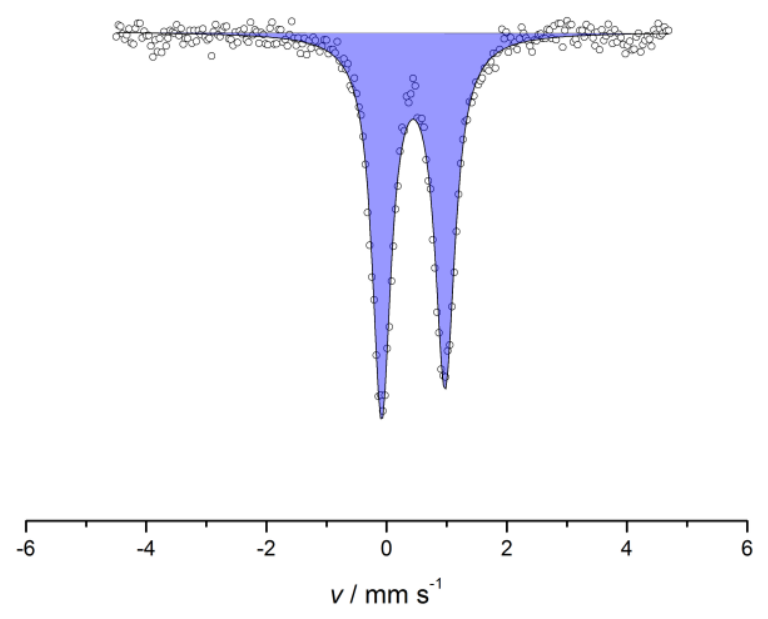

Figure 4.6. $\left(\mathrm{Me}_{3} \mathrm{PhN}\right)_{2} 38$ in frozen solution $(\mathrm{MeCN})$ at $80 \mathrm{~K} . \delta=0.44 \mathrm{~mm} \mathrm{~s}^{-1}, \Delta E_{\mathrm{Q}}=1.05 \mathrm{~mm} \mathrm{~s}^{-1}$, fwhm $=0.4 \mathrm{~mm} \mathrm{~s}^{-1}$, asymmetry factor $\left(l_{\mathrm{R} / \mathrm{L}}\right)=1.02$.

\subsubsection{UV-vis spectroscopy}

Both complexes $\left(\mathrm{Me}_{3} \mathrm{PhN}\right)_{2} \mathbf{3 8}$ and $\left(\mathrm{Et}_{4} \mathrm{~N}\right)_{2} 38$ have bands at $303,350(\mathrm{sh})$ and $484 \mathrm{~nm}$ in the $\mathrm{UV}$-vis spectrum in $\mathrm{MeCN}$ at room temperature regardless of their different constitution in the solid state. This is in accordance to the results from Mössbauer spectroscopy where there is no difference of the four iron ions in slowly cooled solution (Figure 4.6). It was of interest whether the UV-vis spectrum changes when the freedom of movement was inhibited by lowering the temperature. The solvent was changed to EtCN as its melting point is approx. $50^{\circ} \mathrm{C}$ below the melting point of $\mathrm{MeCN}$. Variable temperature UV-vis spectroscopy shows no effect on the bands (Figure 4.7, a). Therefore, there is no hint for constitutional change as the solution cools down. Reflectance spectra of crystalline $\left(\mathrm{Me}_{3} \mathrm{PhN}\right)_{2} 38$ and $\left(\mathrm{Et}_{4} \mathrm{~N}\right)_{2} \mathbf{3 8}$ in the solid state were measured in addition to UV-vis spectra of the solutions (Figure 4.7, b). Overall, both compounds produce similar spectra, however, in the spectrum of $\left(\mathrm{Me}_{3} \mathrm{PhN}\right)_{2} \mathbf{3 8}$ a band at $450 \mathrm{~nm}$ is more pronounced. 
a)

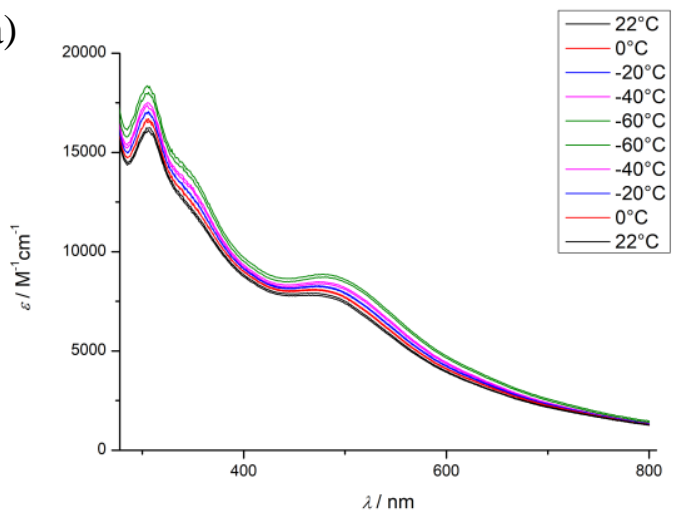

b)

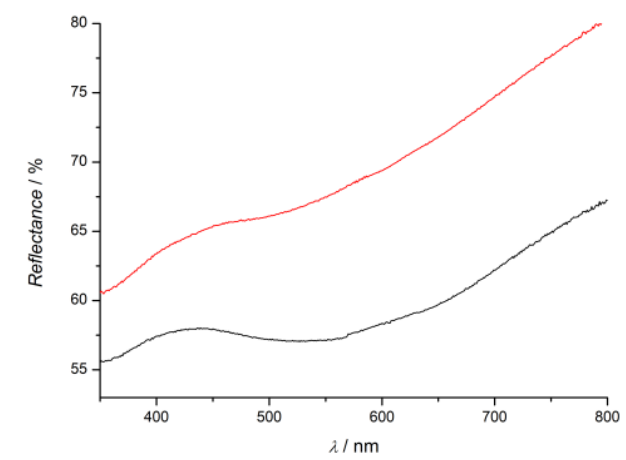

Figure 4.7. a) vt UV-vis spectroscopy of $\left(\mathrm{Me}_{3} \mathrm{PhN}\right)_{2} 38$ in $\mathrm{EtCN}$ and b) reflectance spectrum of crystalline $\left(\mathrm{Me}_{3} \mathrm{PhN}\right)_{2} 38$ (black) and $\left(\mathrm{Et}_{4} \mathrm{~N}\right)_{2} \mathbf{3 8}$ (red) in solid state at rt.

\subsubsection{NMR spectroscopy}

The ${ }^{1} \mathrm{H}$ NMR spectra of both compounds $\left(\mathrm{Me}_{3} \mathrm{PhN}\right)_{2} 38$ and $\left(\mathrm{Et}_{4} \mathrm{~N}\right)_{2} 38$ in acetonitrile at 243-298 K reveal no inequivalence of $o-\mathrm{C}_{6} \mathrm{H}_{4} \mathrm{NH}_{2}$ substituents nor any clear evidence of fluxional processes involving $\mathrm{NH}_{2}$ groups on the NMR time scale (Figure 4.8). Chemical shifts are given in the experimental section (Chapter 8). The signals are well resolved due to the strong antiferromagnetic coupling of two $\left\{\mathrm{Fe}^{2.5} \mathrm{Fe}^{2.5}\right\}$-pairs in the cluster.

a)

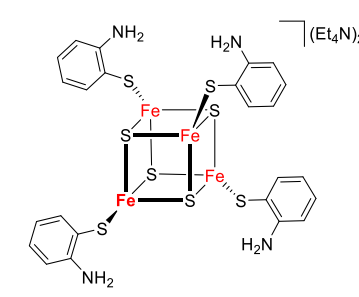

b)

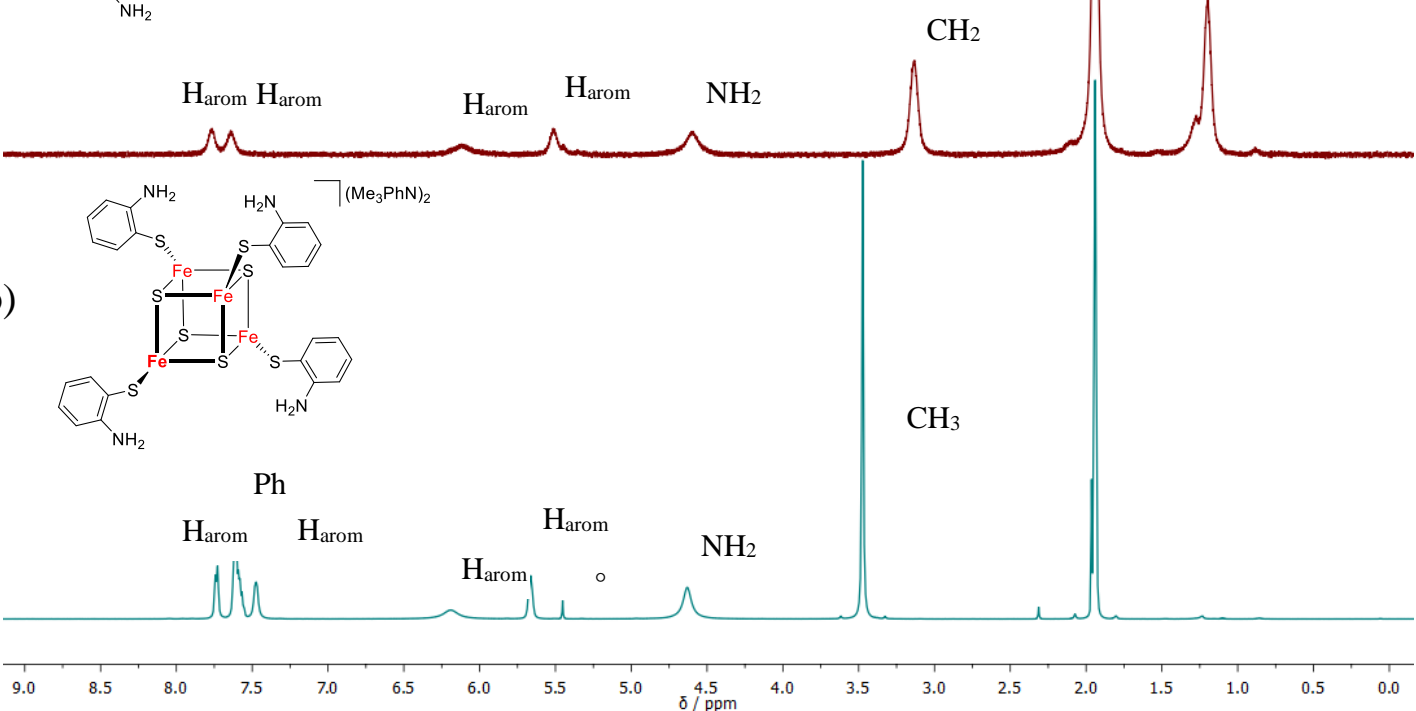

Figure 4.8: ${ }^{1} \mathrm{H}$ NMR spectrum of a) $\left(\mathrm{Et}_{4} \mathrm{~N}\right)_{2} 38$ at $298 \mathrm{~K}$ in $\mathrm{MeCN}-\mathrm{d}_{3}$, b) $\left(\mathrm{Me}_{3} \mathrm{PhN}\right)_{2} 37$ at $243 \mathrm{~K}$ in $\mathrm{MeCN}-\mathrm{d}_{3}$. The asterisk (*) marks residual solvent signal and the circle $\left(^{\circ}\right)$ marks DCM. 


\subsubsection{Cyclic voltammetry}

The cyclic voltammogram of $\left(\mathrm{Me}_{3} \mathrm{PhN}\right)_{2} 38$ in $\mathrm{MeCN}\left(0.1 \mathrm{M}^{-1} \mathrm{Bu}_{4} \mathrm{NPF}_{6}\right)$ compares well to the values measured in literature for $\left(\mathrm{Et}_{4} \mathrm{~N}\right)_{2} 38$ (Table 4.3). The first reduction is reversible with $E_{1 / 2}=-1.48 \mathrm{~V}$ vs. $\mathrm{Fc}^{+/ 0}$ while the second reduction is irreversible with $E_{\mathrm{pc}}=-2.11 \mathrm{~V}$ vs. $\mathrm{Fc}^{+/ 0}$ at $100 \mathrm{mV} / \mathrm{s}$ (Figure 4.9, a). Although oxidative waves are not reported in literature, two irreversible anodic processes were recorded concomitant with precipitation on the working electrode (Figure 4.9, b). It appears that the first oxidation becomes quasireversible at higher scan rates while the second moves out of the measured potential.

Table 4.3. Redox properties of $\left(\mathrm{Et}_{4} \mathrm{~N}\right)_{2} \mathbf{3 8}$ and $\left(\mathrm{Me}_{3} \mathrm{PhN}\right)_{2} \mathbf{3 8}$.

\begin{tabular}{l|c|c|c|c} 
& $E_{1 / 2} / \mathrm{V}$ & $E_{\mathrm{pc}} / \mathrm{V}^{(\mathrm{b})}$ & $E_{\mathrm{pa}} / \mathrm{V}^{(\mathrm{b})}$ & $E_{\mathrm{pa}} / \mathrm{V}^{(\mathrm{b})}$ \\
\hline \hline$\left(\mathrm{Et}_{4} \mathrm{~N}\right)_{2} 38$ in $\mathrm{DMF}^{(\mathrm{c})}$ & -1.45 & -2.07 & - & - \\
\hline$\left(\mathrm{Me}_{3} \mathrm{PhN}\right)_{2} 38$ in $\mathrm{MeCN}^{(\mathrm{d})}$ & -1.48 & $-2.11^{(\mathrm{e})}$ & $-0.47^{(\mathrm{e})}$ & $-0.18^{(\mathrm{e})}$
\end{tabular}

(a) All potentials $v s . \mathrm{Fc}^{+/ 0}$, (b) Irreversible reaction, (c) Johnson et al: glassy carbon, $\mathrm{SCE},\left(n-\mathrm{Bu}_{4} \mathrm{~N}\right) \mathrm{ClO}_{4}, \mathrm{DMF}^{195}$ (d) glassy carbon, Pt-wire, $\mathrm{Ag}$-wire, $\left(n-\mathrm{Bu}_{4} \mathrm{~N}\right) \mathrm{PF}_{6}, \mathrm{MeCN}$, (e) at a scan rate of $100 \mathrm{mV} / \mathrm{s}$.

a)

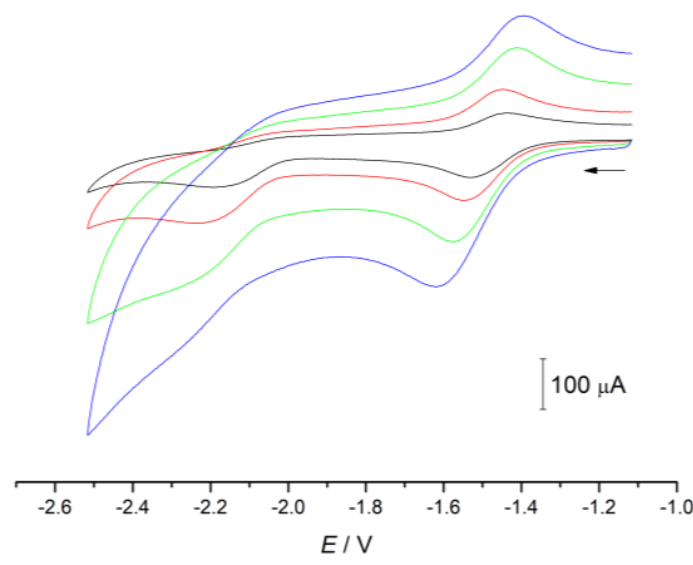

b)

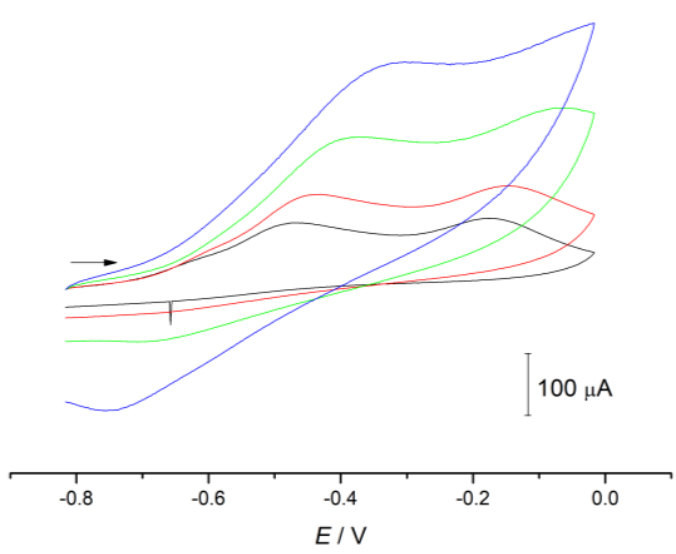

Figure 4.9. Cyclic voltammogram of $\left(\mathrm{Me}_{3} \mathrm{PhN}\right)_{2} \mathbf{3 8}(c=1 \mathrm{mM})$ in $\mathrm{MeCN} / 0.1 \mathrm{M} \mathrm{NBu}_{4} \mathrm{PF}_{6}$ at $\mathrm{rt} v s . \mathrm{Fc}^{0 /+}$ at various scan rates $\left(v=100,200,500,1000 \mathrm{mV} \mathrm{s}^{-1}\right)$. 


\subsection{Conclusion}

A [4Fe-4S] cluster was synthesized with four 2-aminothiophenolate ligands. Interestingly, the counter ion affects the packing of the molecules in the crystal yielding different structures for the anions of $\left(\mathrm{NEt}_{4}\right)_{2} 38$ and $\left(\mathrm{Me}_{3} \mathrm{PhN}\right)_{2} 38$. $\left(\mathrm{NEt}_{4}\right)_{2} 38$ comprises a symmetric cubane core with four equivalent tetrahedral $\left\{\mathrm{FeS}_{4}\right\}$ sites. ${ }^{195}$ The structure of the previously reported compound was now supported by crystallographic data in this work. $\mathrm{Me}_{3} \mathrm{PhN}^{+}$ induces a change of one iron site to become pentacoordinate $\left\{\mathrm{FeS}_{4} \mathrm{~N}\right\}$. The structural difference is reflected in Mössbauer spectroscopy with two doublets in a ratio of 3:1 for $\left(\mathrm{Me}_{3} \mathrm{PhN}\right)_{2} 38$. The unique iron ion exhibits a more positive isomer shift and a larger quadrupole splitting than the other three iron ions. The doublets collapse into one single doublet when a frozen solution of $\left(\mathrm{Me}_{3} \mathrm{PhN}\right)_{2} \mathbf{3 8}$ is measured instead of crystals, suggesting that the site-differentiation is absent in solution. In fact, UV-vis and NMR spectroscopy confirm that the anion $\mathbf{3 8}^{\mathbf{2}-}$ has the same configuration independent of the presence of $\left(\mathrm{NEt}_{4}\right)^{+}$or $\left(\mathrm{Me}_{3} \mathrm{PhN}\right)^{+}$in solution. Finally, cyclic voltammetry was conducted. One reversible and one irreversible reduction was found for $\left(\mathrm{Me}_{3} \mathrm{PhN}\right)_{2} 38$ in accordance to previously reported results for $\left(\mathrm{NEt}_{4}\right)_{2} 38{ }^{195}$ Two irreversible oxidation waves were detected for $\left(\mathrm{Me}_{3} \mathrm{PhN}\right)_{2} \mathbf{3 8}$ of which the first appeared to become more reversible at high scan rates. Further investigations on the oxidation of $\mathbf{3 8}^{\mathbf{2}-}$ are presented in the following chapter. 


\section{Oxidation of $\mathbf{3 8}^{\mathbf{2}}$ with dioxygen and $p$-benzoquinone}

\subsection{Introduction and objective}

Low-potential ferredoxins cycle between the resting state $[4 \mathrm{Fe}-4 \mathrm{~S}]^{2+}$ and $[4 \mathrm{Fe}-4 \mathrm{~S}]^{+}$ (midpoint potential at $-0.4 \mathrm{~V} v s$. SHE) while high-potential iron-sulfur proteins (HiPIPs) are oxidized from $[4 \mathrm{Fe}-4 \mathrm{~S}]^{2+}$ to $[4 \mathrm{Fe}-4 \mathrm{~S}]^{3+}$ (with midpoint potential of $0.3 \mathrm{~V} v s$. SHE). ${ }^{10}$ The protein's structure and environmental influences dictate the potential of the $[4 \mathrm{Fe}-4 \mathrm{~S}]$ cluster. ${ }^{198}$ Therefore, normally only one, either oxidation or reduction, is observed for one specific $[4 \mathrm{Fe}-4 \mathrm{~S}]^{2+}$ cluster in nature. An exception is found in the $[\mathrm{NiFe}]$ hydrogenase of Aquifex aeolicus where a $[4 \mathrm{Fe}-4 \mathrm{~S}]$ cluster is reported to be stable in all three oxidation states $+1,+2$, and $+3 .{ }^{199}$ In its usual enzymatic activity mode, the cluster switches between +1 and +2 . The +3 state is a special response to oxidative stress.

In general, the $[4 \mathrm{Fe}-4 \mathrm{~S}]^{2+}$ state is diamagnetic with two delocalized $\left\{\mathrm{Fe}^{2.5+} \mathrm{Fe}^{2.5+}\right\}$ pairs in the cluster core and the reduced/oxidized +1 and +3 states are paramagnetic (see Introduction 1.2.1). $[4 \mathrm{Fe}-4 \mathrm{~S}]^{3+}$ consists of one delocalized mixed-valence pair $\left\{\mathrm{Fe}^{2.5+} \mathrm{Fe}^{2.5+}\right\}$ and a ferric $\left\{\mathrm{Fe}^{3+} \mathrm{Fe}^{3+}\right\}$ pair. ${ }^{200,201}$ Current research shows that HiPIPs are essential in many processes in the body. For example, the redox reaction between [4Fe$4 \mathrm{~S}]^{2+/ 3+}$ clusters serves as a switch for initiation and termination of human DNA primase ${ }^{202}$ and as a modulator for the DNA-binding affinity of DNA repair proteins. ${ }^{203-205}$

Synthetic clusters imitate the natural ferredoxins well with a reversible redox reaction between the oxidation states $+1 /+2 /+3$ as $\left[\mathrm{Fe}_{4} \mathrm{~S}_{4}(\mathrm{SR})_{4}\right]^{3-/ 2-/ 1-}$ anion. However, the terminal oxidation to all ferric or reduction to all ferrous $[4 \mathrm{Fe}-4 \mathrm{~S}]$ is usually irreversible. ${ }^{10}$ Tuning of the potential is possible via the steric demands of the substituent R, e.g., bulky substituents stabilize +3 states. Examples for synthetic $[4 \mathrm{Fe}-4 \mathrm{~S}]^{3+}$ clusters were given in the introduction $\quad\left(\left[\mathrm{Fe}_{4} \mathrm{~S}_{4}\left(\mathrm{~N}\left\{\mathrm{SiMe}_{3}\right\}_{2}\right)_{4}\right] \quad\left(\mathbf{1 1}^{-}\right), \quad\left[\mathrm{Fe}_{4} \mathrm{~S}_{4}(\mathrm{STip})_{3}\right] \quad\left(\mathbf{1 2}^{\mathbf{0}}\right)\right.$, $\left[\mathrm{Fe}_{4} \mathrm{~S}_{4}(\mathrm{SDmp})_{3}\left(\mathrm{Me}_{4} \mathrm{Im}\right)\right]^{-}\left(\mathbf{1 5}^{\mathbf{0}}\right)$, pp. 14). It is noteworthy that the symmetric cubane cluster with terminal amide ligands $\mathbf{1 1}$ is the only cluster that was isolated in three oxidation states $(+2,+3,+4)$ as the bulky weak-field terminal amide ligands stabilize the high oxidation states of the core. In addition to the clusters above, results will be compared with the data from the symmetric cluster $\left[\mathrm{Fe}_{4} \mathrm{~S}_{4}(\mathrm{SDmp})_{4}\right]^{-}\left(3^{-}\right)$.

In contrast to the isolated $[4 \mathrm{Fe}-4 \mathrm{~S}]^{3+}$ clusters mentioned above, Le Pape et al. produced paramagnetic compounds from asymmetrical $\left(\mathrm{Et}_{4} \mathrm{~N}\right)_{2} 37$ in situ for single-crystal EPR and 
Proton-ENDOR measurements. ${ }^{196,197}$ The diamagnetic $[4 \mathrm{Fe}-4 \mathrm{~S}]^{2+}$ sample was irradiated with $\gamma$-rays which created simultaneously the "oxidized" $[4 \mathrm{Fe}-4 \mathrm{~S}]^{3+}$ and the "reduced" $[4 \mathrm{Fe} 4 \mathrm{~S}]^{+}$species. Both paramagnetic species were trapped at low concentration in a diamagnetic crystalline matrix and then measured.

\subsection{Reaction of $\mathbf{3 8}^{\mathbf{2}-}$ with dioxygen}

The color of the solution of $\mathbf{3 8}^{\mathbf{2}}$ changed from brown to blue-violet once oxygen is allowed to diffuse into the solution via a cannula. This color change is monitored by UV-vis spectroscopy (Figure 5.1, a). The reaction is completed after $30 \mathrm{~min}$ with isobestic points at 354 and $480 \mathrm{~nm}$. Apparently, the reaction rate is mainly controlled by diffusion. When a flask is opened to air and then stirred well or shaken the color change is immediate. The new compound $\mathbf{3 8}^{\mathbf{x}}$ exhibits intense bands at 550 and $305 \mathrm{~nm}$ tentatively assigned to ligand-to-metal charge transfer (LMCT). Similar bathochromic shifts of the major bands are reported for the oxidation of $\mathbf{1 1}^{\mathbf{2}-}$ (amide ligand) and $\mathbf{1 2}^{\mathbf{2}-}$ (thiolate ligand) and for HiPIPs in proteins. ${ }^{206}$ Comparison to other systems (Table 5.1) confirms the general trend, however, reasonable comparison is limited because different solvents are used and, most importantly, the energy of the LMCT severely depends on the ligand.

Although the cluster reacts readily with oxygen from air it is not stable under aerobic conditions for longer times. The characteristic band of $\mathbf{3 8}^{\mathbf{0 x}}$ at $550 \mathrm{~nm}$ in $\mathrm{MeCN}$ fades significantly when the solution is kept under air over 35 hours (Figure 5.1, b) suggesting the products degeneration.

a)

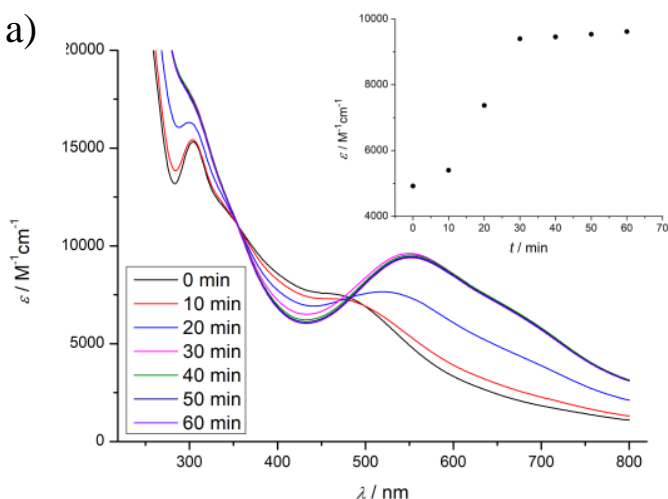

b)

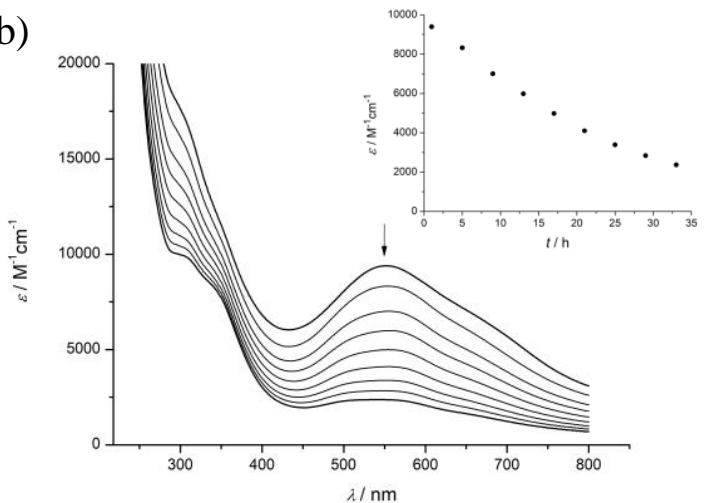

Figure 5.1. Reaction of $\left(\mathrm{Me}_{3} \mathrm{PhN}\right)_{2} 38$ with $\mathrm{O}_{2}$ in $\mathrm{MeCN}$ monitored by UV-vis spectroscopy. a) Reaction to intermediate with strong absorption at $550 \mathrm{~nm}, \mathrm{~b}$ ) decay of $\mathbf{3 8}^{\mathbf{0 x}}$ over several hours. Both inserts depict $\varepsilon$ vs. time at $550 \mathrm{~nm}$. 
Table 5.1. Electronic absorption data of clusters in the oxidation states $[4 \mathrm{Fe} 4 \mathrm{~S}]^{3+/ 4+}$. The oxidation state of $\mathbf{3 8}^{\mathbf{o x}}$ is not assigned.

\begin{tabular}{l||l|l|l|l} 
& & solvent & $\lambda[\mathrm{nm}]\left(\varepsilon\left[\mathrm{M}^{-1} \mathrm{~cm}^{-1}\right]\right)$ & ref \\
\hline $\mathbf{3 8}^{\mathbf{o x}}$ & & MeCN & $302(\mathrm{sh}, 18300), 550(18000), 680(\mathrm{sh}, 9700)$. & - \\
\hline $\mathbf{3 9}^{-}$ & {$[4 \mathrm{Fe} 4 \mathrm{~S}]^{3+}$} & DCM & $\begin{array}{l}236(\mathrm{sh}, 48000), 276(\mathrm{sh}, 23700), 328(13400), 475 \\
(28100) .\end{array}$ & 100 \\
\hline $\mathbf{1 1}^{-}$ & {$[4 \mathrm{Fe} 4 \mathrm{~S}]^{3+}$} & THF & $257(22900), 404(17700), 630(\mathrm{sh}, 2400)$. & 94 \\
\hline $\mathbf{1 1}^{\mathbf{0}}$ & {$[4 \mathrm{Fe} 4 \mathrm{~S}]^{4+}$} & THF & $231(19900), 268(21900), 449(19400)$. & 94 \\
\hline $\mathbf{1 5}^{\mathbf{0}}$ & {$[4 \mathrm{Fe} 4 \mathrm{~S}]^{3+}$} & THF & $348(17000), 446(14000)$. & 100
\end{tabular}

The oxidation product $\mathbf{3 8}^{\mathbf{x}}$ is not reactive towards $\mathrm{H}_{2}$ or TEMPOH. CoCp 2 * and $\mathrm{CoCp}_{2}$ can be used to reverse the oxidation as monitored by UV-vis spectroscopy (Figure 5.2, a). Subsequent opening of the cuvette to air reforges a band at $550 \mathrm{~nm}$, but it is less intense (Figure 5.2, b).

a)

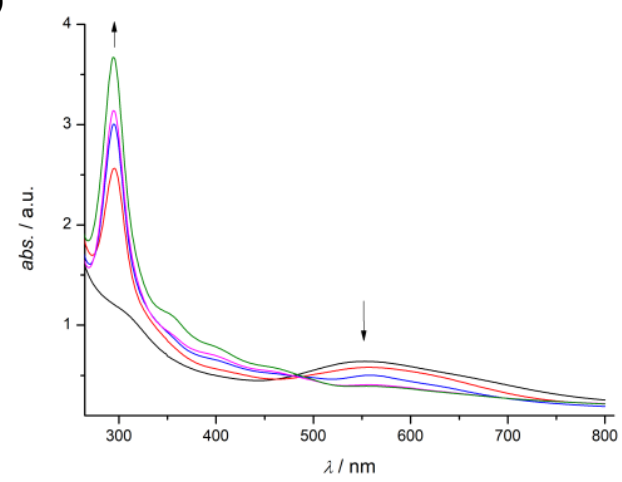

b)

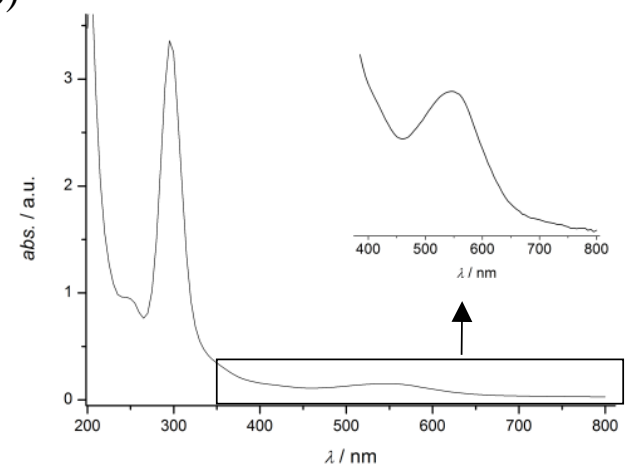

Figure 5.2. UV-vis spectroscopy of a) titration of $\mathbf{3 8}^{\mathbf{o x}}$ with $\mathrm{CoCp}_{2}{ }^{*}$, b) UV-vis spectrum after opening the vessel to air.

When a solution of $\mathbf{3 8}^{\mathbf{0 x}}$ in MeCN is measured a molecule peak at $843.7 \mathrm{~m} / \mathrm{z}$ is detected in ESI(-)MS (Figure 5.3). A simulation of $[38-4 \mathrm{H}]^{-}\left(=\mathrm{C}_{24} \mathrm{H}_{20} \mathrm{Fe}_{4} \mathrm{~S}_{8} \mathrm{~N}_{4}\right)$ calculates for the experimental value and isotopic pattern of that peak. This means that the $[4 \mathrm{Fe}-4 \mathrm{~S}]$ core persist the oxidation process under the loss of 4 hydrogen atoms. The same peak at $843.7 \mathrm{~m} / \mathrm{z}$ with the same isotopic pattern is seen in LIFDI-MS spectrum (Figure 8.7 in appendix). 


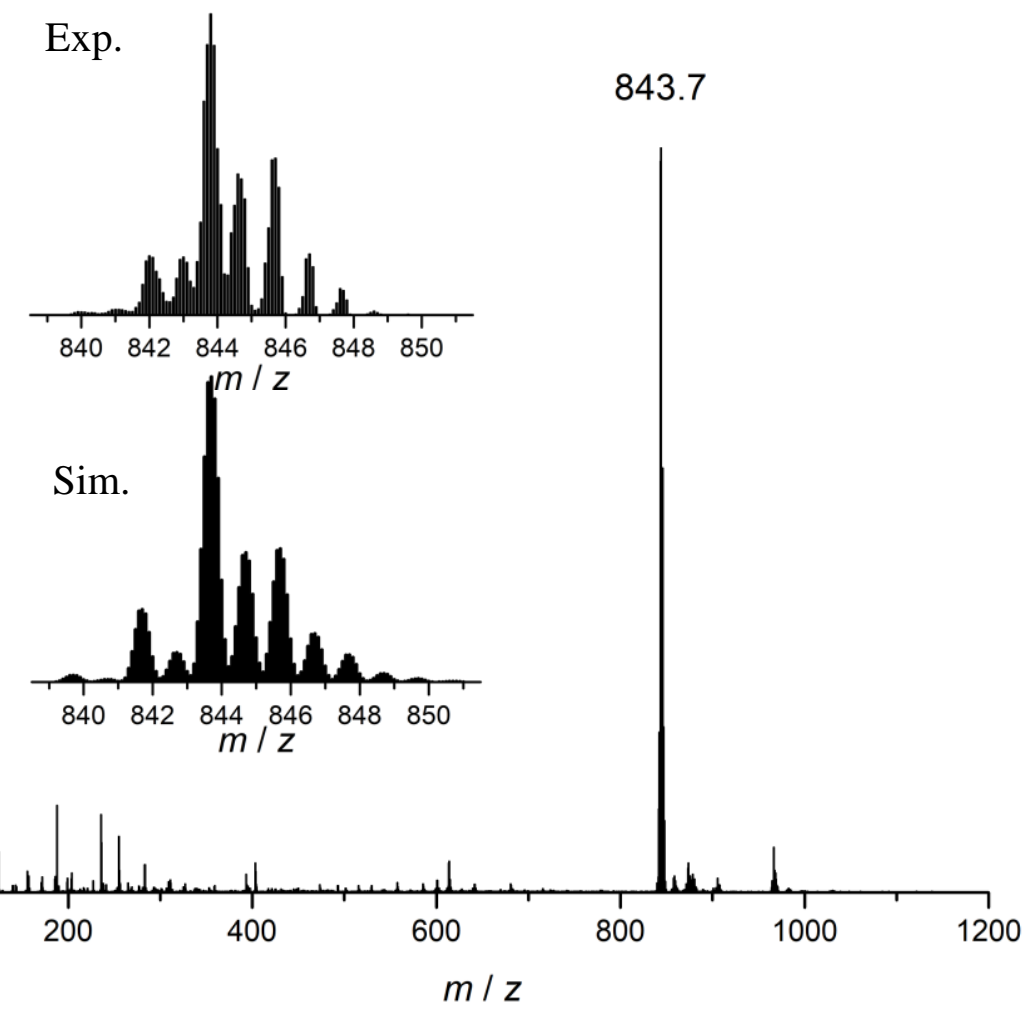

Figure 5.3. $\mathrm{m} / \mathrm{z}$ range 100-1200 of the ESI(-)MS spectrum of $\mathbf{3 8}^{\mathbf{o x}}$ in MeCN. The insert depicts an excerpt of the spectrum from 1098 to $1113 \mathrm{~m} / \mathrm{z}$ (top) and the simulated pattern for $[38-4 \mathrm{H}]^{-}\left(=\mathrm{C}_{24} \mathrm{H}_{20} \mathrm{Fe}_{4} \mathrm{~S}_{8} \mathrm{~N}_{4}\right)$.

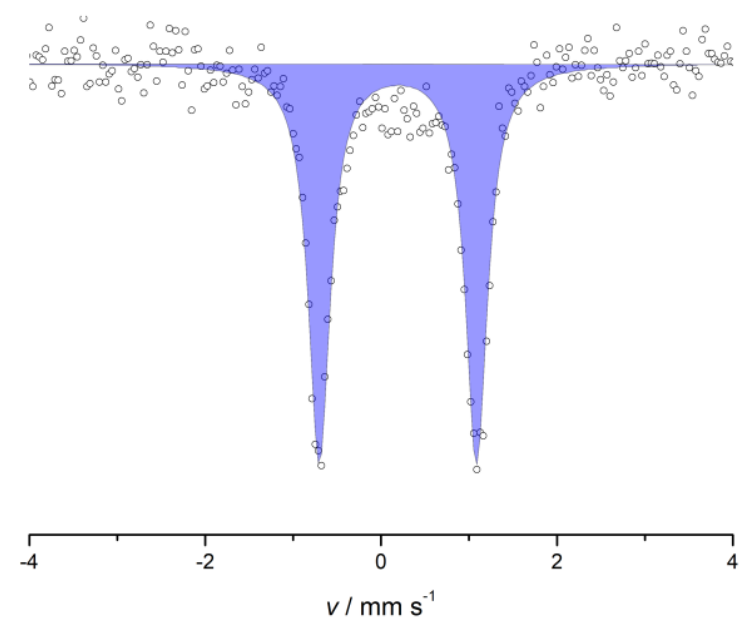

Figure 5.4. $\mathbf{3 8}^{\mathbf{2}-}$ in $\mathrm{MeCN}$ after exposure to air for $30 \mathrm{~min}$ and then frozen at $80 \mathrm{~K}$. $\delta_{\mathrm{IS}}=0.19 \mathrm{~mm} \mathrm{~s}^{-1}, \Delta E_{\mathrm{Q}}=1.79 \mathrm{~mm} \mathrm{~s}^{-1}, \mathrm{fwmh}=0.3 \mathrm{~mm} \mathrm{~s}^{-1}$.

The Mössbauer spectrum of $\mathbf{3 8}^{\mathbf{o x}}$ (Figure 5.4) has only one doublet with a small isomer shift of $0.19 \mathrm{~mm} \mathrm{~s}^{-1}$ and a large quadrupole splitting of $1.79 \mathrm{~mm} \mathrm{~s}^{-1}$. An isomer shift in that range is indicative for iron(III) ions. A guideline for the assignment of oxidation states to 
Fe-S clusters is provided by the formula below for the Mössbauer isomer shift $\delta_{\text {IS }}$ in dependence on the oxidation number $s$ at $77 \mathrm{~K} .{ }^{10}$

$$
\delta_{\mathrm{IS}} / \mathrm{mm} \mathrm{s}^{-1}=1.43-0.40 \mathrm{~s}
$$

The formula was inferred from a data set of known $\mathrm{FeS}_{n}(\mathrm{SR})_{4-\mathrm{n}}$ sites $(\mathrm{n}=0,2,3)$ in synthetic species. It is best applicable to $\left[\mathrm{Fe}_{4} \mathrm{~S}_{4}(\mathrm{SR})_{4}\right]^{2-3-}$ clusters, but the nature of the counterion and the lattice can cause small modulations. For the isomer shift of $\mathbf{3 8}^{\mathbf{o x}}\left(0.19 \mathrm{~mm} \mathrm{~s}^{-1}\right)$ the oxidation number $s$ amounts to 3.1 which supports the assignments of four iron(III) ions. Rao et al. reported that a difference of $0.1 \mathrm{~mm} \mathrm{~s}^{-1}$ is typical for adjoining [4Fe-4S] oxidation levels. ${ }^{10}$ The difference between $\delta_{\mathrm{IS}}\left(\mathbf{3 8}^{\mathbf{2}}\right)$ and $\delta_{\mathrm{IS}}\left(\mathbf{3 8}^{\mathbf{o x}}\right)$ amounts to $0.24 \mathrm{~mm} \mathrm{~s}^{-1}$. Therefore, two oxidation steps seem reasonable for $\mathbf{3 8}^{\mathbf{2}-}$ which again supports the oxidation of two formally $\mathrm{Fe}(\mathrm{II})$ ions to $\mathrm{Fe}(\mathrm{III})$ ions in $\mathbf{3 8}^{\mathbf{0 x}}$.

A large quadrupole splitting implies a large electronic field gradient at the iron nucleus due to valence contributions from 3d-electrons or ligand contributions. As all d-orbitals are singly populated in $\mathrm{Fe}^{\mathrm{III}}$-hs complexes, the valence contribution can be largely excluded as reason. Therefore, deviation from total symmetric coordination, as is the case for five-fold coordination, can be one explanation for the larger quadrupole splitting in comparison to the quadrupole splitting of $\mathbf{3 8}^{\mathbf{2}}$. The small full-width-at-half-maximum (fwhm) of $0.3 \mathrm{~mm} \mathrm{~s}^{-1}$ does not allow for the fitting of several Fe-species. Therefore, all iron ions are probably in the same oxidation state and ligand environment.

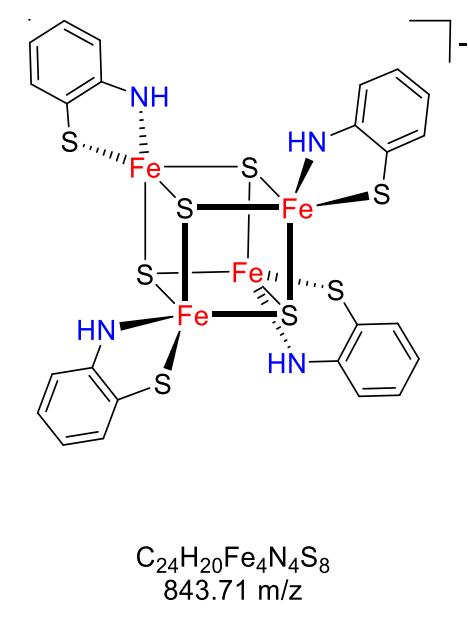

Figure 5.5. Proposed structure of $\mathbf{3 8}^{\mathbf{o x}}$.

The isomer shift for amide ligated $\mathbf{1 1}^{-}$and thiolate ligated $\mathbf{1 2}$ is more positive than for $\mathbf{3 8}^{\mathbf{o x}}$ $\left(12>\mathbf{1 1}^{-}>\mathbf{3 8}^{\mathbf{o x}}\right.$, Table 5.2). Unfortunately, no Mössbauer parameters are reported for $\left[\mathrm{Fe}_{4} \mathrm{~S}_{4}(\mathrm{SDmp})_{4}\right]^{-}$or $\mathbf{1 5}^{\mathbf{0}}$ to compare the data from this thesis to. The quadrupole splitting of 
$\mathbf{3 8}^{\mathbf{o x}}$ is much larger than that of all the clusters in $\left[\mathrm{Fe}_{4} \mathrm{~S}_{4}\right]^{3+}$ state, but similar to that of $\mathbf{1 1}$ in the $\left[\mathrm{Fe}_{4} \mathrm{~S}_{4}\right]^{4+}$ state.

Table 5.2. Mössbauer parameters for $\left[\mathrm{Fe}_{4} \mathrm{~S}_{4}\right]^{3+/ 4+}$ of model compounds and HiPIP protein from C. vinosum. $\alpha$ and $\beta$ refer to the mixed-valence $\mathrm{Fe}^{2.5}-\mathrm{Fe}^{2.5}$ pair or diferric $\mathrm{Fe}^{3+}-\mathrm{Fe}^{3+}$ pair, respectively. $(C .=$ Chromatium $)$

\begin{tabular}{l|l|l|l|l|l|l} 
& & $T / \mathrm{K}$ & & $\delta_{\mathrm{IS}} / \mathrm{mm} \mathrm{s}^{-1}$ & $\Delta E_{\mathrm{QS}} / \mathrm{mm} \mathrm{s}^{-1}$ & reference \\
\hline \hline $\mathbf{3 8}^{\mathbf{0 x}}$ & & 80 & & 0.19 & 1.79 & this work \\
\hline $\mathbf{1 1}^{-}$ & {$\left[\mathrm{Fe}_{4} \mathrm{~S}_{4}\right]^{3+}$} & 4.2 & & 0.33 & 1.35 & 94 \\
\hline $\mathbf{1 1}^{\mathbf{0}}$ & {$\left[\mathrm{Fe}_{4} \mathrm{~S}_{4}\right]^{4+}$} & 4.2 & & 0.26 & 1.67 & 94 \\
\hline $\mathbf{1 2}^{\mathbf{0}}$ & {$\left[\mathrm{Fe}_{4} \mathrm{~S}_{4}\right]^{3+}$} & 4.2 & $\alpha$ & 0.40 & 1.05 & 96 \\
\hline & & & $\beta$ & 0.34 & 0.90 & \\
\hline $\mathbf{1 2}^{\mathbf{0}}$ & {$\left[\mathrm{Fe}_{4} \mathrm{~S}_{4}\right]^{3+}$} & 100 & $\alpha$ & 0.39 & 0.79 & 96 \\
\hline & & & $\beta$ & 0.32 & 0.73 & 207 \\
\hline C. vinosum & {$\left[\mathrm{Fe}_{4} \mathrm{~S}_{4}\right]^{3+}$} & 4.2 & $\alpha$ & 0.40 & 1.03 & \\
\hline & & & $\beta$ & 0.29 & 0.88 &
\end{tabular}

$\mathbf{3 8}^{\mathbf{2}}$ - was dissolved in DCM and exposed to air. Samples for EPR spectroscopy were taken from the reaction mixture after 5, 18, and $30 \mathrm{~min}$, then frozen and measured (Figure 5.6). An isotropic signal with a $g$-value of 2.006 appears and intensifies over time. The EPR spectrum of $\left[\mathrm{Fe}_{4} \mathrm{~S}_{4}\right]^{3+}$ in proteins and model clusters are normally axial and their $g_{\text {av }}$-value is larger than the value for the free electron $\left(g_{\mathrm{e}}=2.0023\right)$. In literature values are found between 2.0555-2.0693 (Table 5.3). Papaefthymiou et al. observed broad EPR lines for synthetic clusters compared to lines of protein due to considerable g-strain. ${ }^{96}$ Nevertheless, model compounds achieve a good agreement with $g$-values for the HiPIP proteins with experimental values between 2.043 and 2.066. Pape et al. excluded that the paramagnetic species are free radicals on the ligands or on the counterions, since they would rather exhibit much less anisotropic g-tensors and resolved proton hyperfine structure. ${ }^{196}$ In the case of $\mathbf{3 8}^{\mathbf{o x}}$, a free radical on the ligand cannot be excluded as the isotropic $g$-value is close to $g_{\mathrm{e}}$. On the other hand, a $\left[\mathrm{Fe}_{4} \mathrm{~S}_{4}\right]^{3+}$ cluster seems not reasonable as the g-tensor is not axial and the $g$-value is too small. 


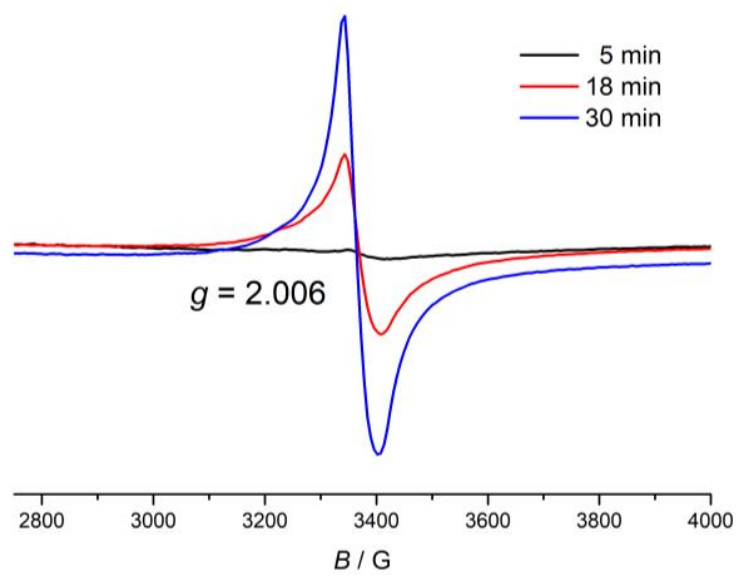

Figure 5.6. EPR spectrum of reaction mixture in frozen solution (DCM) at $159 \mathrm{~K}$ after 5, 18 and 30 min.

Table 5.3. Compilation of $g_{\mathrm{av}}$-values for selected HiPIPs $(A .=$ Allochromatium, $H .=$ Halorhodospira, . $=$ Rhodopila, $E=$ Ectothiorhodospira, $R$ u. $=$ Rubrivivax, Rh. $=$ Rhodocyclus $)$ and model compounds.

\begin{tabular}{|c|c|c|c|}
\hline \multirow{6}{*}{ Model clusters: } & & $g_{\text {av }}$-values & ref \\
\hline & {$\left[\mathrm{Fe}_{4} \mathrm{~S}_{4}(\mathrm{SDmp})_{4}\right]^{-}\left(\mathbf{3 9}^{-}\right)$} & 2.043 & 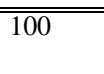 \\
\hline & {$\left[\mathrm{Fe}_{4} \mathrm{~S}_{4}(\mathrm{STip})_{4}\right]\left(\mathbf{1 2}^{\mathbf{0}}\right)$} & 2.066 & 96 \\
\hline & $\begin{array}{l}{\left[\mathrm{Fe}_{4} \mathrm{~S}_{4}\left(\mathrm{SC}_{6} \mathrm{H}_{5}-O-\mathrm{OH}\right)_{4}\right]^{-}\left(37^{-}\right)} \\
\text {a) }\end{array}$ & $2.048,2.041,2.038$ & 196 \\
\hline & {$\left[\mathrm{Fe}_{4} \mathrm{~S}_{4}(\mathrm{SBn})_{4}\right]^{-\mathrm{a})}$} & $\begin{array}{l}\text { 2.053, 2.053, 2.054, } \\
2.038,2.055\end{array}$ & 208 \\
\hline & {$\left[\mathrm{Fe}_{4} \mathrm{~S}_{4}(\mathrm{SPh})_{4}\right]^{-\mathrm{a})}$} & 2.034 & 209,210 \\
\hline \multirow[t]{7}{*}{ HiPIPs } & A. vinosum & 2.0626 & 211 \\
\hline & H. halophila isoprotein I & 2.0693 & 211 \\
\hline & R. globiformis & 2.0640 & 211 \\
\hline & E. vacuolata isoprotein I & 2.0555 & 211 \\
\hline & E. vacuolata isoprotein II & 2.0583 & 211 \\
\hline & Ru. gelantinosus & 2.0579 & 211 \\
\hline & Rh. tenuis & 2.0576 & 211 \\
\hline
\end{tabular}

a) Data from single-crystal EPR measurements. Site multiplicity, i.e. different location for the mixed-valence pairs, was detected for asymmetric $\left(\mathrm{Et}_{4} \mathrm{~N}\right)_{2} 37$ (three centers) and symmetric $\left(\mathrm{Et}_{4} \mathrm{~N}\right)_{2}\left[\mathrm{Fe}_{4} \mathrm{~S}_{4}(\mathrm{SBn})_{4}\right]$ (five centers). In a fully symmetrical cluster each of six possible topologies for the mixed-valence pairs should be equally likely. 


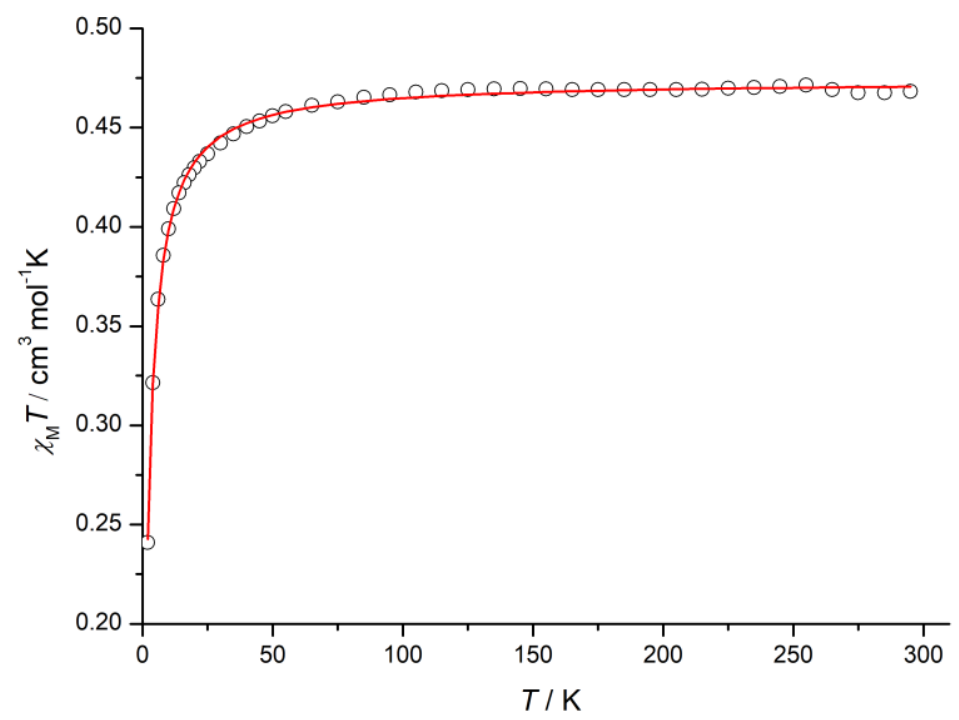

Figure 5.7. Plot of $\chi_{\mathrm{M}} T v s . T$ for $\mathbf{3 8}^{\mathrm{ox}}$ at applied field $B=0.5 \mathrm{~T}$. The red solid line is a fit to the experimental values. Best fit parameters are: $g=2.247$, Curie-Weiss temperature $\Theta=-1.893 \mathrm{~K}, \mathrm{TIP}=1741.4 \times 10^{-6} \mathrm{emu}$ (substracted).

Magnetic susceptibility measurements (SQUID) of precipitated $\mathbf{3 8}^{\mathbf{0 x}}$ confirm a spin of $1 / 2$. The $g$-value is 2.247 and therefore higher than the one determined with EPR spectroscopy. In order to achieve a good fitting of the data, temperature independent paramagnetism (TIP) was substracted $\left(1741.4 \times 10^{-6} \mathrm{emu}\right)$ and the Curie-Weiss parameter was set at $-1.894 \mathrm{~K}$.

In summary, reversible oxidation od $\mathbf{3 8}^{\mathbf{2}}$ is possible with dioxygen as monitored by UVvis spectroscopy. ESI-MS and LIFDI-MS suggest that the cluster is still intact under the loss of four hydrogen atoms. Mössbauer provides evidence that only one iron species is present. The isomer shift is too low for $\left[\mathrm{Fe}_{4} \mathrm{~S}_{4}\right]^{3+}$ suggesting that two oxidation steps took place and both $\mathrm{Fe}^{\mathrm{II}}$ from the starting $\left[\mathrm{Fe}_{4} \mathrm{~S}_{4}\right]^{2+}$ are oxidized to $\mathrm{Fe}^{\mathrm{III}}$. However, this electronic structure would produce an EPR-silent cluster due to antiferromagnetic coupling, as seen in the amide ligated $\left[\mathrm{Fe}_{4} \mathrm{~S}_{4}\right]^{4+}$ cluster 11. EPR and SQUID of $\mathbf{3 8}^{\mathbf{o x}}$ measurements suggest a $S=1 / 2$ spin system. It is not likely that the unpaired electron is localized on an iron as one would expect a more anistropic pattern. The quadrupole splitting of $\mathbf{3 8}^{\mathbf{0 x}}$ is almost as large as for $\mathbf{1 1}$ in the oxidation state $\left[\mathrm{Fe}_{4} \mathrm{~S}_{4}\right]^{4+}$. Normally, quadrupole splitting is a sign for the symmetry around the iron core. It seems to be asymmetric which could be due to a pentacoordination of the iron ions as depicted in Figure 5.5. 


\subsection{Equivalents of oxidant}

It was not sufficiently possible to determine the oxidation state and charge of $\mathbf{3 8}^{\mathbf{o x}}$ with ESI-MS, Mössbauer and UV-vis spectroscopy. Therefore, a Clark electrode was used to identify the number of equivalents of dioxygen necessary for the oxidation of $\mathbf{3 8}^{\mathbf{2}-}$ to give $38^{\text {ox }}$.

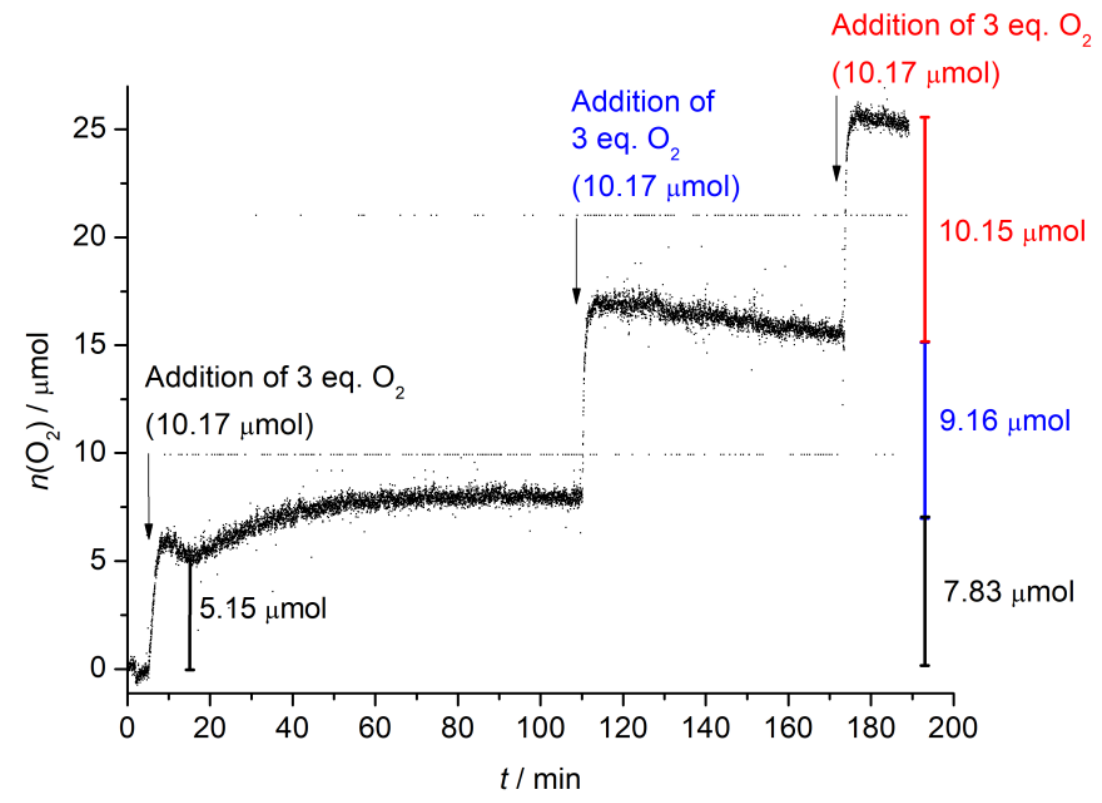

Figure 5.8. Oxygen uptake by $\mathbf{3 8}^{\mathbf{2}}$ in $\mathrm{MeCN}$.

After the calibration of the electrode in an air tight flask, $3 \times 3$ equivalents of dioxygen $(10.17 \mu \mathrm{mol})$ were added with an air-tight Hamilton syringe into a solution of $\left(\mathrm{Me}_{3} \mathrm{PhN}\right)_{2} 38$ in MeCN (Figure 5.8). The electrode detected a minimum of $5.15 \mu \mathrm{mol}$ of oxygen in the gas phase above the solution after an induction period of $11 \mathrm{~min}$. After that the level of oxygen rises to $7.83 \mu \mathrm{mol}$. At the lowest point 1.5 eq. of oxygen were consumed. Some of the oxygen was not detected probably because it was consumed right away by a fast reaction. The rise of dioxygen amount from 17-110 min could be explained by disproportionation of hydrogenperoxide to water and dioxygen (Scheme 5.1). This pathway would explain why the amount of $\mathrm{O}_{2}$ first goes down and then rises again.

$$
\begin{aligned}
& 4 \mathrm{H}^{+}, 4 \mathrm{e}^{-} \text {(from Fe-S) } \\
& 2 \mathrm{O}_{2} \longrightarrow 2 \mathrm{H}_{2} \mathrm{O}_{2} \longrightarrow 2 \mathrm{H}_{2} \mathrm{O}+\mathrm{O}_{2}
\end{aligned}
$$


a)

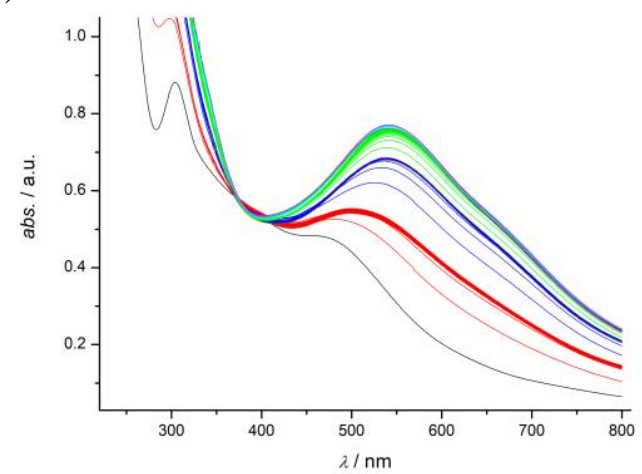

b)

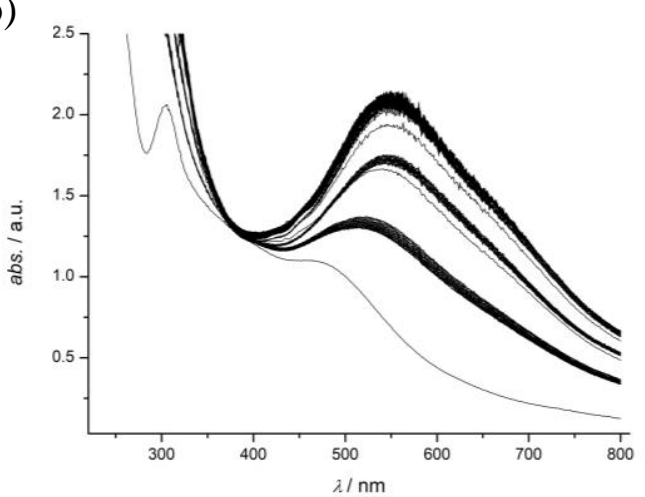

Figure 5.9: Titration of ( $\left.\mathrm{Me}_{3} \mathrm{PhN}\right)_{2} \mathbf{3 8}$ with $p$-benzoquinone monitored by UV-vis spectroscopy. a) 1 eq. (red), 2 eq. (blue), 3 eq. (green), 4 eq. (cyan), 5 eq. (magenta). 30 min between each addition. One spectrum was measured every minute. b) Addition of 1-10 eq. while stirring and waiting in between at least 15 min.

As an alternative to dioxygen, other oxidants were tested in order to find the correct number of equivalents necessary for the reaction to take place. TEMPO did not react at all and a combination of DBU and thianthrenium tetrafluoroborate did not lead to reproducible results. DDQ seemed to degradate the complex, but addition of $p$-benzoquinone produced the characteristic band at $550 \mathrm{~nm}$. It takes three equivalents of $p$-benzoquinone to reach full conversion (Figure 5.9). Addition of further equivalents does not affect a rise in absorption of the band $550 \mathrm{~nm}$. According the reaction in Scheme 5.2 three equivalents of $p$ benzoquinone account for the uptake of 6 protons and 6 electrons.

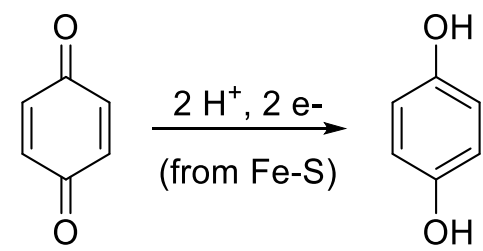


a)

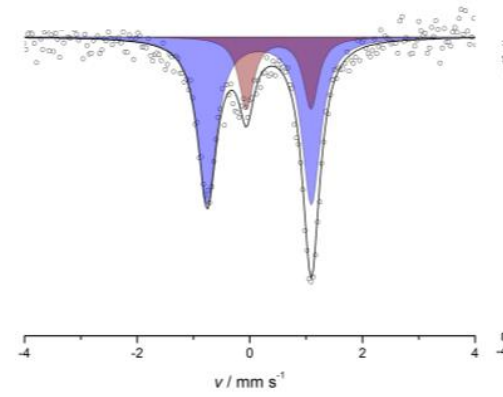

b)

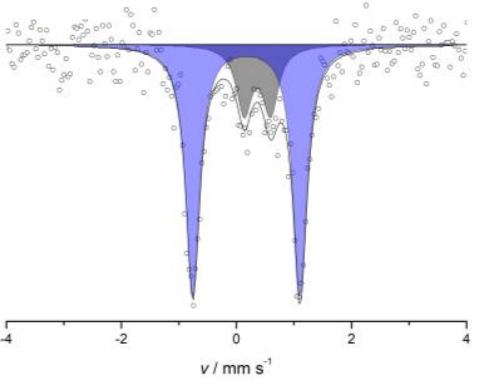

c)

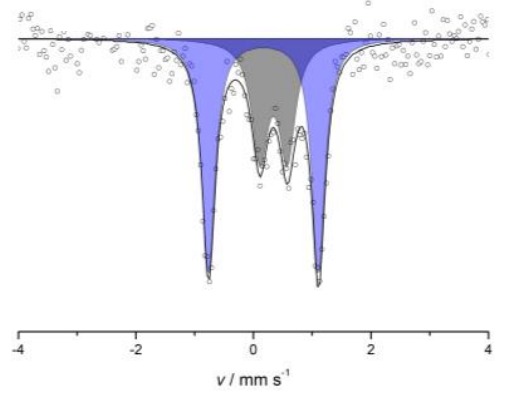

Figure 5.10. Zero-field Mössbauer spectra of $\mathbf{3 8}^{\mathbf{2}-}$ and a) 2 eq. $p$-benzoquinone in THF/MeCN at $80 \mathrm{~K}$, b) 3 eq. $p$ benzoquinone in $\mathrm{MeCN}$ at $80 \mathrm{~K}$, c) 5 eq. $p$-benzoquinone in $\mathrm{MeCN}$ at $80 \mathrm{~K}$.

Mössbauer spectra were measured of $\mathbf{3 8}^{\mathbf{2}}$ with 2, 3, and 5 equivalents of $p$-benzoquinone (Figure 5.10, Table 5.4). The blue subspectra have the same parameters as $\mathbf{3 8}^{\mathbf{2}}$ after the reaction with dioxygen. In the sample with two equivalents of $p$-benzoquinone unreacted starting material is still visible (red subspectrum). Besides $\mathbf{3 8}^{\mathbf{0 x}}$ another Fe containing product can be identified by Mössbauer spectroscopy after addition of 3 and 5 equivalents of $p$-benzoquinone (grey subspectrum). The more $p$-benzoquinone is added, the more side product is formed.

Table 5.4. Mössbauer parameters after addition of 2, 3 or 5 eq. p-benzoquinone to $\mathbf{3 8}^{\mathbf{2}-}$ in $\mathrm{MeCN}$ at $80 \mathrm{~K}$.

\begin{tabular}{l|l|l|l|l} 
& & $\delta_{\mathrm{IS}} / \mathrm{mm} \mathrm{s}^{-1}$ & $\Delta E_{\mathrm{QS}} / \mathrm{mm} \mathrm{s}^{-1}$ & ratio $/ \%$ \\
\hline $\mathbf{3 8}^{2-}+2$ eq. $p$-benzoquinone & blue & 0.17 & 1.85 & 74.30 \\
\cline { 2 - 5 } & red & 0.51 & 1.15 & 25.70 \\
\hline $\mathbf{3 8}^{2-}+3$ eq. $p$-benzoquinone & blue & 0.17 & 1.86 & 77.54 \\
\cline { 2 - 5 } & grey & 0.36 & 0.46 & 22.54 \\
\hline $\mathbf{3 8}^{2-}+5$ eq. $p$-benzoquinone & blue & 0.17 & 1.87 & 62.76 \\
\cline { 2 - 5 } & grey & 0.34 & 0.47 & 37.24
\end{tabular}




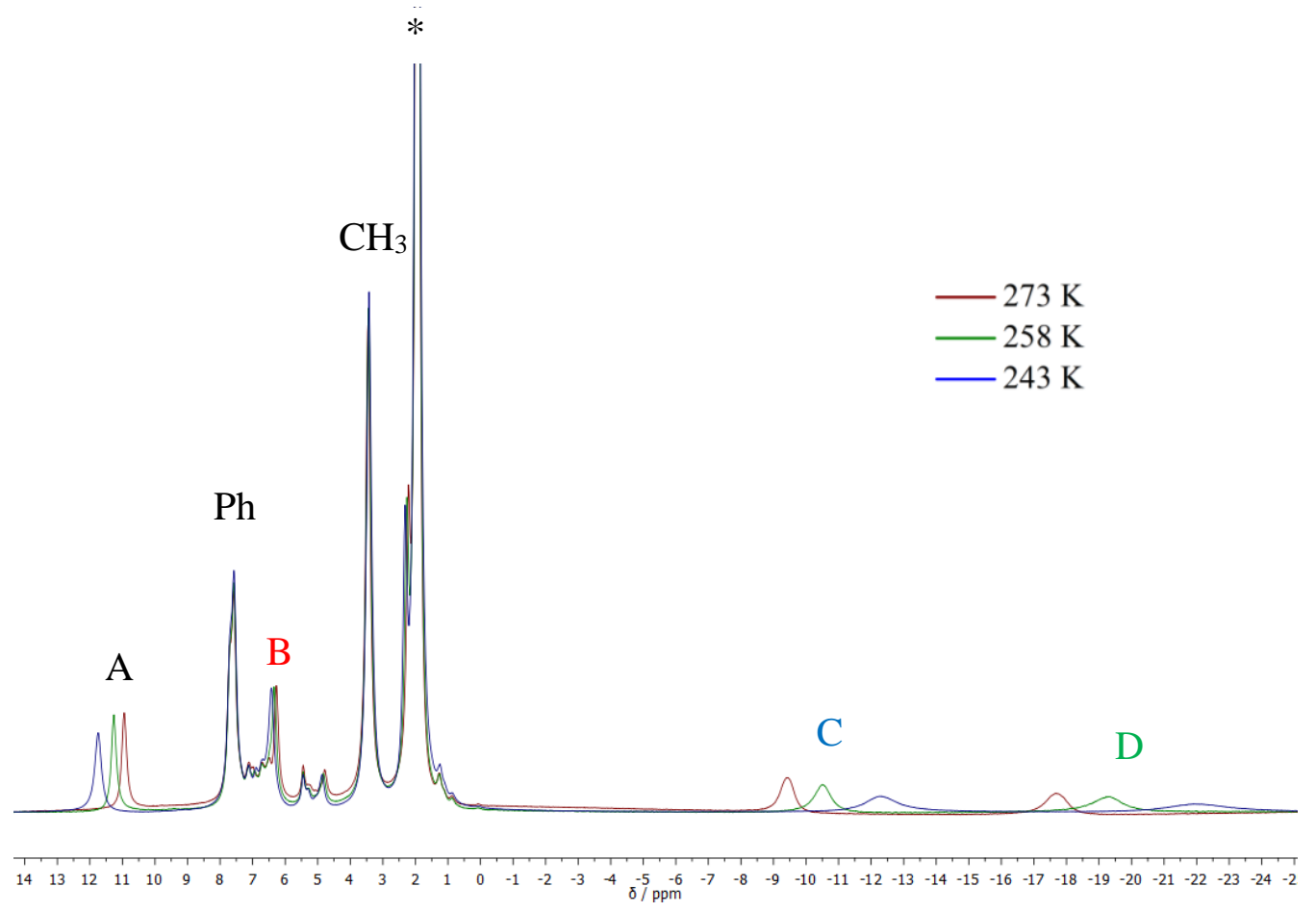

Figure 5.11. 1H NMR spectrum of oxidation product 38ox. (*) denotes residual solvent. Paramagnetic signals that change their position in dependence on the temperature are marked with the letters A-D.

The NMR spectrum in Figure 5.11 was recorded one hour after the sample was exposed to an excess of $\mathrm{O}_{2}$ at $-30{ }^{\circ} \mathrm{C},-15^{\circ} \mathrm{C}$ and $0{ }^{\circ} \mathrm{C}$. While signals for diamagnetic species should show no significant shift with temperature, paramagnetic signals can be influenced quite strongly. Taking this in consideration, it is possible to assign the signals in Table 5.5 to a paramagnetic compound that evolved after exposure to $\mathrm{O}_{2}$. After the addition of $p$ benzoquinone as oxidant the same signals appear (Figure 5.12) in the proton NMR spectrum. Hydroquinone formation is proven by proton NMR spectroscopy ( $\delta=6.60 \mathrm{ppm})$.

Table 5.5. ${ }^{1} \mathrm{H}$ NMR shifts of paramagnetic $\mathbf{3 8}^{\mathbf{o x}}$ in MeCN-d 3 .

\begin{tabular}{c|c|c|c|c|c} 
& $T / \mathrm{K}$ & $\delta / \mathrm{ppm}$ & $\delta / \mathrm{ppm}$ & $\delta / \mathrm{ppm}$ & $\delta / \mathrm{ppm}$ \\
\hline $\mathrm{A}$ & 243 & 11.73 & 6.41 & -12.32 & -21.99 \\
\hline $\mathrm{B}$ & 258 & 11.26 & 6.33 & -10.50 & -19.27 \\
\hline $\mathrm{C}$ & 273 & 10.94 & 6.26 & -9.44 & -17.69 \\
\hline $\mathrm{D}$ & 295 & 10.58 & 6.18 & -8.28 & -16.10
\end{tabular}

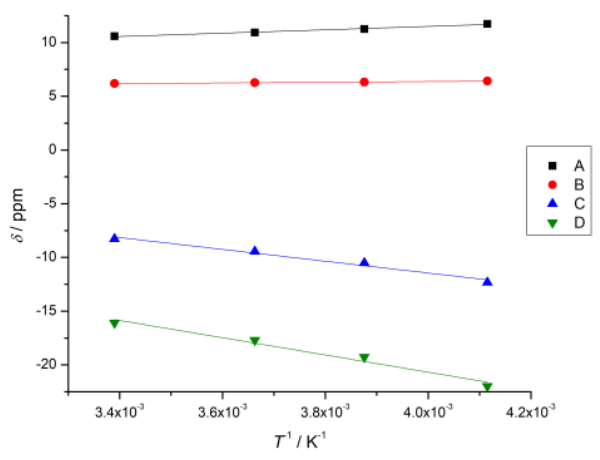




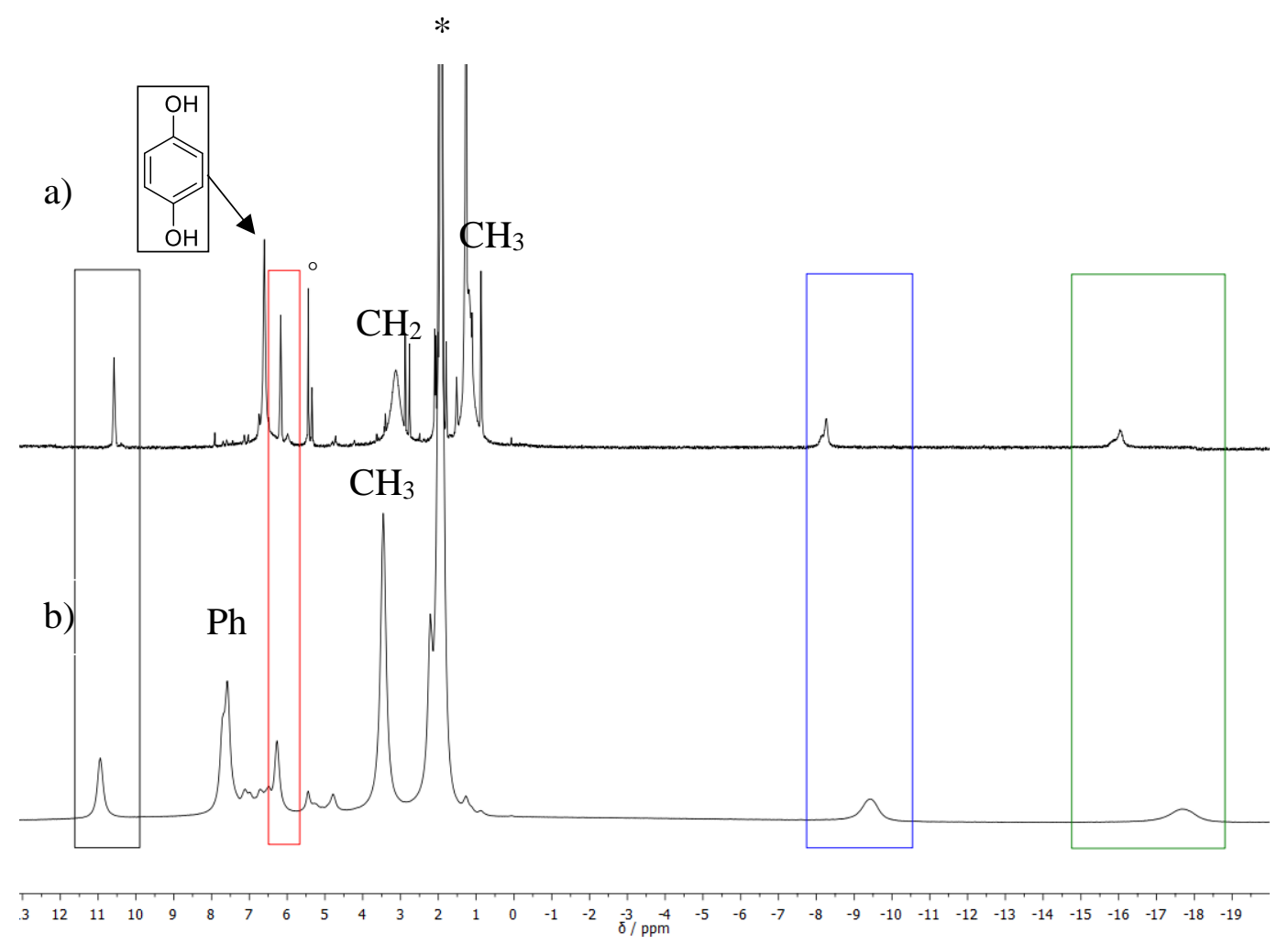

Figure 5.12. Comparison of the ${ }^{1} \mathrm{H}$ NMR spectra of a) $\left(\mathrm{Et}_{4} \mathrm{~N}\right)_{2} \mathbf{3 8}+3$ p-benzoquinone and b) $\left(\mathrm{Me}_{3} \mathrm{PhN}\right)_{2} \mathbf{3 8}+$ dioxygen. Little deviation in the chemical shift of the signals can be attributed to measuring at slightly different room temperature. $\left({ }^{\circ}\right)$ denotes DCM. $\left({ }^{*}\right)$ denotes residual solvent. A spectrum of the reaction in acetone- $\mathrm{d}_{6}$ and Curie behavior thereof can be found in the appendix (Figure 8.8).

In summary, $\mathbf{3 8}^{\mathbf{2}-}$ reacts with approximately 1.5 equivalents of dioxygen or 3 equivalents of $p$-benzoquinone. Both oxidants yield $\mathbf{3 8}^{\mathbf{x}}$ as reaction product according to UV-vis, Mössbauer, and ${ }^{1} \mathrm{H}$ NMR spectroscopy. The number of equivalents was determined by a Clark electrode or UV-vis spectroscopy, respectively. The result would imply that in both cases 6 electrons and 6 protons are abstracted from the cluster according to Scheme 5.1 and Scheme 5.2. However, these numbers should be treated with caution for three reasons. Firstly, dioxygen can be reduced to either $\mathrm{H}_{2} \mathrm{O}_{2}$ or $\mathrm{H}_{2} \mathrm{O}$ and the reaction mechanism is not fully elucidated yet. Secondly, a side product is detected in the Mössbauer spectrum after the reaction of $\mathbf{3 8}^{\mathbf{2}-}$ with $p$-benzoquinone. Apparently, a surplus of oxidant causes the degradation of $\mathbf{3 8}^{\mathbf{0 x}}$ and an increase of the amount of side product. Thirdly, abstraction of $6 \mathrm{H}$ atoms is contradicted by the ESI-MS spectrum of $\mathbf{3 8}^{\mathbf{0 x}}$ (Figure 5.3) in which the molecular ion peak has a mass of $[38-4 \mathrm{H}]$. 


\subsection{Conclusion}

Oxidation of $\mathbf{3 8}^{\mathbf{2}}$ with dioxygen or $p$-benzoquinone afforded a $\mathrm{UV}$-vis spectrum with a prominent band at $550 \mathrm{~nm}\left(\varepsilon=9600 \mathrm{~cm}^{-1} \mathrm{M}^{-1}\right)$. This bathochromic shift from $484 \mathrm{~nm}(\varepsilon=$ $7700)$ is typical for oxidation of [4Fe-4S] clusters. The oxidation product was stable under air for a few hours. The oxidation could be reversed with $\mathrm{CoCp}_{2}{ }_{2}$, however, subsequent exposure to air only retrieved the band at $550 \mathrm{~nm}$ with less intensity in the UV-vis spectrum.

ESI-MS of $\mathbf{3 8}^{\mathbf{0 x}}$ suggested that the cluster core was still intact but indicated the loss of four hydrogen atoms. Mössbauer spectroscopy showed only one doublet with an isomer shift of $0.19 \mathrm{~mm} \mathrm{~s}^{-1}$ and a quadrupole splitting of $1.79 \mathrm{~mm} \mathrm{~s}^{-1}$. According to this data, all four iron ions are in the oxidation state +3 and they are bidentally bound by the amine and the thiolate of 2-aminothiophenolate. Mössbauer data of the only reported all-ferric $[4 \mathrm{Fe}-4 \mathrm{~S}]^{4+}$ cluster 11 compare well to $\mathbf{3 8}^{\mathrm{ox}}$ with an isomer shift of $0.26 \mathrm{~mm} \mathrm{~s}^{-1}$ and a quadrupole splitting of $1.67 \mathrm{~mm} \mathrm{~s}^{-1}$. [4Fe-4S $]^{3+}$ clusters, on the other hand, have a significantly higher isomer shift of $0.32-0.40 \mathrm{~mm} \mathrm{~s}^{-1}$ and smaller quadrupole splitting of $0.73-1.35 \mathrm{~mm} \mathrm{~s}^{-1}$.

All-ferric $[4 \mathrm{Fe}-4 \mathrm{~S}]^{4+}$ clusters are EPR-silent. However, a spin of $S=1 / 2$ was detected on $\mathbf{3 8}^{\mathbf{0 x}}$ with EPR spectroscopy and SQUID magnetometry. NMR-spectroscopy confirmed Curie-behavior of the paramagnetic compound.

The number of equivalents of oxidant was quantified with a Clark electrode $\left(\mathrm{O}_{2}\right)$ and UVvis spectroscopy titration ( $p$-benzoquinone). Results point towards a mechanism involving 6 electrons/6 protons. However, Mössbauer spectroscopy identified a Fe-containing side product insinuating that a surplus of oxidant leads to degradation of $\mathbf{3 8}^{\mathbf{o x}}$.

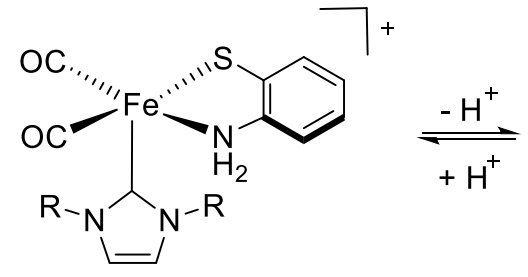

$39^{+}$

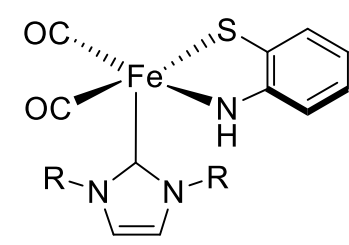

39

Figure 5.13. Iron complex with similar binding motif as $\mathbf{3 8}^{\mathbf{2}-}(\mathrm{R}=\mathrm{Mes})$.

In conclusion, further investigations are necessary to elucidate the structure of $\mathbf{3 8}^{\mathbf{o x}}$. A pentacoordinate iron complex with the same ligand was published in 2016. Jiang et al. synthesized the mononuclear $1 \mathrm{~s}-\mathrm{Fe}^{\mathrm{II}}$ complex $\mathbf{3 9}$ with a similar binding motif as is proposed for $\mathbf{3 8}^{\mathbf{0 x}}$ (Figure 5.13). ${ }^{212}$ A proton can be removed from $\mathbf{3 9}^{+}$with $t$-BuOK and then again 
added with $\mathrm{HBF}_{4}$. This example points towards an easy proton abstraction from the amine and a preferred pentacoordination of the iron ion. However, $\mathbf{3 8}^{\mathbf{0 x}}$ only reacted under simultaneous abstraction of electrons and protons in contrast to $\mathbf{3 9}^{+}$. Also, the strong-field ligands of 39 impose a ls spin state. It is probably due to their different oxidation and spin state that the two complexes exhibit ultimately different reaction behavior. 



\section{Protonation of 5,6-Dithia-1,10-phenanthroline, its application as disulfide/dithiol switch, and as ligand for [2Fe-2S] clusters}

\subsection{Introduction and objective}

2,2'-bipyridines are important ligands for complexation of metal ions and they are widely used as parts of "photosensitizer", especially with ruthenium as central atom $\left(\left[\mathrm{Ru}(\mathrm{bpy})_{3}\right]^{2+}\right) .{ }^{213,214}$ The complex absorbs light via metal to ligand charge transfer (MLCT) at $452 \mathrm{~nm}$, ligand centered transition $(285 \mathrm{~nm})$ and metal centered transition $(350 \mathrm{~nm})$. The resulting MLCT excited state $\left[\mathrm{Ru}(\mathrm{bpy})_{3}\right]^{2+*}$ has a comparatively long lifetime $(0.9 \mu \mathrm{s}$ in $\mathrm{MeCN}$ ) due to a forbitten singlet-triplet transition. The triplet excided state has both oxidizing and reducing properties. Exchange of one pyridine ring with imidazole allows for proton coupled electron transfer (PCET). ${ }^{215}$ Extensive literature is dedicated to modification and functionalization of bipyridines with altered electronic and steric properties. ${ }^{216,217}$

Light-driven reduction of $\mathrm{Fe}_{2} \mathrm{~S}_{2}$ complexes and related systems has been an active topic of research in recent years. ${ }^{218-221}$ Not yet reported complex $\mathbf{4 0}$ combines two active sites: a chromophore $\left(\mathrm{Ru}(\mathrm{bpy})_{3}\right)$ and an electron storage moiety (Fe-S cluster). Due to the covalent linkage, the electronic communication between the two sites would be more effective than in multicomponent systems like the triad system in Figure 6.1, b. ${ }^{222}$ Here, photoinduced electron transfer results ultimately in the reduction of the Fe-Fe complex mimicking the iron-only hydrogenase.
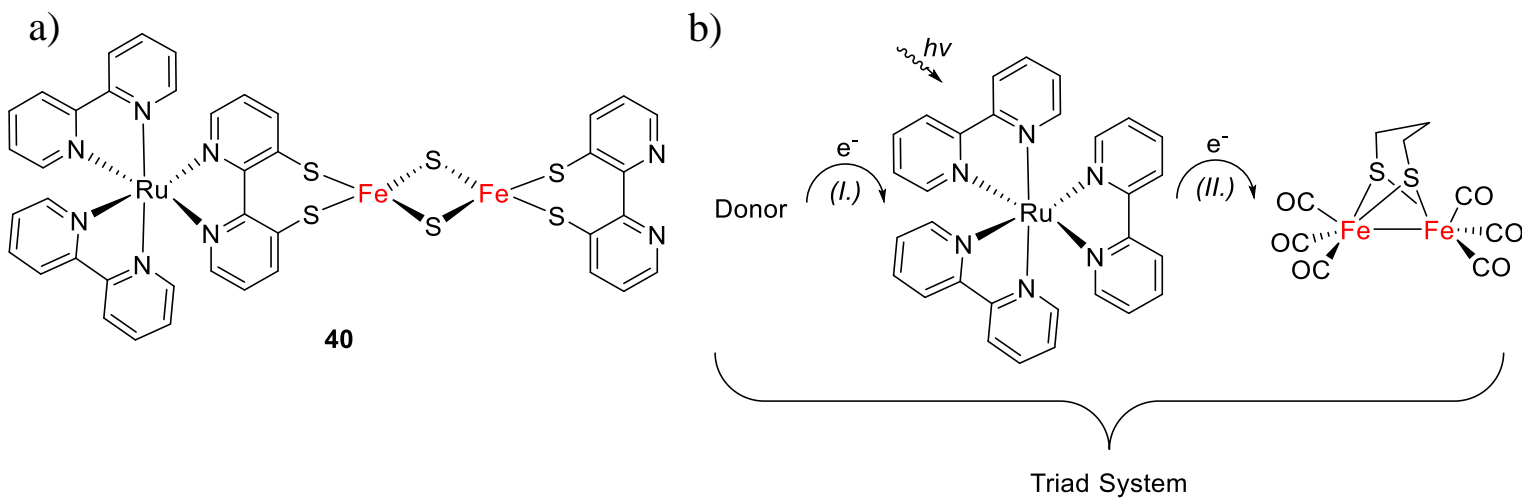

Figure 6.1. a) Target compound 40, a coupled Ru(bpy' $)_{3}-[2 \mathrm{Fe}-2 \mathrm{~S}]$ molecule, b) bioinspired triad system for photoinduced electron transfer, (I.) reductive quenching, (II.) intermolecular electron transfer. ${ }^{222}$ 
6 Protonation of 5,6-Dithia-1,10-phenanthroline, its application as disulfide/dithiol switch, and as ligand for $[2 \mathrm{Fe}-2 \mathrm{~S}]$ clusters

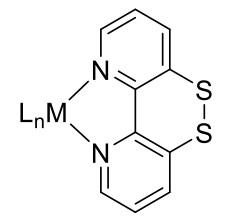

41(N-complex)

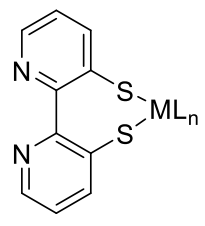

41(S-complex)

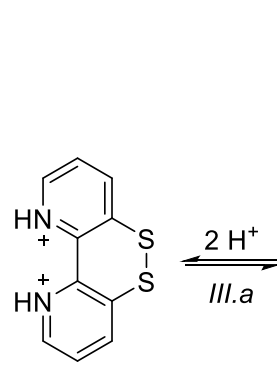

41(N-prot)

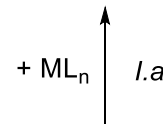

$+\mathrm{ML}_{\mathrm{n}} \uparrow 1 . b$
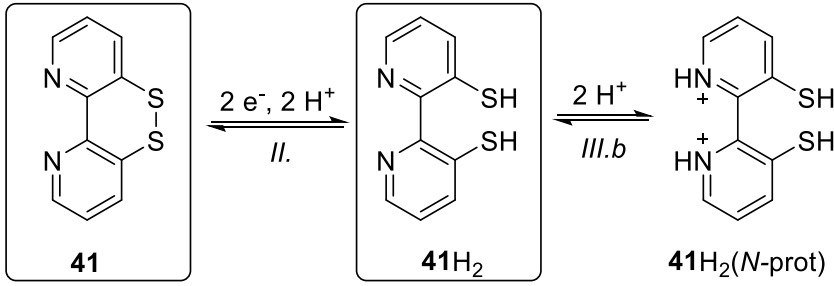

Figure 6.2. Compound 41 and its reactivity: $I . a) N$-coordination to metal, $I . b) S$-coordination to metal, $I I$.) disulfide/dithiol switch, I. $a$ ) and $b$ ) protonation at the pyridine- $N$.

The first step towards target molecule $\mathbf{4 0}$ is the synthesis of the linking bipyridine ligand. Cattaneo developed the synthesis of 5,6-dithia-1,10-phenanthroline (41) in our group. ${ }^{223}$ Patents for $\mathbf{4 1}$ have been filed, but they do not give any details on the synthesis. ${ }^{224,225} \mathbf{4 1}$ is versatile in terms of its application due to two functional sites (Figure 6.2): the bipyridine$N$ atoms on one hand and the disulfide/dithiol on the other. The coordination to a metal ion can take place via the $N$-atoms (I.a) or the $S$-atoms (I.b), if the disulfide bridge is cleaved. Route I. $a$ is preferred for Ru-complexes. In this thesis, route $I . b$ will be explored as $\mathrm{Fe}-\mathrm{S}$ clusters are prone to binding to thiols. Preliminary results on $[2 \mathrm{Fe}-2 \mathrm{~S}]$ cluster $\mathbf{4 2}^{\mathbf{2}-}$ (Figure 6.3) will be presented. Here, the pyridine- $\mathrm{N}$ can serve as coordination site for protons, Lewis acids or, as desired, for metals/complexes.<smiles>C[Te]1(C)Sc2cccnc2-c2[nH+]cccc2S1</smiles>

protons

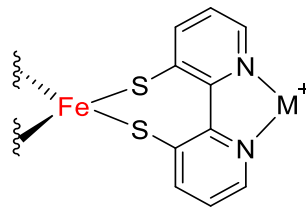

lewis acids

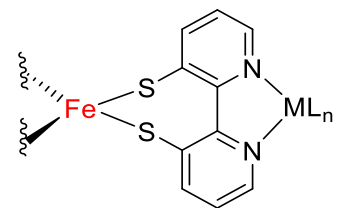

metal complexes

Figure 6.3. [2Fe-2S] cluster with $\mathbf{4 1}$ as ligand $\left(\mathbf{4 2}^{\mathbf{2}}\right.$, top) and possible further reactivity of cluster $\mathbf{4 2}^{\mathbf{2}}$ (bottom).

The redox properties of $\mathbf{4 1}$ were investigated thoroughly as part of this thesis. The disulfide bond can be opened reversibly via a two-electron two-proton reaction (Figure 6.2, step II). These disulfide/dithiol switches are important in redox control and charge storage in biochemical systems and offer the opportunity for multiple electron storage. ${ }^{226,227}$ 
Reactivity of $\mathbf{4 1}$ towards acid is also of interest as protonation can occur on the bipyridine$N$ site (III. $a$ and $b$ ) and will be presented in the subchapter 6.3.

\subsection{Synthesis of the ligand}

Some parts of this chapter have been adapted from a submitted manuscript. ${ }^{223}$

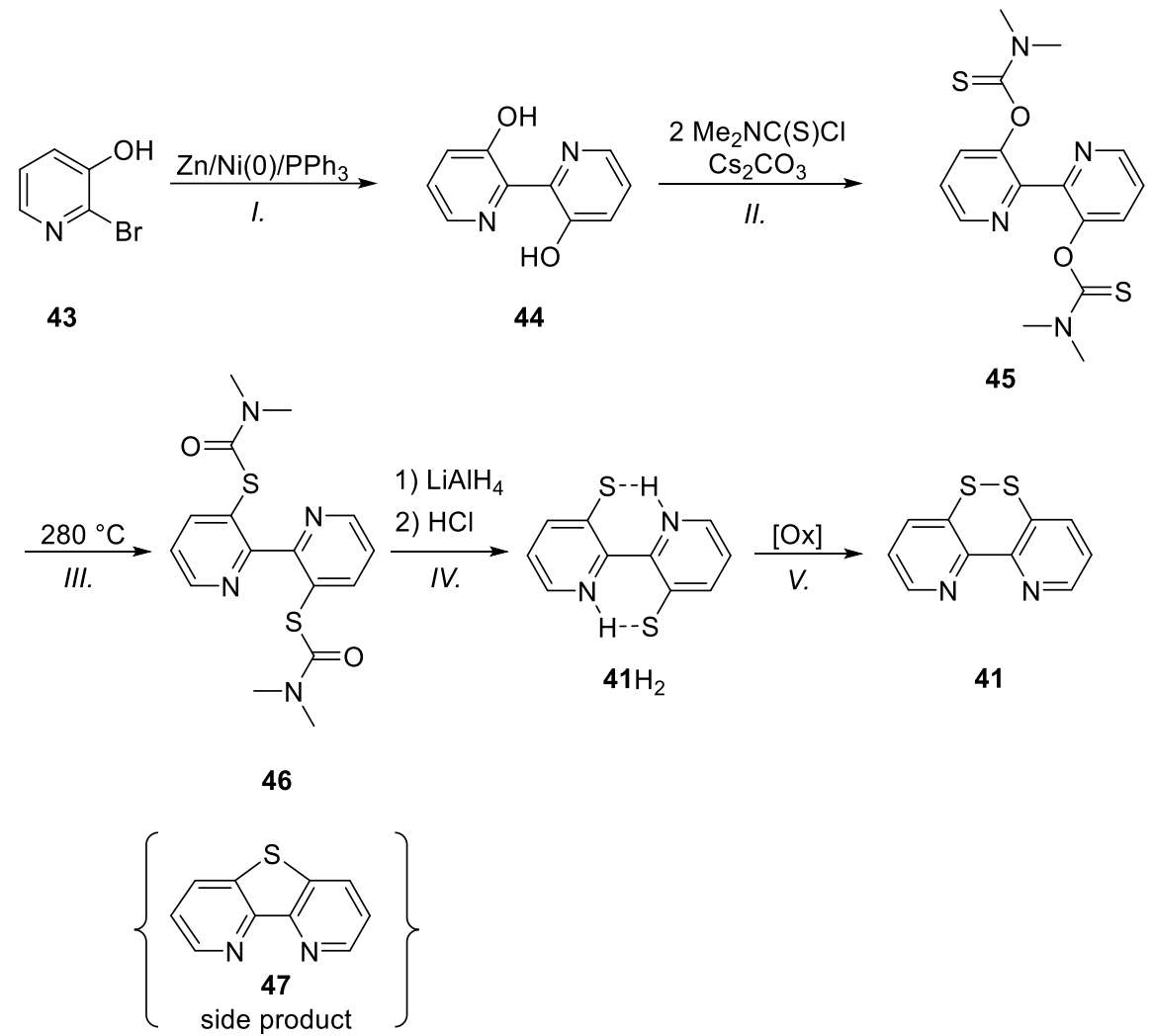

Figure 6.4. Synthesis of [1,2]dithiino[4,3-b:5,6-b']dipyridine 41. I. DMF, $50{ }^{\circ} \mathrm{C}, 24 \mathrm{~h}, I I$. acetone, reflux, $24 \mathrm{~h}, I I I$. powder, $7 \mathrm{~min}, I V$. THF, $50^{\circ} \mathrm{C}, 3 \mathrm{~h}, V . \mathrm{O}_{2}$, DCM.

[1,2]dithiino[4,3-b:5,6-b']dipyridine 41 was obtained by a multistep synthesis initially developed by Cattaneo (Figure 6.4). ${ }^{223}$ For this thesis, the reaction conditions in step II were modified in order to improve the yield of $\mathbf{4 5}$. Caesium carbonate was used instead of sodium hydride as base and the reaction time was increased. Generally, Newman-Kwart rearrangement reactions as in step III require high temperature and a reaction time of 12 hours in order to ensure quantitative yields. However, careful optimization of the reaction condition was necessary in order to minimize the amount of side products, for instance, thieno[3,2-b:4,5-b']bipyridine (47). Experiments with microwave instead of thermal energy to avoid the formation of $\mathbf{4 7}$ were unsuccessful. HPLC was not able to properly separate the not-rearranged (45), once-rearranged, twice rearranged (46), and the monosulfur compound (47). Therefore, the procedure developed by Cattaneo was applied for 
6 Protonation of 5,6-Dithia-1,10-phenanthroline, its application as disulfide/dithiol switch, and as ligand for $[2 \mathrm{Fe}-2 \mathrm{~S}]$ clusters

step $I I I-V$. After reduction with $\mathrm{LiAlH}_{4}($ step $I V$ ) the product oxidizes to $\mathbf{4 1}$ when handled under air. It is obtained as a pale yellow oil. Work-up of $\mathbf{4 6}$ under argon atmosphere and with degassed water results in isolation of the new compound $\mathbf{4 1} \mathrm{H}_{2}$. Recrystallization from toluene yields red crystals suitable for X-ray crystallography (Figure 6.5). $41 \mathrm{H}_{2}$ crystallizes in the space group monoclinic $P 2_{l} / c$. The pyridine units are in anti orientation. The zwitterionic form is preferred for the hydrogen bonding between thiols and pyridinicnitrogen atoms. Hydrogen atom positions have been refined freely giving bond distances to the bridging hydrogen of $d(\mathrm{~S} 1 \cdots \mathrm{H} 1)=2.02(2) \AA$ and $d(\mathrm{~N} 1-\mathrm{H} 1)=0.92(2) \AA$, respectively, and an angle $\Varangle(\mathrm{N} 1-\mathrm{H} 1 \cdots \mathrm{S} 1)$ of $1.58(2)^{\circ}$.

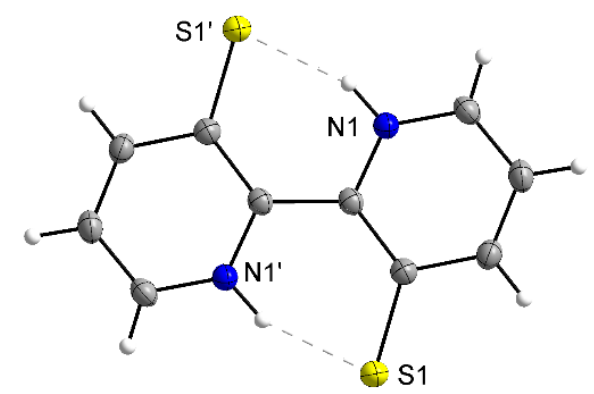

Figure 6.5. Molecular structure of $\mathbf{4 1} \mathrm{H}_{2}$ determined by X-ray crystallography. The thermal displacement ellipsoids are shown at 50\% probability. Selected bond lengths [A] and angles [ $\left.{ }^{\circ}\right]$ : $\mathrm{S}(1)-\mathrm{C}(2) 1.7318(16), \mathrm{N}(1)-\mathrm{C}(5) 1.337(2), \mathrm{N}(1)-$ $\mathrm{C}(1)$ 1.357(2), $\mathrm{C}(5)-\mathrm{N}(1)-\mathrm{C}(1)$ 125.46(15). Hydrogen bonds for $\mathbf{4 0} \mathrm{H}_{2}\left[\AA\right.$ and $\left.{ }^{\circ}\right] \mathrm{N}(1)-\mathrm{H}(1) 0.92(2), \mathrm{S}(1) \cdots \mathrm{H}(1) 2.02(2)$, $\mathrm{N}(1)-\mathrm{H}(1) \cdots \mathrm{S}(1) 1.58(2)$. Symmetry transformation used to generate equivalent atoms: (') $1-x, 1-y, 1-z$.

\subsection{UV-vis titration of $\mathbf{4 1}$ with $\mathrm{PhCOOH}$, TFA and TfOH in MeCN}

Some parts of this chapter have been adapted from a submitted manuscript. ${ }^{223}$

Cattaneo measured UV-vis spectra of pale yellow 41 in buffered, neutral water and reported bands at 270 and $305 \mathrm{~nm}\left(\pi-\pi^{*}\right)$ and a weaker, broad absorption at $380 \mathrm{~nm}\left(\mathrm{n}-\pi^{*}\right)$. He observed that protonation of $\mathbf{4 1}$ causes a bathochromic shift of all bands to 279,322 , and $423 \mathrm{~nm}$ with isosbestic points indicating clean interconversion between $\mathbf{4 1}$ and its protonated form. He derived a $\mathrm{p} K_{\mathrm{a}}$ value of 2.88(1) from $\mathrm{pH}$ dependent $\mathrm{UV}$-vis titrations. The $\mathrm{p} K_{a}$ value of $\mathbf{4 1}$ is substantially lower than that of parent $2,2^{\prime}$-bipyridine $\left(\mathrm{p} K_{\mathrm{a}}=4.45\right)^{228}$ or phenantroline $\left(\mathrm{p} K_{\mathrm{a}}=4.84\right) .{ }^{229} \mathrm{NMR}$ spectroscopy confirmed the bipyridine-N as the protonation site.

Cattaneo conducted his protonation experiments in buffed water. However, a change of the solvent to $\mathrm{MeCN}$ was needed in order to prove that it is appropriate for the $\mathrm{CV}$ experiments presented in chapter 6.4. The band at 270 and $305 \mathrm{~nm}$ of $\mathbf{4 1}$ were badly resolved because 
the window for UV spectra closes around $300 \mathrm{~nm}$ for the solvent $\mathrm{MeCN}$. On grounds of the previous results by Cattaneo, UV-vis titrations were conducted with three different acids, namely, benzoic acid $\left(\mathrm{PhCOOH}, \mathrm{p} K_{\mathrm{a}, \mathrm{MeCN}}=21.51\right),{ }^{230}$ trifluoroacetic acid (TFA, $\left.\mathrm{p} K_{\mathrm{a}, \mathrm{MeCN}}=12.65\right)^{231}$ and trifluoromethanesulfonic acid $\left(\mathrm{TfOH}, \mathrm{p} K_{\mathrm{a}, \mathrm{MeCN}}=2.60\right){ }^{231}$

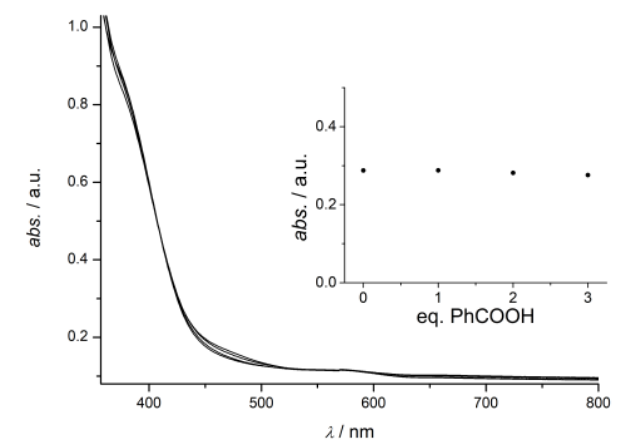

Figure 6.6. Titration of $\mathbf{4 1}$ with benzoic acid $(\mathrm{PhCOOH})$ in $\mathrm{MeCN}$. The insert shows that no change in absorbance is observed at $423 \mathrm{~nm}$.

a)

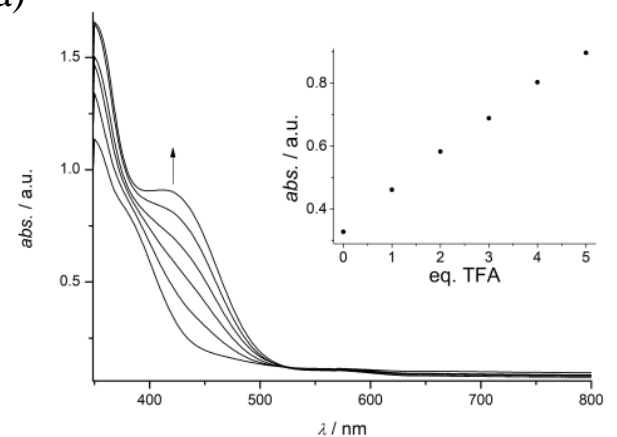

b)

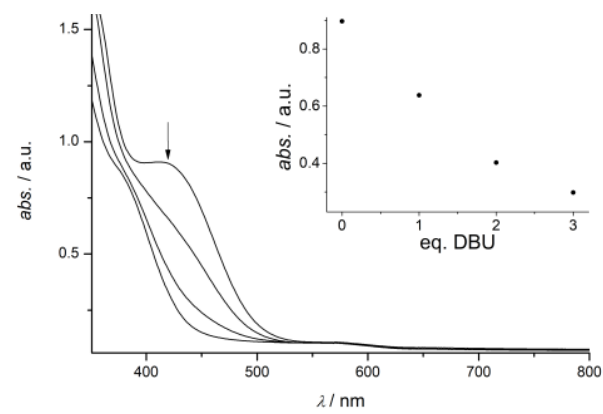

Figure 6.7. a) Titration of $\mathbf{4 1}$ with trifluoroacetic acid (TFA) in MeCN, b) backtitration with 1,8-diazabicyclo(5.4.0)undec7-ene (DBU) in MeCN. Inserts show absorbance vs equivalents of TFA or DBU at $423 \mathrm{~nm}$.

a)

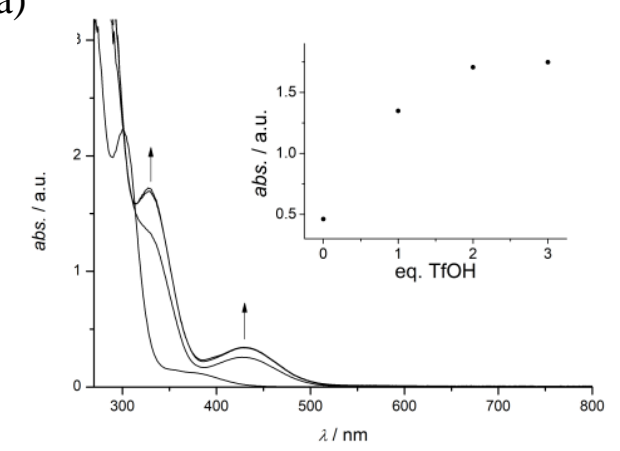

b)

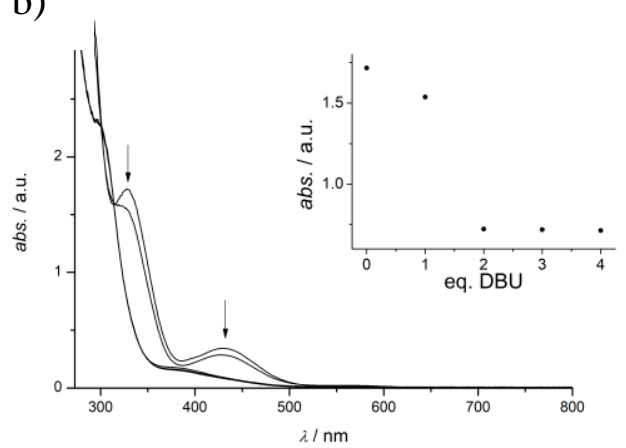

Figure 6.8. a) Titration of $\mathbf{4 1}$ with trifluoromethanesulfonic acid ( $\mathrm{TfOH})$ in $\mathrm{MeCN}$, b) backtitration with 1,8diazabicyclo(5.4.0)undec-7-ene (DBU) in MeCN. Inserts show absorbance vs equivalents of TfOH or DBU at $329 \mathrm{~nm}$. 
6 Protonation of 5,6-Dithia-1,10-phenanthroline, its application as disulfide/dithiol switch, and as ligand for $[2 \mathrm{Fe}-2 \mathrm{~S}]$ clusters

Addition of PhCOOH does not cause a change in the UV-vis spectrum (Figure 6.6) while addition of TFA affects a rise of bands assigned to the protonation product (Figure 6.7, a). Full protonation of $\mathbf{4 1}$ is achieved after addition of 2 equivalents of TfOH (Figure 6.8, a). The same bands are observed as reported for the protonation of $\mathbf{4 1}$ in buffed water by Cattaneo. Backtitration to the original spectrum was possible by addition of DBU (Figure 6.7 and $6.8, b)$.

Based on these observations, $\mathrm{PhCOOH}$ is too weak to protonate $\mathbf{4 1}$ in $\mathrm{MeCN}$, but with TFA the spectrum of the protonated species is replicated. Therefore, the $\mathrm{p} K_{\mathrm{a}}$ for the first protonation of $\mathbf{4 0}$ must be between 21.51 and 12.65 in $\mathrm{MeCN}$. As 2 equivalents of the strong acid $\mathrm{TfOH}$ are needed, it is reasonable to aver that with each equivalent one pyridine$\mathrm{N}$ atom is protonated yielding the proposed structures for the protonated species in Figure 6.9.

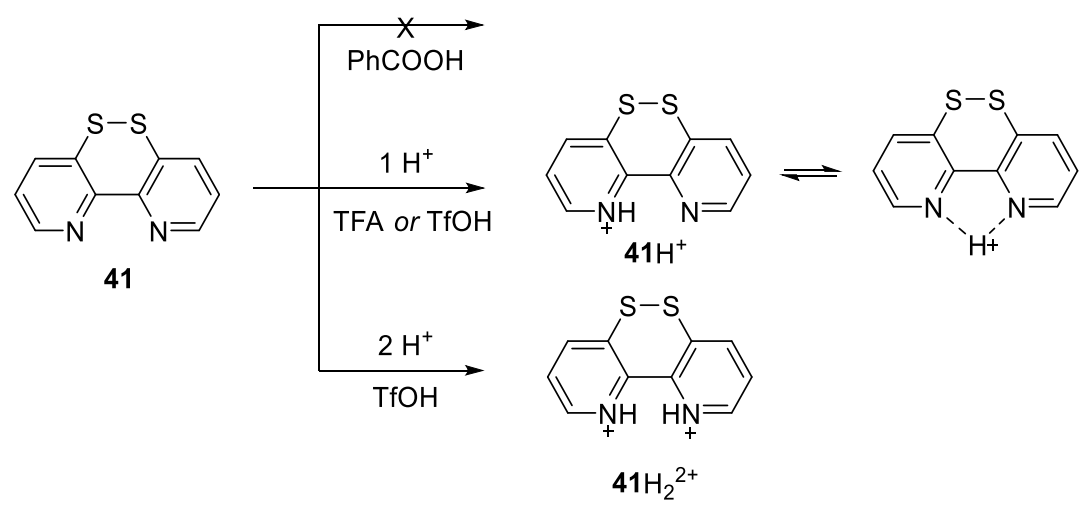

Figure 6.9. Proposed protonation of $\mathbf{4 0}$ with $\mathrm{PhCOOH}$, TFA, and 1 or 2 equivalents of TfOH.

\subsection{S-S bond cleavage mechanism: the disulfide/dithiol switch}

Some parts of this chapter have been adapted from a submitted manuscript. ${ }^{223}$

Cyclic voltammetry and DFT calculations were conducted in order to decipher the mechanism of the reductive S-S bond cleavage of compound 41. The voltammogram of $\mathbf{4 1}$ in $\mathrm{MeCN}\left(0.1 \mathrm{M} \mathrm{Bu}_{4} \mathrm{NPF}_{6}\right)$ exhibits one reduction with a peak potential of $-1.76 \mathrm{~V}$ and a re-oxidation at $-0.74 \mathrm{~V} v s$. ferrocene at a scan rate of $100 \mathrm{mV} \mathrm{s}^{-1}$ (Figure 6.10, a). The absolute value of the peak current $I_{\mathrm{p}, \mathrm{c}}$ of the reduction wave increased linearly with the square root of the scan rate $\left(0.1-10 \mathrm{Vs}^{-1}\right)$, which is characteristic for diffusion controlled processes (Figure 6.10, b). The cathodic and anodic wave are separated by approximately $1000 \mathrm{mV}$. This large separation and the linear shift of the cathodic peak potential $E_{\mathrm{p}, \mathrm{c}}$ per 
$\log (v)$ (Figure 6.10, c) is indicative for either an irreversible electron transfer process or (ir)reversible electron transfer processes followed by a fast chemical reaction. The second would be the case for reductive $\mathrm{S}-\mathrm{S}$ bond cleavage.

a)

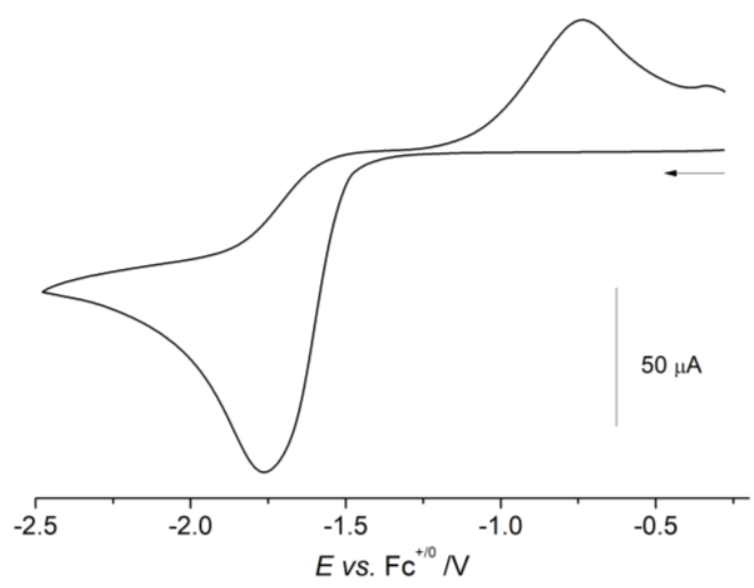

b)

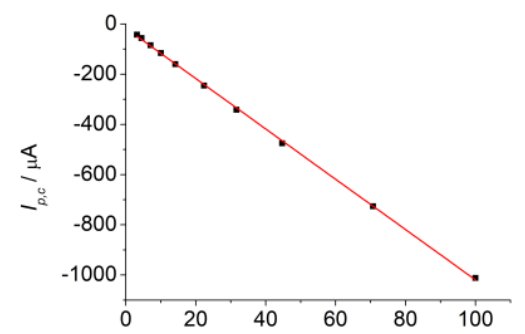

c)

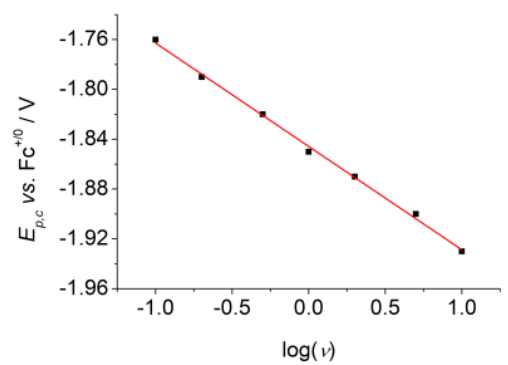

Figure 6.10. a) Cyclic voltammogram of $\mathbf{4 1}$ in $\mathrm{MeCN}_{\mathrm{N}}$ at $\mathrm{rt}\left(0.1 \mathrm{M} \mathrm{Bu} 4 \mathrm{NPF}_{6}, c(\mathbf{4 1})=3.1 \mathrm{mM}\right), v=100 \mathrm{mVs}^{-1}$, b) peak current $\left.I_{\mathrm{p}, \mathrm{c}} v s . v^{1 / 2}, \mathrm{c}\right)$ cathodic peak potential $E_{\mathrm{p}, \mathrm{c}} v s . \log (v)$.

Similar voltammograms have been reported for compounds $\mathbf{4 8}-\mathbf{5 0}$ (Figure 6.11). The S-S bond cleavage mechanism has been thoroughly investigated for 8-diiododibenzo[1,2]dithiine (48), ${ }^{232}$ 4,4'-bipyridyl-3,3'-disulfid (49), ${ }^{233}$ and disulfide-strapped $\mathrm{N}, \mathrm{N}$-alkylated bipyridinium cation (viologen, 50). ${ }^{234}$ The respective authors conclude a EEC mechanism for 48 and EE mechanism for 49 and 50. In other accounts, a ECE mechanism is described for $\mathrm{S}-\mathrm{S}$ bond cleavage in diaryl disulphides. ${ }^{235}$

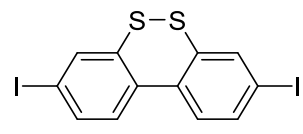

48

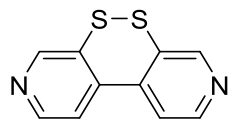

49

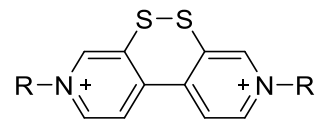

50

Figure 6.11. Well-investigated molecules with disulfide/dithiol switch. ${ }^{232-234}$

In order to elucidate the details of the reduction mechanism of 41, DFT studies were performed by Dr. Dechert in our group; computational details can be found in the respective publication. ${ }^{223}$ It was found that the LUMO of $\mathbf{4 1}$ has antibonding character with respect to the S-S bond provoking a significant elongation of the S-S bond from 2.076 to $2.747 \AA$ upon the first reduction (Figure 6.12). The SOMO of 41- has $\sigma^{*} \mathrm{~S}-\mathrm{S}$ antibonding character (Figure $6.12, \mathrm{~b}$ ). Further reduction of $\mathbf{4 1}^{-}$results in twisting of the pyridine rings and $\mathrm{S}-\mathrm{S}$ 
6 Protonation of 5,6-Dithia-1,10-phenanthroline, its application as disulfide/dithiol switch, and as ligand for $[2 \mathrm{Fe}-2 \mathrm{~S}]$ clusters

bond cleavage according to DFT calculations. The two-electron reduced product, $\mathbf{4 1}^{\mathbf{2}}$, exhibits a $\mathrm{C}-\mathrm{S} \cdots \mathrm{S}-\mathrm{C}$ torsion of $\varphi=94^{\circ}$ and a long $\mathrm{S} \cdots \mathrm{S}$ separation of $4.398 \AA$, thus any bonding interactions are no longer present (Figure 6.12, c). The close to orthogonal orientation of the pyridine rings in $\mathbf{4 1}^{\mathbf{2}-}$ results as a compromise between electrostatic repulsion of the two thiolates and repulsive interactions between the thiolate and pyridine$\mathrm{N}$ lone pairs. In conclusion, the DFT calculations suggest an EEC mechanism for the reduction of 41. After the first reduction the $\mathrm{S}-\mathrm{S}$ bond is elongated, but not cleaved. $\mathrm{S}-\mathrm{S}$ bond breakage occurs only after a second electron is added.

a)

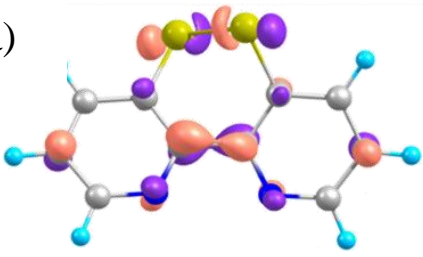

b)

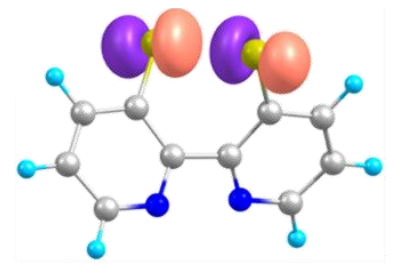

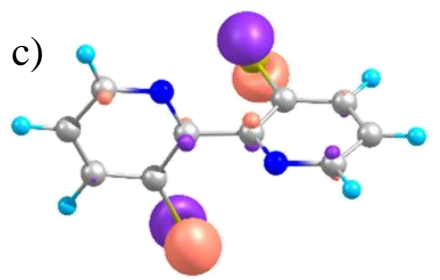

Figure 6.12. a) LUMO of $\mathbf{4 1}$ (contour value: 0.08 ), torsion angle $\Varangle(\mathrm{C}-\mathrm{S}-\mathrm{S}-\mathrm{C})=49.1^{\circ}, d(\mathrm{~S}-\mathrm{S})=2.076 \AA$; b) SOMO of 41- (contour value: 0.08 ), c) HOMO of $\mathbf{4 1}^{2-}$ (at global minimum with $\varphi=94.1^{\circ}$; contour value: 0.08 ), torsion angle $\Varangle(\mathrm{C}-\mathrm{S} \cdots \mathrm{S}-\mathrm{C})=94^{\circ}, d(\mathrm{~S} \cdots \mathrm{S})=4.398 \AA$.

The experimental CV data, which were recorded as part of this thesis, were then simulated by Prof. Dr. Siewert with the software DigiElch to experimentally substantiate the proposed EEC mechanism. Simulations were carried out for sweep rates of 0.1 to $10 \mathrm{Vs}^{-1}$, and the entire curves were simulated (Figure 6.13). Good simulations could be achieved using reasonable values for the various parameters over the entire sweep rate range. The initial reduction of $\mathbf{4 1}$ to give $\mathbf{4 1}^{-}$exhibits a potential of $-1.20 \mathrm{~V}$ at a rather small electron transfer rate $k_{\mathrm{s}, 1}$ of $1 \times 10^{-5} \mathrm{~cm} \mathrm{~s}^{-1}$, likely due to the significant structural change accompanying the reduction. The second reduction to give $\mathbf{4 1}^{\mathbf{2}-}$ occurs at a lightly lower potential of $-1.38 \mathrm{~V}$ $\left(k_{\mathrm{s}, 2}=1 \times 10^{-4} \mathrm{~cm} \mathrm{~s}^{-1}\right)$ and is followed by a fast chemical reaction with a rate constant $k_{\mathrm{c}, 1} \geq$ $50 \mathrm{~s}^{-1}$ leading to $\mathbf{4 1}^{\mathbf{2}-}$ (open). The second reduction hence occurs at a more negative potential than the first reduction, in contrast to what has been proposed previously for related dithiins 48 and 49. Fast chemical reaction upon twofold reduction is consistent with $\mathrm{S}-\mathrm{S}$ bond breaking and twisting of the pyridine units against each other. 
The anodic feature can be modelled by re-oxidation of $\mathbf{4 1}^{-}$(open) at a potential of $E_{3}$ of $-1.15 \mathrm{~V}\left(k_{\mathrm{s}, 3}=1 \times 10^{-4} \mathrm{~cm}^{-1}\right)$ and subsequent very fast chemical reaction forming $\mathbf{4 1}^{-}\left(k_{\mathrm{c}, 2}\right.$ $\left.\geq 100 \mathrm{~s}^{-1}\right)$. A further unproductive pseudo first order chemical side reaction has to be considered to successfully model the data $\left(k_{\mathrm{c}, 3}\right.$ in Figure 6.13$)$, which likely reflects the partial protonation of $\mathbf{4 1}^{\mathbf{2}-}$ (open) forming $\mathbf{4 1} \mathrm{H}_{2}$ due to traces of water in the solvent $\mathrm{MeCN}$.

a)
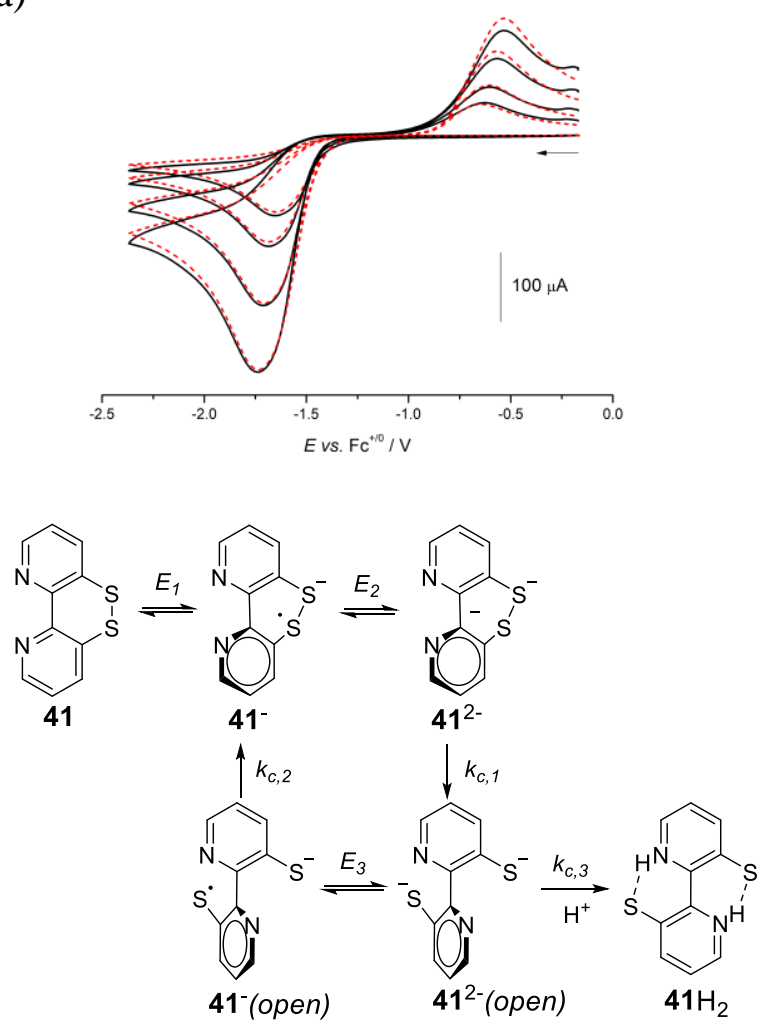

b)

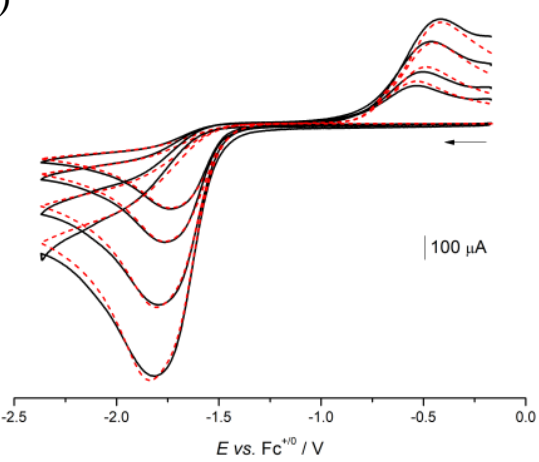

Table 6.1. Fit parameters for simulation.

\begin{tabular}{|l||c|c|c|}
\hline & $\mathrm{x}=1$ & $\mathrm{x}=2$ & $\mathrm{x}=3$ \\
\hline$E_{\mathrm{x}} / \mathrm{V}$ & -1.20 & -1.38 & -1.15 \\
\hline$\alpha_{\mathrm{x}}$ & 0.4 & 0.3 & 0.7 \\
\hline$k_{\mathrm{s}, \mathrm{x}} / \mathrm{cm} \mathrm{s}^{-1}$ & $1 \times 10^{-5}$ & $1 \times 10^{-4}$ & $1 \times 10^{-4}$ \\
\hline$k_{\mathrm{c}, \mathrm{x}} / \mathrm{s}^{-1}$ & $\geq 50$ & $\geq 100$ & 0.02 \\
\hline
\end{tabular}

Figure 6.13. Cyclic voltammograms of $0.31 \mathrm{~mm} 41$ in $\mathrm{MeCN}\left(0.1 \mathrm{M} \mathrm{Bu} 4 \mathrm{NPF}_{6}\right)$ at rt with the scan rates a) $100-1000 \mathrm{mV} / \mathrm{s}$ and b) 1000-10000 mV/s. Black lines correspond to experimental data and red dashed lines to simulation according to the mechanism depicted for reductive $\mathrm{S}-\mathrm{S}$ bond cleavage reaction of $\mathbf{4 1}$ and re-oxidation.

Water strongly influences the redox properties of $\mathbf{4 1}$ as revealed by electrochemical measurements conducted in the presence of water (Figure 6.14). Upon adding 10 eq. of water, the cathodic peak gets much sharper and shifts anodically. This is even more pronounced in the presence of 100 eq. of water. The peak current $I_{\mathrm{p}, \mathrm{c}}$ of the reduction wave increased linearly with the square root of the scan rate $\left(0.1-10 \mathrm{Vs}^{-1}\right)$ indicating a diffusion controlled process (Figure 8.9, a in appendix). The cathodic and anodic waves are largely separated while a linear shift of $E_{\mathrm{p}, \mathrm{c}}$ with $\log (v)$ is still observed, which points to a fast chemical reaction following the reduction (Figure 8.9, $\mathrm{b}$ in the appendix). Initial inspection of the CV data in the presence of 10 and 100 eq. of water suggested an ECE mechanism, the chemical reaction being first order with regard to water. The steep slope of the reduction 
6 Protonation of 5,6-Dithia-1,10-phenanthroline, its application as disulfide/dithiol switch, and as ligand for $[2 \mathrm{Fe}-2 \mathrm{~S}]$ clusters

wave indicates potential inversion of the first and second reduction process. Protonation and bond breaking following the initial reduction was previously reported for $\mathbf{4 8}$ and seemed also reasonable for $\mathbf{4 1}$.

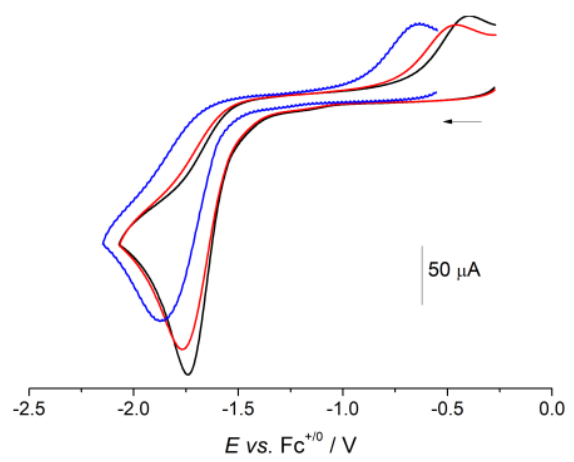

Figure 6.14. Cyclic voltammograms of $\mathbf{4 1}$ (blue) with 10 eq. water (red) and 100 eq. water (black) in MeCN $\left(0.1 \mathrm{M} \mathrm{Bu}_{4} \mathrm{NPF}_{6}, 100 \mathrm{mV} \mathrm{s}^{-1}, \mathrm{rt}\right)$.

However, $\mathbf{4 1}^{-}$possesses a basic $\mathrm{N}$ atom of the pyridine unit in contrast to $\mathbf{4 8}$ which naturally impacts the reaction with water greatly. DFT studies of the protonated reduced form $\mathbf{4 1 \mathrm { H } ^ { - }}$ revealed a global minimum energy structure in the closed form. The $\mathrm{S}-\mathrm{S}$ distance of ground state $41 \mathrm{H}^{-}$is much shorter than in $\mathbf{4 1}^{-}(d(\mathrm{~S}-\mathrm{S})=2.11$ vs. $2.75 \AA)$ and similar to the $\mathrm{S}-\mathrm{S}$ bond length in $\mathbf{4 1}$, and the tilting of the two pyridine rings is less pronounced (C-S-S-C torsion angle $\varphi=27.0^{\circ}$ ). In fact, the SOMO of $41 \mathrm{H}^{-}$has no $\sigma^{*} \mathrm{~S}-\mathrm{S}$ antibonding character as in $\mathbf{4 1}^{-}$, but it of $\pi^{*}$ orbital type and is localized at the bipyridine unit (Figure 6.15 ). Protonation hence changes drastically the electronic structure of the radical $\mathbf{4 1}^{-}$, but does not induce $\mathrm{S}-\mathrm{S}$ bond rupture.

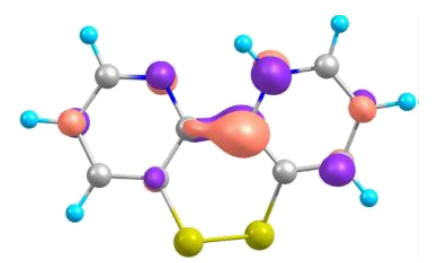

Figure 6.15. SOMO of protonated $\mathbf{4 0 \mathrm { H } ^ { - }}$ (contour value: 0.08 ).

Since protonation of $\mathbf{4 1}^{-}$does not result in any bond cleavage, the CV data of $\mathbf{4 1}$ in the presence of water was simulated by adding to the original model an equilibrium reaction involving $\mathbf{4 1}^{-}$and water, as depicted in Figure 6.16. 
a)

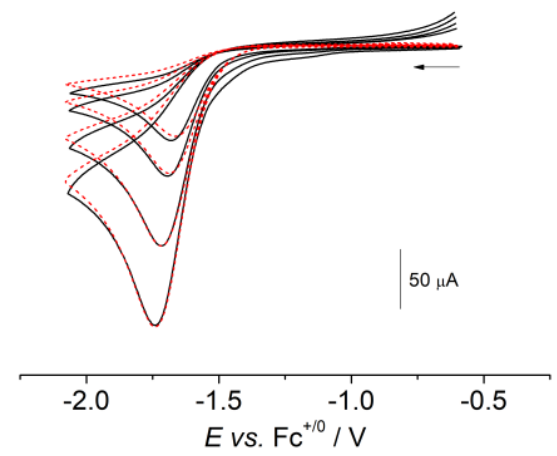

b)

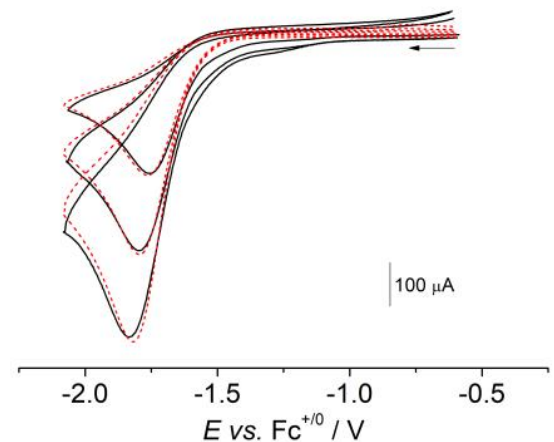

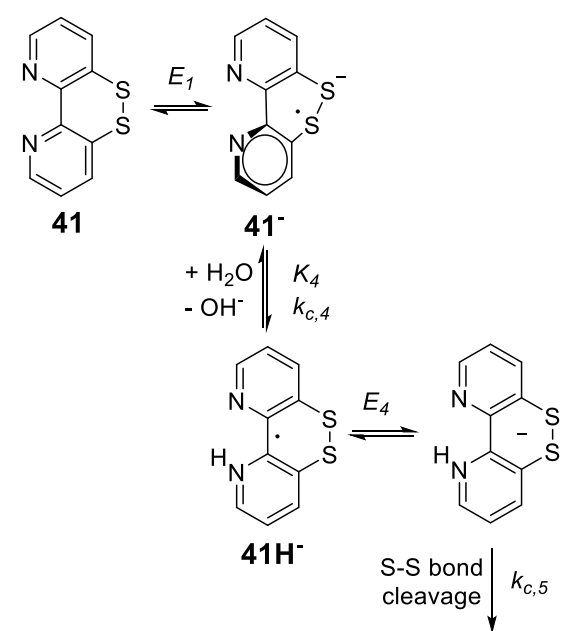

Table 6.2. Fit parameters for simulation.

\begin{tabular}{|l||c|c|c|c|c|}
\hline & $\mathrm{x}=1$ & $\mathrm{x}=2$ & $\mathrm{x}=3$ & $\mathrm{x}=4$ & $\mathrm{x}=5$ \\
\hline$E_{\mathrm{x}} / \mathrm{V}$ & -1.20 & -1.38 & -1.15 & $\geq-1.13$ & - \\
\hline$\alpha_{\mathrm{x}}$ & 0.4 & 0.3 & 0.7 & 0.5 & - \\
\hline$k_{\mathrm{s}, \mathrm{x}} / \mathrm{cm} \mathrm{s}^{-1}$ & $1 \times 10^{-5}$ & $1 \times 10^{-4}$ & $1 \times 10^{-4}$ & $1 \times 10^{-4}$ & - \\
\hline$k_{\mathrm{c}, \mathrm{x}} / \mathrm{s}^{-1}$ & $\geq 50$ & $\geq 100$ & 0.02 & $3000-50000 \mathrm{M}^{-1}$ & $50 \mathrm{M}^{-1}$ \\
\hline$K_{\mathrm{x}}$ & - & - & - & $0.001-$ infinite & - \\
\hline
\end{tabular}

Figure 6.16. Cyclic voltammograms of $1.8 \mathrm{mM} 41$ and $0.21 \mathrm{M}$ water in $\mathrm{MeCN}\left(0.1 \mathrm{M} \mathrm{Bu} 4 \mathrm{NPF}_{6}\right)$ at rt with scan rates of a) $100-1000 \mathrm{mV}$ and b) $2000-10000 \mathrm{mV}$. Black lines correspond to experimental data and red dashed lines to simulation according to mechanism depicted above with the parameter from Table 6.2.

By simulating the data, it became apparent that the equilibrium constant $K_{4}$ and the reaction rate $k_{c, 4}$ are interdependent parameters, i. e. a small equilibrium constant $K_{4}$ can be compensated by a faster reaction rate $k_{\mathrm{c}, 4}$ and vice versa. Therefore, only ranges of the two values are given. Reasonable fits could be obtained by using rather large second order reaction rate constants $\left(k_{\mathrm{c}, 4} \geq 3000 \mathrm{M}^{-1} \mathrm{~s}^{-1}\right)$ and equilibrium constants between 0.001 and infinite, the latter describing an irreversible reaction. Interestingly, the generated $\mathbf{4 1} \mathrm{H}^{-}$ species exhibits a further reduction potential of $\geq-1.13 \mathrm{~V}$, hence it is easier to reduce than 41 and non-protonated $41^{-}$. The potential of $41 \mathrm{H}^{-}$is shifted by $\geq+250 \mathrm{mV}$ with regard to $\mathbf{4 1}^{-}$due to the charge compensation by protonation. Subsequently, the $\mathrm{S}-\mathrm{S}$ bond in $\mathbf{4 1 H}^{\mathbf{2}}$ breaks with a rate constant $k_{\mathrm{c}, 5} \geq 50 \mathrm{~s}^{-1}$.

In conclusion, 41 exhibits two chemically reversible reduction processes. The potential of the second reduction event can be tuned via protonation of $\mathbf{4 1}^{-}$by a weak acid such as 
6 Protonation of 5,6-Dithia-1,10-phenanthroline, its application as disulfide/dithiol switch, and as ligand for $[2 \mathrm{Fe}-2 \mathrm{~S}]$ clusters

water. Protonation triggers potential inversion which means that the second reduction becomes easier than the first one.

\subsection{Preliminary application as a chelate ligand for [2Fe-2S] clusters}

46 was reacted with of $\mathrm{KH}$ to yield $\mathbf{4 1} \mathrm{K}_{2}$ in THF. The solution was cooled to $-35^{\circ} \mathrm{C}$ and slowly added to $\left(\mathrm{Me}_{3} \mathrm{PhN}\right)_{2} 51$ in $\mathrm{MeCN}$. The reaction mixture was stirred for 3 hours and slowly warmed to room temperature. Removal of the solvent under reduced pressure afforded $\left(\mathrm{Me}_{3} \mathrm{PhN}\right)_{2} \mathbf{4 2}$ (Figure 6.17). Unfortuneately, attemps to obtain crystals suitable for $\mathrm{X}$-ray cristallography failed. Therefore, characterization of $\left(\mathrm{Me}_{3} \mathrm{PhN}\right)_{2} \mathbf{4 2}$ was pursuited with polycrystalline material.
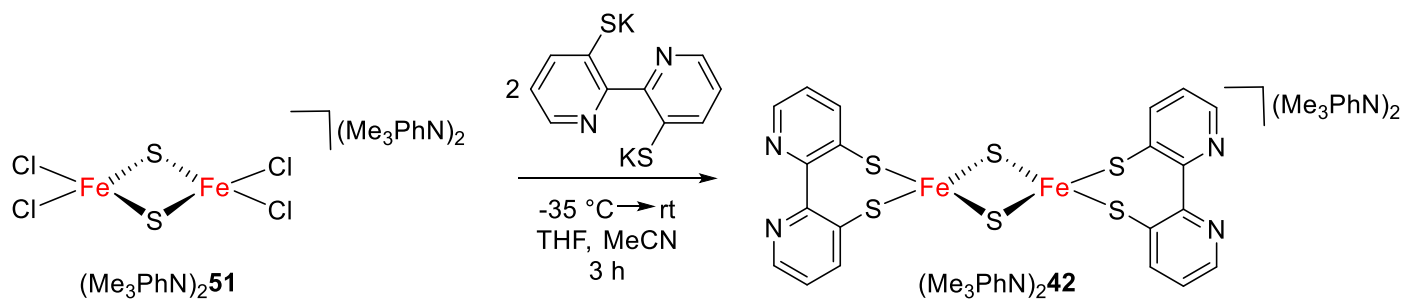

Figure 6.17. Synthesis of $\left(\mathrm{Me}_{3} \mathrm{PhN}\right)_{2} \mathbf{4 2}$.

First evidence on the formation of $\left(\mathrm{Me}_{3} \mathrm{PhN}\right)_{2} \mathbf{4 2}$ is found in ESI(-)MS (Figure 6.18, a) and ESI(+)MS (Figure 8.10, in appendix). The main peaks at high $\mathrm{m} / \mathrm{z}$ can be assigned to adducts of $\mathbf{4 2}^{2-}$. A UV-vis spectrum of a recrystallized sample was recorded in DMF (Figure $6.18, \mathrm{~b}$ ). The bands that are detected compare well to related thiophenyl clusters $\mathbf{5 2}^{\mathbf{2}-} \mathbf{- 5 4} \mathbf{2}^{\mathbf{2}}$ (Figure 6.19, Table 6.3); only the extinction coefficient is smaller.
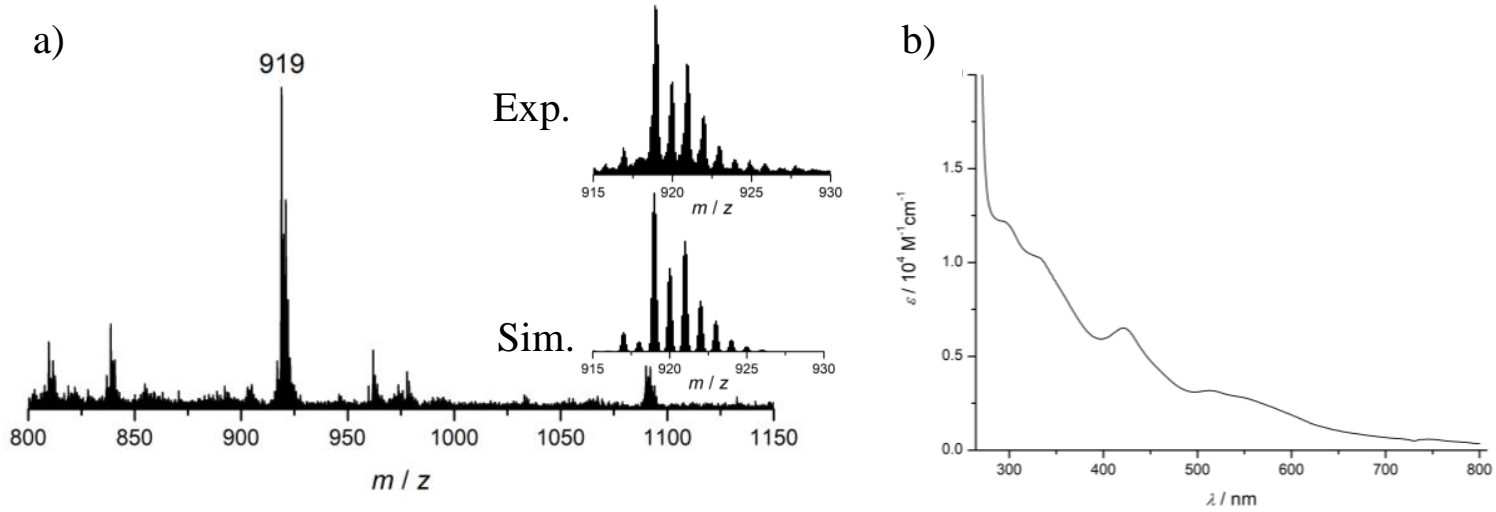

Figure 6.18. a) $m / z$ 800-1150 range of ESI(-)MS spectrum of cluster $\left(\mathrm{Me}_{3} \mathrm{PhN}\right)_{2} 42$. The inserted graphs depict an excerpt from the spectrum and the simulation with $\left[\mathbf{4 2}+2\left(\mathrm{Me}_{3} \mathrm{PhN}\right)+\mathrm{Cl}\right]^{-}$. b) $\mathrm{UV}$-vis spectrum of cluster $\left(\mathrm{Me}_{3} \mathrm{PhN}\right)_{2} \mathbf{4 2}$ in $\mathrm{DMF}$. 


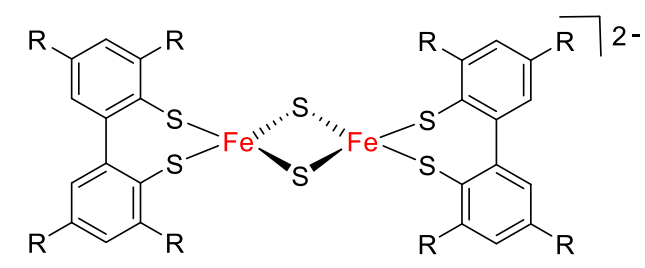

Figure 6.19.[2Fe-2S] clusters with 2,2'-dithiobiphenyl chelate ligands with three different back-bone substituents $(\mathrm{R}=$ $\mathrm{Cl}\left(\mathbf{5 2}^{2-}\right), \mathrm{H}\left(\mathbf{5 3}^{2-}\right),{ }^{\mathrm{H}} \mathrm{Bu}\left(\mathbf{5 4}^{2-}\right)$.

Table 6.3. Electronic absorption data of $[2 \mathrm{Fe}-2 \mathrm{~S}]$ clusters with dithiobipyridin and dithiobiphenyl ligation.

\begin{tabular}{l|l|l} 
& $\lambda[\mathrm{nm}]\left(\varepsilon\left[\mathrm{M}^{-1} \mathrm{~cm}^{-1}\right]\right)$ & ref. \\
\hline \hline $\mathbf{4 2}^{\mathbf{2}}$ & $291(11700), 339(9500), 421(6250), 512(3050) 559(2500)$ & this work \\
\hline $\mathbf{5 2}^{\mathbf{2}}$ & $260(44000), 350(37000), 424(30000), 523(12500)$ & 236 \\
\hline $\mathbf{5 3}^{2-}$ & $257(47500), 336(33400), 425(29500), 520(13250), 547(13500)$ & 236 \\
\hline $\mathbf{5 4}^{\mathbf{2}}$ & $260(45000), 345(26500), 383(23600), 443(22000), 550(12000)$ & 236
\end{tabular}

These preliminary results attest that $\mathbf{4 1}$ is suitable as ligand for $\mathrm{Fe}-\mathrm{S}$ clusters. It is impossible to infer from ESI-MS or UV-vis spectroscopy whether the iron ions are coordinated by the pyridine-N atoms or the thiolate. However, the proposed structure $\left(\mathrm{Me}_{3} \mathrm{PhN}\right)_{2} \mathbf{4 2}$ seems most probable given the high preference for sulfur-ligands by $\mathrm{Fe}-\mathrm{S}$ clusters.

\subsection{Conclusion and Outlook}

The synthesis of $\mathbf{4 1}$ was optimized prior to investigation of its properties and reactivity. The molecular structure of $\mathbf{4 1} \mathrm{H}_{2}$ in crystal was elucidated by X-ray crystallography. It was shown that the protonation of $\mathbf{4 1}$ proceeds in $\mathrm{MeCN}$ in the same manner as in water. Full protonation of the pyridine-N atoms is only achieved by addition of the strong acid $\mathrm{TfOH}$.

The disulfide/dithiole switch of $\mathbf{4 1}$ was studied thoroughly with cyclic voltammetry and DFT calculations. An EEC mechanism was found for the reductive $S-S$ bond cleavage. The mechanism changes to ECEC in the presence of a weak acid like water: After the first reduction a protonation takes place followed by the second reduction. The breakage of the $\mathrm{S}-\mathrm{S}$ bond is the final step. 
6 Protonation of 5,6-Dithia-1,10-phenanthroline, its application as disulfide/dithiol switch, and as ligand for $[2 \mathrm{Fe}-2 \mathrm{~S}]$ clusters

Finally, preliminary results on the formation of [2Fe-2S] complexes with $\mathbf{4 1}$ as ligand open the field for further investigations towards a directly coupled $\mathrm{Ru}(\mathrm{bpy})_{3}-[2 \mathrm{Fe}-2 \mathrm{~S}]$ system 40 (Figure 6.1, a). 


\section{Experimental Section}

\subsection{Author contributions}

Prof. Dr. Inke Siewert simulated the electrochemical data and Dr. Sebastian Dechert carried out the theoretical calculations in chapter 6.4. Dr. Sebastian Dechert and Dr. Nicole Kindermann performed X-ray analysis of all compounds. Dr. Serhiy Demeschko measured and fitted the SQUID data. Dr. Marie Bergner measured and simulated all EPR spectra.

\subsection{Materials and methods}

All manipulations of air- and moisture-sensitive materials were carried out under an anaerobic and anhydrous atmosphere of dry dinitrogen or argon gas by standard Schlenk techniques or in a MBraun glovebox. Glassware was dried prior to use at $120^{\circ} \mathrm{C}$ overnight in a heating oven. Diethyl ether and pentane were dried over sodium benzophenone ketyl, THF over $\mathrm{Na} / \mathrm{K}$ alloy and hexane over potassium benzophenone ketyl, $\mathrm{MeCN}$ over $\mathrm{CaH}_{2}$, acetone over $\mathrm{P}_{2} \mathrm{O}_{5} \mathrm{MeOH}$ over $\mathrm{Mg}$, and distilled prior to use. Deuterated solvents were dried and distilled according to the undeuterated analogues. For reactions involving NO, care was taken to prevent light exposure by covering reaction glassware in aluminum foil or by performing experiments in a darkened glovebox. Nitric oxide (Linde, 2.5) was purified by passing the $\mathrm{NO}$ gas stream through an Ascarite column $(\mathrm{NaOH}$ fused on silica gel) and a cooling trap with glass spikes at $-78^{\circ} \mathrm{C}$. If not mentioned otherwise all chemicals were acquired from commercial sources (Acros, Sigma Aldrich, abcr, Deutero, Merck) and used without further purification.

${ }^{1}$ H NMR spectra were recorded on an Avance III 300, HD 400 or HD 500 spectrometer from Bruker. Chemical shifts are reported in ppm relative to residual proton signals of $\mathrm{CDCl}_{3}$ (7.26 ppm for ${ }^{1} \mathrm{H}$ NMR experiments, $77.2 \mathrm{ppm}$ for ${ }^{13} \mathrm{C}$ NMR experiments), MeCN$\mathrm{d}_{3}$ (1.94 ppm for ${ }^{1} \mathrm{H}$ NMR experiments, $118.3 \mathrm{ppm}$ for ${ }^{13} \mathrm{C}$ NMR experiments) and DMF$\mathrm{d}_{7}$ (8.03 ppm for ${ }^{1} \mathrm{H}$ NMR experiments) at $298 \mathrm{~K}$ unless stated otherwise. ${ }^{237}$ The following abbreviations were used for the multiplicity of the NMR signals: $s$ (singlet), $d$ (doublet), $t$ (triplet), q (quartet), m (multiplet). 
Elemental analyses were submitted to the analytical laboratory of the department of inorganic chemistry at the Georg-August-Universität Göttingen and performed on an Elementar Vario EL III.

UV-vis spectra were recorded with a Cary5000 Bio Spectrophotometer, using Schlenk quartz cuvettes. Spectra were analyzed by Cary Win UV software.

IR spectra were measured on an Agilent Technologies Cary 630 FTIR. Intensities of the observed bands in the spectra are abbreviated as follows: s (strong), m (medium), w (weak).

ESI mass spectra were measured on a Thermo Finnigan Trace LCQ spectrometer.

Mössbauer spectra were recorded with a ${ }^{57} \mathrm{Co}$ source in a $\mathrm{Rh}$ matrix using an alternating constant acceleration Wissel Mössbauer spectrometer operated in the transmission mode and equipped with a Janis closed-cycle helium cryostat. Isomer shifts are given relative to iron metal at ambient temperature. Simulation of the experimental data was performed with the Mfit program using Lorentzian line doublets: E. Bill, Max-Planck Institute for Chemical Energy Conversion, Mülheim/Ruhr, Germany.

EPR spectra were measured with a Bruker E500 ELEXSYS X-band spectrometer equipped with a standard cavity (ER4102ST, $9.45 \mathrm{GHz}$ ). The sample temperature was maintained constant with an Oxford instrument Helium flow cryostat (ESP910) and an Oxford temperature controller (ITC-4). The microwave frequency was measured with the built-in frequency counter and the magnetic field was calibrated by using a NMR field probe (Bruker ER035M). The spectra were simulated with easy spin.

Cyclic voltammetry experiments were carried out in $\mathrm{CH}_{3} \mathrm{CN}$ with a Gamry Reference 600 . A silver wire as (pseudo)reference electrode was used with ferrocene as internal standard, a glassy carbon disk electrode as working electrode (IJ Cambria, $A=0.707 \mathrm{~cm}^{2}$ ), a Pt wire as auxiliary electrode, and $0.1 \mathrm{M}^{n} \mathrm{Bu}_{4} \mathrm{NPF}_{6}$ as supporting electrolyte. All electrochemical measurements were conducted in a glove box, those in the presence of water in a homemade tight $\mathrm{CV}$ cell. $\mathrm{i} R$ compensation was applied by the positive feedback method, which is implemented in the PHE200 software of Gamry. CV data was simulated with DigiElch 8 FD purchased from Gamry.

X-ray data for all compounds were collected on a STOE IPDS II diffractometer (graphite monochromated Mo-K $\alpha$ radiation, $\lambda=0.71073 \AA$ ) by use of $w$ scans at $133 \mathrm{~K}$. The structures were solved by direct methods with SHELXS and refined on $F^{2}$ using all 
reflections with SHELXL. ${ }^{238}$ Most non-hydrogen atoms were refined anisotropically. Hydrogen atoms were placed in calculated positions and assigned to an isotropic displacement parameter of $1.2 / 1.5 U_{\text {eq }}(\mathrm{C})$. Face-indexed absorption corrections were performed numerically with the program X-RED. ${ }^{239}$

\subsection{Synthesis}

\subsubsection{Fe-S clusters}

29-2 $\mathbf{2 9}^{3-}, \mathbf{2 9} \mathrm{H}_{2}, \mathbf{3 0}^{2-}, \mathbf{3 0}{ }^{3-}, \mathbf{3 0 \mathrm { H } _ { 2 }}$ and $\left(\mathrm{Et}_{4} \mathrm{~N}\right)\left[\mathrm{FeCl}_{2}(\mathrm{NO})_{2}\right]$ were prepared according to reported methods. ${ }^{90,163,168}$ The synthesis of $\left(\mathrm{Et}_{4} \mathrm{~N}\right)_{2} \mathbf{3 8}$ is already published, but the authors followed a different protocol, namely, ligand substitution reaction of $\left[\mathrm{Fe}_{4} \mathrm{~S}_{4}\left(\mathrm{~S}{ }^{\text {tert }} \mathrm{Bu}\right)_{4}\right]^{2-}{ }^{2.95}$

\section{Bis(tetraethylammonium)-tetrakis[(2-aminothiophenolato $)\left(\mu^{3}\right.$-sulfido)-}

\section{ferrate(II,III)] [(Et 4 N) $\left.)_{2} 38\right]$ and Bis(trimethylphenylammonium) tetrakis[(2-amino- thiophenolato $\left.)\left(\mu^{3} \text {-sulfido)-ferrate(II,III)] [( } \mathrm{Me}_{3} \mathrm{PhN}\right)_{2} 38\right]$}

Sodium methoxide $(0.25 \mathrm{~g}, 4.50 \mathrm{mmol})$ and 2-aminothiophenol $(0.48 \mathrm{~mL}, 4.50 \mathrm{mmol})$ were mixed in $\mathrm{MeOH}(10 \mathrm{~mL})$. Iron(III)chloride $(0.244 \mathrm{~g}, 1.50 \mathrm{mmol})$ in $\mathrm{MeOH}(6 \mathrm{~mL})$ was added dropwise to the solution which turned into a black suspension. Dilithiumsulfide $(0.070 \mathrm{~g}, 1.5 \mathrm{mmol})$ was added in one portion and the suspension was stirred overnight.

The halide salt of the counterion in $\mathrm{MeOH}(5 \mathrm{~mL})$ was added: trimethylphenylammonium chloride $(0.216 \mathrm{~g}, 1.25 \mathrm{mmol})$ or tetraethylammonium chloride $(0.208 \mathrm{~g}, 1.25 \mathrm{mmol})$, respectively. The black precipitate was filtered off and washed with $\mathrm{MeOH}(3 \times 10 \mathrm{~mL})$. The product was extracted with $\mathrm{MeCN}(5 \times 5 \mathrm{~mL})$. Crystals suitable for X-ray crystallography were obtained from slow diffusion of diethyl ether into a $\mathrm{MeCN}$ solution of the product. The yield was not determined.

Analytical data of $\left(\mathrm{Et}_{4} \mathrm{~N}\right)_{2} \mathbf{3 8}$ :

${ }^{1} \mathbf{H}$ NMR (400 MHz, MeCN-d $\left.6,298 \mathrm{~K}\right): \delta[\mathrm{ppm}]=1.18\left(\mathrm{sbr}_{2}, 24 \mathrm{H}, 8 \mathrm{CH}_{3}\right), 3.12(\mathrm{sbr}, 16 \mathrm{H}$, $\left.8 \mathrm{CH}_{2}\right), 4.59\left(\mathrm{sbr}, 8 \mathrm{H}, \mathrm{NH}_{2}\right), 5.50(\mathrm{sbr}, 4 \mathrm{H}, p-\mathrm{H}), 6.10(\mathrm{sbr}, 4 \mathrm{H}, o-\mathrm{H}), 7.63(\mathrm{sbr}, 4 \mathrm{H}, m-\mathrm{H})$, $7.75(\mathrm{sbr}, 4 \mathrm{H}, m-\mathrm{H}) . \mathbf{U V}$-vis $(\mathrm{MeCN}): \lambda[\mathrm{nm}]\left(\varepsilon_{\text {rel }}\left[\mathrm{M}^{-1} \mathrm{~cm}^{-1}\right]\right)=484(7700), 350(\mathrm{sh}), 303$ (14000). EA calculated (\%) for $\mathrm{C}_{40} \mathrm{H}_{64} \mathrm{Fe}_{4} \mathrm{~N}_{6} \mathrm{~S}_{8}$ (no solvent molecule in crystal structure): C 43.33, H 5.82, N 7.58, S 23.13; found: C 43.06, H 5.72, N 7.47, S 22.77. 
Analytical data of $\left(\mathrm{Me}_{3} \mathrm{PhN}\right)_{2} \mathbf{3 8}$ :

${ }^{1}$ H NMR (500 MHz, MeCN-d $): \delta[p p m]=3.46\left(\mathrm{sbr}, 18 \mathrm{H}, 6 \mathrm{CH}_{3}\right), 4.62\left(\mathrm{sbr}, 8 \mathrm{H}, \mathrm{NH}_{2}\right)$, 5.65 ( $\left.\mathrm{sbr}_{\mathrm{br}}, 4 \mathrm{H}, \mathrm{ar}-\mathrm{H}\right), 6.18\left(\mathrm{~s}_{\mathrm{br}}, 4 \mathrm{H}, \mathrm{ar}-\mathrm{H}\right), 7.46\left(\mathrm{~s}_{\mathrm{br}}, 4 \mathrm{H}, \mathrm{ar}-\mathrm{H}\right), 7.53-7.64(\mathrm{~m}, 10 \mathrm{H}, 2 \mathrm{Ph})$, $7.73\left(\mathrm{~d}, J=7.3 \mathrm{~Hz}, 4 \mathrm{H}\right.$, ar-H). UV-vis $(\mathrm{MeCN}): \lambda[\mathrm{nm}]\left(\varepsilon_{\mathrm{rel}}\left[\mathrm{M}^{-1} \mathrm{~cm}^{-1}\right]\right)=484(7700), 350$ (sh), 303 (14000). EA calculated (\%) for $\mathrm{C}_{44} \mathrm{H}_{55} \mathrm{Fe}_{4} \mathrm{~N}_{7} \mathrm{~S}_{8}$ (complex + one MeCN molecule which cocrystallizes in the unit cell): C 45.49, H 4.77, N 8.44, S 22.08; found: C 45.44, H 4.72, N 8.22, S 22.41. ATR-IR [cm $\left.{ }^{-1}\right]=3457,3346,3058,2930,1600$ (s), 1498, 1475 (s), 1442, 1370, 1291, 1247, 1156, 1078, 1027, 947, 845, 768, 746 (s), 690, 670.

\section{Oxidation of $38^{2-}$ :}

$\left(\mathrm{Et}_{4} \mathrm{~N}\right)_{2} 38(20.0 \mathrm{mg}, 18.0 \mu \mathrm{mol})$ or $\left(\mathrm{Me}_{3} \mathrm{PhN}\right)_{2} \mathbf{3 8}(22.2 \mathrm{mg}, 18.0 \mu \mathrm{mol})$ was dissolved in $\mathrm{MeCN}(20 \mathrm{~mL})$ and exposed to dioxygen, or $p$-benzoquinone $(5.84 \mathrm{mg}, 54.0 \mu \mathrm{mol})$ was added to the solution. The solvent was removed under reduced pressure after stirring for 30 min at rt. The dark blue solid was washed with $\mathrm{Et}_{2} \mathrm{O}$ and pentane. The yield was not determined.

UV-vis $(\mathrm{MeCN}): \lambda[\mathrm{nm}]\left(\varepsilon_{\mathrm{rel}}\left[\mathrm{M}^{-1} \mathrm{~cm}^{-1}\right]\right)=550\left(9\right.$ 600). ATR-IR $\left[\mathrm{cm}^{-1}\right]=1618,1561,1539$, 1497, 1487, 1448, 1435, 1329, 1313 (s), 1251 (s), 1152, 1123, 1053 (s), 1020, 947, 852, 750, 724, 689. ESI(-)MS $(\mathrm{MeCN}) m / z(\%)=1113(100)[38-4 \mathrm{H}]^{-}$.

\section{Bis(trimethylphenylammonium)-bis-[(2,2'-bipyridine-3,3'-dithiolato)-( $\mu$-sulfido)- ferrate(III)] [( $\left.\left.\mathrm{Me}_{3} \mathrm{PhN}\right)_{2} 42\right]$}

45 (50.0 mg, $0.139 \mathrm{mmol})$ was dissolved in THF (20 mL) and $\mathrm{K}(11.0 \mathrm{mg}, 0.278 \mathrm{mmol})$ was added. $\left(\mathrm{Me}_{3} \mathrm{PhN}\right)_{2} \mathbf{5 0}(40.9 \mathrm{mg}, 69.3 \mu \mathrm{mol})$ was dissolved in $\mathrm{MeCN}(20 \mathrm{~mL})$. Both solutions were cooled to $-35{ }^{\circ} \mathrm{C}$ and then slowly combined. The solvent was removed under reduced pressure yielding $\left(\mathrm{Me}_{3} \mathrm{PhN}\right)_{2} \mathbf{4 1}$ as brown precipitate. The yield was not determined.

UV-vis (DMF): $\lambda[\mathrm{nm}]\left(\varepsilon_{\text {rel }}\left[\mathrm{M}^{-1} \mathrm{~cm}^{-1}\right]\right)=290$ (1200), 340 (950), 420 (625), 515 (305), 560 (250), 750 (55). ESI(-)MS (MeCN) $m / z(\%)=919.0(6)\left[\mathbf{4 1}+2\left(\mathrm{Me}_{3} \mathrm{PhN}\right)+\mathrm{Cl}\right]^{-}$. ESI(+)MS $(\mathrm{MeCN}) m / z(\%)=1020.2(4)\left[\mathbf{4 1}+\mathrm{Me}_{3} \mathrm{PhN}\right]^{+}, 1191.3(1)\left[\mathbf{4 1}+2 \mathrm{NMe}_{3} \mathrm{Ph}+\mathrm{Cl}\right]^{+} .{ }^{\mathbf{1}} \mathbf{H} \mathbf{~ N M R}$ $\left(400 \mathrm{MHz}, \mathrm{MeCN}-\mathrm{d}_{3}\right): \delta[\mathrm{ppm}]=4.24(\mathrm{~d}, J=48 \mathrm{~Hz}, 2 \mathrm{H}), 4.62(\mathrm{sbr}, 2 \mathrm{H}), 8.89(\mathrm{~d}, J=28$ Hz, 2 H). 


\subsubsection{DNICS}

$\left[\mathrm{Fe}(\mathrm{NN})(\mathrm{NO})_{2}\right]^{-}\left(3^{-}\right)$and $\left[\mathrm{Fe}(\mathrm{SN})(\mathrm{NO})_{2}\right]^{-}\left(3^{-}\right)$

Route 1: $\mathbf{2 9}^{\mathbf{2}-}$ or $\mathbf{3 0}^{\mathbf{2}}(0.231 \mathrm{mmol})$ was dissolved in $\mathrm{MeCN}(40 \mathrm{~mL})$ and NO (22.7 $\mathrm{mL}$, $0.924 \mathrm{mmol}$ ) was added into the headspace of the flask. After stirring the reaction mixture for three hours the solvent was removed under reduced pressure and the remaining solid was washed with $\mathrm{Et}_{2} \mathrm{O}(3 \times 5 \mathrm{~mL}) . \mathbf{3 3}^{-}$or $\mathbf{3 4}^{-}$was taken up in THF $(10 \mathrm{~mL})$ and dried in vacuo to afford the DNIC as a brown powder. Layering of a saturated THF solution with MTBE or hexane afforded dark crystals suitable for X-ray crystallography in the case of 33- $^{-}$34- $^{-}$was crystallized from slow diffusion of $\mathrm{Et}_{2} \mathrm{O}$ in a $\mathrm{MeCN}$ solution of the complex after repetitive recrystallization. The yield was not determined.

Route 2 was partially adapted from literature. ${ }^{168}$ It offers a convenient path to introduce two different ligands, Phenylbis(benzimidazol-2-yl)methane NN and Benzimidazolthiophenol $\mathbf{S N}$, to the scaffold. KH $(0.030 \mathrm{~g}, 0.758 \mathrm{mmol})$ was added to a solution of $\mathbf{N N}(0.123 \mathrm{~g}$, $0.379 \mathrm{mmol}$ ) or $\mathbf{S N}$ in THF (5 mL) and stirred at rt overnight. A flask was charged with $\left(\mathrm{Et}_{4} \mathrm{~N}\right)\left[\mathrm{FeCl}_{2}(\mathrm{NO})_{2}\right](0.120 \mathrm{~g}, 0.379 \mathrm{mmol})$ in THF $(10 \mathrm{~mL})$ and both solutions were cooled to $-35^{\circ} \mathrm{C}$ before mixing. The mixture was allowed to stir at ambient temperature for $2 \mathrm{~h}$. Then the solvent was removed under reduced pressure affording the corresponding DNIC as brown powder. The yield was not determined.

Analytics 33-: UV-vis (THF): $\lambda[\mathrm{nm}]\left(\varepsilon_{\text {rel }}\left[\mathrm{M}^{-1} \mathrm{~cm}^{-1}\right]\right)=430$ (1480), 705 (300). DialPathIR $v_{\mathrm{NO}}\left[\mathrm{cm}^{-1}\right]=1780,1714(\mathrm{MeCN}) ; 1773,1705$ (THF).

Analytics 34-: UV-vis (THF): $\lambda[\mathrm{nm}]\left(\varepsilon_{\text {rel }}\left[\mathrm{M}^{-1} \mathrm{~cm}^{-1}\right]\right)=470$ (340), 545 (260), 685 (200).

DialPath-IR $v_{\mathrm{NO}}\left[\mathrm{cm}^{-1}\right]=1751,1700(\mathrm{MeCN}) ; 1744,1695$ (THF).

\subsubsection{3,3'-Disulfur-2,2'-bipyridine}

The synthesis of 45, 46, and 41 was adapted from unpublished results by Mauricio Cattaneo. ${ }^{223}$

\section{3,3'-dihydroxy-dimethylthiocarbamoyl-2,2'-bipyridine (45)}

3,3'-dihydroxy-2,2'-bipyridine (1.3 g, $6.9 \mathrm{mmol})$ was dissolved in anhydrous and degassed acetone $(130 \mathrm{ml})$ under inert conditions. Dimethylthiocarbamoyl chloride $(2.56 \mathrm{~g}, 20.7$ mmol) and $\mathrm{CsCO}_{3}(6.75 \mathrm{~g}, 20.7 \mathrm{mmol})$ was then added and the reaction mixture was stirred for 24 hours at $65{ }^{\circ} \mathrm{C}$. The solution was allowed to cool to rt and the solvent was removed under reduced pressure. The solid was dissolved in demineralized water and neutralized 
with $\mathrm{HCl}(0.1 \mathrm{M})$. The aqueous solution was extracted with $\mathrm{DCM}(3 \times 100 \mathrm{ml})$. The combined organic phases were evaporated to dryness under reduced pressure. Column chromatography (silica gel, $R_{\mathrm{f}}($ ethyl acetate $)=0.06$ ) of the resulting brown oil afforded a yellow solid (yield $60 \%$ ). EA for $\mathrm{C}_{16} \mathrm{H}_{18} \mathrm{~N}_{4} \mathrm{O}_{2} \mathrm{~S}_{2}$ (\%): C 53.02, H 5.00, N 15.46, S 17.69. Found: C 53.05, H 4.93, N 15.65, S 17.85. IR (KBr pellets) [ $\left.\mathrm{cm}^{-1}\right]: 3065$ (w), 2940 (w), 2880 (w), 1627 (w), 1537 (s), 1454 (w), 1441 (w), 1419 (s), 1394 (s), 1289 (s), 1240 (s), 1202 (s), 1178 (m), 1126 (s), 1106 (m), 1060 (w), 1039 (m), 819 (w), 791 (w), 756 (w), $687(\mathrm{w}), 619(\mathrm{w}) .{ }^{1} \mathbf{H}$ NMR $\left(300 \mathrm{MHz}, \mathrm{CDCl}_{3}\right): \delta[\mathrm{ppm}]=8.52\left(2, \mathrm{dd}, 2 \mathrm{H},{ }^{2-3} J=4.6 \mathrm{~Hz}\right.$, $\left.{ }^{2-4} J=1.4 \mathrm{~Hz}\right), 7.76\left(4, \mathrm{dd}, 2 \mathrm{H},{ }^{4-3} \mathrm{~J}=8.2 \mathrm{~Hz},{ }^{4-2} \mathrm{~J}=1.4 \mathrm{~Hz}\right), 7.38\left(3, \mathrm{dd}, 2 \mathrm{H},{ }^{3-4} \mathrm{~J}=8.3 \mathrm{~Hz}\right.$, $\left.{ }^{3-2} J=4.7 \mathrm{~Hz}\right), 3.29(11, \mathrm{~s}, 6 \mathrm{H}), 3.03(12, \mathrm{~s}, 6 \mathrm{H}) .{ }^{13} \mathbf{C ~ N M R}\left(75 \mathrm{MHz}, \mathrm{CDCl}_{3}\right) \delta[\mathrm{ppm}]=$ 185.99, 148.74, 148.63, 146.09, 133.03, 123.47, 43.35, 38.97. ${ }^{15} \mathbf{N}$ NMR (30 MHz, $\left.\mathrm{CDCl}_{3}\right)$ : $\delta[\mathrm{ppm}]=-62.8,-262.2$. ESI(+)MS $(\mathrm{MeCN}) \mathrm{m} / \mathrm{z}(\%):[\mathrm{M}+\mathrm{H}]^{+} 363.1$ (100). UV-vis $\left(\mathrm{CH}_{3} \mathrm{CN}\right): \lambda_{\max }[\mathrm{nm}]\left(\varepsilon_{\mathrm{rel}}\left[\mathrm{M}^{-1} \mathrm{~cm}^{-1}\right]\right)=251(34600)$.

\section{3,3'-dithio-dimethylcarbamoyl-2,2'-bipyridine (46) and 3,3'-thiocyclo-2,2'-bipyridine} (47)

After extensive optimization of the reaction conditions, best results were obtained by heating neat $45(100 \mathrm{mg})$ to $280{ }^{\circ} \mathrm{C}$ under argon atmosphere for $7 \mathrm{~min} .{ }^{1} \mathrm{H} \mathrm{NMR}$ spectroscopy suggested the black product mixture to contain 47 ( 36\%), 45 with only one rearranged arm ( 26\%) and $46(\sim 16 \%)$ besides some remaining 45 and other unidentified side products. The compounds were separated by column chromatography (silica gel, hexanes/diethyl acetate 1:1).

The first fraction is 47 ( $R_{\mathrm{f}}$ in ethyl acetate (3×TLC) $\left.\sim 0.71\right)$. EA $\mathrm{C}_{10} \mathrm{H}_{6} \mathrm{~N}_{2} \mathrm{~S}(\%)$ : C 64.29, $\mathrm{H}$ 3.60, N 14.37, S 16.40. Found: C 64.12, H 3.82, N 14.07, S 16.18. IR (KBr pellets) [ $\mathrm{cm}^{-1}$ ]: 3046 (w), 2925 (w), 2956 (w), 1541 (s), 1462 (w), 1395 (s), 1335 (w), 1288 (m), 1225 (w), 1196 (m), 1146 (m), 1067 (s), 1040 (w), 1031 (w), 986 (w), 967 (w), 814 (w), $801(\mathrm{~m}), 789$ (s), 733 (s), 696 (m), 621 (m). ${ }^{\mathbf{1}} \mathbf{H}$ NMR (300 MHz, $\left.\mathrm{CDCl}_{3}\right): \delta[\mathrm{ppm}]=8.91$ $\left(2, \mathrm{dd}, 2 \mathrm{H},{ }^{2-3} \mathrm{~J}=4.6 \mathrm{~Hz},{ }^{2-4} \mathrm{~J}=1.4 \mathrm{~Hz}\right), 8.23\left(4, \mathrm{dd}, 2 \mathrm{H},{ }^{4-3} \mathrm{~J}=8.2 \mathrm{~Hz},{ }^{4-2} \mathrm{~J}=1.4 \mathrm{~Hz}\right), 7.48$ $\left(3, \mathrm{dd}, 2 \mathrm{H},{ }^{3-4} \mathrm{~J}=8.2 \mathrm{~Hz},{ }^{3-2} J=4.5 \mathrm{~Hz}\right) .{ }^{13} \mathbf{C ~ N M R}\left(75 \mathrm{MHz}, \mathrm{CDCl}_{3}\right): \delta[\mathrm{ppm}]=150.54$, 148.08, 134.63, 131.09, 120.40. ${ }^{15} \mathbf{N}$ NMR $\left(30 \mathrm{MHz}, \mathrm{CDCl}_{3}\right): \delta[\mathrm{ppm}]=-78$. ESI-MS $(\mathrm{MeCN}) \mathrm{m} / \mathrm{z}(\%):[\mathrm{M}+\mathrm{H}]^{+} 187.03(100)$. UV-vis $\left(\mathrm{CH}_{3} \mathrm{CN}\right): \lambda_{\max }[\mathrm{nm}]\left(\varepsilon_{\text {rel }}\left[\mathrm{M}^{-1} \mathrm{~cm}^{-1}\right]\right)=298$ (14300), 290 (sh), 257 (10700), 228 (38200), 210 (15800).

The second fraction is the starting material 45 ( $R_{\mathrm{f}}$ in ethyl acetate $\left.(3 \times \mathrm{TLC}) \sim 0.58\right)$. 
The third fraction is the singly rearranged product $\mathbf{4 5}$ ( $R_{\mathrm{f}}$ in ethyl acetate $(3 \times \mathrm{TLC}) \sim 0.26$ ). EA $\mathrm{C}_{16} \mathrm{H}_{18} \mathrm{~N}_{4} \mathrm{O}_{2} \mathrm{~S}_{2}$ (\%): C 53.02, H 5.00, N 15.46. Found: C 53.25, H 5.10, N 15.17. IR (KBr pellets) [ $\left.\mathrm{cm}^{-1}\right]$ : 3055 (w), 3014 (w), 2956 (w), 2918 (w), 2856 (w), 1635 (m), 1594 (s), 1552 (s), 1458 (m), 1432 (m), 1371 (s), 1327 (m), 1277 (w), 1218 (w), 1156 (w), 1106 (w), $1066(\mathrm{w}), 988(\mathrm{w}), 970(\mathrm{w}), 903(\mathrm{w}), 826(\mathrm{~s}), 748(\mathrm{w}), 684(\mathrm{~m}), 669(\mathrm{w}), 530(\mathrm{~m}), 414$ (w). ${ }^{1} \mathbf{H}$ NMR $\left(300 \mathrm{MHz}, \mathrm{CDCl}_{3}\right): \delta[\mathrm{ppm}]=8.61\left(2, \mathrm{dd}, 1 \mathrm{H},{ }^{2-3} \mathrm{~J}=4.6 \mathrm{~Hz},{ }^{2-4} \mathrm{~J}=1.7 \mathrm{~Hz}\right)$, $8.52\left(2^{\prime}\right.$, dd $\left., 1 \mathrm{H},{ }^{2-3} \mathrm{~J}=4.7 \mathrm{~Hz},{ }^{2-4} \mathrm{~J}=1.4 \mathrm{~Hz}\right), 7.97\left(4, \mathrm{dd}, 1 \mathrm{H},{ }^{3-4} \mathrm{~J}=8.0 \mathrm{~Hz},{ }^{2-4} \mathrm{~J}=1.7 \mathrm{~Hz}\right)$, $7.77\left(4^{\prime}, \mathrm{dd}, 1 \mathrm{H},{ }^{3-4} J=8.3 \mathrm{~Hz},{ }^{2-4} J=1.4 \mathrm{~Hz}\right), 7.37\left(3^{\prime}, \mathrm{dd}, 1 \mathrm{H},{ }^{3-2} J=4.7 \mathrm{~Hz},{ }^{3-4} J=8.3 \mathrm{~Hz}\right)$, $7.35\left(3, \mathrm{dd}, 1 \mathrm{H},{ }^{3-2} \mathrm{~J}=4.7 \mathrm{~Hz},{ }^{3-4} \mathrm{~J}=8.0 \mathrm{~Hz}\right), 3.21(11$ ', s, 3H), $2.89(11-12$, s, 6H), 2.86 $\left(12\right.$ ', s, 3H). $\left.{ }^{13} \mathbf{C ~ N M R ~ ( 2 0 0 ~ M H z , ~} \mathrm{CDCl}_{3}\right): \delta[\mathrm{ppm}]=185.12,164.88,157.52,150.44$, $148.55,147.78,145.77,145.69,132.69,127.01,123.27,123.23,42.93,38.37,36.88$. ${ }^{15} \mathbf{N}$ NMR $(30 \mathrm{MHz}, \mathrm{CDCl} 3): \delta[\mathrm{ppm}]=-63.2,-65.7,-262.5$. ESI-MS $(\mathrm{MeCN}) \mathrm{m} / \mathrm{z}(\%)$ : $[\mathrm{M}+\mathrm{H}]^{+} 363.09(100)$.

The last fraction is $\mathbf{4 6}\left(R_{\mathrm{f}}\right.$ in ethyl acetate (3×TLC) $\left.\sim 0.17\right)$. $\mathbf{E A ~} \mathrm{C}_{16} \mathrm{H}_{18} \mathrm{~N}_{4} \mathrm{O}_{2} \mathrm{~S}_{2}(\%)$ : C 53.02, H 5.00, N 15.46, S 17.69. Found: C 53.67, H 4.97, N 15.34, S 17.60. IR (KBr pellets) [cm ${ }^{-1}$ ]: $3056(\mathrm{w}), 3017(\mathrm{w}), 2916(\mathrm{w}), 1626(\mathrm{~s}), 1553$ (m), $1477(\mathrm{w}), 1459(\mathrm{w}), 1434(\mathrm{~m})$, 1400 (s), 1369 (s), 1257 (m), 1099 (m), 1072 (w), 1043 (m), 1037 (w), 906 (w), 813 (w), 801 (m), 786 (w), 774 (w), 685 (s), 648 (w), 623 (w), 525 (w). ${ }^{1} \mathbf{H}$ NMR (300 MHz, $\left.\mathrm{CDCl}_{3}\right)$ : $\delta[\mathrm{ppm}]=8.65\left(2, \mathrm{dd}, 2 \mathrm{H},{ }^{2-3} \mathrm{~J}=4.8 \mathrm{~Hz},{ }^{2-4} \mathrm{~J}=1.6 \mathrm{~Hz}\right), 8.01\left(4, \mathrm{dd}, 2 \mathrm{H},{ }^{4-3} \mathrm{~J}=8.0 \mathrm{~Hz},{ }^{4-2} J\right.$ $=1.6 \mathrm{~Hz}), 7.39\left(3, \mathrm{dd}, 2 \mathrm{H},{ }^{3-4} \mathrm{~J}=8.0 \mathrm{~Hz},{ }^{3-2} \mathrm{~J}=4.8 \mathrm{~Hz}\right), 2.91(11, \mathrm{~s}, 12 \mathrm{H}) .{ }^{13} \mathbf{C ~ N M R}$ $\left(75 \mathrm{MHz}, \mathrm{CDCl}_{3}\right): \delta[\mathrm{ppm}]=165.15,159.80,148.88,145.33,126.52,123.42,37.04$. ${ }^{15} \mathbf{N}$ NMR $\left(30 \mathrm{MHz}, \mathrm{CDCl}_{3}\right): \delta[\mathrm{ppm}]=-66.0,-285.5$. ESI-MS $(\mathrm{MeCN}) \mathrm{m} / \mathrm{z}(\%):[\mathrm{M}+\mathrm{H}]^{+}$ 368.09 (100).

\section{[1,2]dithiino[4,3-b:5,6-b']dipyridine (41)}

To a solution of $\mathrm{LiAlH}_{4}(190 \mathrm{mg}, 5 \mathrm{mmol})$ in dry THF under argon atmosphere was added 46 (234 mg, $0.645 \mathrm{mmol})$ dissolved in dry THF $(15 \mathrm{ml})$. The reaction mixture was stirred under argon atmosphere for $30 \mathrm{~min}$ and then heated to $50{ }^{\circ} \mathrm{C}$ for $3 \mathrm{~h}$. After cooling down to $0{ }^{\circ} \mathrm{C}, 0.1 \mathrm{M}$ aqueous $\mathrm{HCl}(10 \mathrm{ml})$ was added slowly until the solution turned to intense red. The product was extracted with DCM $(4 \times 50 \mathrm{ml})$ and the combined organic phases were exposed to air, causing the color of the solution to turn yellow. The solution was concentrated in vacuo and the yellow oil was chromatographed on silica gel with ethyl acetate. 41 was isolated as a yellow oil ( $R_{\mathrm{f}}$ in ethyl acetate $\left.\sim 0.1\right) .{ }^{1} \mathbf{H}$ NMR (300 MHz, 
$\left.\mathrm{CDCl}_{3}\right): \delta[\mathrm{ppm}]=8.68\left(2, \mathrm{dd}, 2 \mathrm{H},{ }^{2-3} \mathrm{~J}=4.6 \mathrm{~Hz},{ }^{2-4} \mathrm{~J}=1.6 \mathrm{~Hz}\right), 7.72\left(4, \mathrm{dd}, 2 \mathrm{H},{ }^{4-3} J=7.9\right.$ $\left.\mathrm{Hz},{ }^{4-2} J=1.6 \mathrm{~Hz}\right), 7.22\left(3, \mathrm{dd}, 2 \mathrm{H},{ }^{3-4} \mathrm{~J}=7.9 \mathrm{~Hz},{ }^{3-2} \mathrm{~J}=4.7 \mathrm{~Hz}\right) .{ }^{13} \mathbf{C}$ NMR $(75 \mathrm{MHz}$, CDCl3): $\delta[\mathrm{ppm}]=153.08,149.44,136.01,133.94,123.67 .{ }^{15} \mathbf{N}$ NMR $(30 \mathrm{MHz}, \mathrm{CDCl} 3)$ : $\delta[\mathrm{ppm}]=-70.6$. ESI-MS $(\mathrm{MeCN}) \mathrm{m} / \mathrm{z}(\%):[\mathrm{M}+\mathrm{H}]^{+} 219.00(100 \%),[\mathrm{M}+\mathrm{Na}]^{+} 240.99$ (30\%). UV-vis $\left(\mathrm{CH}_{3} \mathrm{CN}\right): \lambda_{\max }[\mathrm{nm}]\left(\varepsilon_{\mathrm{rel}}\left[\mathrm{M}^{-1} \mathrm{~cm}^{-1}\right]\right)=360$ (360), 302 (5900), 265 (9400).

\section{3,3'-dithiol-2,2'-bipyridine $\left(41 \mathrm{H}_{2}\right)$}

$\mathbf{4 1} \mathrm{H}_{2}$ was synthesized following the procedure for $\mathbf{4 1}$, but the reaction mixture was kept under inert conditions throughout. $\mathrm{LiAlH}_{4}(200 \mu \mathrm{L}$ of a $1.0 \mathrm{M}$ solution in THF, $200 \mu \mathrm{mol}$ ) was added to 46 ( $8.0 \mathrm{mg}, 22 \mu \mathrm{mol})$ under an atmosphere of dry Ar and the reaction mixture stirred for $5 \mathrm{~min}$, then heated to $50{ }^{\circ} \mathrm{C}$ for $3 \mathrm{~h}$. After cooling to $0{ }^{\circ} \mathrm{C}, 0.1 \mathrm{M}$ aqueous $\mathrm{HCl}$ ( $3 \mathrm{ml}$ ) were added slowly. The aqueous phase was further diluted with $0.1 \mathrm{M}$ aqueous $\mathrm{HCl}$ $(50 \mathrm{ml})$ and the solution turned intense red. $41 \mathrm{H}_{2}$ was extracted with DCM $(6 \times 5 \mathrm{ml})$ under argon atmosphere. The solvent was then removed under reduced pressure and the remaining red solid was recrystallized from DCM/toluene. ${ }^{1} \mathrm{H}$ NMR $\left(300 \mathrm{MHz}, \mathrm{CDCl}_{3}\right) \delta[\mathrm{ppm}]=$ $8.39\left(2, \mathrm{dd}, 2 \mathrm{H},{ }^{2-3} J=8.3 \mathrm{~Hz},{ }^{2-4} J=1.6 \mathrm{~Hz}\right), 8.01\left(4, \mathrm{dd}, 2 \mathrm{H},{ }^{4-3} J=5.1 \mathrm{~Hz},{ }^{4-2} J=1.6 \mathrm{~Hz}\right)$, $7.31\left(3, \mathrm{dd}, 2 \mathrm{H},{ }^{3-4} J=5.1 \mathrm{~Hz},{ }^{3-2} J=8.3 \mathrm{~Hz}\right)$. 


\subsection{DFT calculations}

All computations were carried out with the ORCA program package. ${ }^{240} \mathrm{X}$-ray data of the DNIC anions were employed as starting coordinates for the geometry optimization. For the protonated species $\mathrm{H}$-atoms were added to the structure with the program Chemcraft and the charge was changed to zero. The spin-unrestricted Kohn-Sham approach was used in all cases to account for the unpaired spin of the $S=1 / 2$ system. Geometry optimizations and frequency calculations were performed with the BP86, ${ }^{241-243}$ TPSS, ${ }^{244,245} \mathrm{~B}^{2} \mathrm{LYP}^{246,247}$ and TPSSh $^{248}$ density functionals. The def2-TZVP basis set was applied in combination with the auxiliary basis set def2-TZV/J. ${ }^{249-251}$ The RI approximation was used to accelerate the calculations. The Mössbauer spectroscopic parameters were computed using the CP(PPP) basis set for Fe and def2-TZVP for the other atoms. ${ }^{186}$ Counterions or crystal inclusions were omitted since Lippard and Zhang showed before that counterions and cocrystallized neutral molecules have only a marginal influence on Mössbauer parameters of iron complexes. ${ }^{252,253}$ The COSMO package included in ORCA was employed to mimic MeCN or THF as solvent in form of an infinite dielectric field.

Isomer shifts $\delta_{\text {IS }}$ were calculated from the electron densities at the Fe nucleus $\rho_{0}$ employing the linear regression formula: $\delta_{\mathrm{IS}}=\alpha\left(\rho_{0}-\mathrm{C}\right)+\beta$. Here, $\alpha, \beta$ and $\mathrm{C}$ are the fit parameters. Neese and coworkers published their values for different combinations of the functionals and basis sets. ${ }^{184}$ Quadrupole splittings $\Delta E_{\mathrm{Q}}$ were obtained from electric field gradients $V_{\mathrm{i}}$ ( $\mathrm{i}=\mathrm{x}, \mathrm{y}, \mathrm{z} ; V_{\mathrm{i}}$ are the eigenvalues of the electric field gradient tensor) employing a nuclear quadrupole moment $Q\left({ }^{57} \mathrm{Fe}\right)=0.16$ barn: $\Delta E_{\mathrm{Q}}=1 / 2$ e $Q V_{\mathrm{z}}\left(1+1 / 2 \eta^{2}\right)^{1 / 2}$. Here, $\eta=\left(V_{\mathrm{x}}-V_{\mathrm{y}}\right) / V_{\mathrm{z}}$ is the asymmetry parameter. 



\section{Appendix}

\subsection{Benchmark substances for X-ray spectroscopy of iron-sulfur clusters}

Samples of $\left(\mathrm{NEt}_{4}\right)_{2} 29$ and $\left(\mathrm{NEt}_{4}\right)_{3} 29$ were prepared and sent to the group of Prof. Serena DeBeer at the Max-Planck Institute for Chemical Energy Conversion in Mülheim for iron and sulfur K-edge X-ray absorption (XAS), iron $\mathrm{K} \beta$ and valence-to-core X-ray emission (XES) and X-ray magnetic circular dichroism (XMCD) measurements of iron complexes in different redox states. The results allowed quantitative assessment of the electronic structure of iron-sulfur clusters and were published in the Journal Inorganic Chemistry in 2016 and $2017 .^{254,255}$

More precisely, Fe K edge XAS in combination with DFT calculations allowed for a distinction between localized valence and delocalized valence species on basis of pre-edge and K-edge energies. Fe K $\beta$ XES mainlines, on the other hand, were found not suitable for the elucidation of oxidation states of iron-sulfur clusters as isolated method because of cancelling effects of covalency and spin state. XMCD proved to be an effective tool for the elucidation of oxidation states as distinct features appear at the $\mathrm{L}_{3}$ and $\mathrm{L}_{2}$ edges. The signal's intensity correlates to the molecule's covalency. With knowledge obtained from the test molecules, spectra of $\left[\mathrm{MoFe}_{3} \mathrm{~S}_{4}\right]^{3+}$ and $\left[\mathrm{VFe}_{3} \mathrm{~S}_{4}\right]^{2+}$ as models for FeMoCo and FeVCo of nitrogenase were analyzed. XMCD delivers more precise information on the oxidation state distribution than XAS alone. To summarize, most information can be obtained in the order XMCD > XAS > XES. Well characterized molecules in different oxidation states like $\left(\mathrm{NEt}_{4}\right)_{2} 29$ and $\left(\mathrm{NEt}_{4}\right)_{3} \mathbf{2 9}$ served as benchmark in order to understand the effect of oxidation state and covalency on the three methods. The elucidation of the electronic structure of iron-sulfur clusters in proteins can be supported by them in the future. 


\subsection{Supplementary spectra and information}

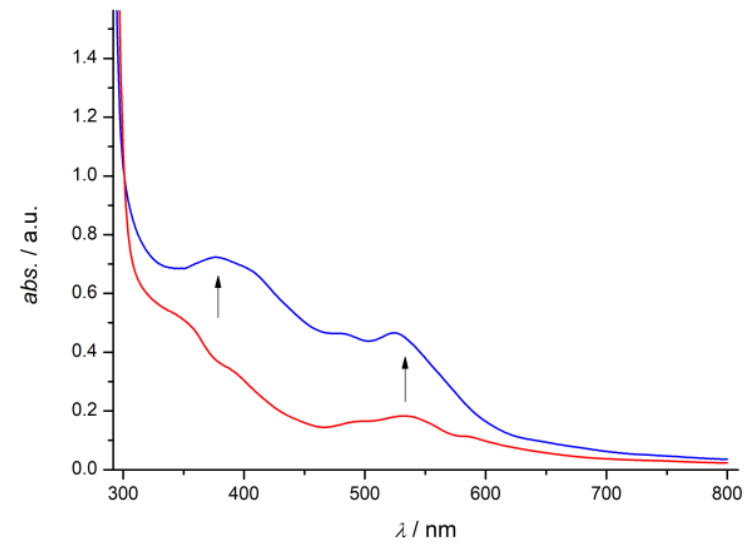

Figure 8.1. UV-vis of starting material 29-3 ${ }^{3-}$ in DMF (red) and reaction mixture after 35 min in MeCN (blue).
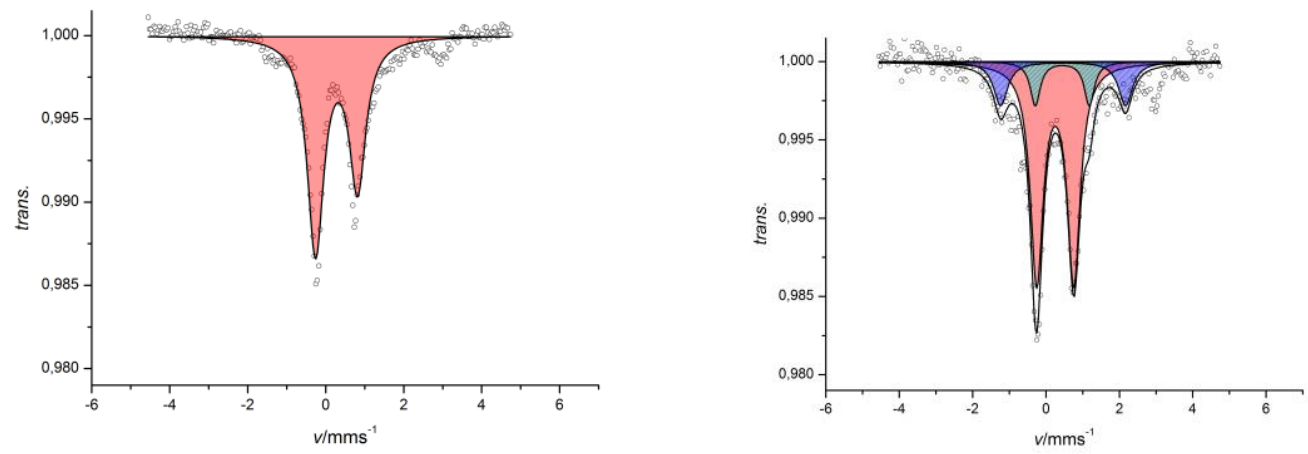

Figure 8.2. Zero-field Mössbauer spectrum of intermediate 1 at $80 \mathrm{~K}$ (left) and $6 \mathrm{~K}$ (right).

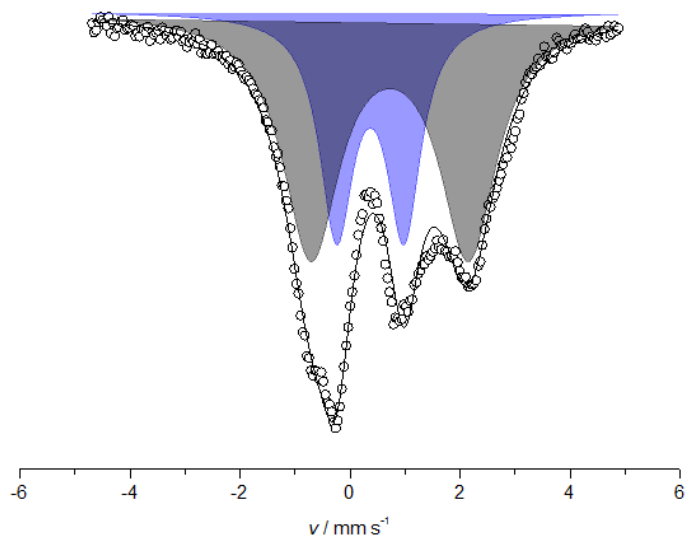

Figure 8.3. Mössbauer spectrum of $33 \%{ }^{57} \mathrm{Fe}$ enriched $\mathbf{2 9}^{\mathbf{3}-}$. 


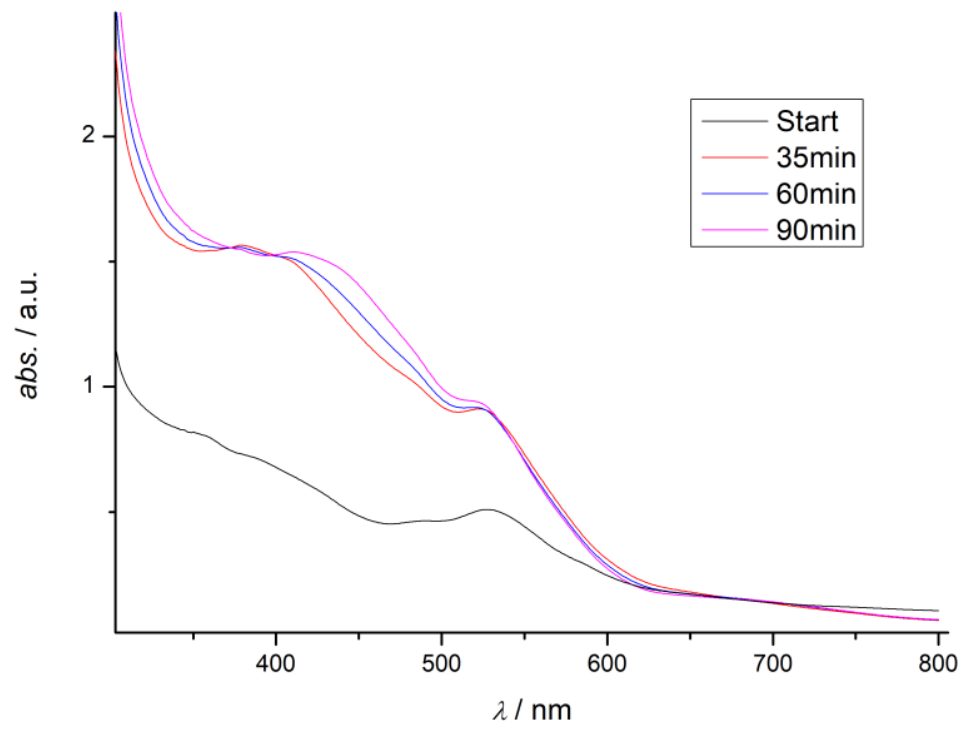

Figure 8.4. UV-vis spectra of the ${ }^{57}$ Fe enriched $2^{3-}$ in DMF (black) and after 35 (red), 60 (blue), and 90 min (magenta) after addition of NO.

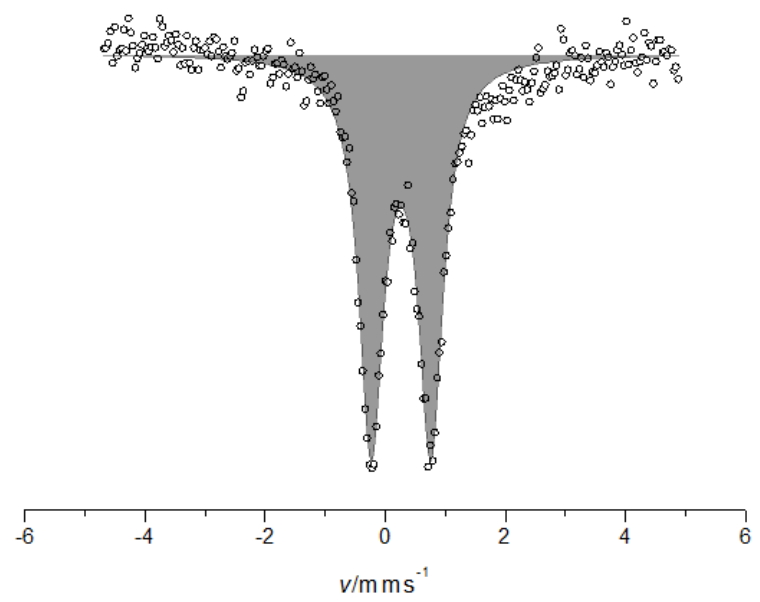

Figure 8.5. Mössbauer spectrum of intermediate 2 in frozen MeCN solution. 
a)

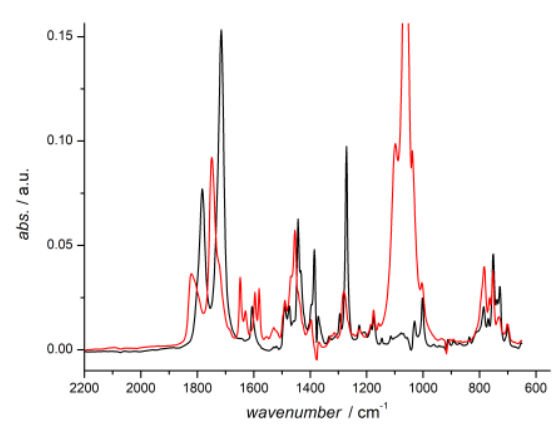

b)

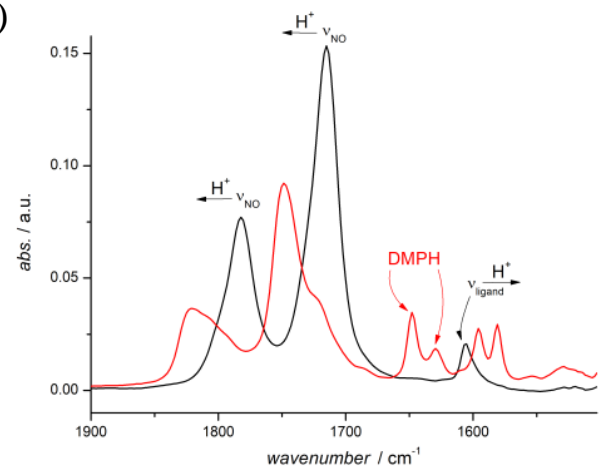

Figure 8.6 (a) IR spectra of $\mathbf{3 3}^{-}$(black) after addition of 1 eq. DMPH (red), (b) excerpt of $v_{\mathrm{NO}}$ region of IR spectrum. Upon protonation $v_{\mathrm{NO}}$ shift to higher wavenumbers while $v_{\text {ligand }}$ splits in two signals and shifts to lower wavenumbers.

Table 8.1. Experimental and calculated infrared spectroscopic parameters for $v_{\mathrm{NO}}$ of $\mathbf{3 3}^{-}$and $\mathbf{3 4}^{-}$in MeCN and THF.

\begin{tabular}{|c|c|c|c|c|c|}
\hline & solvent & functional & IR $v_{\mathrm{NO}} / \mathrm{cm}^{-1}$ & $\Delta\left(v_{\mathrm{NO}, \exp }-v_{\mathrm{NO}, \text { calc }}\right) / \mathrm{cm}^{-1}$ & Figure 3.5 \\
\hline $33 \exp$ & $\mathrm{MeCN}$ & - & 1714,1780 & - & - \\
\hline 33 calc & $\mathrm{MeCN}$ & BP86 & 1673,1749 & 41,31 & a) \\
\hline & $\mathrm{MeCN}$ & TPSS & 1671,1752 & 43,28 & - \\
\hline $34 \exp$ & $\mathrm{MeCN}$ & - & 1700,1751 & - & - \\
\hline 34 calc & $\mathrm{MeCN}$ & BP86 & 1643,1709 & 57,42 & b) \\
\hline $33 \exp$ & THF & - & 1705,1773 & - & - \\
\hline 33 calc & THF & BP86 & 1681,1752 & 24,21 & c) \\
\hline $34 \exp$ & THF & - & 1694,1744 & - & - \\
\hline 34 calc & THF & BP86 & 1657,1716 & 37,28 & d) \\
\hline
\end{tabular}

Table 8.2. Experimental and calculated infrared spectroscopic parameters for $v_{\mathrm{NO}}$ of $\mathbf{3 3 H}$ and $\mathbf{3 4 H}$ in MeCN and THF.

\begin{tabular}{c|c|c|c|c|c} 
& & functional & solvent & $v_{\mathrm{NO}} / \mathrm{cm}^{-1}$ & $\Delta\left(v_{\mathrm{NO}, \text { exp }}-v_{\mathrm{NO}, \text { calc }}\right) / \mathrm{cm}^{-1}$ \\
\hline \hline 33H & exp & - & THF & 1743,1820 & - \\
\hline $\begin{array}{c}\text { 33H- } \\
\text { rearranged }\end{array}$ & calc & BP86 & MeCN & 1648,1680 & 95,140 \\
\hline $\mathbf{3 3 H}$ & calc & BP86 & MeCN & 1697,1775 & 46,45 \\
\hline $\mathbf{3 4 H}$ & exp & - & THF & 1722,1775 & - \\
\hline $\mathbf{3 4 H}$ & calc & BP86 & MeCN & 1667,1735 & 55,40
\end{tabular}


Table 8.3 Calculated Mössbauer parameters.

\begin{tabular}{c|c|c|c|c|c} 
& functional & $\mathbf{3 3}$ & $\mathbf{3 4}$ & $\mathbf{3 3 H}$ & $\mathbf{3 4 H}$ \\
\hline \hline \multirow{2}{*}{$\delta_{\mathrm{IS}} / \mathrm{mm} \mathrm{s}^{-1}$} & B3LYP & 0.0513 & 0.0043 & 0.1005 & 0.0511 \\
\cline { 2 - 6 } & TPSS & 0.1062 & 0.0631 & - & - \\
\cline { 2 - 6 } & TPSSH & 0.0405 & -0.0049 & - & - \\
\hline \multirow{2}{*}{$\Delta E_{\mathrm{Q}} / \mathrm{mm} \mathrm{s}^{-1}$} & B3LYP & 1.0730 & 0.981 & 1.326 & 1.163 \\
\cline { 2 - 6 } & TPSS & 0.7530 & -0.668 & - & - \\
\cline { 2 - 6 } & TPSSH & 0.9170 & 0.832 & - & -
\end{tabular}

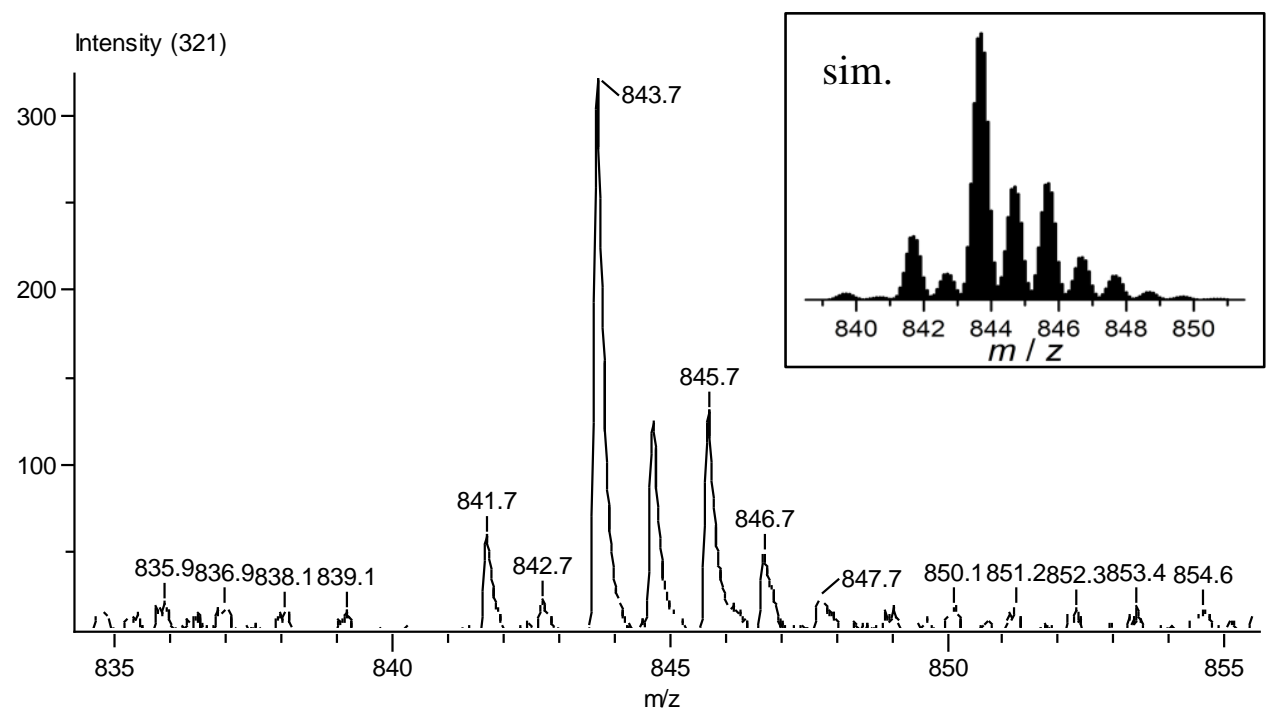

Figure 8.7. Excerpt from LIFDI spectrum of $\mathbf{3 8}^{\mathbf{0 x}}$ in THF. The insert depicts the simulation of the isotopic pattern. 
a)

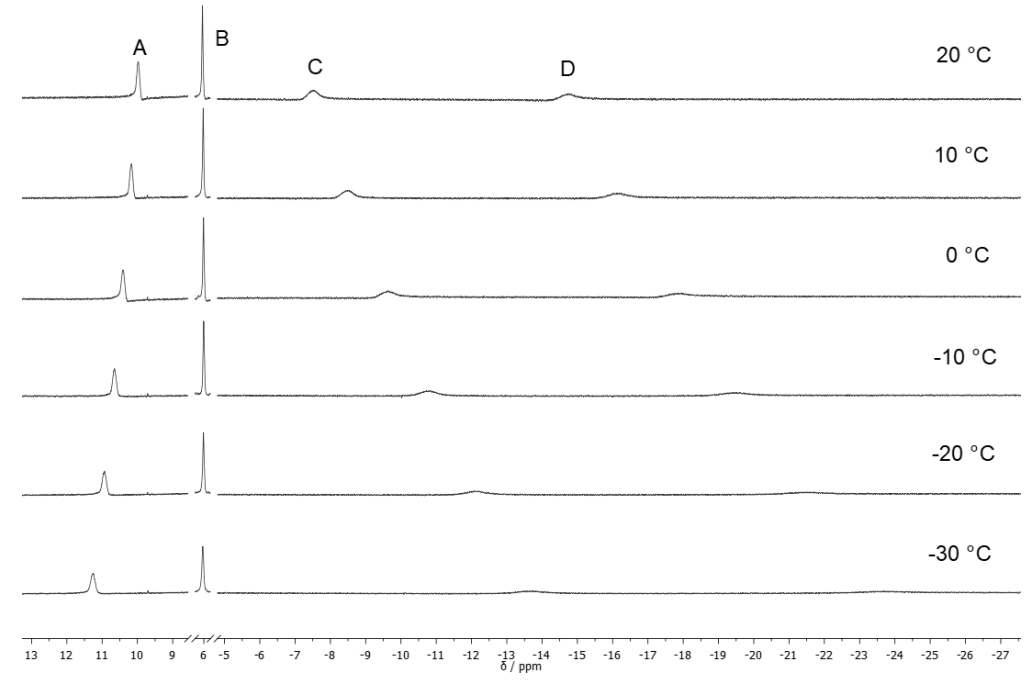

b)

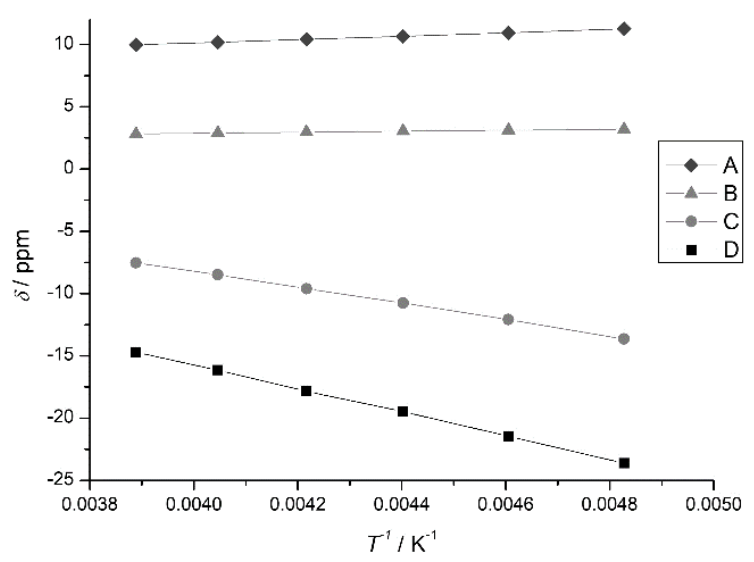

Figure 8.8. a) Paramagnetic signals of the oxidation product in acetone- $\mathrm{d}_{6}$ at various temperatures. b) Curie behavior of the signals.

a)

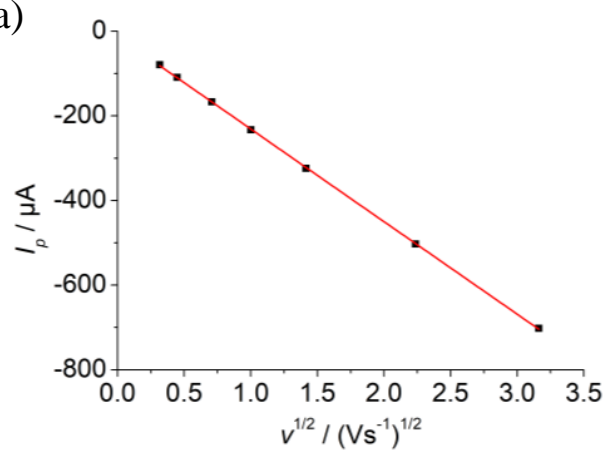

b)

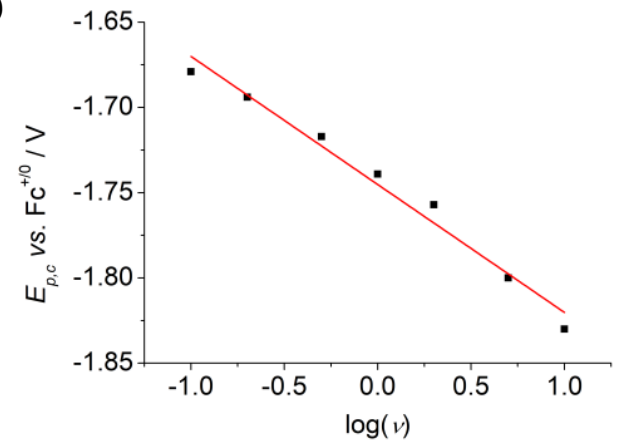

Figure 8.9. a) Plot of the peak current $I_{p, c} v s$. the square root of the scan rate $\left(0.1 \mathrm{M} \mathrm{Bu}_{4} \mathrm{NPF}_{6}, c(\mathbf{4 1})=1.8 \mathrm{mM}, c\left(\mathrm{H}_{2} \mathrm{O}\right) \sim\right.$ $0.21 \mathrm{M}), \mathrm{b})$ plot of the peak potential of the reduction wave at different scan rates $v s$. the logarithm of the scan rate $(0.1 \mathrm{M}$ $\left.\mathrm{Bu}_{4} \mathrm{NPF}_{6}, c(\mathbf{4 1})=1.8 \mathrm{mM}\right)$. 


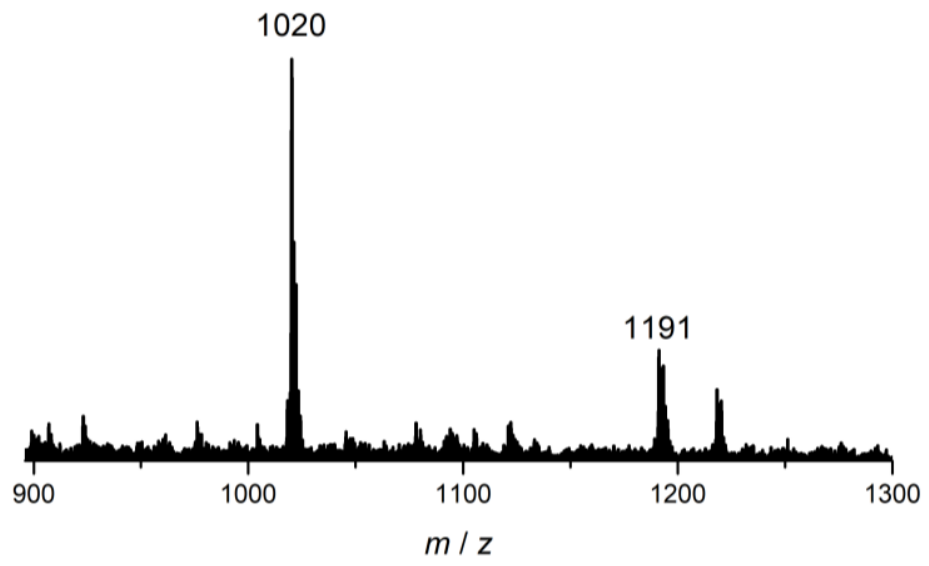

Excerpt from spectrum:
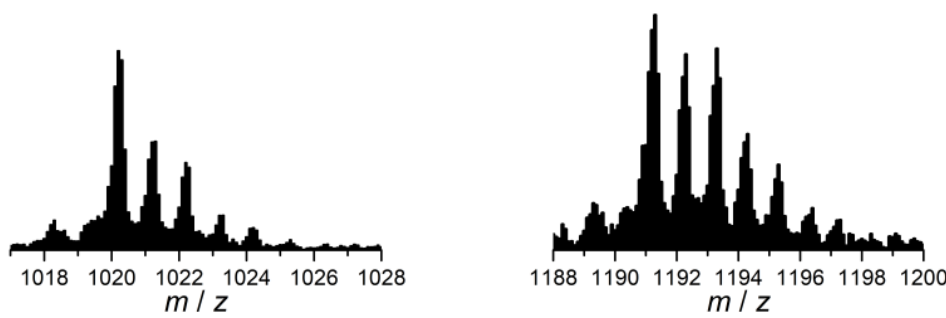

Simulation:

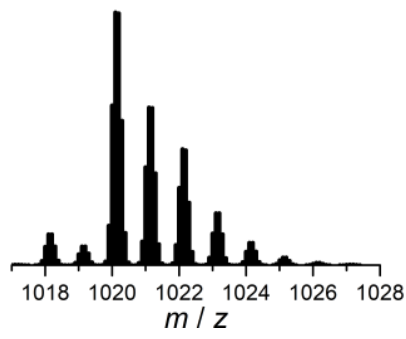

$\left[\left(\mathrm{Me}_{3} \mathrm{PhN}\right)_{3} \mathbf{4 2}+\mathrm{Cl}\right]^{+}$

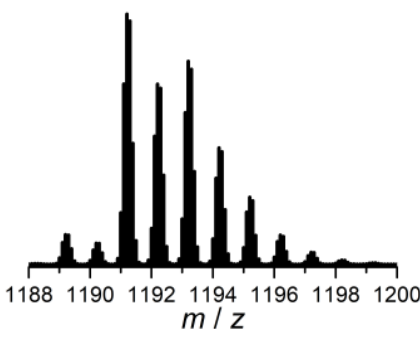

$\left[\left(\mathrm{Me}_{3} \mathrm{PhN}\right)_{4} \mathbf{4 2}+2 \mathrm{Cl}\right]^{+}$

Figure 8.10. ESI(+)MS of $\left(\mathrm{Me}_{3} \mathrm{PhN}\right)_{3}$ 42. Excerpt of spectrum and simulation. 


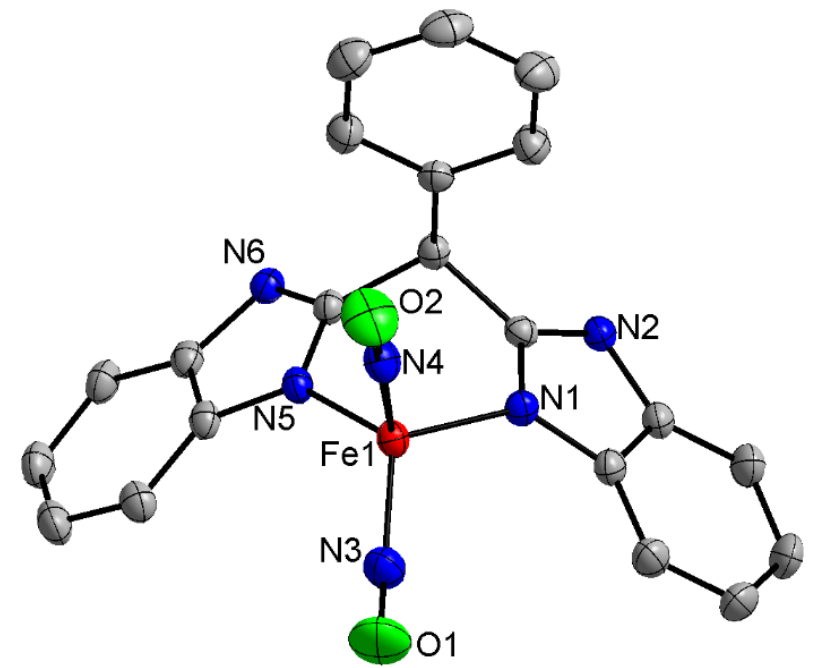

Figure 8.11. Plot (50\% probability thermal ellipsoids) of the anion of (PPN)33 (hydrogen atoms and counter ions omitted for clarity). Selected bond lengths $[\AA ̊]$ and angles [ $\left.{ }^{\circ}\right]$ : Fe1-N4 1.683(2), Fe1-N3 1.701(3), Fe1-N1 1.979(2), Fe1-N5 1.996(2); N1-Fe1-N5 93.75(9), N4-Fe1-N5 108.80(11), N4-Fe1-N3 111.52(13), N4-Fe1-N1 111.77(10), N3-Fe1-N1 111.90(11), N3-Fe1-N5 117.92(10), C2-N1-Fe1 120.08(16), C9-N5-Fe1 120.27(14), C3-N1-Fe1 132.69(18), C10N5-Fe1 134.83(18), O1-N3-Fe1 157.3(3), O2-N4-Fe1 171.3(3).

Table 8.4 Crystal data and refinement details for (PPN)33.

\begin{tabular}{|c|c|}
\hline compound & $(\mathrm{PPN}) 33$ \\
\hline empirical formula & $\mathrm{C}_{57} \mathrm{H}_{44} \mathrm{FeN}_{7} \mathrm{O}_{2} \mathrm{P}_{2}$ \\
\hline formula weight & 976.78 \\
\hline$T[\mathrm{~K}]$ & $133(2)$ \\
\hline crystal size $\left[\mathrm{mm}^{3}\right]$ & $0.530 \times 0.230 \times 0.150$ \\
\hline crystal system & monoclinic \\
\hline space group & $P 2{ }_{1}($ No. 4$)$ \\
\hline$a[\AA]$ & $10.635(2)$ \\
\hline$b[\AA]$ & $22.009(4)$ \\
\hline$c[\AA]$ & $10.688(2)$ \\
\hline$\alpha\left[^{\circ}\right]$ & 90 \\
\hline$\beta\left[^{\circ}\right]$ & $104.51(3)$ \\
\hline$\gamma\left[{ }^{\circ}\right]$ & 90 \\
\hline$V\left[\AA^{3}\right]$ & $2421.8(9)$ \\
\hline$Z$ & 2 \\
\hline$\rho\left[\mathrm{g} \cdot \mathrm{cm}^{-3}\right]$ & 1.339 \\
\hline$F(000)$ & 1014 \\
\hline$\mu\left[\mathrm{mm}^{-1}\right]$ & 0.429 \\
\hline$\theta$-range $\left[{ }^{\circ}\right]$ & $1.851-26.723$ \\
\hline$h k l$-range & $\pm 13, \pm 27, \pm 13$ \\
\hline measured refl. & 18082 \\
\hline unique refl. $\left[R_{\text {int }}\right]$ & $9407[0.0415]$ \\
\hline observed refl. $(I>2 \sigma(I))$ & 8975 \\
\hline data / restr. / param. & $9407 / 1$ / 622 \\
\hline goodness-of-fit $\left(F^{2}\right)$ & 0.922 \\
\hline$R 1, w R 2(I>2 \sigma(I))$ & $0.0284 / 0.0730$ \\
\hline$R 1, w R 2$ (all data) & $0.0300 / 0.0739$ \\
\hline res. el. dens. $\left[\mathrm{e} \cdot \AA^{-3}\right]$ & $-0.333 / 0.432$ \\
\hline
\end{tabular}




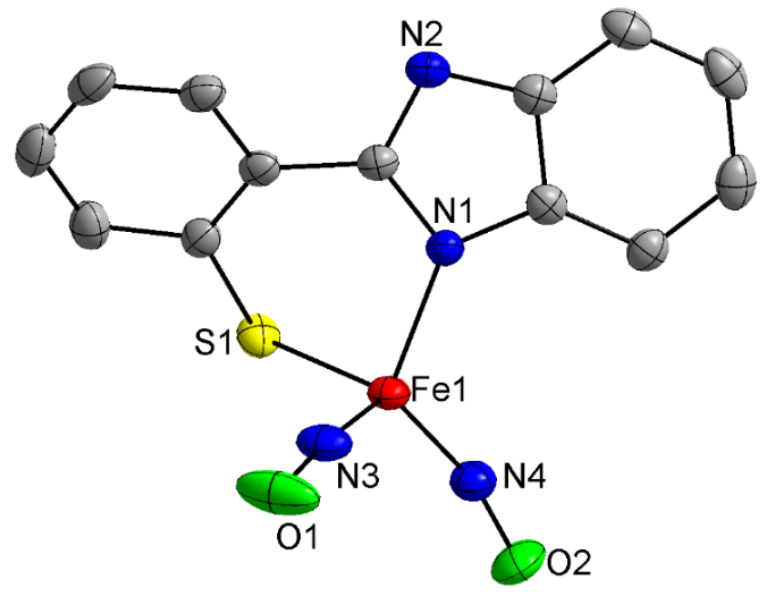

Figure 8.12. Plot (50\% probability thermal ellipsoids) of the anion of (PPN)34 (hydrogen atoms and counter ions omitted for clarity). Selected bond lengths $[\AA ̊ 0]$ and angles $\left[{ }^{\circ}\right]$ : $\mathrm{Fe}(1)-\mathrm{N}(3)$ 1.676(2), $\mathrm{Fe}(1)-\mathrm{N}(4)$ 1.681(2), $\mathrm{Fe}(1)-\mathrm{N}(1)$ 1.970(2), $\mathrm{Fe}(1)-\mathrm{S}(1) \quad 2.2544(8), \quad \mathrm{O}(1)-\mathrm{N}(3) \quad 1.171(3), \quad \mathrm{O}(2)-\mathrm{N}(4) \quad 1.185(3) ; \quad \mathrm{N}(3)-\mathrm{Fe}(1)-\mathrm{N}(4) \quad 113.70(12), \quad \mathrm{N}(3)-\mathrm{Fe}(1)-\mathrm{N}(1)$ 111.34(10), N(4)-Fe(1)-N(1) 117.04(10), N(3)-Fe(1)-S(1) 105.36(10), N(4)-Fe(1)-S(1) 112.76(8), N(1)-Fe(1)-S(1) 94.51(6), O(1)-N(3)-Fe(1) 169.1(2), O(2)-N(4)-Fe(1) 160.5(2).

Table 8.5. Crystal data and refinement details for (PPN)34.

\begin{tabular}{|c|c|}
\hline compound & $(\mathrm{PPN}) 34$ \\
\hline empirical formula & $\mathrm{C}_{49} \mathrm{H}_{38} \mathrm{FeN}_{5} \mathrm{O}_{2} \mathrm{P}_{2} \mathrm{~S}$ \\
\hline formula weight & 878.69 \\
\hline$T[\mathrm{~K}]$ & $133(2)$ \\
\hline crystal size $\left[\mathrm{mm}^{3}\right]$ & $0.340 \times 0.140 \times 0.100$ \\
\hline crystal system & monoclinic \\
\hline space group & $P 2{ }_{1} / n$ (No. 14 ) \\
\hline$a[\AA]$ & $10.62000(10)$ \\
\hline$b[\AA]$ & $30.8737(6)$ \\
\hline$c[\AA]$ & $12.9499(2)$ \\
\hline$\alpha\left[^{\circ}\right]$ & 90 \\
\hline$\beta\left[^{\circ}\right]$ & $95.1970(10)$ \\
\hline$\gamma\left[{ }^{\circ}\right]$ & 90 \\
\hline$V\left[\AA^{3}\right]$ & $4228.54(11)$ \\
\hline$Z$ & 4 \\
\hline$\rho\left[\mathrm{g} \cdot \mathrm{cm}^{-3}\right]$ & 1.380 \\
\hline$F(000)$ & 1820 \\
\hline$\mu\left[\mathrm{mm}^{-1}\right]$ & 0.529 \\
\hline$T_{\min } / T_{\max }$ & 0.8854 / 0.9672 \\
\hline$\theta$-range $\left[{ }^{\circ}\right]$ & $1.711-25.660$ \\
\hline$h k l$-range & $\pm 12, \pm 37,-14$ to 15 \\
\hline measured refl. & 42573 \\
\hline unique refl. $\left[R_{\text {int }}\right]$ & $7958[0.0504]$ \\
\hline observed refl. $(I>2 \sigma(I))$ & 6398 \\
\hline data / restr. / param. & 7958 / 0 / 541 \\
\hline goodness-of-fit $\left(F^{2}\right)$ & 1.126 \\
\hline$R 1, w R 2(I>2 \sigma(I))$ & $0.0420 / 0.0934$ \\
\hline$R 1, w R 2$ (all data) & $0.0605 / 0.1049$ \\
\hline res. el. dens. $\left[\mathrm{e} \cdot \AA^{-3}\right]$ & $-0.330 / 0.606$ \\
\hline
\end{tabular}




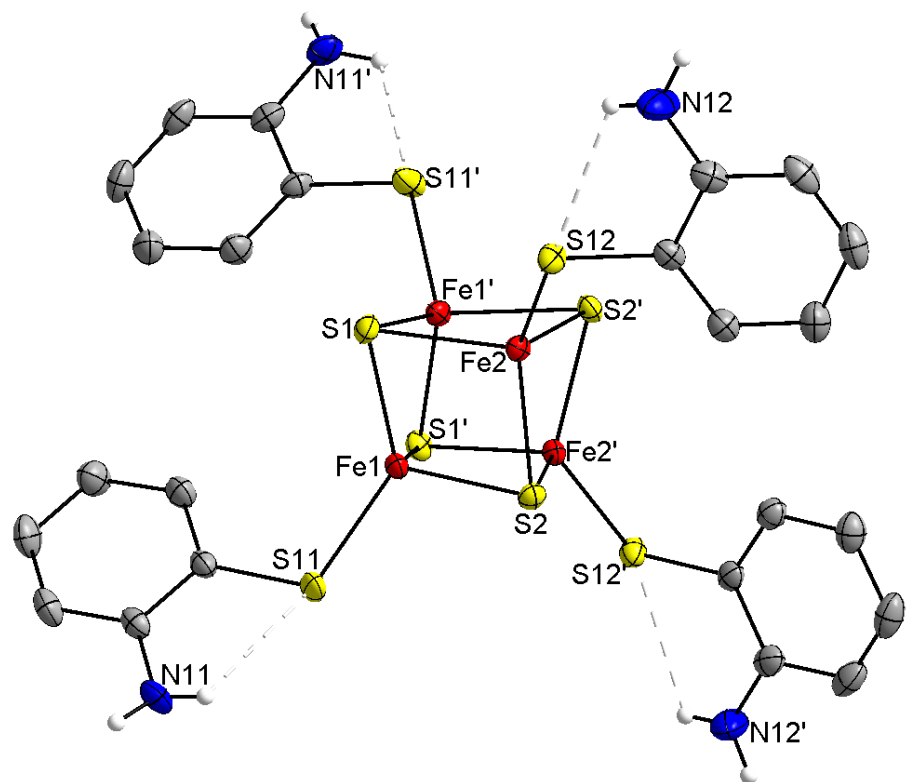

Figure 8.13. Plot (50\% probability thermal ellipsoids) of the anion of $\left(\mathrm{Et}_{4} \mathrm{~N}\right)_{2} \mathbf{3 8}$ (hydrogen atoms bound to carbons and counter ions omitted for clarity). Selected bond lengths $[\AA]$ and angles $\left[{ }^{\circ}\right]$ : $\mathrm{Fe}(1)-\mathrm{S}(11) 2.2666(6), \mathrm{Fe}(2)-\mathrm{S}(12) 2.2725(6)$, $\mathrm{Fe}(1)-\mathrm{S}(1)$ 2.2315(6), Fe(1)-S(2) 2.3154(6), Fe(2)-S(2) 2.2418(6), Fe(2)-S(1) 2.3145(6), S(1)-Fe(1)-S(11) 124.19(3), $\mathrm{S}(1)-\mathrm{Fe}(1)-\mathrm{S}(2)$ 102.86(2), S(11)-Fe(1)-S(2) 103.86(2), S(2)-Fe(2)-S(1) 102.57(2), S(12)-Fe(2)-S(1) 103.59(2), S(2)$\mathrm{Fe}(2)-\mathrm{S}(12)$ 124.42(2).

Table 8.6. Crystal data and refinement details for $\left(\mathrm{Et}_{4} \mathrm{~N}\right)_{2} \mathbf{3 8}$.

\begin{tabular}{|c|c|}
\hline compound & $\left(\mathrm{Et}_{4} \mathrm{~N}\right)_{2} \mathbf{3 8}$ \\
\hline empirical formula & $\mathrm{C}_{40} \mathrm{H}_{64} \mathrm{Fe}_{4} \mathrm{~N}_{6} \mathrm{~S}_{8}$ \\
\hline formula weight & 1108.85 \\
\hline$T[\mathrm{~K}]$ & $133(2)$ \\
\hline crystal size $\left[\mathrm{mm}^{3}\right]$ & $0.500 \times 0.470 \times 0.410$ \\
\hline crystal system & orthorhombic \\
\hline space group & Aba2 (No. 41) \\
\hline$a[\AA]$ & $19.1273(6)$ \\
\hline$b[\AA]$ & $17.6918(5)$ \\
\hline$c[\AA]$ & $14.4661(5)$ \\
\hline$\alpha\left[^{\circ}\right]$ & 90 \\
\hline$\beta\left[^{\circ}\right]$ & 90 \\
\hline$\gamma\left[{ }^{\circ}\right]$ & 90 \\
\hline$V\left[\AA^{3}\right]$ & $4895.3(3)$ \\
\hline$Z$ & 4 \\
\hline$\rho\left[\mathrm{g} \cdot \mathrm{cm}^{-3}\right]$ & 1.505 \\
\hline$F(000)$ & 2312 \\
\hline$\mu\left[\mathrm{mm}^{-1}\right]$ & 1.539 \\
\hline$T_{\min } / T_{\max }$ & $0.4823 / 0.7049$ \\
\hline$\theta$-range $\left[{ }^{\circ}\right]$ & $2.107-26.706$ \\
\hline$h k l$-range & $\pm 24, \pm 22, \pm 18$ \\
\hline measured refl. & 33515 \\
\hline unique refl. $\left[R_{\text {int }}\right]$ & $5182[0.0623]$ \\
\hline observed refl. $(I>2 \sigma(I))$ & 5166 \\
\hline data / restr. / param. & $5182 / 1 / 282$ \\
\hline goodness-of-fit $\left(F^{2}\right)$ & 1.099 \\
\hline$R 1, w R 2(I>2 \sigma(I))$ & $0.0192 / 0.0494$ \\
\hline$R 1, w R 2$ (all data) & $0.0193 / 0.0494$ \\
\hline res. el. dens. $\left[\mathrm{e} \cdot \AA^{-3}\right]$ & $-0.409 / 0.453$ \\
\hline
\end{tabular}




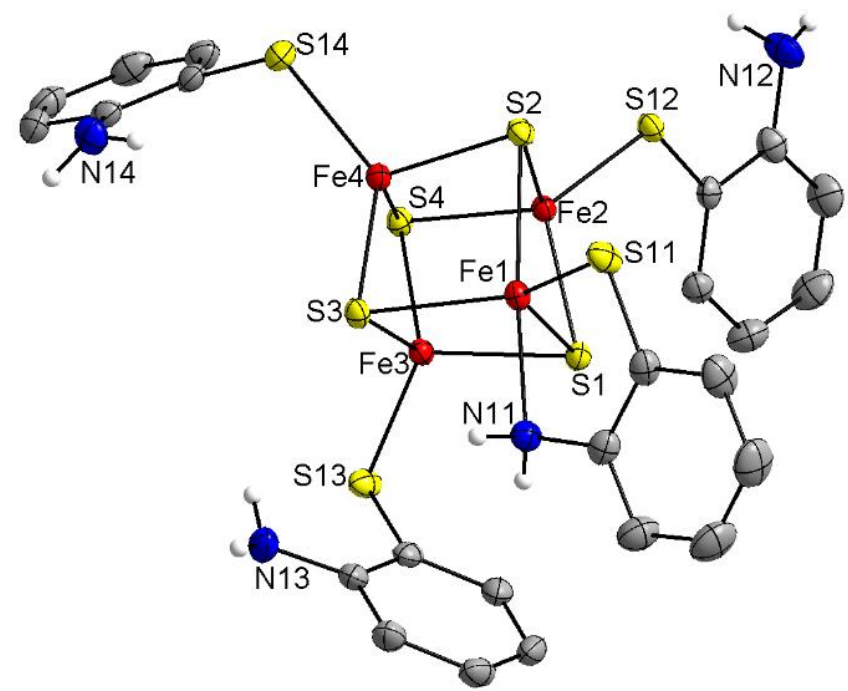

Figure 8.14. Plot (50\% probability thermal ellipsoids) of the anion of $\left(\mathrm{Me}_{3} \mathrm{PhN}\right)_{2} \mathbf{3 8}$ (hydrogen atoms bound to carbons, counter ions and solvent molecules omitted for clarity). Selected bond lengths [ $\AA$ ] and angles $\left[{ }^{\circ}\right]$ : $\mathrm{Fe}(1)-\mathrm{N}(11) 2.2770(13)$, Fe(1)-S(1) 2.2790(4), Fe(1)-S(11) 2.3318(4), Fe(1)-S(3) 2.3462(4), Fe(1)-S(2) 2.4500(4), Fe(2)-S(2) 2.2168(4), Fe(2)$\mathrm{S}(12)$ 2.2707(4), Fe(2)-S(1) 2.2818(4), Fe(2)-S(4) 2.3073(4), Fe(3)-S(3) 2.2562(4), Fe(3)-S(13) 2.2711(4), Fe(3)-S(1) 2.2905(4), Fe(3)-S(4) 2.3075(4), Fe(4)-S(4) 2.2486(4), Fe(4)-S(2) 2.2740(4), Fe(4)-S(14) 2.2756(4), Fe(4)-S(3) 2.2928(4), N(11)-Fe(1)-S(1) 90.40(4), N(11)-Fe(1)-S(11) 79.64(4), S(1)-Fe(1)-S(11) 124.115(17), N(11)-Fe(1)-S(3) 89.96(4).

Table 8.7. Crystal data and refinement details for $\left(\mathrm{Me}_{3} \mathrm{PhN}\right)_{2} 38$.

\begin{tabular}{|c|c|}
\hline compound & $\left(\mathrm{Me}_{3} \mathrm{PhN}\right)_{2} \mathbf{3 8}$ \\
\hline empirical formula & $\mathrm{C}_{40} \mathrm{H}_{64} \mathrm{Fe}_{4} \mathrm{~N}_{6} \mathrm{~S}_{8}$ \\
\hline formula weight & 1108.85 \\
\hline$T[\mathrm{~K}]$ & $133(2)$ \\
\hline crystal size $\left[\mathrm{mm}^{3}\right]$ & $0.500 \times 0.470 \times 0.410$ \\
\hline crystal system & orthorhombic \\
\hline space group & Aba2 (No. 41) \\
\hline$a[\AA]$ & $19.1273(6)$ \\
\hline$b[\AA]$ & $17.6918(5)$ \\
\hline$c[\AA]$ & $14.4661(5)$ \\
\hline$\alpha\left[^{\circ}\right]$ & 90 \\
\hline$\beta\left[^{\circ}\right]$ & 90 \\
\hline$\gamma\left[{ }^{\circ}\right]$ & 90 \\
\hline$V\left[\AA^{3}\right]$ & $4895.3(3)$ \\
\hline$Z$ & 4 \\
\hline$\rho\left[\mathrm{g} \cdot \mathrm{cm}^{-3}\right]$ & 1.505 \\
\hline$F(000)$ & 2312 \\
\hline$\mu\left[\mathrm{mm}^{-1}\right]$ & 1.539 \\
\hline$T_{\min } / T_{\max }$ & $0.4823 / 0.7049$ \\
\hline$\theta$-range $\left[{ }^{\circ}\right]$ & $2.107-26.706$ \\
\hline$h k l$-range & $\pm 24, \pm 22, \pm 18$ \\
\hline measured refl. & 33515 \\
\hline unique refl. $\left[R_{\text {int }}\right]$ & $5182[0.0623]$ \\
\hline observed refl. $(I>2 \sigma(I))$ & 5166 \\
\hline data / restr. / param. & $5182 / 1 / 282$ \\
\hline goodness-of-fit $\left(F^{2}\right)$ & 1.099 \\
\hline$R 1, w R 2(I>2 \sigma(I))$ & $0.0192 / 0.0494$ \\
\hline$R 1, w R 2$ (all data) & $0.0193 / 0.0494$ \\
\hline res. el. dens. $\left[\mathrm{e} \cdot \AA^{-3}\right]$ & $-0.409 / 0.453$ \\
\hline
\end{tabular}




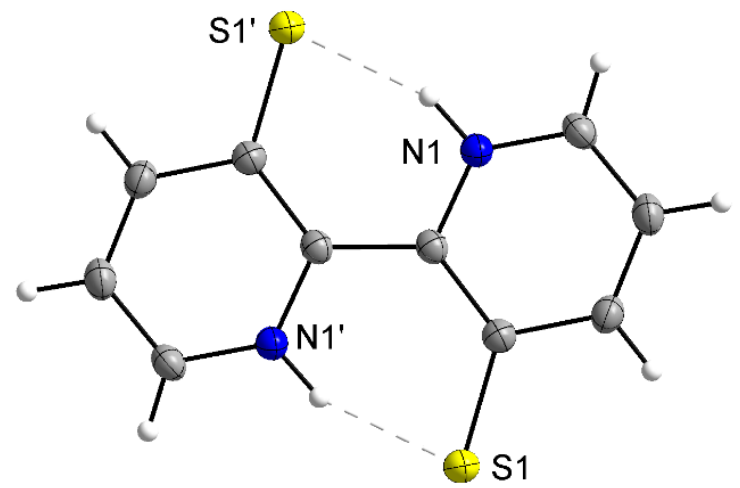

Figure 8.15. Plot (50\% probability thermal ellipsoids) of the anion of $\mathbf{4 1} \mathrm{H}_{2}$ (hydrogen atoms bound to carbons, counter ions and solvent molecules omitted for clarity). Selected bond lengths $[\AA]$ and angles $\left[{ }^{\circ}\right]$ : S(1)-C(2) 1.7318(16), N(1)$\mathrm{C}(5)$ 1.337(2), N(1)-C(1) 1.357(2), C(5)-N(1)-C(1) 125.46(15).

Table 8.8. Crystal data and refinement details for $\mathbf{4 1} \mathrm{H}_{2}$.

\begin{tabular}{|c|c|}
\hline compound & $41 \mathrm{H}_{2}$ \\
\hline empirical formula & $\mathrm{C}_{10} \mathrm{H}_{8} \mathrm{~N}_{2} \mathrm{~S}_{2}$ \\
\hline formula weight & 220.30 \\
\hline$T[\mathrm{~K}]$ & $133(2)$ \\
\hline crystal size $\left[\mathrm{mm}^{3}\right]$ & $0.310 \times 0.230 \times 0.120$ \\
\hline crystal system & monoclinic \\
\hline space group & $P 2_{1} / c$ (No. 14$)$ \\
\hline$a[\AA]$ & $4.1146(3)$ \\
\hline$b[\AA]$ & $10.8240(11)$ \\
\hline$c[\AA]$ & $10.4628(9)$ \\
\hline$\alpha\left[{ }^{\circ}\right]$ & 90 \\
\hline$\beta\left[{ }^{\circ}\right]$ & $90.143(7)$ \\
\hline$\gamma\left[{ }^{\circ}\right]$ & 90 \\
\hline$V\left[\AA^{3}\right]$ & $465.97(7)$ \\
\hline$Z$ & 2 \\
\hline$\rho\left[\mathrm{g} \cdot \mathrm{cm}^{-3}\right]$ & 1.570 \\
\hline$F(000)$ & 228 \\
\hline$\mu\left[\mathrm{mm}^{-1}\right]$ & 0.525 \\
\hline$T_{\min } / T_{\max }$ & $0.8526 / 0.9390$ \\
\hline$\theta$-range $\left[{ }^{\circ}\right]$ & $2.708-26.796$ \\
\hline$h k l$-range & $\pm 5, \pm 13, \pm 13$ \\
\hline measured refl. & 5273 \\
\hline unique refl. [ $R$ int $]$ & $991[0.0214]$ \\
\hline observed refl. $(I>2 \sigma(I))$ & 889 \\
\hline data / restr. / param. & $991 / 0 / 80$ \\
\hline goodness-of-fit $\left(F^{2}\right)$ & 1.087 \\
\hline$R 1, w R 2(I>2 \sigma(I))$ & $0.0296 / 0.0786$ \\
\hline$R 1, w R 2$ (all data) & $0.0344 / 0.0819$ \\
\hline res. el. dens. $\left[\mathrm{e} \cdot \AA^{-3}\right]$ & $-0.172 / 0.357$ \\
\hline
\end{tabular}

Table 8.9 Hydrogen bonds for $\mathbf{4 1} \mathrm{H}_{2}\left[\AA\right.$ and $^{\circ}$ ].

\begin{tabular}{c|c|c|c|c}
$\mathrm{D}-\mathrm{H} \ldots \mathrm{A}$ & $\mathrm{d}(\mathrm{D}-\mathrm{H})$ & $\mathrm{d}(\mathrm{H} . . \mathrm{A})$ & $\mathrm{d}(\mathrm{D} \ldots \mathrm{A})$ & $<(\mathrm{DHA})$ \\
\hline $\mathrm{N}(1)-\mathrm{H}(1) \ldots \mathrm{S}(1) \# 1$ & $0.92(2)$ & $2.02(2)$ & $2.8844(15)$ & $158(2)$
\end{tabular}

Symmetry transformations used to generate equivalent atoms:

$\# 1-\mathrm{x}+1,-\mathrm{y}+1,-\mathrm{z}+1$ 


\section{Literature}

(1) Beinert, H.; Holm, R. H.; Münck, E. Science 1997, 277, 653.

(2) Wächtershäuser, G. Prog. Biophys. molec. Biol. 1992, 58, 85.

(3) Wächtershäuser, G. Chem. Biodivers. 2007, 4, 584.

(4) Huber, C.; Wächtershäuser, G. Science 1997, 276, 245.

(5) Daniel, R. M.; Danson, M. J. J. Mol. Evol. 1995, 40, 559.

(6) Bonfio, C.; Valer, L.; Scintilla, S.; Shah, S.; Evans, D. J.; Jin, L.; Szostak, J. W.; Sasselov, D. D.; Sutherland, J. D.; Mansy, S. S. Nat. Chem. 2017, 9, 1229.

(7) Hagen, W. R. Adv. Inorg. Chem. 1992, 38, 165.

(8) Beinert, H.; Sands, R. H. Biochem. Biophys. Res. Commun. 1960, 3, 41.

(9) Gibson, J. F.; Hall, D. O.; Thornley, J. H. M.; Whatley, F. R. Proc. Natl. Acad. Sci. 1966, 56, 987.

(10) Rao, P. V.; Holm, R. H. Chem. Rev. 2004, 104, 527.

(11) Lee, S. C.; Lo, W.; Holm, R. H. Chem. Rev. 2014, 114, 3579.

(12) Yao, W.; Gurubasavaraj, P. M.; Holland, P. L. In Molecular Design in Inorganic Biochemistry; Rabinovich, D., Ed.; Springer: Berlin, 2014; pp 1-36.

(13) Kennedy, M. C.; Kent, T. A.; Emptage, M.; Merkle, H.; Beinert, H. J. Biol. Chem. 1984, 259, 14463.

(14) Khoroshilova, N.; Popescu, C.; Munck, E.; Beinert, H.; Kiley, P. J. Proc. Natl. Acad. Sci. 1997, 94, 6087.

(15) Rees, D. C.; Howard, J. B. Science 2003, 300 (May), 929.

(16) Bak, D. W.; Elliott, S. J. Curr. Opin. Chem. Biol. 2014, 19, 50.

(17) Link, T. A. Adv. Inorg. Chem. 1999, 47, 83.

(18) Calzolai, L.; Zhou, Z. H.; Adams, M. W. W.; La Mar, G. N. J. Am. Chem. Soc. 1996, $118,2513$.

(19) Hunsicker-Wang, L. M.; Heine, A.; Chen, Y.; Luna, E. P.; Todaro, T.; Zhang, Y. M.; Williams, P. A.; McRee, D. E.; Hirst, O. J.; Stout, C. D.; Fee, J. A. Biochemistry 2003, 42, 7303.

(20) Konkle, M. E.; Muellner, S. K.; Schwander, A. L.; Dicus, M. M.; Pokhrel, R.; Britt, R. D.; Taylor, A. B.; Hunsicker-Wang, L. M. Biochemistry 2009, 48, 9848.

(21) Lill, R. Nature 2009, 460, 831.

(22) Malkin, R.; Rabinowitz, J. C. Biochem. Biophys. Res. Commun. 1966, 23, 822.

(23) Py, B.; Barras, F. Nat. Rev. Microbiol. 2010, 8, 436.

(24) Roche, B.; Aussel, L.; Ezraty, B.; Mandin, P.; Py, B.; Barras, F. Biochim. Biophys. Acta 2013, 1827, 455. 
(25) Takahashi, Y.; Tokumoto, U. J. Biol. Chem. 2002, 277, 28380.

(26) Fontecave, M.; Choudens, S. O. De; Py, B.; Barras, F. J. Biol. Inorg. Chem. 2005, 10,713 .

(27) Lill, R.; Dutkiewicz, R.; Freibert, S. A.; Heidenreich, T.; Mascarenhas, J.; Netz, D. J.; Paul, V. D.; Pierik, A. J.; Richter, N.; Stümpfig, M.; Srinivasan, V.; Stehling, O.; Mühlenhoff, U. Eur. J. Cell Biol. 2015, 94, 280.

(28) Braymer, J. J.; Lill, R. J. Biol. Chem. 2017, 292, 12754.

(29) Maio, N.; Rouault, T. A. Biochim. Biophys. Acta 2015, 1853, 1493.

(30) Netz, D. J. A.; Mascarenhas, J.; Stehling, O.; Pierik, A. J.; Lill, R. Trends Cell Biol. 2014, 24, 303.

(31) Freibert, S.-A.; Goldberg, A. V; Hacker, C.; Molik, S.; Dean, P.; Williams, T. A.; Nakjang, S.; Long, S.; Sendra, K.; Bill, E.; Heinz, E.; Hirt, R. P.; Lucocq, J. M.; Embley, T. M.; Lill, R. Nat. Commun. 2017, 8, 13932.

(32) Tanaka, N.; Kanazawa, M.; Tonosaki, K.; Yokoyama, N.; Kuzuyama, T.; Takahashi, Y. Mol. Microbiol. 2016, 99, 835.

(33) Vaccaro, B. J.; Clarkson, S. M.; Holden, J. F.; Lee, D.; Wu, C.; Poole II, F. L.; Cotelesage, J. J. H.; Hackett, M. J.; Mohebbi, S.; Sun, J.; Li, H.; Johnson, M. K.; George, G. N.; Adams, M. W. W. Nat. Commun. 2017, 8, 16110.

(34) Campuzano, V.; Montermini, L.; Molto, M. D.; Pianese, L.; Cossee, M.; Cavalcanti, F.; Monros, E.; Rodius, F.; Duclos, F.; Monticelli, A.; Zara, F.; Canizares, J.; Koutnikova, H.; Bidichandani, S.; Gellera, C.; Brice, A.; Trouillas, P.; Michele, G. De; Filla, A.; Frutos, R. De; Patel, P.; Donato, S. Di; Mandel, J.; Cocozza, S.; Koenig, M.; Pandolfoll, M. Science 1996, 271, 1423.

(35) Colin, F.; Martelli, A.; Clémancey, M.; Latour, J.-M.; Gambarelli, S.; Zeppieri, L.; Birck, C.; Page, A.; Puccio, H.; Ollagnier de Choudens, S. J. Am. Chem. Soc. 2013, $135,733$.

(36) Johnson, D. C.; Dean, D. R.; Smith, A. D.; Johnson, M. K. Annu. Rev. Biochem. 2005, 74, 247.

(37) Capozzi, F.; Ciurli, S.; Luchinat, C. In Structure and Bonding; 1998; Vol. 90, pp 127-160.

(38) Noodleman, L.; Lovell, T.; Liu, T.; Himo, F.; Torres, R. A. Curr. Opin. Chem. Biol. 2002, 6, 259.

(39) Peters, J. W.; Stowell, M. H. B.; Soltis, S. M.; Finnegan, M. G.; Johnson, M. K.; Rees, D. C. Biochemistry 1997, 36, 1181.

(40) Crouse, B. R.; Meyer, J.; Johnson, M. K. J. Am. Chem. Soc. 1995, 117, 9612.

(41) Yoo, S. J.; Angove, H. C.; Burgess, B. K.; Hendrich, M. P.; Münck, E. J. Am. Chem. Soc. 1999, 121, 2534.

(42) Hans, M.; Buckel, W.; Bill, E. J. Biol. Inorg. Chem. 2008, 13, 563.

(43) Takeda, K.; Miki, K. FEBS J. 2017, 284, 2163. 
(44) Banci, L.; Bertini, I.; Ciurli, S.; Ferretti, S.; Luchinat, C.; Picciolit, M. Biochemistry 1993, 32, 9387.

(45) Meyer, J. J. Biol. Chem. 2008, 13, 157.

(46) Bartsch, R. Methods Enzymol. 1978, 53, 329.

(47) Ohta, S.; Ohki, Y. Coord. Chem. Rev. 2017, 338, 207.

(48) Colbert, C. L.; Couture, M. M.; Eltis, L. D.; Bolin, J. T.; Lafayette, W. Structure 2000, 8, 1267.

(49) Link, T. A. Biochim. Biophys. Acta 1994, 1185, 81.

(50) Hsueh, K.-L.; Westler, W. M.; Markley, J. L. J. Am. Chem. Soc. 2010, 132, 7908.

(51) Zu, Y.; Couture, M. M.; Kolling, D. R. J.; Crofts, A. R.; Eltis, L. D.; Fee, J. A.; Hirst, J. Biochemistry 2003, 42, 12400.

(52) Paddock, M. L.; Wiley, S. E.; Axelrod, H. L.; Cohen, A. E.; Roy, M.; Abresch, E. C.; Capraro, D.; Murphy, A. N.; Nechushtai, R.; Dixon, J. E.; Jennings, P. A. Proc. Natl. Acad. Sci. 2007, 104, 14342.

(53) Lin, J.; Zhang, L.; Lai, S.; Ye, K. PLoS One 2011, 6, 24790.

(54) Bak, D. W.; Elliott, S. J. Biochemistry 2013, 52, 4687.

(55) Fontecilla-Camps, J. C.; Volbeda, A.; Cavazza, C.; Nicolet, Y. Chem. Rev. 2007, 107, 4273.

(56) Kiley, P. J.; Beinert, H. Curr. Opin. Microbiol. 2003, 6, 181.

(57) Mettert, E. L.; Kiley, P. J. Biochim. Biophys. Acta 2015, 1853, 1284.

(58) Miller, H. K.; Auerbuch, V. Metallomics 2015, 7, 943.

(59) Kobayashi, K. Acc. Chem. Res. 2017, 50, 1672.

(60) Gu, M.; Imlay, J. A. Mol. Microbiol. 2011, 79, 1136.

(61) Rouault, T. A.; Klausner, R. D. Trends Biochem. Sci. 1996, 21, 174.

(62) Crack, J. C.; Thomson, A. J.; LeBrun, N. E. Proc. Natl. Acad. Sci. 2017, 114, 3215.

(63) Tucker, N. P.; Brun, N. E. Le; Dixon, R.; Hutchings, M. I. Trends Microbiol. 2010, $18,149$.

(64) Volbeda, A.; Dodd, E. L.; Darnault, C.; Crack, J. C.; Renoux, O.; Hutchings, M. I.; Brun, N. E. Le; Fontecilla-camps, J. C. Nat. Commun. 2017, 8, 15052.

(65) Anderson, C. P.; Shen, M.; Eisenstein, R. S.; Leibold, E. A. Biochim. Biophys. Acta 2012, 1823, 1468.

(66) Spatzal, T.; Aksoyoglu, M.; Zhang, L.; Andrade, S. L. A.; Schleicher, E.; Weber, S.; Rees, D. C.; Einsle, O. Science 2011, 334, 940.

(67) Lancaster, K. M.; Roemelt, M.; Ettenhuber, P.; Hu, Y.; Ribbe, M. W.; Neese, F.; Bergmann, U.; DeBeer, S. Science 2011, 334, 974.

(68) Grunenberg, J. Angew. Chem. 2017, 56, 7288. 
(69) Eady, R. R. Chem. Rev 1996, 962, 3013.

(70) Lee, C. C.; Hu, Y.; Ribbe, M. W. Science 2010, 329, 642.

(71) Vincent, K. A.; Parkin, A.; Armstrong, F. A. Chem. Rev. 2007, 107, 4366.

(72) Beinert, H.; Kennedy, M. C.; Stout, C. D. Chem. Rev. 1996, 96, 2335.

(73) Kennedy, M. C.; Werst, M.; Telser, J.; Emptage, M. H.; Beinert, H.; Hoffman, B. M. Proc. Natl. Acad. Sci. 1987, 84, 8854.

(74) Frey, P. A.; Hegeman, A. D.; Ruzicka, F. J.; Frey, P. A.; Hegeman, A. D.; Ruzicka, F. J.; Radical, T.; Frey, P. A.; Hegeman, A. D.; Ruzicka, F. J. Crit. Rev. Biochem. Mol. Biol. 2017, 43, 63.

(75) Walsby, C. J.; Ortillo, D.; Broderick, W. E.; Broderick, J. B.; Hoffman, B. M. J. Am. Chem. Soc. 2002, 124, 11270.

(76) Hiscox, M. J.; Driesener, R. C.; Roach, P. L. Biochim. Biophys. Acta 2012, 1824, 1165 .

(77) Lanz, N. D.; Booker, S. J. Biochim. Biophys. Acta 2012, 1824, 1196.

(78) Hutcheson, R. U.; Broderick, J. B. Metallomics 2012, 4, 1149.

(79) Shisler, K. A.; Broderick, J. B. Curr. Opin. Struct. Biol. 2012, 22, 701.

(80) Broach, R. B.; Jarrett, J. T. Biochemistry 2006, 45, 14166.

(81) Jarrett, J. T. Arch. Biochem. Biophys. 2005, 433, 312.

(82) Harmer, J.; Hiscox, M. J.; Dinis, P. C.; Fox, S. J.; Iliopoulos, A.; Hussey, J. E.; Sandy, J.; Van Beek, F. T.; Essex, J. W.; Roach, P. L. Biochem. J. 2014, 464, 123.

(83) Que, L.; Holm, R. H. J. Am. Chem. Soc. 1975, 97, 463.

(84) Herskovitz, T.; Averill, B. A.; Holm, R. H.; Ibers, J. A.; Phillips, W. D.; Weiher, J. F. Proc. Natl. Acad. Sci. 1972, 69, 2437.

(85) Mayerle, J. J.; Frankel, R. B.; Holm, R. H.; Ibers, J. A.; Phillips, W. D.; Weiher, J. F. Proc. Natl. Acad. Sci. 1973, 70, 2429.

(86) Lane, R. W. Proc. Natl. Acad. Sci. 1975, 72, 2868.

(87) Hagen, K. S.; Watson, A. D.; Holm, R. H. J. Am. Chem. Soc. 1983, 105, 3905.

(88) Zhou, J.; Holm, R. H. J. Am. Chem. Soc. 1995, 117, 11353.

(89) Beardwood, P.; Gibson, J. F. J. Chem. Soc. Chem. Commun. 1986, 490.

(90) Beardwood, P.; Gibson, J. F. J. Chem. Soc. Dalt. Trans. 1992, 2457.

(91) Ohki, Y.; Sunada, Y.; Tatsumi, K. Chem. Lett. 2005, 34, 172.

(92) Ballmann, J.; Albers, A.; Demeschko, S.; Dechert, S.; Bill, E.; Bothe, E.; Ryde, U.; Meyer, F. Angew. Chem. 2008, 47, 9537.

(93) Qi, W.; Li, J.; Chain, C. Y.; Pasquevich, G. A.; Pasquevich, A. F.; Cowan, J. A. Chem. Commun. 2013, 49, 6313.

(94) Sharp, C. R.; Duncan, J. S.; Lee, S. C. Inorg. Chem. 2010, 49, 6697. 
(95) Sullivan, T. O.; Millar, M. M. J. Am. Chem. Soc. 1985, 107, 4096.

(96) Papaefthymiou, V.; Millar, M. M.; Münck, E. Inorg. Chem. 1986, 25, 3010.

(97) Job, R. C.; Bruice, T. C. Proc. Natl. Acad. Sci. 1975, 72, 2478.

(98) Carrell, H. L.; Glusker, J. P.; Bruice, T. C.; Job, R. J. Am. Chem. Soc. 1977, 99, 3683.

(99) Deng, L.; Holm, R. H. J. Am. Chem. Soc. 2008, 130, 9878.

(100) Ohki, Y.; Tanifuji, K.; Yamada, N.; Imada, M.; Tajima, T.; Tatsumi, K. Proc. Natl. Acad. Sci. 2011, 108, 12635.

(101) Stack, T. D. . P.; Holm, R. H. J. Am. Chem. Soc. 1988, 110, 2484.

(102) Ciurli, S.; Carney, J.; Weigel, J. A.; Carney, M. J.; Stack, T. D. P.; Papaefthymiou, G. C.; Holm, R. H. J. Am. Chem. Soc. 1990, 112, 2654.

(103) Holm, R. H. Adv. Inorg. Chem. 1992, 38, 1.

(104) Johnson, M. K.; Duderstadt, R. E. Adv. Inorg. Chem. 1999, 47, 1.

(105) Corlic, I.; Mercado, B. Q.; Bill, E.; Vinyard, D. J.; Holland, P. L. Nature 2015, 526, 96.

(106) Ilija, C.; Holland, P. L. J. Am. Chem. Soc. 2016, 138, 7200.

(107) Stamler, J.; Singel, D.; Loscalzo, J. Science 1992, 258, 1898.

(108) Murad, F. Angew. Chem. 1999, 38, 1856.

(109) Brown, G. C. Front. Biosci. 2007, 12, 1024.

(110) Watmough, N. J.; Butland, G.; Cheesman, M. R.; Moir, J. W.; Richardson, D. J.; Spiro, S. Biochim. Biophys. Acta 1999, 1411, 456.

(111) Derbyshire, E. R.; Marletta, M. A. In Handbook of Experimental Pharmacology; Schmidt, H., Hofmann, F., Stasch, J.-P., Eds.; Springer-Verlag: Berlin, Heidelberg, 2009; pp 17-31.

(112) Ibrahim, M.; Derbyshire, E. R.; Soldatova, A. V; Marletta, M. A.; Spiro, T. G. Biochemistry 2010, 49, 4864.

(113) Furchgott, R. F. Angew. Chem. 1999, 38, 1870.

(114) Ignarro, L. J. Angew. Chem. 1999, 38, 1882.

(115) Prast, H.; Philippu, A. Prog. Neurobiol. 2001, 64, 51.

(116) Bogdan, C. Nat. Immunol. 2001, 2, 907.

(117) Bronte, V.; Zanovello, P. Nat. Rev. Immunol. 2005, 5, 641.

(118) Calabrese, V.; Mancuso, C.; Calvani, M.; Rizzarelli, E.; Butterfield, D. A.; Stella, A. M. G. Nat. Rev. Neurosci. 2007, 8, 766.

(119) Richardson, D. R.; Lok, H. C. Biochim. Biophys. Acta 2008, 1780, 638.

(120) Enemark, J. H.; Feltham, R. D. Coord. Chem. Rev. 1974, 13, 339. 
(121) Roussin, M. L. Ann. Chim. Phys. 1858, 52, 285.

(122) Butler, A. R.; Megson, I. L. Chem. Rev. 2002, 102, 1155.

(123) Lu, T.-T.; Tsou, C. C.; Huang, H. W.; Hsu, I. J.; Chen, J. M.; Kuo, T. S.; Wang, Y.; Liaw, W. F. Inorg. Chem. 2008, 47, 6040.

(124) Seto, M.; Yoda, Y.; Kikuta, S.; Zhang, X. W.; Ando, M. Phys. Rev. Lett. 1995, 74, 3828 .

(125) Wang, H.; Alp, E.; Yoda, Y.; Cramer, S. P. Methods Mol. Biol. 2014, 1122, 125.

(126) Tonzetich, Z. J.; Wang, H.; Mitra, D.; Tinberg, C. E.; Do, L. H.; Jenney, F. E.; Adams, M. W. W.; Cramer, S. P.; Lippard, S. J. J. Am. Chem. Soc. 2010, 132, 6914.

(127) Tinberg, C. E.; Tonzetich, Z. J.; Wang, H.; Do, L. H.; Yoda, Y.; Cramer, S. P.; Lippard, S. J. J. Am. Chem. Soc. 2010, 132, 18168.

(128) Serrano, P. N.; Wang, H.; Crack, J. C.; Prior, C.; Hutchings, M. I.; Thomson, A. J.; Kamali, S.; Yoda, Y.; Zhao, J.; Hu, M. Y.; Alp, E. E.; Oganesyan, V. S.; Brun, N. E. Le; Cramer, S. P. Angew. Chem. 2016, 55, 14575.

(129) Xiao, Y.; Wang, H.; George, S. J.; Smith, M. C.; Adams, M. W. W.; Jenney, F. E.; Sturhahn, W.; Alp, E. E.; Zhao, J.; Yoda, Y.; Dey, A.; Solomon, E. I.; Cramer, S. P. J. Am. Chem. Soc. 2005, 127, 14596.

(130) Lauterbach, L.; Wang, H.; Horch, M.; Gee, L. B.; Yoda, Y.; Tanaka, Y.; Zebger, I.; Lenz, O.; Cramer, S. P. Chem. Sci. 2015, 6, 1055.

(131) Kamali, S.; Wang, H.; Mitra, D.; Ogata, H.; Lubitz, W.; Manor, B. C.; Rauchfuss, T. B.; Byrne, D.; Bonnefoy, V.; Jenney, F. E.; Adams, M. W. W.; Yoda, Y.; Alp, E.; Zhao, J.; Cramer, S. P. Angew. Chem. 2013, 52, 724.

(132) Mitra, D.; Pelmenschikov, V.; Guo, Y.; Case, D. A.; Wang, H.; Dong, W.; Tan, M.; Ichiye, T.; Jenney, F. E.; Adams, M. W. W.; Yoda, Y.; Zhao, J.; Cramer, S. P. Biochemistry 2011, 50, 5220.

(133) Ogata, H.; Krämer, T.; Wang, H.; Schilter, D.; Pelmenschikov, V.; van Gastel, M.; Neese, F.; Rauchfuss, T. B.; Gee, L. B.; Scott, A. D.; Yoda, Y.; Tanaka, Y.; Lubitz, W.; Cramer, S. P. Nat. Commun. 2015, 6, 7890.

(134) Tsai, M.-L.; Tsou, C.-C.; Liaw, W.-F. Acc. Chem. Res. 2015, 48, 1184.

(135) Fitzpatrick, J.; Kalyvas, H.; Shearer, J.; Kim, E. Chem. Commun. 2013, 49, 5550.

(136) Drapier, J. C. Methods 1997, 11, 319.

(137) Lu, T.-T.; Huang, H.-W.; Liaw, W.-F. Inorg. Chem. 2009, 48, 9027.

(138) Yang, W.; Rogers, P. A.; Ding, H. J. Biol. Chem. 2002, 277, 12868.

(139) Rogers, P. A.; Ding, H. J. Biol. Chem. 2001, 276, 30980.

(140) Kennedy, M. C.; Antholine, W. E.; Beinert, H. J. Biol. Chem. 1997, 272, 20340.

(141) Foster, M. W.; Cowan, J. A. J. Am. Chem. Soc. 1999, 121, 4093.

(142) D’Autréaux, B.; Horner, O.; Oddou, J.; Jeandey, C.; Gambarelli, S.; Berthomieu, C.; Latour, J.; Michaud-Soret, I. J. Am. Chem. Soc. 2004, 126, 6005. 
(143) D’Autréaux, B.; Tucker, N. P.; Dixon, R.; Spiro, S. Nature 2005, 437, 769.

(144) Strube, K.; de Vries, S.; Cramm, R. J. Biol. Chem. 2007, 282, 20292.

(145) Landry, A. P.; Duan, X.; Huang, H.; Ding, H. Free Radic. Biol. Med. 2011, 50, 1582.

(146) Yukl, E.; Elbaz, M.; Nakano, M.; Moënne-Loccoz, P. Biochemistry 2008, 47, 13084.

(147) Cruz-Ramos, H.; Crack, J.; Wu, G.; Hughes, M. N.; Scott, C.; Thomson, A. J.; Green, J.; Poole, R. K. EMBO J. 2002, 21, 3235.

(148) Crack, J. C.; Svistunenko, D. A.; Munnoch, J.; Thomson, A. J.; Hutchings, M. I.; Brun, N. E. Le. J. Biol. Chem. 2016, 291, 8663.

(149) Crack, J. C.; Smith, L. J.; Stapleton, M. R.; Peck, J.; Watmough, N. J.; Buttner, M. J.; Buxton, R. S.; Green, J.; Oganesyan, V. S.; Thomson, A. J.; Le Brun, N. E. J. Am. Chem. Soc. 2011, 133, 1112.

(150) Crack, J. C.; Stapleton, M. R.; Green, J.; Thomson, A. J.; Le Brun, N. E. J. Biol. Chem. 2013, 288, 11492.

(151) Ding, H.; Demple, B. Proc. Natl. Acad. Sci. 2000, 97, 5146.

(152) Lo, F. C.; Lee, J. F.; Liaw, W. F.; Hsu, I. J.; Tsai, Y. F.; Chan, S. I.; Yu, S. S. F. Chem. Eur. J. 2012, 18, 2565.

(153) Fujikawa, M.; Kobayashi, K.; Kozawa, T. J. Biochem. 2014, 156, 163.

(154) Grabarczyk, D. B.; Ash, P. A.; Vincent, K. A. J. Am. Chem. Soc. 2014, 136, 11236.

(155) Cheng, Z.; Landry, A. P.; Wang, Y.; Ding, X. H. J. Biol. Chem. 2017, 292, 3146.

(156) Lin, Z.; Lo, F.; Li, C.; Chen, C.; Huang, W.; Hsu, I.; Lee, J.; Horng, J.; Liaw, W. Inorg. Chem. 2011, 50, 10417.

(157) Tsai, M.-C.; Tsai, F.-T.; Lu, T.-T.; Tsai, M.-L.; Wei, Y.-C.; Hsu, I.-J.; Lee, J.-F.; Liaw, W.-F. Inorg. Chem. 2009, 48, 9579.

(158) Harrop, T. C.; Tonzetich, Z. J.; Reisner, E.; Lippard, S. J. J. Am. Chem. Soc. 2008, 130, 15602 .

(159) Butler, A. R.; Glidewell, C.; Hyde, A. R.; Walton, J. C. Inorg. Chim. Acta 1985, 106, L7.

(160) Tonzetich, Z. J.; McQuade, L. E.; Lippard, S. J. Inorg. Chem. 2010, 49, 6338.

(161) Tran, C. T.; Williard, P. G.; Kim, E. J. Am. Chem. Soc. 2014, 136, 11874.

(162) Victor, E.; Lippard, S. J. Inorg. Chem. 2014, 53, 5311.

(163) Albers, A.; Bayer, T.; Demeshko, S.; Dechert, S.; Meyer, F. Chem. Eur. J. 2013, 19, 10101.

(164) Albers, A.; Demeshko, S.; Dechert, S.; Saouma, C. T.; Mayer, J. M.; Meyer, F. J. Am. Chem. Soc. 2014, 136, 3946.

(165) Albers, A.; Demeshko, S.; Dechert, S.; Bill, E.; Bothe, E.; Meyer, F. Angew. Chem. 2011, 50, 9191.

(166) Bergner, M.; Dechert, S.; Demeshko, S.; Kupper, C.; Mayer, J. M.; Meyer, F. J. Am. 
Chem. Soc. 2017, 139, 701.

(167) Bergner, M.; Roy, L.; Dechert, S.; Neese, F.; Ye, S.; Meyer, F. Angew. Chem. 2017, $56,4882$.

(168) Tonzetich, Z. J.; Do, L. H.; Lippard, S. J. J. Am. Chem. Soc. 2009, 131, 7964.

(169) Schiewer, C. E. Master Thesis: Reactions of Biomimetic Iron-Sulfur Clusters, Georg-August-Universität Göttingen, 2013.

(170) Hung, M.; Tsai, M.; Lee, G.; Liaw, W. Inorg. Chem. 2006, 45, 6041.

(171) Pulukkody, R.; Darensbourg, M. Y. Acc. Chem. Res. 2015, 48, 2049.

(172) Tran, C. T.; Skodje, K. M.; Kim, E. In Progress in Inorganic Chemistry; Karlin, K. D., Ed.; John Wiley \& Sons, 2014; Vol. 59, pp 339-379.

(173) Shih, W. C.; Lu, T. Te; Yang, L. B.; Tsai, F. Te; Chiang, M. H.; Lee, J. F.; Chiang, Y. W.; Liaw, W. F. J. Inorg. Biochem. 2012, 113, 83.

(174) Tsou, C.; Tsai, F.; Chen, H.; Hsu, I.; Liaw, W. Inorg. Chem. 2013, 52, 1631.

(175) Vanin, A. F. Nitric Oxide 2016, 54, 15.

(176) Vanin, A. F. Biophysics 2017, 62, 509.

(177) Fitzpatrick, J.; Kim, E. Acc. Chem. Res. 2015, 48, 2453.

(178) Yuan, S.; Liaw, W.; Wang, Y. Inorg. Chem. 2016, 55, 9383.

(179) Li, M.; Bonnet, D.; Bill, E.; Neese, F.; WeyhermUller, T.; Blum, N.; Sellmann, D.; Wieghardt, K. Inorg. Chem. 2002, 41, 3444.

(180) Kupper, C.; Rees, J. A.; Dechert, S.; Debeer, S.; Meyer, F. J. Am. Chem. Soc. 2016, $138,7888$.

(181) Speelman, A. L.; Zhang, B.; Silakov, A.; Skodje, K. M.; Alp, E. E.; Zhao, J.; Hu, M. Y.; Kim, E.; Krebs, C.; Lehnert, N. Inorg. Chem. 2016, 55, 5485.

(182) Ye, S.; Neese, F. J. Am. Chem. Soc. 2010, 132, 3646.

(183) Neese, F. Wiley Interdiscip. Rev. - Comput. Mol. Sci. 2012, 2, 73.

(184) Römelt, M.; Ye, S.; Neese, F. Inorg. Chem. 2009, 48, 784.

(185) Sinnecker, S.; Slep, L. D.; Bill, E.; Neese, F. Inorg. Chem. 2005, 44, 2245.

(186) Neese, F. Inorg. Chim. Acta 2002, 337, 181.

(187) Berkovitch, F.; Nicolet, Y.; Wan, J. T.; Jarrett, J. T.; Drennan, C. L. Science 2004, 303, 76.

(188) Costanzo, L. Di; Flores Jr., L. V; Christianson, D. W. Proteins 2006, 65, 637.

(189) Ballmann, J.; Dechert, S.; Bill, E.; Ryde, U.; Meyer, F. Inorg. Chem. 2008, 47, 1586.

(190) Fuchs, M. G. G.; Dechert, S.; Demeshko, S.; Ryde, U.; Meyer, F. Inorg. Chem. 2010, 49, 5853.

(191) Werst, M. M.; Kennedy, I. M. C.; Houseman, A. L. P.; Beinert, H.; Hoffman, B. M. Biochemistry 1990, 29, 10533. 
(192) Armstrong, F. A.; George, S. J.; Cammack, R.; Hatchikian, E. C.; Thomson, A. J. Biochem. J. 1989, 264, 265.

(193) George, S. J.; Armstrong, F. A.; Hatchikiant, E. C.; Thomson, A. J. Biochem. J. 1989, 264, 275.

(194) Conover, R. C.; Kowal, A. T.; Fu, W.; Park, J. B.; Aono, S.; Adams, M. W. W.; Johnson, M. K. J. Biol. Chem. 1990, 265, 8533.

(195) Johnson, R. E.; Papaefthymiou, G. C.; Frankel, R. B.; Holm, R. H. J. Am. Chem. Soc. 1983, 105, 7280.

(196) Pape, L. Le; Lamotte, B.; Mouesca, J. J. Am. Chem. Soc. 1997, 119, 9757.

(197) Pape, L. Le; Lamotte, B.; Mouesca, J. J. Am. Chem. Soc. 1997, 119, 9771.

(198) Dey, A.; Jenney, F. E.; Adams, M. W. W.; Babini, E.; Takahashi, Y.; Fukuyama, K.; Hodgson, K. O.; Hedman, B.; Solomon, E. I. Science 2007, 318, 1464.

(199) Pandelia, M.-E.; Nitschke, W.; Infossi, P.; Giudici-Orticoni, M.-T.; Bill, E.; Lubitz, W. Proc. Natl. Acad. Sci. 2011, 108, 6097.

(200) Rius, G.; Larnotte, B. J. Am. Chem. Soc. 1989, 111, 2464.

(201) Mouesca, J.-M.; Rills, G.; Lamotte, B. J. Am. Chem. Soc. 1993, 115, 4714.

(202) Brien, E. O.; Holt, M. E.; Thompson, M. K.; Salay, L. E.; Ehlinger, A. C.; Chazin, W. J.; Barton, J. K. Science 2017, 355, 813.

(203) Tse, E. C. M.; Zwang, T. J.; Barton, J. K. J. Am. Chem. Soc. 2017, 139, 12784.

(204) Boon, E. M.; Livingston, A. L.; Chmiel, N. H.; David, S. S.; Barton, J. K. Proc. Natl. Acad. Sci. 2003, 100, 12543.

(205) Bartels, P. L.; Zhou, A.; Arnold, A. R.; Nun, N. N.; Crespilho, F. N.; David, S. S.; Barton, J. K. Langmuir 2017, 33, 2523.

(206) Dus, K.; De Klerk, H.; Sletten, K.; Bartsch, R. G. Biochim. Biophys. Acta 1967, 140, 291.

(207) Middleton, P.; Dickson, D. P. E.; Johnson, C. E.; Rush, J. D. Eur. J. Biochem. 1980, 104, 289.

(208) Gloux, J.; Gloux, P.; Lamotte, B.; Mouesca, J.-M.; Rius, G. J. Am. Chem. Soc. 1994, 116, 1953.

(209) Gloux, J.; Gloux, P.; Lamotte, B.; Rius, G. Phys. Rev. Lett. 1985, 54, 599.

(210) Gloux, J.; Gloux, P.; Hendriks, H.; Rius, G. J. Am. Chem. Soc. 1987, 109, 3220.

(211) Priem, A. H.; Klaassen, A. A. K.; Reijerse, E. J.; Meyer, T. E.; Luchinat, C.; Capozzi, F.; Dunham, W. R.; Hagen, W. R. J. Biol. Inorg. 2005, 10, 417.

(212) Jiang, S.; Zhang, T.; Zhang, X.; Zhang, G.; Hai, L.; Li, B. RSC Adv. 2016, 6, 84139.

(213) Thompson, D. W.; Ito, A.; Meyer, T. J. Pure Appl. Chem. 2013, 85, 1257.

(214) Dongare, P.; Myron, B. D. B.; Wang, L.; Thompson, D. W.; Meyer, T. J. Coord. Chem. Rev. 2017, 345, 86. 
(215) Pannwitz, A.; Prescimone, A.; Wenger, O. S. Eur. J. Inorg. Chem. 2017, 609.

(216) Kaes, C.; Katz, A.; Hosseini, M. W. Chem. Rev. 2000, 100, 3553.

(217) Newkome, G. R.; Patri, A. K.; Holder, E.; Schubert, U. S. Eur. J. Org. Chem. 2004, 235.

(218) Wang, M.; Chen, L.; Li, X.; Sun, L. Dalt. Trans. 2011, 40, 12793.

(219) Lomoth, R.; Ott, S. Dalt. Trans. 2009, 9952.

(220) Summers, P. A.; Calladine, J. A.; Ghiotto, F.; Dawson, J.; Sun, X. Z.; Hamilton, M. L.; Towrie, M.; Davies, E. S.; McMaster, J.; George, M. W.; Schröder, M. Inorg. Chem. 2016, 55, 527.

(221) Li, P.; Amirjalayer, S.; Hartl, F.; Lutz, M.; Bruin, B. De; Becker, R.; Woutersen, S.; Reek, J. N. H. Inorg. Chem. 2014, 53, 5373.

(222) Na, Y.; Pan, J.; Wang, M.; Sun, L. Inorg. Chem. 2007, 46, 3813.

(223) Cattaneo, M.; Schiewer, C. E.; Schober, A.; Dechert, S.; Siewert, I.; Meyer, F. manuscript submitted.

(224) Lu, Y. Patent. US 20150336884 A1 20151126, 2015.

(225) Baek, J. Y.; Lee, S. H.; Lee, J. U.; Lee, D. W.; Kim, S. H. Patent. KR 2014121991 A 20141017, 2014.

(226) Sevier, C. S.; Kaiser, C. A. Nat. Rev. Mol. Cell Biol. 2002, 3, 836.

(227) Ragsdale, S. W.; Yi, L. Antioxid. Redox Signal. 2011, 14, 1039.

(228) Babic, S.; Horvat, A. J. M.; Pavlovic, D. M.; Kastelan-Macan, M. Trends Anal. Chem. 2007, 26, 1043.

(229) In CRC Handb. Chem. Physics; Lide, D. R., Ed.; 2005; pp 42-51.

(230) Kütt, A.; Leito, I.; Kaljurand, I.; Sooväli, L.; Vlasov, V. M.; Yagupolskii, L. M.; Koppel, I. A. J. Org. Chem. 2006, 71, 2829.

(231) Muckerman, J. T.; Skone, J. H.; Ning, M.; Wasada-Tsutsui, Y. Biochim. Biophys. Acta 2013, 1827, 882 .

(232) Benniston, A. C.; Allen, B. D.; Harriman, A.; Llarena, I.; Rostron, J. P.; Stewart, B. New J. Chem. 2009, 33, 417.

(233) Hall, G. B.; Kottani, R.; Felton, G. a N.; Yamamoto, T.; Evans, D. H.; Glass, R. S.; Lichtenberger, D. L. J. Am. Chem. Soc. 2014, 136, 4012.

(234) Benniston, A. C.; Hagon, J.; He, X.; Yang, S.; Harrington, R. W. Org. Lett. 2012, 14,506 .

(235) Maran, F.; Wayner, D. D. M.; Workentin, M. S. Adv. Phys. Org. Chem. 2001, 36, 85 .

(236) Ballmann, J.; Dechert, S.; Demeshko, S.; Meyer, F. Eur. J. Inorg. Chem. 2009, 3219.

(237) Fulmer, G. R.; Miller, A. J. M.; Sherden, N. H.; Gottlieb, H. E.; Nudelman, A.; Stoltz, B. M.; Bercaw, J. E.; Goldberg, K. I. Organometallics 2010, 29, 2176. 
(238) Sheldrick, G. M. Acta Crystallogr. Sect. A. Found. Crystallogr. 2008, 64, 112.

(239) X-Red. STOE \& CIE GmbH, Darmstadt, Germany, 2002.

(240) Neese, F. WIREs Comput. Mol. Sci. 2012, 2, 73.

(241) Becke, A. Phys. Rev. A 1988, 38, 3098.

(242) Perdew, J. P. Phys. Rev. B 1986, 33, 8822.

(243) Perdew, J. P. Phys. Rev. B 1986, 34, 7406.

(244) Tao, J.; Perdew, J. P.; Staroverov, V. N.; Scuseria, G. E. Phys. Rev. Lett. 2003, 91, 146401.

(245) Perdew, J. P.; Tao, J.; Staroverov, V. N.; Scuseria, G. E. J. Chem. Phys. 2004, 120, 6898.

(246) Becke, A. D. J. Chem. Phys. 1993, 98, 1372.

(247) Lee, C.; Yang, W.; Parr, R. G. Phys. Rev. B 1988, 37, 785.

(248) Staroverov, V. N.; Scuseria, G. E.; Tao, J.; Perdew, J. P. Chem. Phys. 2003, 119, 12129.

(249) Schafer, A.; Horn, H.; Ahlrichs, R. J. Chem. Phys. 1992, 97, 2571.

(250) Schäfer, A.; Huber, C.; Ahlrichs, R. J. Chem. Phys. 1994, 100, 5829.

(251) Weigend, F.; Ahlrichs, R. Phys. Chem. Chem. Phys. 2005, 7, 3297.

(252) Bochevarov, A. D.; Friesner, R. a; Lippard, S. J. J. Chem. Theory Comput. 2010, 6, 3735 .

(253) Zhang, Y.; Oldfield, E. J. Phys. Chem. B 2003, 107, 7180.

(254) Kowalska, J. K.; Hahn, A. W.; Albers, A.; Schiewer, C. E.; Bjornsson, R.; Lima, F. A.; Meyer, F.; DeBeer, S. Inorg. Chem. 2016, 55, 4485.

(255) Kowalska, J. K.; Nayyar, B.; Rees, J. A.; Schiewer, C. E.; Lee, S. C.; Kovacs, J. A.; Meyer, F.; Weyhermüller, T.; Otero, E.; DeBeer, S. Inorg. Chem. 2017, 56, 8147. 


\section{Abbreviations}

$\alpha \quad$ Charge transfer coefficient from Butler-Volmer equation

Arg Arginine

Bn Benzyl

Bpy 2,2'-Bipyridine

br Broad

$\mathrm{Bu} \quad$ Butyl

$\mathrm{Cp} \quad$ Cyclopentadiene

Cp* Pentamethylcyclopentadiene

Cys Cysteine

d Doublet

DBU 1,8-Diazabicyclo(5.4.0)undec-7-ene

DCM Dichloromethane

DDQ 2,3-Dichloro-5,6-dicyano-1,4-benzoquinone

DMF Dimethylformamide

DMPH 2,6-Dimethylpyridinium tetrafluoroborate

DNA Deoxyribonucleic acid

DNIC Dinitrosyl Iron Complex

EDTA Ethylenediaminetetraacetic acid

EFG Electric Field Gradient

EPR Electron Paramagnetic Resonance

eq Equivalent

ESI Electrospray Ionization

Et Ethyl

$\mathrm{Et}_{2} \mathrm{O} \quad$ Diethylether

EtCN Propionitrile

Fc Ferrocene

FeMoCo Iron-Molybdenum Cofactor

FNR Transcriptional Activator of Fumarate and Nitrate Redcutase

fwhm Full width half maximum

$g \quad$ Landé factor 
HiPIP High Potential Iron-Sulfur Protein

His Histidine

hs $\quad$ High spin

HSDmp 2,6-(2,4,6- $\left.\mathrm{Me}_{3} \mathrm{C}_{6} \mathrm{H}_{2}\right)_{2} \mathrm{C}_{6} \mathrm{H}_{3}$

int. intermediate

ISC Iron Sulfur Cluster Formation System

IscR Iron Sulfur Cluster Regulator

IscU Scaffold Protein in ISC System

IUPAC International Union of Pure and Applied Chemistry

$k_{\mathrm{c}} \quad$ Rate of chemical reaction

$k_{\mathrm{S}} \quad$ Rate constant for electron transfer

LIFDI Liquid Injection Field Desorption Ionization

LMCT Ligand to Metal Charge Transfer

Lys Lysine

m Multiplett

Me Methyl

$\mathrm{MeCN}$ Acetonitrile

MS Mass Spectrometry

NMR Nuclear Magnetic Resonance

obs Observed

OTf Triflate $\left(\mathrm{CF}_{3} \mathrm{SO}_{3}\right)^{-}$

PCET Proton Coupled Electron Transfer

$\mathrm{Ph} \quad$ Phenyl

ppm Parts per million

PPN Bis(triphenylphosphine)iminium

Pr Propyl

q Quartet

RBS Roussin's Black Salt $\left[\mathrm{Fe}_{4} \mathrm{~S}_{3}(\mathrm{NO})_{7}\right]^{-}$

RNA Ribonucleic Acid

RRE Roussin's Red Ester $\left[\mathrm{Fe}_{2}(\mathrm{SR})_{2}(\mathrm{NO})_{4}\right]$

RRS Roussin's Red Salt $\left[\mathrm{Fe}_{2} \mathrm{~S}_{2}(\mathrm{NO})_{4}\right]^{2-}$

rt Room temperature 
Ser Serine

sh Shoulder

SHE Standard Hydrogen Electrode

SQUID Superconducting Quantum Interference Device

SUF Sulfur Formation System

TEMPO 2,2,6,6-Tetramethylpiperidinyloxyl

tert Tertiary

THF Tetrahydrofuran

TIP Temperature-Independent Paramagnetism

tRNA Transfer Ribonucleic Acid

TS Transition State

UV-vis Ultraviolet and visible 


\section{Curriculum Vitae}

Christine Elisabeth Schiewer

Date and Place of Birth: 10/10/1988 in Menden (Sauerland)

\section{Education}

$\begin{array}{lll}\text { PhD Thesis } & \text { PhD student in the group of Prof. Dr. Franc Meyer, } & 12 / 2013- \\ & \text { Department of Inorganic Chemistry, Georg-August }\end{array}$ University Göttingen, Germany.

Thesis: "Nitric Oxide Reactivity and Unusual Redox

Properties of Biomimetic Iron-Sulfur Clusters with

Alternative Cluster Ligands"

Research Stays Visiting research scientist in the group of Prof. Dr. Ulf

Abroad

Ryde, Lund University, Sweden.

$09 / 2015-$

$10 / 2015$

Research student in the group of Prof. Dr. Martina 10/2012 -

Lahmann, Bangor University, UK.

$01 / 2013$

M. Sc. Studies

in Chemistry at Georg-August University Göttingen,

$10 / 2011-$

Germany; cumulative grade: 1.4 (with distinction).

$11 / 2013$

Master thesis in the group of Prof. Dr. Franc Meyer,

Department of Inorganic Chemistry.

Thesis: "Biomimetic Iron-Sulfur Clusters" (grade 1.0)

B. Sc. Studies in Chemistry at Georg-August University Göttingen,

$10 / 2008-$

Germany; cumulative grade: 1.7 .

$06 / 2011$

Master Thesis in the group of Prof. Dr. Franc Meyer,

Department of Inorganic Chemistry.

Thesis: "Biomimetic Iron-Sulfur Clusters" (grade 1.0)

Secondary

Abitur (university-entrance diploma) at Pestalozzi-

$09 / 1999$

School

Gymnasium Unna, Germany:

$06 / 2008$

Cumulative grade: 1.5

High School Diploma (cum laude) at MacArthur High $\quad$ 06/2006 School, San Antonio, USA. 


\section{Method Courses}

03/2015 Advanced Electrochemistry (Prof. M. Robert)

02/2015 Introduction to Electrochemistry (Prof. C. Jooß, Prof. S. Schneider)

12/2014 X-Ray Absorption Spectroscopy (Prof. S. De Beer)

WiSe $14 \quad$ Practical NMR Spectroscopy (Dr. M. John)

09/2013 Summer School on Methods in Molecular Energy Research (organized by

Max Planck Institute for Chemical Energy Conversion Mühlheim)

\section{Teaching Experience}

- Supervision of a bachelor thesis

- Seminars in Advanced Analytical Methods in Inorganic Chemistry, Coordination Chemistry,

- Supervision of Inorganic Chemistry Practical Courses and Advanced Analytical Methods Practical Course (EPR- and Mössbauer spectroscopy, Cyclic Voltammetry, and SQUID magnetometry)

\section{Soft Skill Courses}

- Good Scientific Practice

- Project Management

- Leadership

- Intercultural Competence

- Academic Writing

IT

- Origin, MestReNova, MS Office, DFT calculations with ORCA

\section{Languages}

- German (native speaker)

- English (fluent)

- French (A2 of European Reference Framework) 


\section{Scientific Contributions}

\section{Publications}

M. Cattaneo, ${ }^{\S}$ C. E. Schiewer, ${ }^{\S}$ A. Schober, S. Dechert, I. Siewert, F. Meyer, 2,2 '-Bipyridine Equipped with a Disulfide/Dithiol Switch for Coupled Two Electron and Proton Transfer, submitted. ${ }^{\S}$ These authors contributed equally to the work.

J. K. Kowalska, B. Nayyar, J. A. Rees, C. E. Schiewer, S. C. Lee, J. A. Kovacs, F. Meyer, T. Weyhermüller, E. Otero, S. DeBeer Inorg. Chem. 2017, 56, 8147-8158. 'Iron L2,3-Edge Xray Absorption and X-ray Magnetic Circular Dichroism Studies of Molecular Iron Complexes with Relevance to the FeMoco and FeVco Active Sites of Nitrogenase'.

J. K. Kowalska, A. W. Hahn, A. Albers, C. E. Schiewer, R. Bjornsson, F. A. Lima, F. Meyer, S. DeBeer Inorg. Chem. 2016, 55, 4485-4497. X-ray Absorption and Emission Spectroscopic Studies of $\left[\mathrm{L}_{2} \mathrm{Fe}_{2} \mathrm{~S}_{2}\right]^{n-}$ Model Complexes: Implications for the Experimental Evaluation of Redox States in Iron-Sulfur Clusters.

\section{Presentations at International Conferences and Workshops}

AGIChem, Göttingen, Germany, August 2017 (Poster).

$42^{\text {nd }}$ ICCC, Brest, France, July 2016 (Poster).

$6^{\text {th }}$ IMBG Meeting, Grenoble, France, September 2015 (Poster).

Final Symposium of the IRTG 1422, Göttingen, Germany, August 2015 (Poster).

Workshop of the IRTG 1422, Katlenburg, Germany, May 2015 (Oral contribution \& poster).

Trends in Inorganic Chemistry (TINC), Lund, Sweden, May 2014 (Poster). 


\section{Acknowledgements}

Ich möchte mich herzlich bei meinem Doktorvater Prof. Dr. Franc Meyer dafür bedanken, dass ich in seinem Arbeitskreis promovieren durfte. Ich danke ihm für die freundliche Betreuung und die Vermittlung diverser Kooperationen.

Prof. Dr. Kai Tittmann danke ich für die Übernahme des Koreferats. Ich freue mich, dass es ihm nach schwerer Krankheit wieder besser geht und er weiterhin bereit ist, mein Zweitbetreuer zu sein.

Prof. Dr. Ebbe Nordländer danke ich für die Übernahme der Aufgabe des dritten Betreuers; auch wenn wir uns wegen die räumliche Distanz nur auf Workshops und dem Abschlusssymposium des IRTGs treffen konnten.

Dr. Serhiy Demeschko danke ich für die Einweisung in die Mössbauerspektroskopie und das Anlernen der Bedienung des Gerätes. Mössbauerspektroskopie hat mich schon als Student fasziniert und ich bin froh, dass ich während meiner Doktorarbeit meine Kenntnisse auf diesem Gebiet erweitern konnte. Zudem danke ich Serhiy für Ausführung und Auswertung magnetischer Messungen.

Prof. Dr. Ulf Ryde danke ich für die Betreuung in Lund und die Einweisung in DFTRechnungen. Die IT-Kenntnisse, die ich in Lund gelernt habe, konnte ich in Göttingen einfach auf ORCA übertragen, womit ich dann die Rechnungen in dieser Arbeit durchgeführt habe.

Prof. Dr. Inke Siewert danke ich für ihre ansteckende Begeisterung für das BipyridinProjekt. Ich danke ihr für die Beratung bei der Messung von CVs und die Simulation der entstandenen Voltammogramme.

Dr. Sebastian Dechert danke ich für die Beratung bei Fragen zu ORCA und anderen ITProblemen. Zudem danke ich ihm dafür, dass ich seine DFT-Berechnung zum BipyridinThema in meine Arbeit einfließen lassen durfte. Schließlich danke ich ihm und Nicole Kindermann für das Messen und Auswerten von Kristallstrukturen.

Desweiteren möchte ich mich bei meinen Kooperationspartnern bedanken: Christina Müller und Prof. Volker Schünemann für die NIS-Messung an deprotonierten und protonierten DNICs. 
Marie Bergner danke ich für das Messen und Simulieren von ESR-Spektren. Als Laborkolleginnen, die beide an Eisen-Schwefel Clustern arbeiteten, sind wir auf den meisten Konferenzen zusammen gewesen und hatten viel Spaß. Neben Marie danke ich noch Mattia Veronelli für die tolle Zeit im Labor.

Ich danke meiner Vorgängerin Antonia Albers für das Anlernen im Labor. Durch sie bin ich auf die Idee gekommen meine Bachelorarbeit über Eisen-Schwefel Cluster zu schreiben. Diese zufällige Begegnung im AC-Synthese Praktikum hatte nun letztendlich einen entscheiden Einfluss auf meinen Lebenslauf genommen, für den ich ihr sehr dankbar bin.

Ich danke der Analytikabteilung und den Werkstätten, ohne deren Hilfe eine solche Doktorarbeit nicht möglich gewesen wäre. Insbesondere herausstellen möchte ich Andreas Schwarz und Jörg Teichgräber, die mir bei praktischen Problemen mir mit Rat und Tat zur Seite standen. Frau Dr. Claudia Stückl, Britta Müller, Petra Unger und Petra Gaugel danke ich für die Unterstützung in administrativen Dingen. Ich bedanke mich bei meiner Bachelorstudentin Julia Struwe und bei meinem Hiwi Svenja Neumann für ihre tatkräftige Unterstützung.

Dem IRTG 1422 danke ich für finanzielle Unterstützung und für die Möglichkeit an zahlreichen Seminaren, Workshops und Konferenzen teilnehmen zu können.

Ich möchte mich bei Arne Glüer, Marie Bergner, Claudia Schremmer, Sebastian Neske und Fabian Rabe von Pappenheim für das Korrekturlesen meiner Arbeit danken.

Schließlich danke ich allen Mitgliedern des Arbeitskreises, meinen Freunden und meiner Familie, die mich während der Doktorarbeit begleitet und stets unterstützt haben.

Vielen Dank, Arne, dass du an meiner Seite stehst und immer für mich da bist. 